IZA DP No. 10358

Higher Education Access and Outcomes for the 2008 South African National Matric Cohort

Hendrik van Broekhuizen

Servaas van der Berg

Heleen Hofmeyr

November 2016 


\title{
Higher Education Access and Outcomes for the 2008 South African National Matric Cohort
}

\author{
Hendrik van Broekhuizen \\ University of Stellenbosch \\ Servaas van der Berg \\ University of Stellenbosch \\ and IZA \\ Heleen Hofmeyr \\ University of Stellenbosch
}

Discussion Paper No. 10358
November 2016

\author{
IZA \\ P.O. Box 7240 \\ 53072 Bonn \\ Germany \\ Phone: +49-228-3894-0 \\ Fax: +49-228-3894-180 \\ E-mail: iza@iza.org
}

Any opinions expressed here are those of the author(s) and not those of IZA. Research published in this series may include views on policy, but the institute itself takes no institutional policy positions. The IZA research network is committed to the IZA Guiding Principles of Research Integrity.

The Institute for the Study of Labor (IZA) in Bonn is a local and virtual international research center and a place of communication between science, politics and business. IZA is an independent nonprofit organization supported by Deutsche Post Foundation. The center is associated with the University of Bonn and offers a stimulating research environment through its international network, workshops and conferences, data service, project support, research visits and doctoral program. IZA engages in (i) original and internationally competitive research in all fields of labor economics, (ii) development of policy concepts, and (iii) dissemination of research results and concepts to the interested public.

IZA Discussion Papers often represent preliminary work and are circulated to encourage discussion. Citation of such a paper should account for its provisional character. A revised version may be available directly from the author. 


\section{ABSTRACT \\ Higher Education Access and Outcomes for the 2008 South African National Matric Cohort ${ }^{*}$}

This study uses a unique dataset to investigate university access, throughput, and dropout for the 2008 South African national matric cohort. The findings show that university access in South Africa is limited, even among learners who perform relatively well in matric. In addition, those who do gain access to university often take a long time to complete their studies, with many never completing at all. As a result, only a select minority of matric learners manage to obtain university qualifications. Significant inequalities in university outcomes between race groups and across geographical space also remain evident. However, the results from the analysis suggests that observed patterns of university access and university success are strongly influenced by school results. The weak school system has a major influence on who reaches matric, and how they perform in matric. This, and particularly the achievement of Bachelor passes, explains much of the differences in university outcomes by race, gender and province.

JEL Classification: $\quad$ I21, I23, I24

Keywords: $\quad$ higher education, university access, post-school transitions

Corresponding author:

Hendrik van Broekhuizen

Department of Economics

University of Stellenbosch

Private Bag X1

7602 Matieland

South Africa

E-mail: hendrikvanb@sun.ac.za

\footnotetext{
* The authors would like to thank the Department of Basic Education (DBE) and the Department of Higher Education and Training (DHET) who were jointly responsible for the provision of the NSC and HEMIS databases used in this research. In particular, we would like to that Kirstin Barth for linking and anonymising the NSC and HEMIS datasets.
} 


\section{Contents}

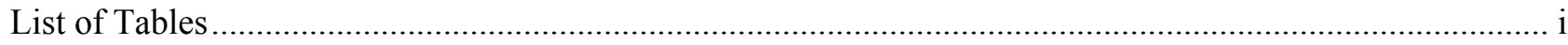

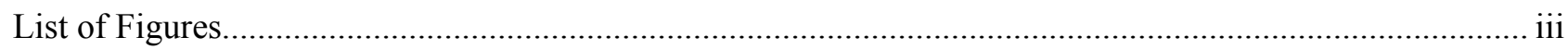

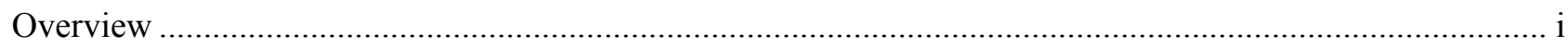

How many qualifying students never attend university? ...................................................................... i

Is access to university skewed for those who qualify for university? ....................................................... ii

How many matriculants delay entry into university studies? ................................................................ vi

How good are matric marks as predictor of university access and of university success? ......................... vi

How much do matric results differ across the universities that students attend? ..................................... vii

How long does it take students to complete degrees or diplomas? ........................................................ vii

How high are dropout rates from university? ................................................................................... viii

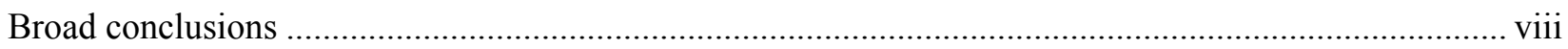

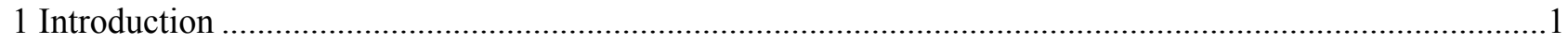

NSC exam results for the 2008 - 2013 national cohorts .................................................................................

1.2. University access for the 2008 - 2013 matric cohorts .....................................................................

1.3. University access, entrance, completion, and exit patterns among matric cohorts................................ 4

1.4. University access, entrance, completion, and exit patterns among the 2008 matric cohort ...................6

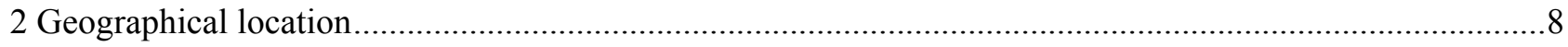

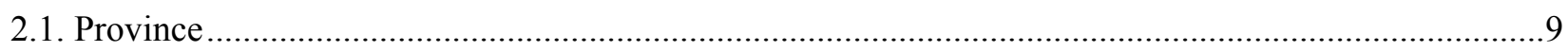

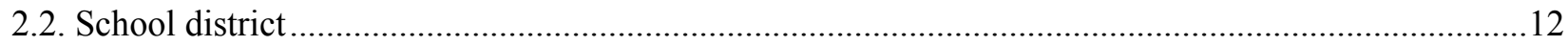

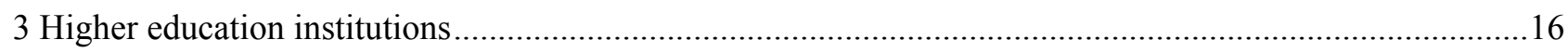

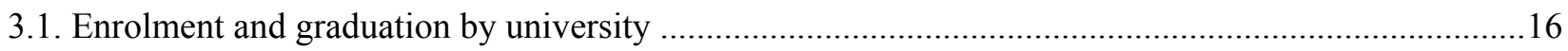

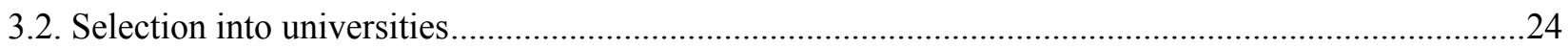

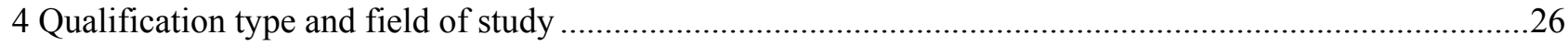

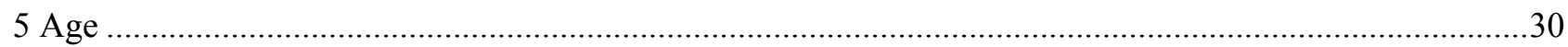

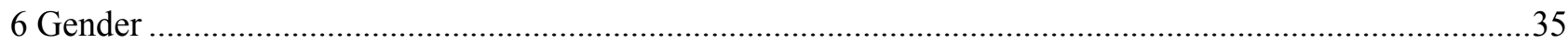

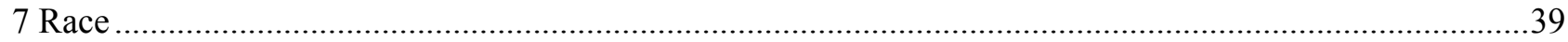

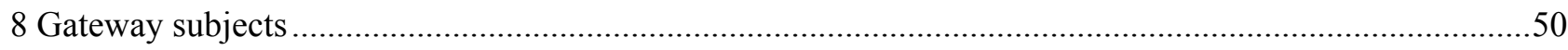

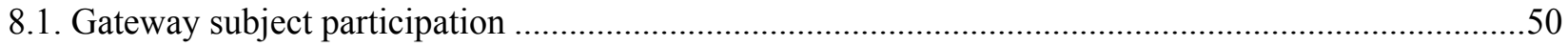

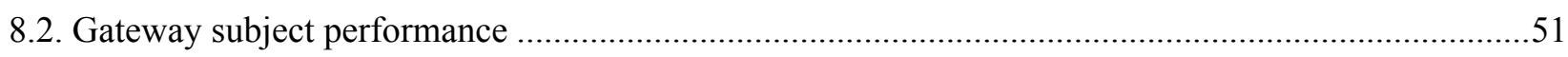

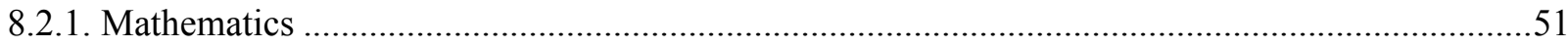

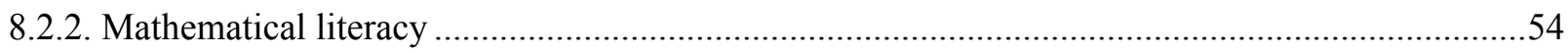




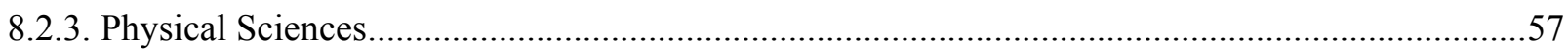

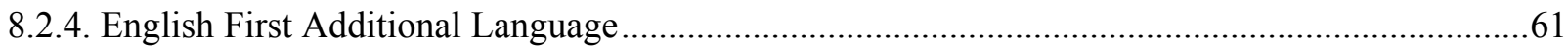

8.3 An articulation gap between school and university? ........................................................................64

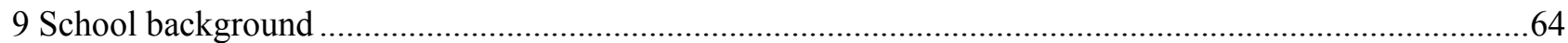

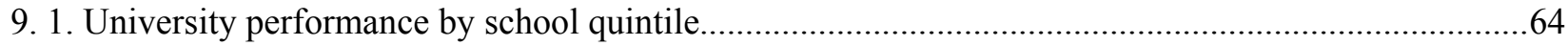

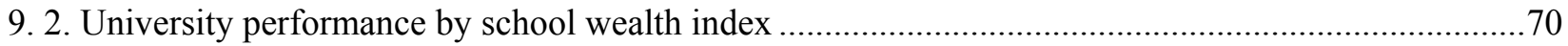

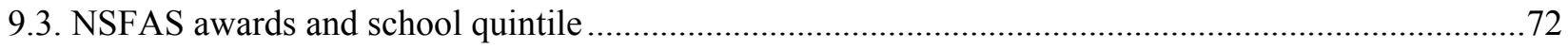

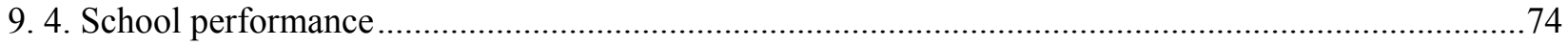

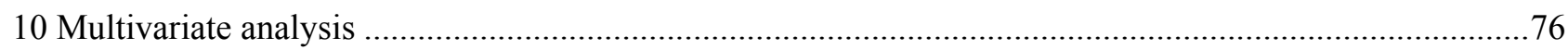

10.1. Racial differentials in university access, completion, conversion, and dropout.................................76

10.2. Correlates of university access, completion, conversion, and dropout..............................................79

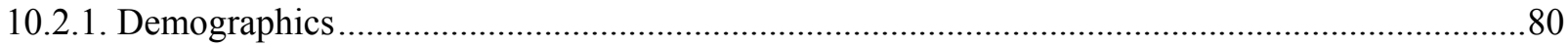

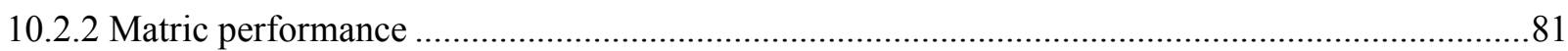

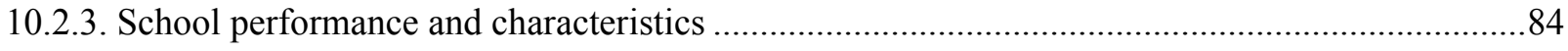

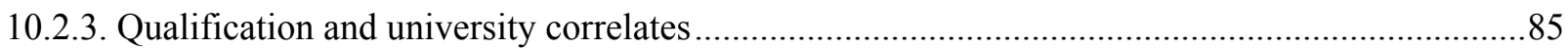

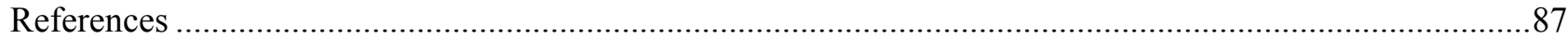

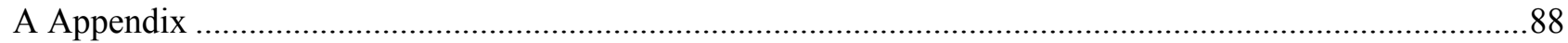

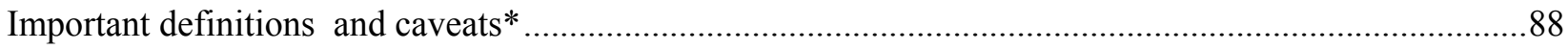

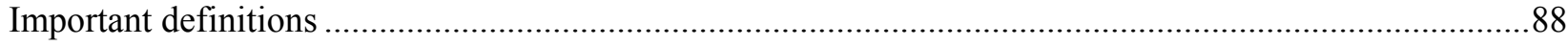

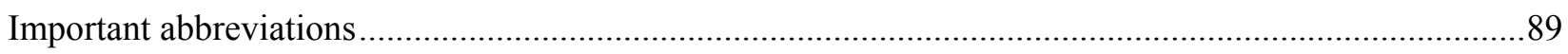

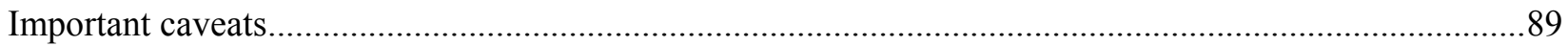

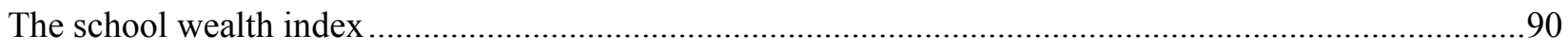

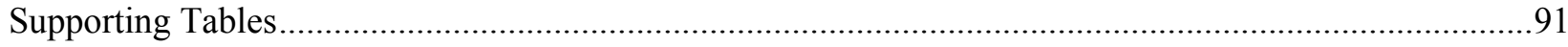




\section{List of Tables}

Table 1: Characteristics of learners from the 2008 matric cohort who achieved Bachelor passes by access to university $(2009-2014)$..................................................................................................... ii

Table 2: Characteristics of learners from the 2008 matric cohort who achieved a matric average of $60 \%$ or higher by access to university $(2009-2014)$ .iii

Table 3: Characteristics of learners from the 2008 matric cohort who achieved $55 \%$ or higher in NSC Mathematics by access to university $(2009-2014)$

Table 4: Characteristics of learners from the 2008 matric cohort who achieved (1) Bachelor passes, (2) a 60\% overall matric average or higher, and (3) 55\% or higher in NSC Mathematics by access to university $(2009-2014)$

Table 1.1: Cumulative percentage of the 2008 - 2013 matric cohorts who completed undergraduate qualifications, by pass type

Table 1.2: University enrolment, exit and completion for the 2008 matric cohort $(2009-2014)$..................7

Table 2.1: Universities attended by university participants from the 2008 matric cohort, by school province

Table 2.2: Province of university attended by university participants from the 2008 matric cohort, by school province (\%)

Table 3.1: University enrolments and graduations for the 2008 matric cohort (2009 - 2014), by university .18

Table 3.2: Share of university enrolments and graduations for the 2008 matric cohort (2009 - 2014), by university.

Table 4.1: University enrolments for the 2008 matric cohort, by qualification level and broad field of study

Table 4.2: University graduations for the 2008 matric cohort who enrolled in undergraduate studies over the period $2009-2014$, by qualification type and broad field of study

Table 4.3: University completion rates for 2009 FTEN students from the 2008 matric cohort (2009 - 2014), by broad qualification type and field of study.

Table 5.1: NSC examination results for the 2008 matric cohort, by age group

Table 5.2: University enrolment, exit, and completion for the 2008 matric cohort (2009 - 2014), by age group in Grade 12

Table 5.3: University access, completion, dropout, and retention rates (\%) for the 2008 matric cohort (2009 2014), by age group in Grade 12 .

Table 5.4: The 2008 matric cohort after six years (end of 2014), by age group in Grade 12 .....

Table 5.5: University access, completion, and dropout rate summaries for learners who achieved Bachelor passes in the 2008 NSC exams, by age group in Grade 12

Table 6.1: NSC exam results for the 2008 matric cohort, by gender.

Table 6.2: University enrolment, exit, and completion for the 2008 matric cohort (2009 - 2014), by gender 36

Table 6.3: University access, completion, dropout, and retention rates (\%) for the 2008 matric cohort (2009 2014), by gender

Table 6.4: The 2008 matric cohort after six years (end of 2014), by gender.

Table 6.5: NSC pass type and university access, completion, and dropout rate summaries for the 2008 NSC, by gender.

Table 6.6: University access, completion, and dropout rate summaries for learners who achieved Bachelor

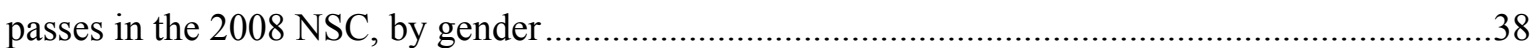

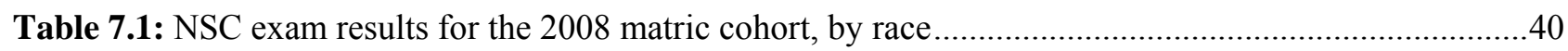

Table 7.2: University enrolment, exit, and completion for the 2008 matric cohort (2009 - 2014), by race ....41

Table 7.3: University access, completion, dropout, and retention rates (\%) for black learners from the 2008 matric cohort (2009 - 2014)

Table 7.4: The 2008 matric cohort after six years (end of 2014), by race group 
Table 7.5: University access, completion, and dropout rate summaries for learners who achieved Bachelor passes in the $2008 \mathrm{NSC}$, by race group

Table 8.1: Participation in gateway NSC subjects among the 2008 matric cohort, by undergraduate sub-group

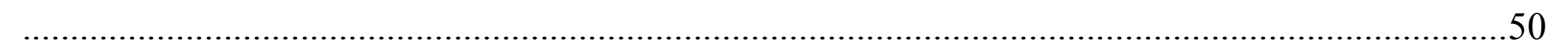

Table 9.1: NSC exam results for the 2008 matric cohort, by school quintile ...........................................65

Table 9.2: University enrolment, exit, and completion for learners from quintile $1-3$ schools in the 2008 matric cohort (2009 - 2014)

Table 9.3: NSFAS award recipiency in first year of undergraduate studies for learners from the 2008 matric cohort, by school quintile.

Table 10.1: Estimated racial differentials in university access, completion, conversion, and dropout rates for

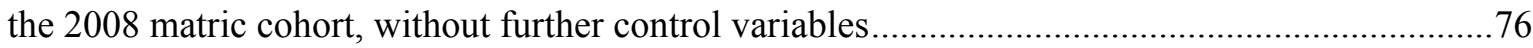

Table 10.2: Estimated racial differentials in university access, completion, conversion, and dropout rates for the 2008 matric cohort after controlling for matric pass result ...................................................... 78

Table 10.3: Estimated racial differentials in university access, completion, conversion, and dropout rates for the 2008 matric cohort after controlling for matric average achievement

Table 10.4: Correlates of university access, completion, conversion, and dropout rates for the 2008 matric

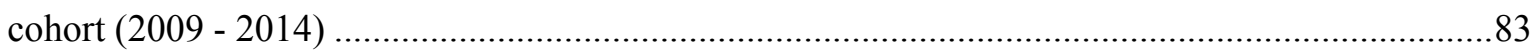

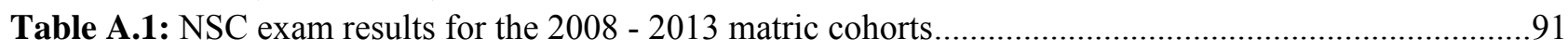

Table A.2: University access rates (\%) for the 2008 - 2013 matric cohorts, by pass type............................92

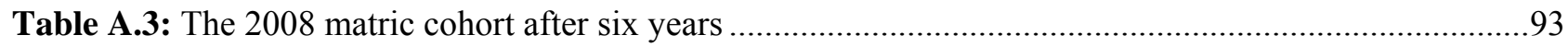

Table A.4: NSC exam results for the 2008 matric cohort, by province....................................................94

Table A.5: The 2008 national and provincial matric cohorts after six years (end of 2014) ..........................95

Table A.6: University access, completion, and dropout rate summaries for the 2008 Western Cape matric

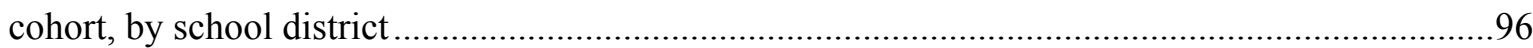

Table A.7: University access, completion, and dropout rate summaries for the 2008 Northern Cape matric

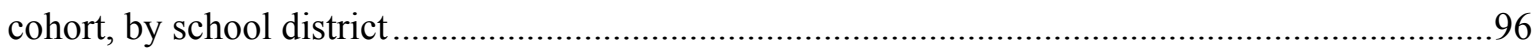

Table A.8: University access, completion, and dropout rate summaries for the 2008 Eastern Cape matric

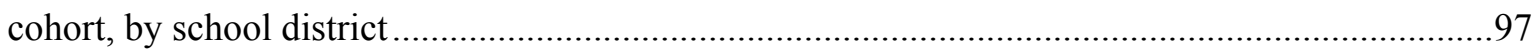

Table A.9: University access, completion, and dropout rate summaries for the 2008 Free State matric cohort,

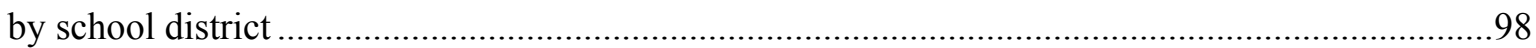

Table A.10: University access, completion, and dropout rate summaries for the 2008 North West matric

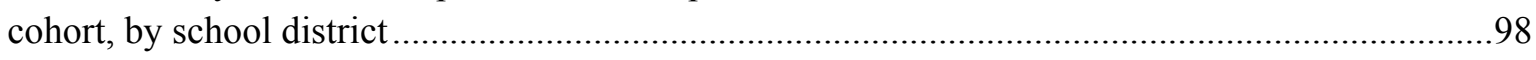

Table A.11: University access, completion, and dropout rate summaries for the 2008 Mpumalanga matric

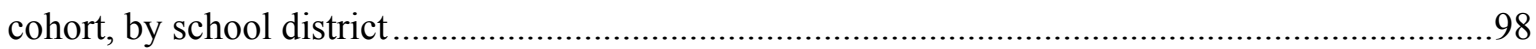

Table A.12: University access, completion, and dropout rate summaries for the $2008 \mathrm{KwaZulu}$ Natal matric cohort, by school district.

Table A.13: University access, completion, and dropout rate summaries for the 2008 Limpopo matric cohort, by school district

Table A.14: University access, completion, and dropout rate summaries for the 2008 Gauteng matric cohort, by school district

Table A.15: Undergraduate completion rates for learners from the 2008 matric cohort who entered undergraduate studies in 2009, by university of first enrolment.

Table A.16: Undergraduate degree completion rates for learners from the 2008 matric cohort who entered undergraduate degree programmes in 2009 , by university of first enrolment

Table A.17: Undergraduate dropout rates for learners from the 2008 matric cohort who entered undergraduate

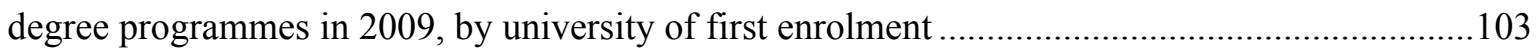

Table A.18: The 2008 matric cohort after six years (end of 2014), by school quintile................................104

Table A.19: NSC pass type and university access, completion, and dropout rate summaries for the 2008 matric cohort, by school quintile. 
Table A.20: University access, completion, and dropout rate summaries for learners who achieved Bachelor passes in the $2008 \mathrm{NSC}$, by school quintile

\section{List of Figures}

Figure 1: One to six year access rates for the 2008 to 2013 matric cohorts (\% of matriculants) vi

Figure 2: Cumulative Matric average achievement distribution for the 2008 matric cohort by enrolment and completion of undergraduate degree programmes between 2009 and 2014 ............................. vii

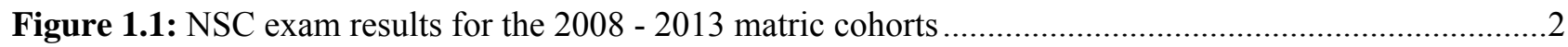

Figure 1.2: Matric average achievement distributions for the 2008 - 2013 matric cohorts.............................

Figure 1.3: 1-year university access rates for the 2008 - 2013 matric cohorts by pass type ...........................

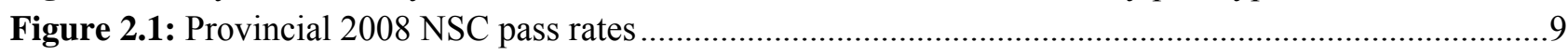

Figure 2.2: Cumulative matric average achievement distribution for the 2008 matric cohort, by province ... 10

Figure 2.3: Provincial university access, completion, and dropout rates (\%) for the 2008 matric cohort.......10

Figure 2.4: Provincial university access, completion, and dropout rates (\%) for learners who achieved

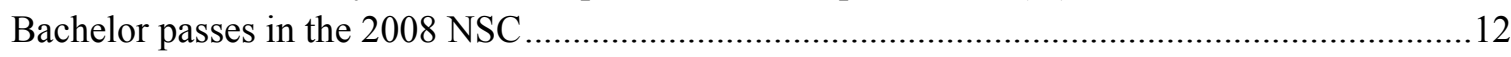

Figure 2.5: Bachelor pass rates (\%) by school district for the 2008 matric cohort ......................................13

Figure 2.6: Six-year university access rates (\%) for the 2008 matric cohort, by school district....................13

Figure 2.7: Six-year university access rates (\%) for Bachelor pass candidates from the 2008 matric cohort,by school district.

Figure 3.1: Undergraduate degree enrolments as percentage of all undergraduate enrolments in a university for the 2008 matric cohort (2009 - 2014)

Figure 3.2: Undergraduate graduations as a percentage of undergraduate enrolments for the 2008 matric cohort (2009 - 2014), by university

Figure 3.3: Undergraduate completion rates for 2009 FTEN students from the 2008 matric cohort (2009 2014), by university of first enrolment

Figure 3.4: Undergraduate degree completion rates for 2009 FTEN students from the 2008 matric cohort (2009 - 2014), by university of first enrolment

Figure 3.5: Undergraduate dropout rates for 2009 FTEN students from the 2008 matric cohort (2009 - 2014), by university of first enrolment

Figure 3.6: Matric average distributions for the 2009 FTEN undergraduate students from the 2008 matric cohort (2009 - 2014), by university of first enrolment

Figure 3.7: Matric average distributions for the 2009 FTEN undergraduate degree students from the 2008 matric cohort (2009 - 2014), by university of first enrolment.

Figure 4.1: Cumulative matric average achievement distribution for first-year students from the 2008 matric cohort (2009 - 2014), by undergraduate qualification level and broad field of study .....

Figure 4.2: Cumulative matric average achievement distribution for completers from the 2008 matric cohort (2009 - 2014), by undergraduate qualification level and broad field of study

Figure 4.3: University completion rates for the 2009 undergraduate intake from the 2008 matric cohort (2009 -2014), by broad qualification type and field of study.

Figure 7.1: Cumulative matric average achievement distribution for the 2008 matric cohort, by race ..........41

Figure 7.2: University access, completion, and dropout rates (\%) for the 2008 matric cohort (2009 - 2014), by race

Figure 7.3: Expected 1-year access rates for the 2008 matric cohort by race and matric average achievement (\%) (2009)

Figure 7.4: Expected 6-year access rates for the 2008 matric cohort by race and matric average achievement (\%) (2009)

Figure 7.5: Expected 6-year completion rates for learners from the 2008 matric cohort who enrolled in university in 2009 by race and matric average achievement (\%) (2009 - 2014).....

Figure 7.6: Expected 5-year dropout rates for learners from the 2008 matric cohort who enrolled in university in 2009 by race and matric average achievement (\%) (2009 - 2014) 
Figure 8.1: Cumulative NSC Mathematics performance distribution for the 2008 matric cohort by enrolment and completion of undergraduate programmes between 2009 and 2014 ....................................52

Figure 8.2: Enrolment in and completion of undergraduate degree programmes for the 2008 matric cohort (2009 - 2014), by NSC Mathematics achievement.

Figure 8.3: Percentage of undergraduate degree students from the 2008 matric cohort who completed undergraduate degrees between 2009 and 2014, by NSC Mathematics performance. .53

Figure 8.4: Expected access, completion, and dropout rates for learners from the 2008 matric cohort (20092014), by NSC Mathematics achievement

Figure 8.5: Cumulative NSC Mathematical Literacy performance distribution for the 2008 matric cohort by enrolment and completion of undergraduate degree programmes between 2009 and $2014 \ldots \ldots \ldots . . .55$

Figure 8.6: Enrolment in and completion of undergraduate degree programmes for the 2008 matric cohort (2009 - 2014), by NSC Mathematical Literacy achievement.

Figure 8.7: Percentage of undergraduate degree students from the 2008 matric cohort who completed undergraduate degrees between 2009 and 2014, by NSC Mathematical Literacy performance ....57

Figure 8.8: Expected access, completion, and dropout rates for learners from the 2008 matric cohort (2009 2014), by NSC Mathematical Literacy achievement.

Figure 8.9: Cumulative NSC Physical Sciences performance distribution for the 2008 matric cohort by enrolment and completion of undergraduate degree programmes between 2009 and 2014 ...........58

Figure 8.10: Enrolment in and completion of undergraduate degree programmes for the 2008 matric cohort (2009 - 2014), by NSC Physical Sciences achievement.

Figure 8.11: Percentage of undergraduate degree students from the 2008 matric cohort who completed undergraduate degrees between 2009 and 2014, by NSC Physical Sciences performance............60

Figure 8.12: Expected access, completion, and dropout rates for learners from the 2008 matric cohort (20092014), by NSC Physical Sciences achievement

Figure 8.13: Cumulative NSC English First Additional Language performance distribution for the 2008 matric cohort by enrolment and completion of undergraduate degree programmes between 2009 and 2014

Figure 8.14: Enrolment in and completion of undergraduate degree programmes for the 2008 matric cohort (2009 - 2014), by NSC English FAL achievement.

Figure 8.15: Percentage of undergraduate degree students from the 2008 matric cohort who completed undergraduate degrees between 2009 and 2014, by NSC English First Additional Language performance.

Figure 8.16: Expected access, completion, and dropout rates for learners from the 2008 matric cohort (2009 2014), by NSC English First Additional Language achievement.

Figure 9.1: Cumulative matric average achievement distribution for the 2008 matric cohort, by school quintile

Figure 9.2: University access, completion, and dropout rates (\%) for the 2008 matric cohort (2009 - 2014), by school quintile.

Figure 9.3: University access, completion, and dropout rates (\%) for learners who achieved Bachelor passes

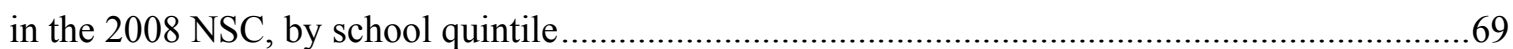

Figure 9.4: Wealth index distributions for the 2008 matric cohort, by school quintile................................70

Figure 9.5: Expected bachelor pass, access, completion, and dropout rates for learners from the 2008 matric

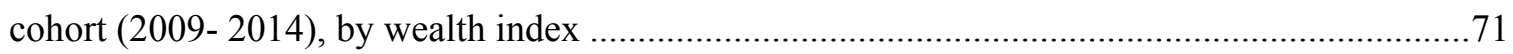

Figure 9.6: Expected access, completion, and dropout rates for learners from the 2008 matric cohort who achieve Bachelor passes (2009- 2014), by school wealth index ................................................. 72

Figure 9.7: University completion and dropout rates (\%) for learners from quintile 1 - 3 schools in the 2008 matric cohort by NSFAS recipiency in first year of undergraduate studies, $(2009-2014)$...........73

Figure 9.8: Expected access, completion, and dropout rates for learners from the 2008 matric cohort by Bachelor pass rate in learner's school (\%) (2009 - 2014) 
Figure 9.9: Expected access, completion, and dropout rates for learners from the 2008 matric cohort by overall matric average achievement in learner's school (\%) (2009 - 2014).

Figure 9.10: Distribution of NSC candidates, Bachelor passes, university participants, and university

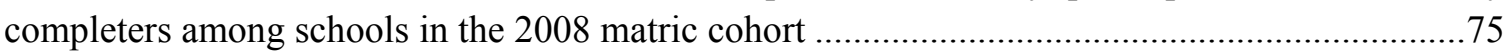




\section{Overview}

This research project uses a unique dataset that combines matric examinations data from 2008 to 2013 with data from all South Africans universities (HEMIS data) from 2009 to 2014, and adds to that data from the EMIS Masterlist and the 2011 national census. The combined dataset allows novel analyses of the transition from school (matric) to university, i.e. university access, and how matric results influence university outcomes (completion and dropout). Also, as data are available for all public universities, it is possible to track students not only from school into university, but also within the same university over time, and even between universities.

Extensive results from the analysis of these data are presented in the following ten chapters, arranged according to different themes. In contrast, this chapter rather focuses on providing a broad overview of the results, with the focus particularly on unexpected results that provide new insights that would not have been possible to obtain before. This illustrates the immense value of this dataset.

The main new insights that were derived were the following:

1) Approximately one-third of matriculants ${ }^{1}$ that obtained Bachelor passes never go to university.

2) When considering only those matriculants who obtained Bachelor passes (the group considered as potential candidates for university degree programmes), overall university access is not biased against black students or significantly biased against students from lower quintile (poorer) schools. However, differences in access specifically to undergraduate degree programmes remain evident.

3) A large proportion of matriculants who do go to university do not enter university in the year following matric, but only one or more years later.

4) Matric marks are a good indicator of university access, but are only weakly related to eventual university success.

5) There are extremely large differences across universities in the average matric performance of students who attend these universities.

6) It takes a long time for many students to successfully obtain university qualifications.

7) Dropout rates at university, though high, are not as high as are often reported, because many students that are considered "drop-outs" from university in official statistics did not leave the university system, but changed their degree programme, switched from a degree to a diploma or certificate programme, or enrolled in a different university.

The analysis undertaken below is focused on these findings.

\section{How many qualifying students never attend university?}

A Bachelor pass in the National School Certificate (NSC) exams - these exams have been written since 2008 - is usually regarded as an indication that a student should be able to successfully enrol and complete a degree

\footnotetext{
${ }^{1}$ The term "matriculant" is here used to refer to all those full time candidates that write the NSC or matric exam, and to exclude those who may have attended grade 12 but were not full time candidates that wrote the exam.
} 
(Bachelor's) course at university ${ }^{2}$, though in practice universities and degree programmes use many different criteria. Nevertheless, Bachelor level passes can be used as a rough proxy for university readiness and is included in the minimum criteria for admission into undergraduate degree studies at most universities.

As many students only enter university a few years after having written the matric examinations, the final university access rate for a particular cohort of matriculants cannot be determined until quite a few years after they matriculate. One-year access rates do not give an accurate reflection of the eventual access rate, so it is desirable to investigate access rates over at least a few years. For the full 2008 matric cohort, the main focus of this study, the six-year access rate (i.e. access over the six years 2009 to 2014, the years for which HEMIS data were available) was $20.0 \%$ (Table A2). Amongst those who achieved Bachelor passes, the rate was $68.5 \%$, i.e. 76487 out of 111680 Bachelor passes. That means that just under a third of those who did perform well enough to achieve a Bachelor pass did not enrol in university in the next six years. Judging by the shorter period access data available for more recent matric cohorts in Table A2, the proportion of Bachelor pass students who enter university may be declining rather than increasing, though a trend towards later enrolment may be obscuring the trend in access.

Altogether 35193 matriculants who achieved Bachelors passes in 2008 did not continue on to university studies of any nature in the public sector. Of these, 13303 attended quintile 1 to 3 schools, and altogether 18195 were black Africans (Table 1). Even amongst the smaller group of 62873 matriculants who achieved $60 \%$ or above as matric average, almost a quarter (23.2\%) or 14582 did not attend university in the next six years (Table 2). Amongst the 52678 matriculants who achieved $55 \%$ or more for Mathematics, about one in five (20.6\%) or 10840 never entered university (Table 3). Amongst the select group of only 36812 matriculants who achieved a Bachelor pass, at least $60 \%$ in matric and at least 55\% in Mathematics, 4664 $(12.7 \%)$ did not attend university.

From the perspective of human resources, it thus appears as if there is a lot of "waste" in the sense that many students performing well in matric never go on to further university studies. ${ }^{3}$ In a skills hungry economy, this is surprising and worrying. It is even more so when this is the case for black students, or for students from poor backgrounds. The next section thus turns to evaluating to what extent access to university is skewed against black students or students from lower quintiles.

\section{Is access to university skewed for those who qualify for university?}

It is widely believed that access to university amongst those who qualify to go to university is skewed in favour of wealthier matriculants, and particularly to whites. This data for the first time allow a nationally representative analysis of university access. The results are surprising, in that there are only small differences in the composition of the two sub-groups of students who achieved Bachelor passes, namely those who do and those who do not access university in the subsequent six years. Only $63.4 \%$ of white matriculants from 2008

\footnotetext{
${ }^{2}$ Before the NSC, such passes were more appropriately referred to as university endorsements or university exemptions.

${ }^{3}$ It is likely that at least some of the learners who do not go to university may go to TVET colleges instead. Unfortunately, the HEMIS data used in this study contains no information on enrolments at private or public TVET colleges. Moreover, there is (to the authors' knowledge) no existing study or data source that provides information on the numbers of matric learners who continue on to TVET studies, despite having performed well enough in Matric to go to university.
} 
who had achieved Bachelor passes went on to study at university in the next six years, as against $71.2 \%$ for black matriculants with Bachelor passes. (Table 7.5). However, while 93\% of white students in this group entered for degree studies, only $75 \%$ of black students did. In other words, black learners who achieved Bachelor passes were comparatively more likely to enrol in undergraduate certificate or diploma programmes rather than undergraduate degree programmes than their white counterparts.

The black share of Bachelor passes for the 2008 matric cohort was 56.4\% (see Table 1), whereas the black share of students with Bachelor passes who gained access to university was even slightly higher, at 58.6\%. Matriculants in the poorest three school quintiles constituted $35.2 \%$ of all Bachelor passes, and a slightly lower $34.0 \%$ of those who gained university access, indicating that matriculants from such schools were slightly less inclined than average to gain university access. But the differences are not large.

Table 1: Characteristics of learners from the 2008 matric cohort who achieved Bachelor passes by access to university $(2009-2014)$

\begin{tabular}{lrrr}
\hline & No access $^{\mathrm{a}}$ & Access $^{\mathrm{b}}$ & \multicolumn{1}{c}{ All } \\
\cline { 2 - 4 } Number of candidates & 35193 & 76487 & 111680 \\
Share of 2008 matric cohort & 6.3 & 13.6 & 19.9 \\
Share of Bachelor passes & 31.5 & 68.5 & 100.0 \\
\hline \% Over-aged & 23.5 & 14.1 & 17.1 \\
\% Female & 53.6 & 56.9 & 55.9 \\
\% Black & 51.7 & 58.6 & 56.4 \\
\hline Matric average & 59.0 & 64.3 & 62.7 \\
\% offering Mathematics & 45.4 & 70.3 & 62.4 \\
Average Mathematics score & 51.7 & 64.7 & 61.7 \\
Average Mathematical Literacy score & 70.9 & 73.0 & 72.0 \\
\% offering Physical Sciences & 34.0 & 53.4 & 47.3 \\
Average Physical Sciences score & 47.4 & 56.9 & 54.8 \\
\% offering English Home Language & 33.4 & 43.1 & 40.0 \\
Average English Home Language score & 62.0 & 66.0 & 65.0 \\
Average English FAL score & 61.1 & 65.1 & 63.7 \\
\hline Average School Bachelor pass rate & 42.7 & 48.4 & 46.6 \\
\% in Quintile 1 - 3 schools & 37.8 & 34.0 & 35.2 \\
Average school wealth index & 0.9 & 1.0 & 1.0 \\
\hline
\end{tabular}

NOTES: Figures are calculated only for those learners from the 2008 matric cohort who achieved Bachelor passes and are disaggregated by whether or not they never enrolled ${ }^{[a]}$ or did enrol ${ }^{[b]}$ in undergraduate studies at some stage between 2009 and 2014.

Tables 2 and 3 provide similar information, but set as criterion not whether matriculants achieved Bachelor passes, but rather whether they achieved a matric average of $60 \%$, or whether they achieved a $55 \%$ or higher in Mathematics in matric. Both these tables indicate that, given such performances, blacks are slightly more likely to access university than the population as a whole. Considering their matric results, university access amongst black matriculants is significantly better than for white matriculants (given performance, white access is the lowest of all population groups). For the lower quintiles, the order varies, but again it does not appear as if there are large deficits in university access for children from the poorest quintiles who perform well in matric. 
Table 4 shows that even amongst the much smaller group of matriculants who achieved a Bachelor pass as well as an aggregate matric score of $60 \%$ and $55 \%$ in Mathematics, black students were slightly more likely to access university that their counterparts.

Table 2: Characteristics of learners from the 2008 matric cohort who achieved a matric average of $60 \%$ or higher by access to university $(2009-2014)$

\begin{tabular}{|c|c|c|c|}
\hline & No access $^{\mathrm{a}}$ & Access $^{b}$ & All \\
\hline Number of candidates & 14582 & 48291 & 62873 \\
\hline Share of 2008 matric cohort & 2.6 & 8.6 & 11.2 \\
\hline Share of $60 \%+$ achievers & 23.2 & 76.8 & 100.0 \\
\hline$\%$ Over-aged & 15.3 & 9.7 & 11.0 \\
\hline$\%$ Female & 59.7 & 58.8 & 59.0 \\
\hline$\%$ Black & 29.0 & 45.9 & 42.0 \\
\hline$\%$ achieving Bachelor passes & 92.5 & 99.0 & 97.5 \\
\hline$\%$ offering Mathematics & 41.1 & 73.8 & 66.2 \\
\hline Average Mathematics score & 65.3 & 72.4 & 71.4 \\
\hline Average Mathematical Literacy score & 79.9 & 79.7 & 79.8 \\
\hline$\%$ offering Physical Sciences & 30.6 & 56.9 & 50.8 \\
\hline Average Physical Sciences score & 56.2 & 62.7 & 61.8 \\
\hline$\%$ offering English Home Language & 43.0 & 49.4 & 47.9 \\
\hline Average English Home Language score & 66.0 & 69.2 & 68.6 \\
\hline Average English FAL score & 66.9 & 69.7 & 69.0 \\
\hline Average School Bachelor pass rate & 57.7 & 57.3 & 57.4 \\
\hline$\%$ in Quintile 1 - 3 schools & 16.9 & 23.0 & 21.6 \\
\hline Average school wealth index & 1.4 & 1.2 & 1.3 \\
\hline
\end{tabular}

Multivariate regression analysis (see section 10 below) also supports the conclusion that black learners are more likely to access university at a given level of matric performance than others, rather than the opposite, as is usually assumed. This applies even when one considers the socio-economic status (quintile and wealth index) of the school attended. This brings strong evidence that access to university amongst the black population is largely constrained by poor school results amongst many black matriculants, rather than other barriers to access. 
Table 3: Characteristics of learners from the 2008 matric cohort who achieved $55 \%$ or higher in NSC Mathematics by access to university $(2009-2014)$

\begin{tabular}{lrrr}
\hline & No access $^{\mathbf{a}}$ & Access $^{\mathrm{b}}$ & \multicolumn{1}{c}{ All } \\
\cline { 2 - 4 } Number of candidates & 10840 & 41838 & 52678 \\
Share of 2008 matric cohort & 1.9 & 7.4 & 9.4 \\
Share of 55\%+ Maths learners & 20.6 & 79.4 & 100.0 \\
\hline \% Over-aged & 25.4 & 10.8 & 13.8 \\
\% Female & 38.0 & 50.5 & 47.9 \\
\% Black & 61.5 & 51.6 & 53.6 \\
\hline Matric average & 59.3 & 67.7 & 66.0 \\
\% offering Physical Sciences & 81.4 & 80.2 & 80.4 \\
Average Physical Sciences score & 49.0 & 59.6 & 57.4 \\
\% offering English Home Language & 32.8 & 46.2 & 43.4 \\
Average English Home Language score & 64.4 & 69.0 & 68.3 \\
Average English FAL score & 57.8 & 66.8 & 64.6 \\
Average School Bachelor pass rate & 39.3 & 52.5 & 49.8 \\
\% in Quintile 1 - 3 schools & 48.4 & 29.9 & 33.7 \\
Average school wealth index & 0.7 & 1.1 & 1.0 \\
\hline
\end{tabular}

NOTES: Figures are calculated only for those learners from the 2008 matric cohort who achieved $55 \%$ or higher in NSC Mathematics and are disaggregated by whether or not they never enrolled ${ }^{[a]}$ or did enrol ${ }^{[b]}$ in undergraduate studies at some stage between 2009 and 2014.

Table 4: Characteristics of learners from the 2008 matric cohort who achieved (1) Bachelor passes, (2) a $60 \%$ overall matric average or higher, and (3) $55 \%$ or higher in NSC Mathematics by access to university $(2009-2014)$

\begin{tabular}{lrrr}
\hline & No access $^{\mathrm{a}}$ & Access $^{\mathrm{b}}$ & \multicolumn{1}{c}{ All } \\
\cline { 2 - 4 } Number of candidates & 4664 & 32148 & 36812 \\
Share of 2008 matric cohort & 0.8 & 5.7 & 6.6 \\
Share of 55\%+ Maths learners & 12.7 & 87.3 & 100.0 \\
\hline \% Over-aged & 13.7 & 7.8 & 8.6 \\
\% Female & 49.2 & 54.1 & 53.5 \\
\% Black & 35.4 & 42.6 & 41.7 \\
\hline \% offering Physical Sciences & 71.8 & 78.0 & 77.2 \\
Average Physical Sciences score & 59.2 & 63.9 & 63.4 \\
\% offering English Home Language & 47.9 & 50.5 & 50.2 \\
Average English Home Language score & 69.4 & 71.4 & 71.2 \\
Average English FAL score & 68.8 & 70.9 & 70.6 \\
Average School Bachelor pass rate & 58.0 & 58.9 & 58.8 \\
\% in Quintile 1 - 3 schools & 22.4 & 22.3 & 22.3 \\
Average school wealth index & 1.3 & 1.3 & 1.3 \\
\hline
\end{tabular}

NOTES: Figures are calculated only for those learners from the 2008 matric cohort who achieved $55 \%$ or higher in NSC Mathematics and are disaggregated by whether or not they never enrolled ${ }^{[a]}$ or did enrol $^{[b]}$ in undergraduate studies at some stage between 2009 and 2014. 


\section{How many matriculants delay entry into university studies?}

A fairly large proportion of matriculants who do go to university do not enter university in the year following matric, but only one or more years later. Figure 1 shows, for different matric cohorts, how access to university rises with each additional year after leaving school. The 2008 cohort is the only cohort that could be tracked for as long as six years. For this cohort, the access rate in the first year was $13.0 \%$ of all matriculants, while the 6 -year access rate eventually reached $20.0 \%$, implying that at most $65 \%$ of the cohort who accessed university did so immediately after matric. Amongst students who attained Bachelor passes in 2008, the oneyear and six-year university access rates were respectively $51.2 \%$ and $68.5 \%$ (Table A2). Trends for the subsequent cohorts are not very clear, though over the period 2008 to 2013, the one-year access rate has been improving. Although it appears as if delayed entry to university is also rising, the 2011 cohort appears to be an outlier and trends thereafter seem to have deviated from earlier trends, thus it is difficult to draw firm conclusions.

Figure 1: One to six year access rates for the 2008 to 2013 matric cohorts (\% of matriculants)

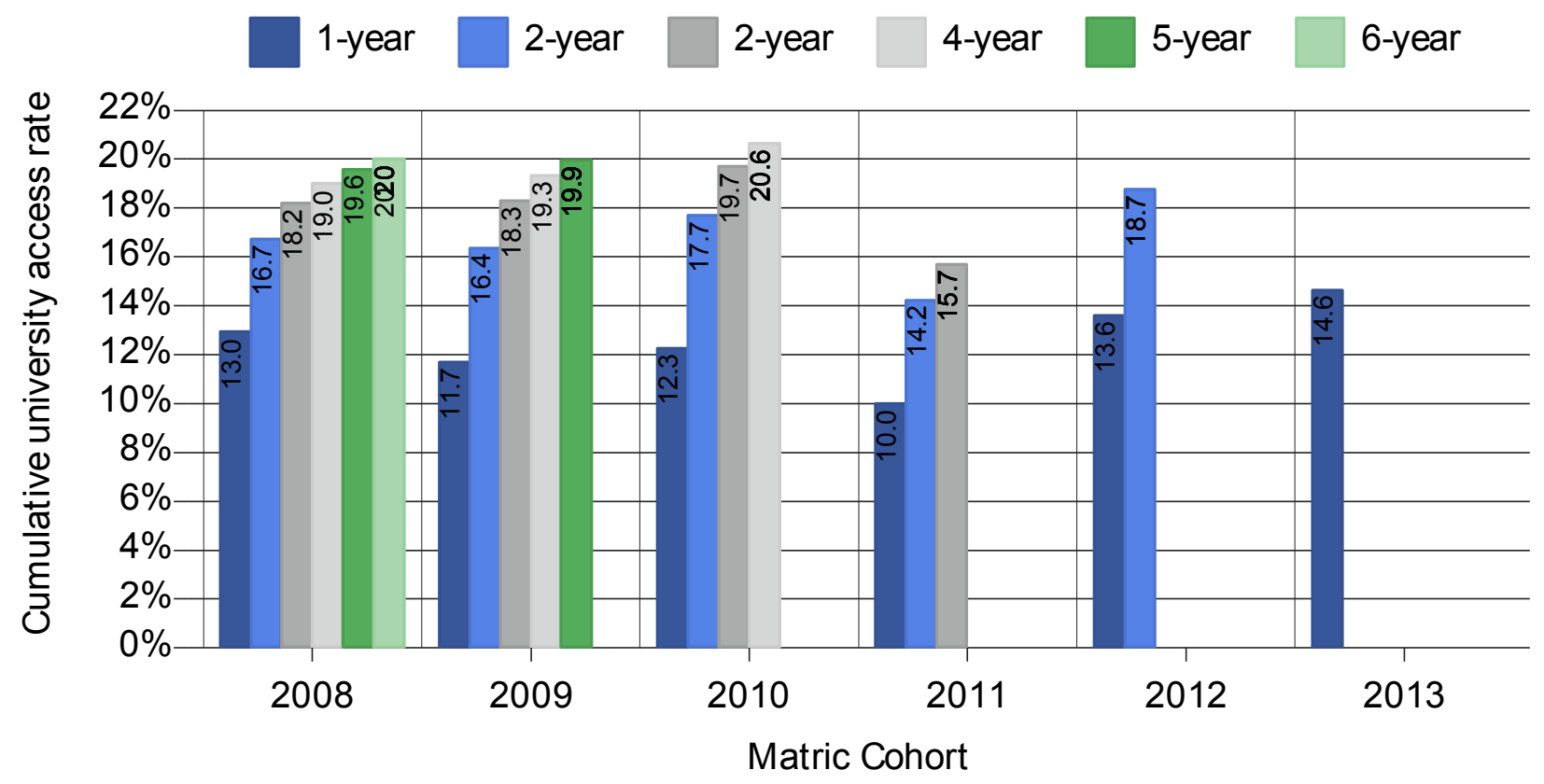

NOTES: Figures represent the estimated 1-year to 6-year university access rates for the 2008 to 2013 matric cohorts

\section{How good are matric marks as predictor of university access and of university success?}

Matric results to a large degree determine entry to university, but can also be expected to be a relatively good indicator of how well students are prepared for the demands that they are likely to face at university. One would thus expect matric results to act as predictor of both university access and university success. As Figure 2 shows, they do indeed, but not to the same extent. While the relationship between the average matric results obtained and university access over both a 1 and a 6 year timeframe is strong and positive, this relationship is somewhat weaker, though still positive, for university success, and negative for university dropout. The 
multivariate regression results (presented in Chapter 10 below) confirm that even once controls are added for race and other covariates, the influence of matric results on university access and university success remains, though the coefficient is much lower for the latter. Predicting university success based on observable factors is more difficult than predicting university access, which may be indicative of an articulation gap between school and university.

Figure 2: Cumulative Matric average achievement distribution for the 2008 matric cohort by enrolment and completion of undergraduate degree programmes between 2009 and 2014

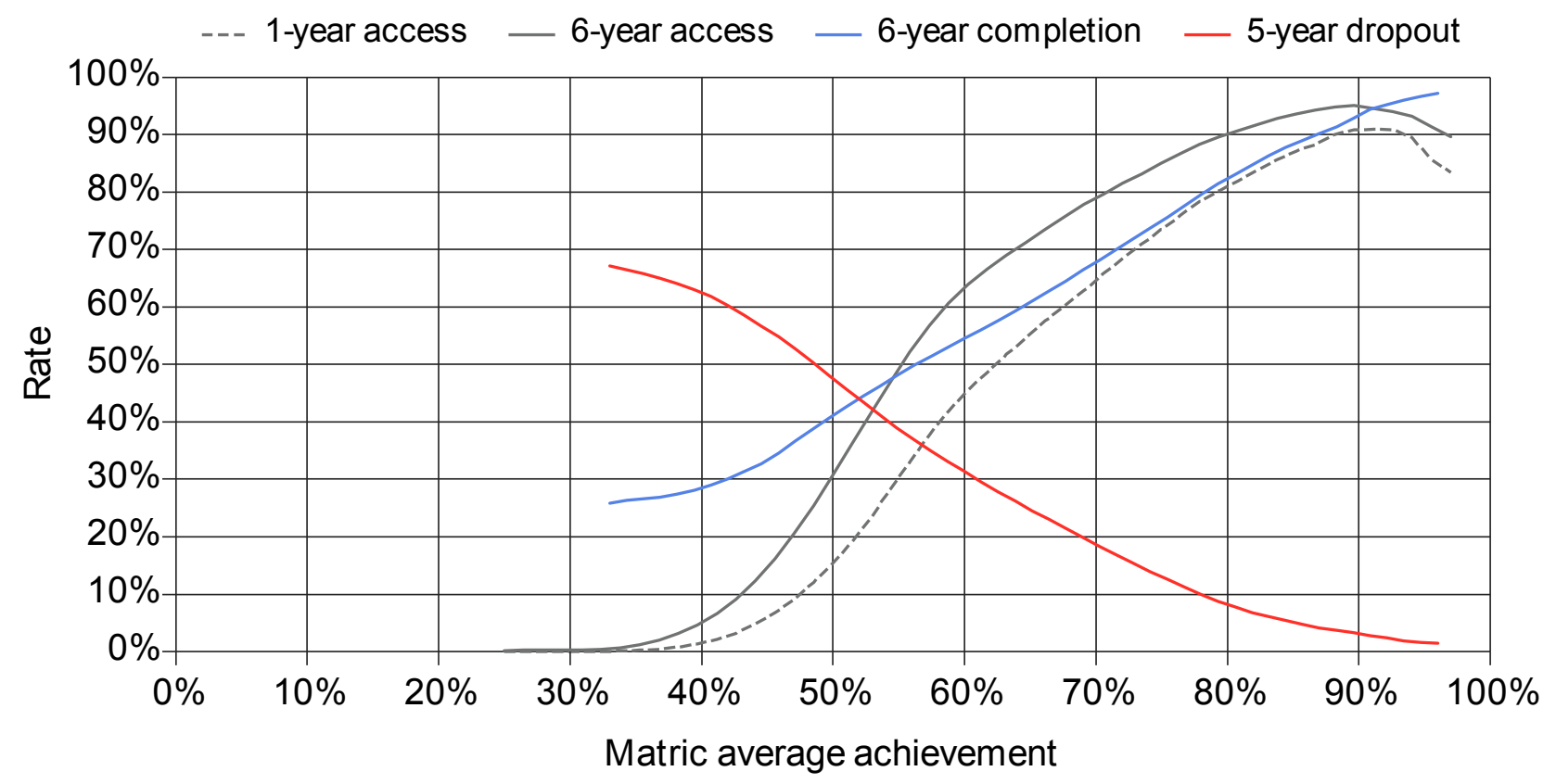

NOTES: Lines represent the expected 6-year access, 1-year access, 6-year completion, and 5-year dropout rates conditional on matric average achievement for learners from the 2008 matric cohort and were drawn using local polynomial regression. The curves for completion and dropout are only drawn for those learners from the cohort who enrolled in undergraduate studies for the first time in 2009.

\section{How much do matric results differ across the universities that students attend?}

There are extremely large differences across universities in the average matric performance of students who attend these universities. The range of these differences can be seen in Figure 3.6, which shows that the University of Cape Town, Stellenbosch University and University of Pretoria enrolled students who had average matric marks well above $70 \%$, while some other universities enrolled students that performed at around $55 \%$. One of the contributing factors is that some universities are more inclined to attract students for degree studies, while many technical universities have a smaller component of degree courses and more certificate and diploma students (see Figure 3.1). Nonetheless, Figure 3.7 shows that large differences in average matric performance between universities remain even when one considers only those students enrolled in undergraduate degree programmes.

\section{How long does it take students to complete degrees or diplomas?}

The maximum length of time that students could be tracked at university in the data at the disposal of the research team is six years, if they had enrolled in 2009. Of 2008 matriculants, 9.9\% (55 721) had completed an undergraduate qualification of some type by 2014; of those who had achieved Bachelor passes in 2008, $39.2 \%$ had (Table 1.1). Only 37862 matriculants from 2008 had completed a degree (as opposed to another 
qualification) by 2014 (Table 4.2), which is only $61.8 \%$ of those 2008 matriculants who had enrolled for a degree at a university (Table 4.3).

There is a substantial difference of 22 percentage points between four-year and six-year completion rates (Figure 3.3). This finding is of particular significance given that the vast majority of undergraduate programmes at South Africa universities have at most a 4-year minimum study time requirement for completion. Yet, there is clearly a significant share of students who only complete their qualifications after 5 or 6 years.

\section{How high are dropout rates from university?}

Dropout rates at university, though high, are not as high as are often reported, because many students that are considered "drop-outs" in official university statistics did not leave the university system, but changed their degree programme, switched from a degree to a diploma or certificate programme, or enrolled in a different university. Of the 112000 learners from the 2008 matric cohort who entered university, about 34000 or 30\% had dropped out before 2014 (Table 6.4). The five-year dropout rate was somewhat higher amongst coloured and black students (33\% and 32\%) than amongst Asians and whites (23\% and 17\%) (Table 7.3$)$.

\section{Broad conclusions}

The results reported here allow a much more nuanced understanding than available before of the transitions from school to university, and of how school results influence pathways through university. Clearly many of the patterns of university access and to a lesser extent university success that are observed are strongly influenced by school results. The weak school system has a major influence on who reaches matric, and how they perform in matric. This, and particularly the achievement of Bachelor passes, explains much of the differences in access to university by race, gender and province. Thus, for instance, the low university access rate observed for matriculants in the Eastern Cape to a large extent can be explained by the low proportion of its learners that achieved Bachelor passes.

The results reported here can be extended considerably through further analysis to focus on more specific questions. The unique nature of the data set used here provides many possibilities for further analysis. To improve the general understanding of the processes at school level that influence access to and success at university, two further steps are required. Firstly, the data set created and used in this analysis should be made available as a public resource, with the anonymisation that has already taken place. Secondly, this dataset should be expanded and updated annually, so that changing trends can be observed and addressed early, where required. 


\section{Introduction}

This summary report provides an overview of higher education (hereafter HE, or university ${ }^{4}$ ) access, entrance, completion, and exit patterns for the 2008 National Senior Certificate (hereafter NSC or matric) cohort over the period 2009 to $2014 .{ }^{5}$ The results are based on analysis of integrated data on NSC exam candidates and data on university enrolments and graduations across two separate databases. The data on the NSC candidates comes from the 2008 matric database, which contains learner-level unit-record information on all learners who wrote the NSC examinations in 2008. The information on university outcomes, on the other hand, was drawn from the Higher Education Management Information System (HEMIS) for the period 2009 to 2014 and contains student-level unit-record data on all enrolments and graduations in South Africa's public HE or university system. Provision, linking, and subsequent anonymisation of the NSC and HEMIS databases were done jointly by the Department of Basic Education (DBE) and the Department of Higher Education and Training (DHET).

\section{NSC exam results for the 2008 - 2013 national cohorts}

It is instructive to consider the relative matric performance of the 2008 matric cohort, compared with the 2009 - 2014 cohorts. Doing so provides some indication of the extent to which one can generalise the patterns of university outcomes observed for the 2008 matric cohort. Figure 1.1 shows the NSC exam results in terms of pass type for each matric cohort over the period 2008 - 2013. (The exact estimates corresponding with the information in this figure can be found in Table A1 in the Appendix.)

Aside from an initial decline in NSC candidate numbers between 2008 and 2011 and a subsequent increase thereafter, there appears to be a broad trend of improving matric results over time. Figure 1.1 shows that eversmaller percentages of candidates are failing the matric examinations, while larger shares are now passing with diploma and bachelor level passes. While only $42 \%$ of candidates passed with diploma or bachelor passes in 2008, for example, the corresponding figure for 2013 was $61 \%$. The improvement in average performance is also reflected in Figure 1.2, which shows the matric average distribution for all candidates who passed the matric exams from 2008 to $2013 .{ }^{6}$ The graph shows a consistent rightward shift in the performance distribution, i.e. that each year saw an improvement in matric results.

\subsection{University access for the 2008 - 2013 matric cohorts}

If matric performance is positively associated with university outcomes such as access and throughput, it would suggest that more recent cohorts should perform slightly better with respect to these outcomes than the 2008 matric cohort, which forms the focus of this report. Figure 1.3, which shows the one-year university access rates for matric cohorts by type of pass achieved, provides further support for this. ${ }^{7}$ It indicates that the

\footnotetext{
${ }^{4}$ Since the time when former technikons became universities of technology, there now no longer exist any public higher education institutions that are not universities. For the period under consideration, the terms HE and university are synonyms.

${ }^{5}$ Unless explicitly stated otherwise, the sample under consideration throughout includes only full-time matric learners who wrote the NSC exams at some stage between 2008 and 2013. Data on part-time learners appears to be incomplete and was only available for some years in the database received. ${ }^{6}$ In this report, the matric average refers to the average across the six highest marks that a learner achieved among the subjects that they offered in the NSC exam, provided that those subjects collectively satisfy the requirements for the NSC as described in DBE (2010: $3-5$ ).

${ }^{7}$ In the current context, the 1-year HE access rate expresses the number of learners enrolling in undergraduate studies immediately after completing matric as a percentage of the number of candidates in the original national matric cohort. See the Important definitions and caveats section at the end of this report for the definitions of HE participation, the HE access rate, and other important metrics used below.
} 
percentage of learners enrolling in undergraduate studies immediately after matric increased marginally from $13 \%$ in 2008 to 15\% in 2013 (see also Table A2 in the Appendix). Though this is appears encouraging, it is worth noting that the one-year access rate for learners achieving Higher Certificate, Diploma, or Bachelor passes has actually declined over time. For example, while roughly half of learners who achieved Bachelor level passes in the 2008 NSC examinations enrolled in undergraduate studies in the following year, only $43 \%$ of the 2013 NSC examination cohort followed suit. In other words, it would appear as though declining percentages of learners eligible for entry into undergraduate programmes are accessing universities immediately after completing matric.

The reason for these two seemingly contradictory trends in initial university participation among secondary school leavers is that learners who pass the matric examinations represent a rising share of candidates for each subsequent matric cohort. This rise in the percentage of candidates passing the NSC examinations has been sufficiently rapid to effectively counteract the decline in the percentage of passing learners who immediately continue on to HE studies.

Figure 1.1: NSC exam results for the 2008 - 2013 matric cohorts

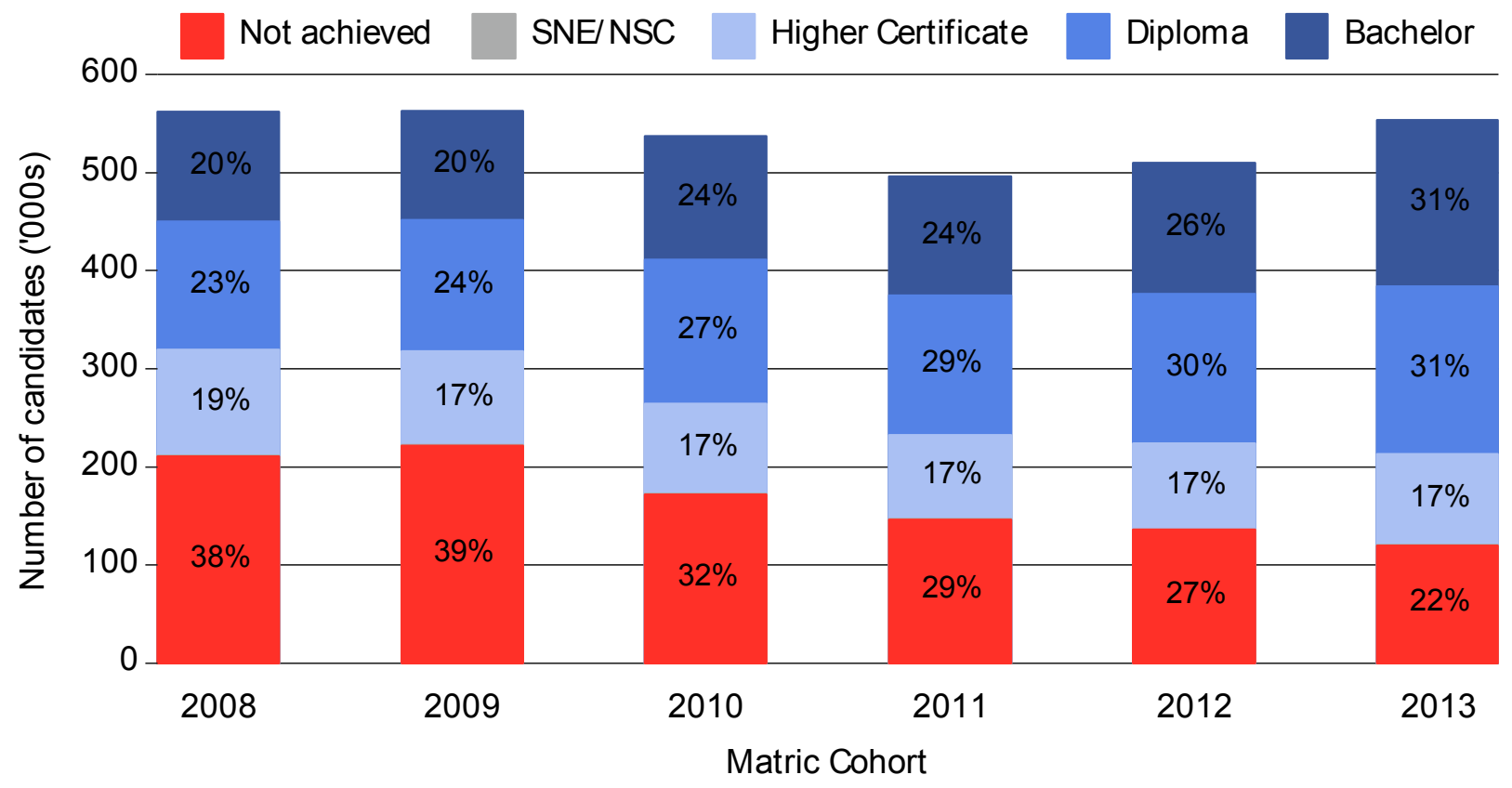

NOTES: Each bar reflects the NSC exam pass type composition for a particular matric cohort with the various segments reflecting the number/percentages of candidates from the cohort who achieved a particular pass result. The percentage values indicated have been rounded to the nearest integer. Estimates are based on the numbers in Table 1 ( $\mathrm{p} 1$ of the Appendix). 
Figure 1.2: Matric average achievement distributions for the 2008 - 2013 matric cohorts

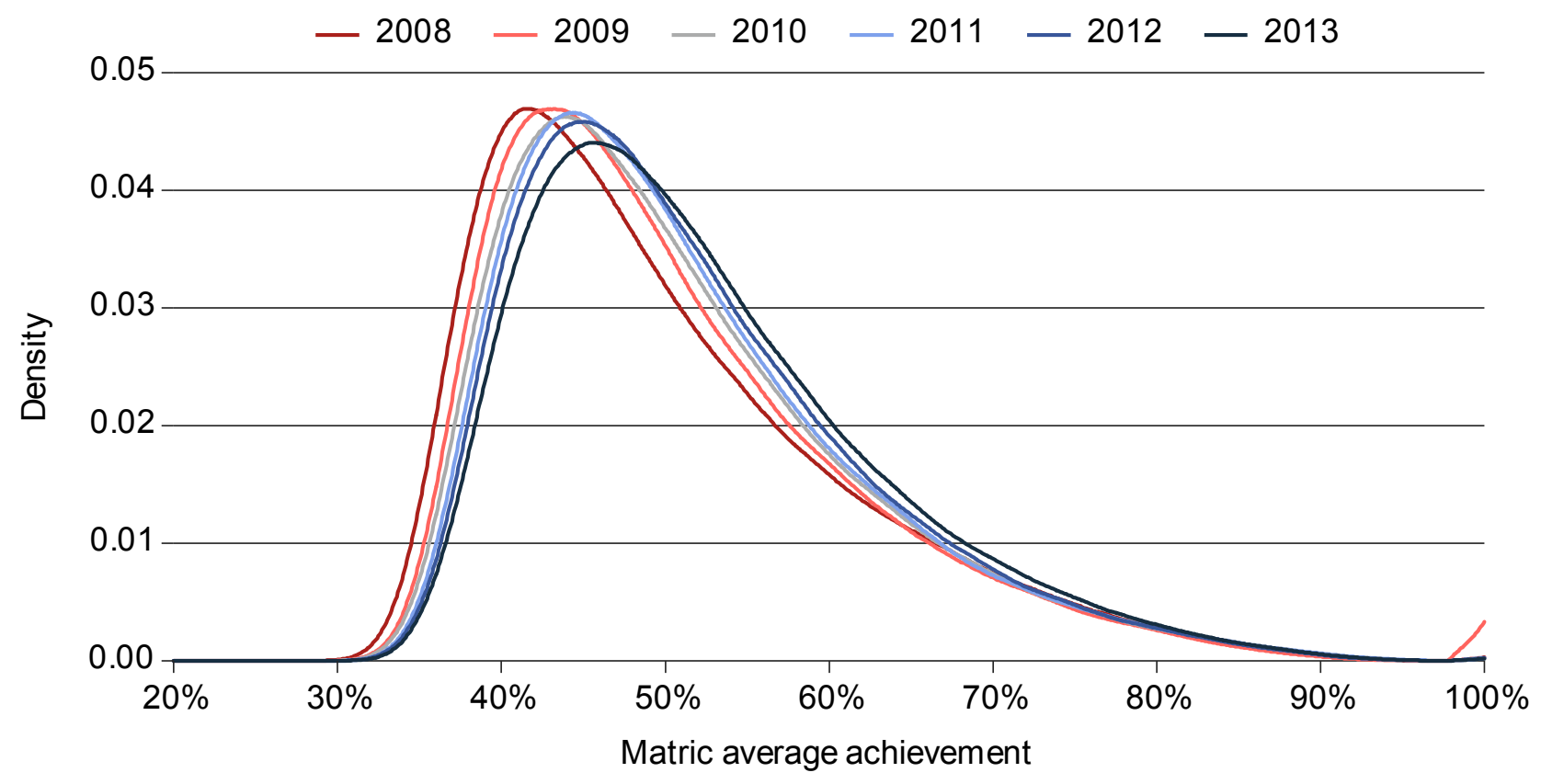

NOTES: Each line represents the matric average achievement distribution for a particular matric cohort.

Figure 1.3: 1-year university access rates for the 2008 - 2013 matric cohorts by pass type

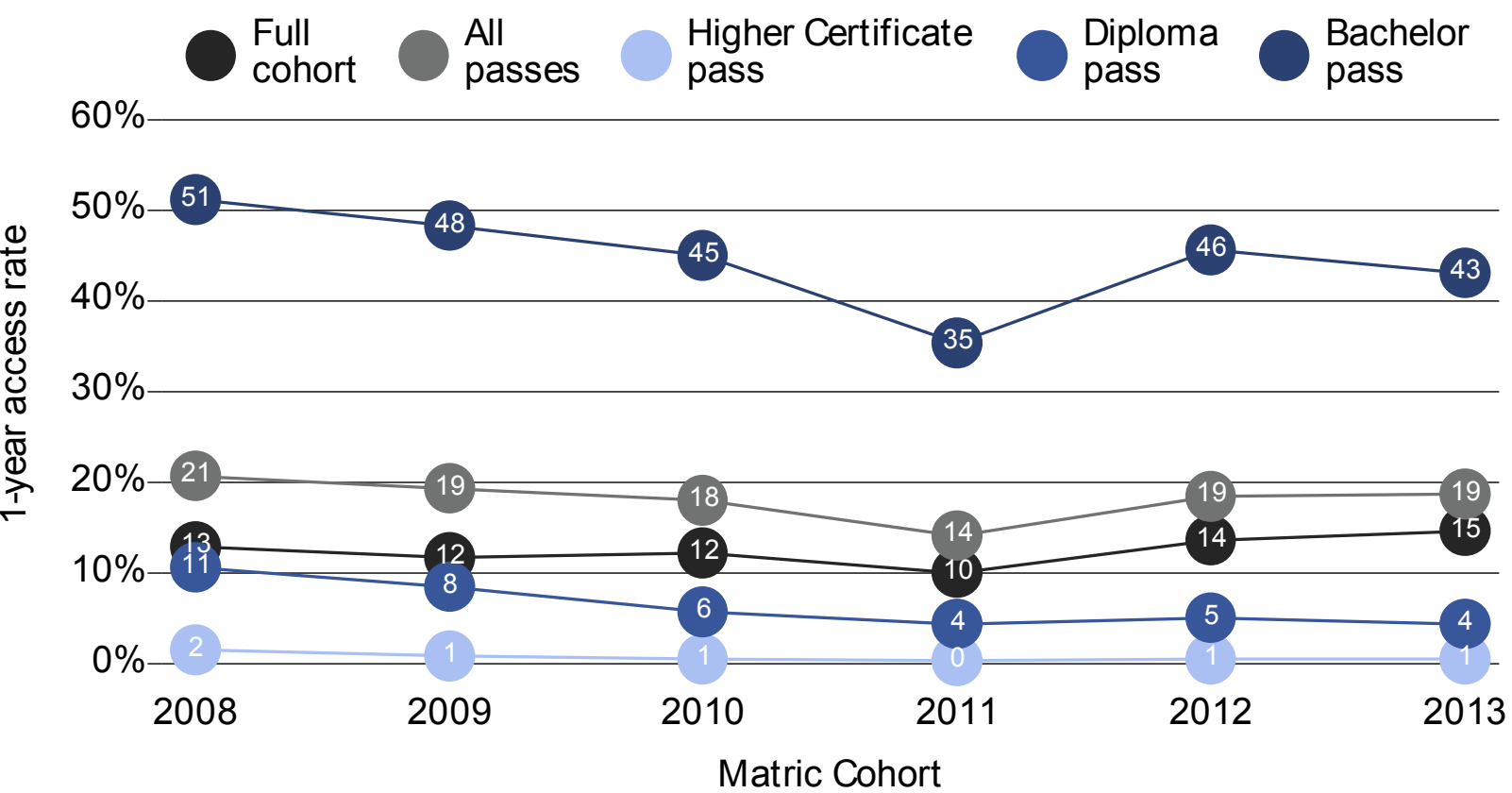

NOTES: Dots represent the estimated 1-year university access rates for the $2008-2013$ matric cohorts, disaggregated by the type of pass achieved in the NSC exams. Numbers inside the dots have been rounded to the nearest integer.

Thus, while only $13 \%$ of the 2008 matric cohort acceded into university in the year immediately following matriculation, and 15\% of the 2013 matric cohort did so, a larger proportion (21\%) of those who were eligible for entry into university from the 2008 matric cohort enrolled in undergraduate studies in 2009 than was the case for eligible candidates from the 2013 cohort who enrolled in 2014 (19\%). Of course, the one-year university access rate only provides an indication of initial participation in university, while many individuals 
only access university with some delay after matriculating. ${ }^{8}$ Table A2 in the Appendix presents one-year to six-year university access rates for the 2008 - 2013 matric cohorts. A number of inferences about the extent and nature of delayed entry can be drawn from this.

First, the extent of delayed entry into university is substantial. The figures for the $2008-2010$ cohorts suggest that only between $59 \%$ and $69 \%$ of the learners who enter undergraduate studies within four years of writing the NSC examinations do so in the year immediately after matric. ${ }^{9}$ Second, delayed university entry is most severe for learners who achieve Diploma or Higher Certificate passes. Third, there is a marked difference in university participation among learners who achieve Higher Certificate, Diploma, or Bachelor passes in matric. This is hardly surprising, as there are many reasons why learners who perform better in matric are more likely to access university, not least because having achieved a certain type of pass generally serves as a prerequisite for entry into specific undergraduate programmes ${ }^{10}$. While these differences decline over time, they remain large even four years after writing matric. For example, the four-year access rates for Bachelor pass candidates from the 2008 - 2010 matric cohorts was between 3 and 4 times greater than the four-year access rates for Diploma pass candidates, and between 15 to 20 times greater than for Higher Certificate pass candidates. Finally, the data suggests that the extent and timing of university participation among matric cohorts may be changing over time. Specifically, the extent of university participation over the short-run access horizon seems to be declining over time, delayed entry seems to be increasing over time, and the gap in university access rates between Higher Certificate, Diploma, and Bachelor pass candidates appears to be growing. However, as shown above, one should be careful of drawing inferences about changes in university participation when it is not possible to observe the extent of university access among cohorts for the same number of years.

\subsection{University access, entrance, completion, and exit patterns among matric cohorts}

Table 1.1 shows the cumulative percentage of the 2008 - 2013 matric cohorts who had completed undergraduate qualifications by the end of 2014, further disaggregated by the type of pass achieved in the NSC examinations.

Only a small percentage of all matriculants complete any undergraduate qualification (whether a degree, a diploma or a certificate) within the first four to six years following matric. The figures for the $2008-2010$ cohorts suggest that only between $5 \%$ and $6 \%$ of learners entered and completed undergraduate studies within four years of writing the NSC examinations. As for university success, there is a marked difference in the percentage of Higher Certificate, Diploma, and Bachelor pass candidates who achieve undergraduate qualifications within four to six years following matric.

Apart from the two inferences above, it would be imprudent to draw any further conclusions about university programme completion or dropout from the estimates in Table 3 . The problem lies in the fact that the table

\footnotetext{
${ }^{8}$ See Van Broekhuizen (2016: 51 - 54) for a discussion of delayed HE entry among secondary school leavers in the Western Cape, for example.

${ }^{9}$ Delayed entry is particularly prevalent at UNISA. The figures for the $2008-2010$ matric cohorts show that between $27 \%$ and $33 \%$ of learners who enter undergraduate studies at UNISA within four years of writing the NSC exams do so in the year immediately after matric. The comparable figures for the rest of the system (i.e. excluding UNISA) are between $63 \%$ and $74 \%$.

${ }^{10}$ See Van Broekhuizen (2016) for a discussion of some of these factors.
} 
shows how many students completed undergraduate qualifications between 2009 and 2014 as a percentage of all candidates in the respective matric cohorts, many of whom either never enrolled in university or did not do so in the period for which HEMIS data was available, i.e. up to 2014. This makes sensible comparison of programme completion and dropout over time nearly impossible.

Table 1.1: Cumulative percentage of the 2008 - 2013 matric cohorts who completed undergraduate qualifications, by pass type

\begin{tabular}{|c|c|c|c|c|c|c|c|}
\hline & \multirow[b]{2}{*}{ Year $^{\mathrm{a}}$} & \multicolumn{6}{|c|}{ Matric Cohort } \\
\hline & & 2008 & 2009 & 2010 & 2011 & 2012 & 2013 \\
\hline \multirow{6}{*}{ 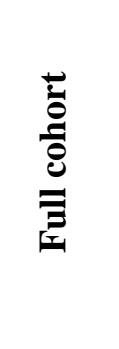 } & 1 & 0.0 & 0.0 & 0.0 & 0.0 & 0.0 & 0.0 \\
\hline & 2 & 0.1 & 0.1 & 0.1 & 0.1 & 0.2 & - \\
\hline & 3 & 2.0 & 2.2 & 2.3 & 2.0 & - & - \\
\hline & 4 & 5.4 & 5.8 & 6.3 & - & - & - \\
\hline & 5 & 8.1 & 8.7 & - & - & - & - \\
\hline & 6 & 9.9 & - & - & - & - & - \\
\hline \multirow{6}{*}{ 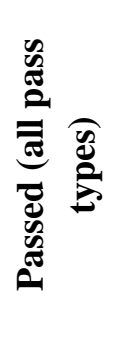 } & 1 & 0.0 & 0.0 & 0.0 & 0.0 & 0.0 & 0.1 \\
\hline & 2 & 0.1 & 0.1 & 0.2 & 0.2 & 0.3 & - \\
\hline & 3 & 3.3 & 3.6 & 3.4 & 2.8 & - & - \\
\hline & 4 & 8.7 & 9.5 & 9.1 & - & - & - \\
\hline & 5 & 13.0 & 14.2 & - & - & - & - \\
\hline & 6 & 15.8 & - & - & - & - & - \\
\hline \multirow{6}{*}{ 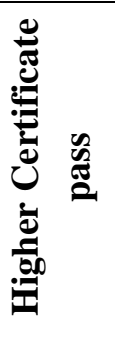 } & 1 & 0.0 & 0.0 & 0.0 & 0.0 & 0.0 & 0.0 \\
\hline & 2 & 0.0 & 0.0 & 0.1 & 0.1 & 0.2 & - \\
\hline & 3 & 0.2 & 0.2 & 0.2 & 0.2 & - & - \\
\hline & 4 & 0.5 & 0.5 & 0.5 & - & - & - \\
\hline & 5 & 1.0 & 1.0 & - & - & - & - \\
\hline & 6 & 1.4 & - & - & - & - & - \\
\hline \multirow{6}{*}{ 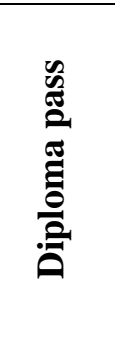 } & 1 & 0.0 & 0.1 & 0.0 & 0.0 & 0.0 & 0.1 \\
\hline & 2 & 0.1 & 0.1 & 0.2 & 0.2 & 0.5 & - \\
\hline & 3 & 1.3 & 1.3 & 1.1 & 0.9 & - & - \\
\hline & 4 & 3.6 & 3.8 & 3.0 & - & - & - \\
\hline & 5 & 6.0 & 6.5 & - & - & - & - \\
\hline & 6 & 7.9 & - & - & - & - & - \\
\hline \multirow{6}{*}{ 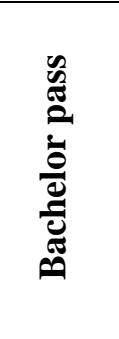 } & 1 & 0.0 & 0.0 & 0.0 & 0.0 & 0.0 & 0.1 \\
\hline & 2 & 0.2 & 0.2 & 0.2 & 0.2 & 0.2 & - \\
\hline & 3 & 8.6 & 9.4 & 8.4 & 7.0 & - & - \\
\hline & 4 & 22.5 & 24.1 & 22.6 & - & - & - \\
\hline & 5 & 32.8 & 34.9 & - & - & - & - \\
\hline & 6 & 39.2 & - & - & - & - & - \\
\hline
\end{tabular}

NOTES: Figures represent the cumulative percentage of the respective matric cohorts who completed undergraduate qualifications in the public university system within a specified number of years after writing the NSC examinations, disaggregated by the type of pass achieved in the NSC exams. ${ }^{[a]}$ Number of years following the NSC exams (e.g. 1 year represents the year immediately following the year in which the NSC was written). 
Blom (2014: 12) notes that tracking cohorts through undergraduate study in South Africa for the purposes of estimating completion or dropout rates requires a minimum time frame of four years. Parker \& Sheppard (2015: 15) argue that the estimation of completion and dropout rates in university requires data that extends at least two years beyond the formal minimum time requirements for programme study, i.e. five years for the typical three year Bachelor degree programme. For this reason, this report focuses on university outcomes of the 2008 matric cohort. While this limits the generalisability of the findings, it allows a comprehensive analysis of university entrance, completion and exit patterns of a cohort of matriculants for six years following matric. To the extent that broadly similar patterns can be expected for the 2009 - 2013 matric cohorts, focussing on the cohort that can be tracked the longest provides valuable insight into patterns of university access and success in South Africa.

\subsection{University access, entrance, completion, and exit patterns among the 2008 matric cohort}

Table 1.2 summarises the university enrolment flows for the 2008 national matric cohort along with dropout and completion estimates for the years 2009 to 2014 . Roughly $20 \%$ of the cohort accessed university at some stage during the first six years following the 2008 matric exams. However, only about $65 \%$ of this group commenced with their undergraduate studies in the year immediately following matriculation. A significant share of the university participants from the cohort thus only entered the university system two years or longer after writing matric. The rate of decline in the marginal access rates over the first six years suggest that less than $22 \%$ of the cohort will ultimately have enrolled in university.

In $2014,7 \%$ of the cohort was still enrolled in undergraduate programmes with a further $1.3 \%$ enrolled in postgraduate programmes. The bulk of this group (78\%) were non-first-time entering students who had not yet completed any undergraduate qualification prior to 2014 . Only $5 \%$ were first-time entering students and the remaining $16 \%$ were students who had already completed some sort of undergraduate qualification and were enrolled for a further postgraduate programme. Furthermore, by the start of $2014,40 \%$ of the learners who entered university between 2009 and 2014 were no longer enrolled in university. Roughly half of this group were students who dropped out of university without completing any formal qualification, while the other half were no longer enrolled on account of the fact that they had already completed their undergraduate studies prior to 2014. In other words, the estimates in Table 1.2 suggest that the number of students from the cohort who left university over the first five years because of dropout was roughly equal to the number of students who left because of completion.

The proportion of university participants who had successfully completed an undergraduate qualification increased dramatically in the sixth year following matriculation of the 2008 matric cohort. By the end of 2014, 49.6\% of learners who had enrolled in university between 2009 and 2014 had completed at least one undergraduate qualification. This amounts to about $10 \%$ of the 2008 matric cohort successfully completing undergraduate qualifications within 6 years of writing the NSC exams. Given the extent of delayed university entry, it is likely that these completion figures would have continued to rise in the years after 2014. It is worth noting, however, that only $69 \%$ of the students from the cohort who completed undergraduate qualifications 
over this period completed undergraduate degrees (see Table A3 in the appendix). This amounts to just 7\% of the original 2008 matric cohort completing undergraduate degrees within six years of writing the NSC exams.

Table 1.2: University enrolment, exit and completion for the 2008 matric cohort (2009 - 2014)

\begin{tabular}{|c|c|c|c|c|c|c|}
\hline & \multicolumn{6}{|c|}{ Percentage of the 2008 matric cohort } \\
\hline & 2009 & 2010 & 2011 & 2012 & 2013 & 2014 \\
\hline Enrolled & 12.9 & 14.9 & 15.0 & 13.8 & 11.0 & 8.1 \\
\hline - First-time entering & 12.9 & 3.8 & 1.4 & 0.8 & 0.6 & 0.4 \\
\hline - Non-entering undergraduate & - & 11.1 & 13.5 & 12.2 & 9.2 & 6.3 \\
\hline - Non-entering postgraduate & - & - & 0.0 & 0.8 & 1.2 & 1.3 \\
\hline Not enrolled & 87.1 & 85.1 & 85.0 & 86.2 & 89.0 & 91.9 \\
\hline - Non-participants & 87.1 & 83.3 & 81.8 & 81.0 & 80.4 & 80.0 \\
\hline - Exit HE - Completers ${ }^{\mathrm{a}}$ & - & 0.0 & 0.0 & 0.6 & 3.0 & 5.9 \\
\hline - Exit HE - Non-Completers ${ }^{\mathrm{a}}$ & - & 1.2 & 2.4 & 3.6 & 4.7 & 6.1 \\
\hline Completers $^{\mathrm{a}}$ & 0.0 & 0.1 & 2.0 & 5.4 & 8.1 & 9.9 \\
\hline - Completers (non-cumulative) & 0.0 & 0.1 & 2.0 & 3.4 & 2.7 & 1.8 \\
\hline Dropouts $^{a}$ & 1.2 & 2.4 & 3.6 & 4.7 & 6.1 & - \\
\hline - Dropouts (non-cumulative) & 1.2 & 1.2 & 1.2 & 1.1 & 1.4 & - \\
\hline
\end{tabular}

NOTES: Estimates are expressed as a percentage of the number of learners in the 2008 matric cohort. 'Completers' refers to students who successfully completed undergraduate qualifications between 2009 and 2014 whereas 'Dropouts' refers to students who left university prior to 2014 without having completed any undergraduate qualification. ${ }^{[\mathrm{a}]}$ Numbers are cumulative.

While Table 1.2 provides a useful summarisation of university completion and dropout among the 2008 matric cohort between 2009 and 2014, it does not accurately reflect university completion, dropout, and retention rates among first-time entering university students. This is because learners from the cohort who entered university in 2013 are lumped together with learners who entered university in 2009. Yet, it should be obvious that learners who entered the university system in 2009 would have had more opportunity to complete their qualifications or drop out of their studies by the end of 2014 than learners who only entered university in 2013. For this reason, it is preferable to focus on a specific first-time entering undergraduate cohort when estimating completion, dropout, and retention rates. This is particularly true if one wishes to compare university completion, dropout, and retention between different matric cohorts. In addition, it is preferable to focus on first-time entering undergraduate cohorts that can be tracked through university for as long a period as is possible. In effect, the longer one can track any first-time entering undergraduate cohort through university, the closer estimates of dropout and completion rates will be to the ultimate dropout and completion rates for that cohort (see the 'Important definitions and caveats' section at the end of this report).

In order to overcome these limitations, Table 1.3 therefore presents the access rates for the learners from the 2008 matric cohort along with the respective completion, dropout, and retention rates for students from the cohort who commenced with their undergraduate studies in 2009. This particular undergraduate cohort is 
hereafter referred to as the '2009 first-time entering undergraduate cohort' and was chosen primarily because it could be tracked through university for a period of six years. ${ }^{11}$

The estimates in the table indicate almost $60 \%$ of the NSC 2009 first-time entering undergraduate cohort completed their undergraduate qualifications within the first six years of their studies while nearly $30 \%$ had dropped out within five years. The table also reflects an important fact about the structure of programme completion and university dropout over the enrolment horizon, namely that programme completion is subject to the minimum study time requirements associated with a particular program whereas university dropout is not. For example, it is possible to drop out of university after one year of studying a four-year Bachelor's degree, but it is not possible to complete that programme within one year. This explains why the estimated dropout rate for the NSC 2009 first-time entering undergraduate cohort exceeded the estimated completion rate over the first three years of the enrolment horizon, particularly considering the fact that $94 \%$ of the NSC 2009 first-time entering undergraduate cohort were enrolled for three or four-year undergraduate programmes in 2009. It is only after four years (2012) that the completion rate overtook the dropout rate for the cohort. Despite this, the four-year completion rate for the cohort was still fairly low at about $37 \%$.

Extrapolating from the observed completion and dropout rate schedules in Table 1.3, it seems likely that two thirds of the NSC 2009 first-time entering undergraduate cohort will have ultimately completed their undergraduate qualifications, with the remaining third dropping out of university without completion.

Table 1.3: University access, completion, dropout, and retention rates (\%) for the 2008 matric and 2009 firsttime entering undergraduate NSC cohorts (2009 - 2014)

\begin{tabular}{|c|c|c|c|c|c|c|}
\hline & $\begin{array}{l}1 \text { year } \\
\text { (2009) }\end{array}$ & $\begin{array}{c}2 \text { years } \\
(2010)\end{array}$ & $\begin{array}{c}3 \text { years } \\
(2011)\end{array}$ & $\begin{array}{l}4 \text { years } \\
\text { (2012) }\end{array}$ & $\begin{array}{c}5 \text { years } \\
(2013)\end{array}$ & $\begin{array}{c}6 \text { years } \\
(2014)\end{array}$ \\
\hline Access rate & 12.9 & 16.7 & 18.2 & 19.0 & 19.6 & 20.0 \\
\hline Completion rate & 0.2 & 0.5 & 15.4 & 36.9 & 50.3 & 58.1 \\
\hline Dropout rate & 9.2 & 14.5 & 19.2 & 23.4 & 28.4 & \\
\hline Retention rate ${ }^{a}$ & 85.6 & 80.4 & 60.9 & 36.9 & 21.1 & \\
\hline
\end{tabular}

NOTES: Access rates are estimated for learners from the 2008 matric cohort while completion, dropout, and retention rates are only estimated for students from this cohort who enrolled in undergraduate studies for the first time in 2009. Access, completion, and dropout rates are cumulative. ${ }^{[a]}$ The retention rate presented in the table reflects the estimated percentage of students from the 2009 first-time entering cohort who had not yet completed any qualification, but were still enrolled in undergraduate studies in the following year.

\section{Geographical location}

This section examines the extent to which university outcomes are associated with the province and district of the secondary school attended by learners from the 2008 matric cohort to establish whether there is an association between the geographical location of the school and subsequent university performance.

\footnotetext{
${ }^{11}$ Note that, unless otherwise specified, any reference to first-time entering undergraduate cohort(s) in this report refers specifically to learners from the 2008 matric cohort who enrolled in undergraduate studies in the public university system for the first time in a particular year.
} 
As the 'school district' field in the Department of Basic Education's (DBE) Masterlist of schools is notoriously poorly captured, some members of the 2008 matric cohort could not be linked to school district information.

\subsection{Province}

Figure 2.1 summarises the 2008 NSC exam results by school province. The differences between provinces is striking: the two best-performing provinces (Western Cape and Gauteng) achieved pass rates in excess of 75\% (see Table A4 in the Appendix for exact figures), while the Eastern Cape, Mpumalanga and Limpopo all achieved pass rates below 55\%. In Gauteng and the Western Cape, roughly $40 \%$ of the passes achieved were Bachelor passes. On the other hand, less than a quarter of the passes in Mpumalanga and Limpopo were Bachelor passes. While less than half (47.6\%) of all national Bachelor passes were achieved in schools in the Eastern Cape, KwaZulu Natal, Mpumalanga and Limpopo, these four provinces accounted for nearly two thirds (62\%) of the 2008 matric cohort (see Table A4 in Appendix).

Figure 2.1: Provincial 2008 NSC pass rates

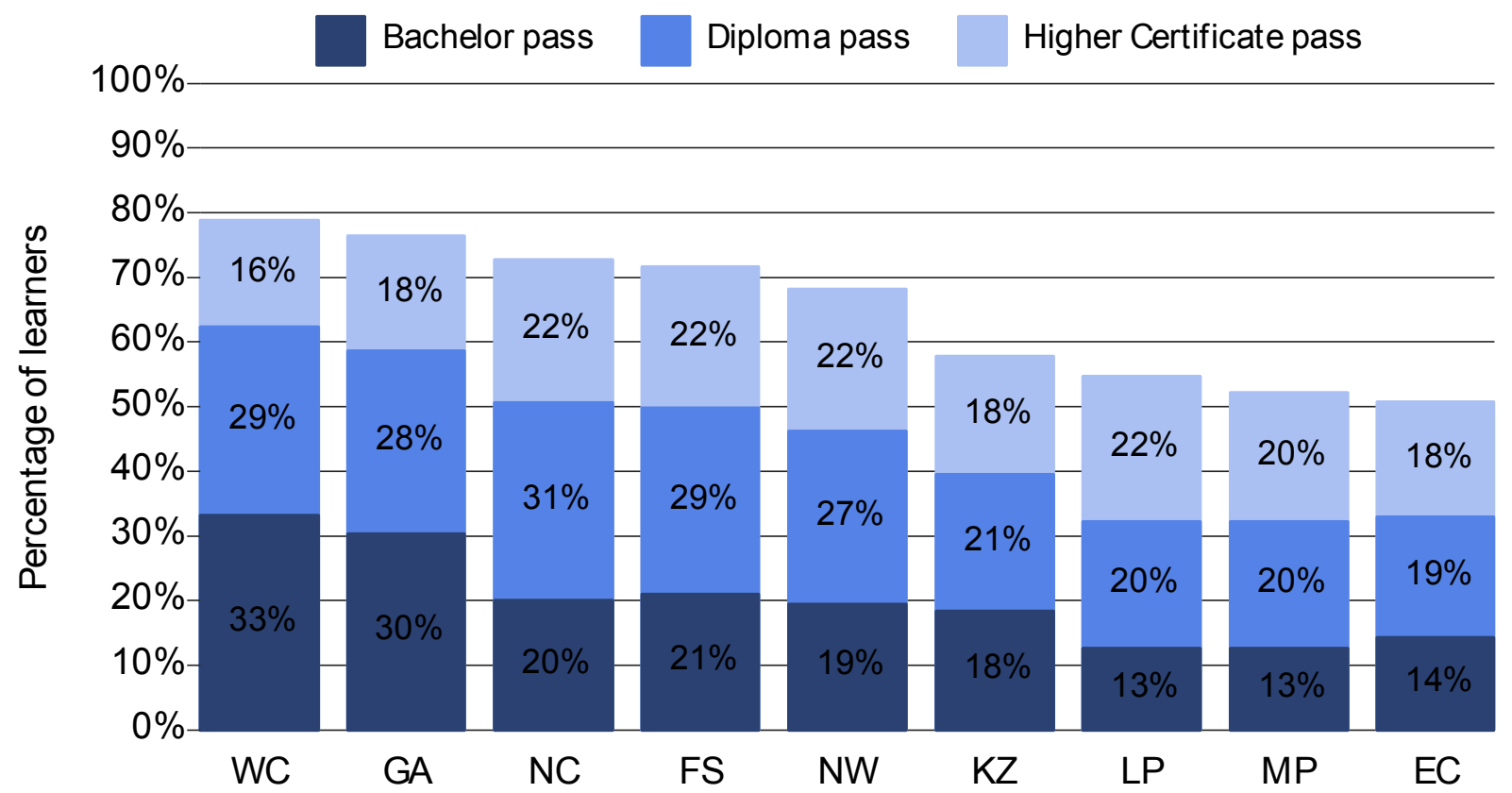

NOTES: Bars respectively represent the percentage of candidates in each provincial 2008 matric cohort who passed with Bachelor, Diploma, or Higher Certificate passes. The percentage values indicated have been rounded to the nearest integer. Estimates are based on the numbers in Table A4 of the Appendix.

Figure 2.2 compares the cumulative matric average achievement distributions for the respective provincial 2008 matric cohorts. There are significant differences in the proportions of learners achieving an average grade of above $50 \%$ in matric: while this proportion is roughly $40 \%$ for the Western Cape, it is about $25 \%$ for KwaZulu Natal and North West, and less than 20\% for both Limpopo and the Eastern Cape. The provincial differences in the proportions of learners who achieved an average matric grade of $60 \%$ or above are just as striking: roughly $21 \%$ of learners from the Western Cape achieved this grade, while only about $6 \%$ and $7 \%$ from learners from Limpopo and Eastern Cape did so. 
Given these vast provincial differences in matric performance, one might also expect provincial differences in university access and success. Figure 2.3 below and Table A5 in the Appendix summarise university access, completion, and dropout rates for the 2008 provincial matric cohorts. Dropout and completion rates are calculated only for those learners who enrolled in university in 2009, the year immediately following their matric examinations, in order to exclude the effect of delayed entry into university.

Figure 2.2: Cumulative matric average achievement distribution for the 2008 matric cohort, by province

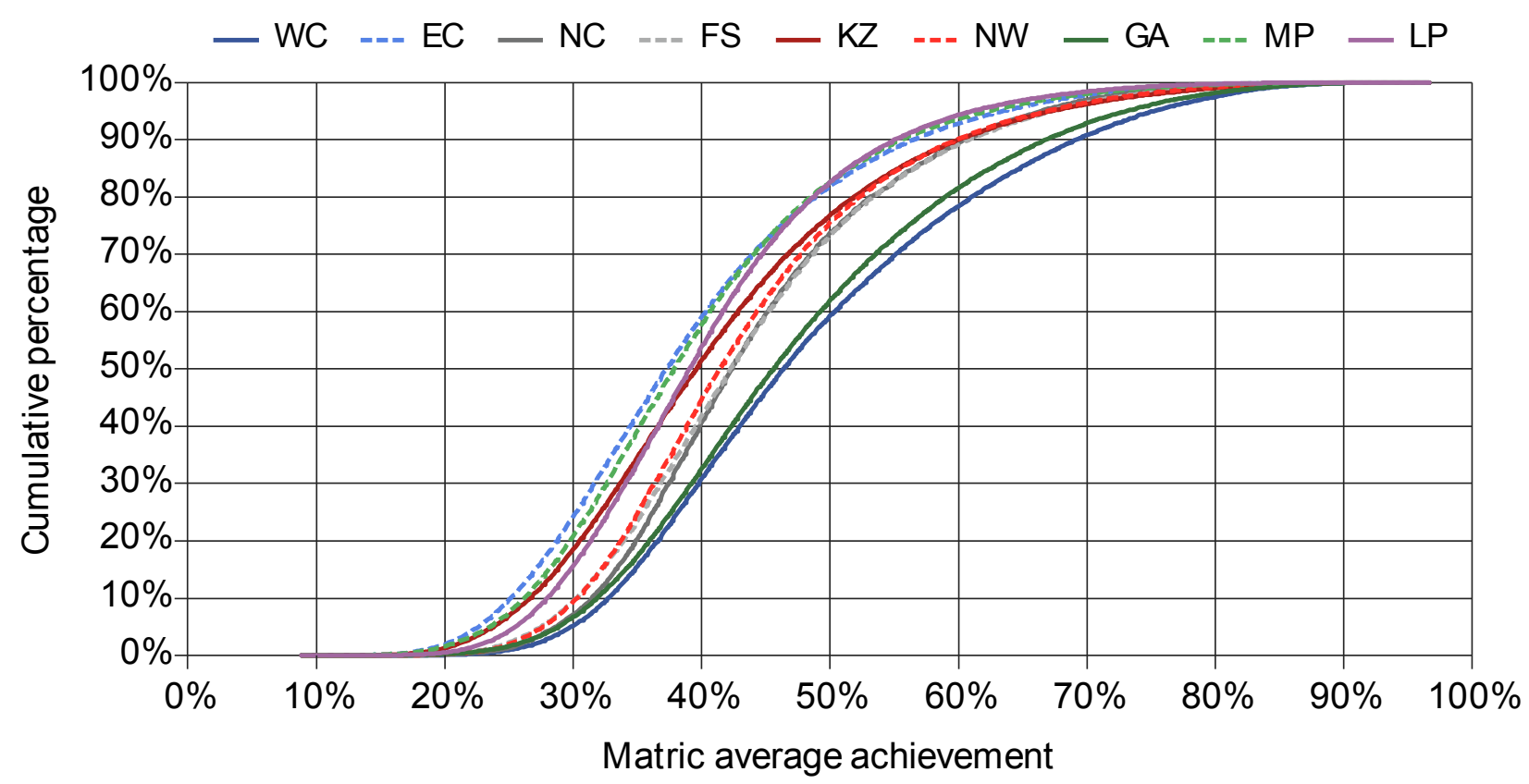

NOTES: Each line represents the cumulative percentage of a group that performed below a given level of 2008 NSC matric average achievement.

Figure 2.3: Provincial university access, completion, and dropout rates (\%) for the 2008 matric cohort

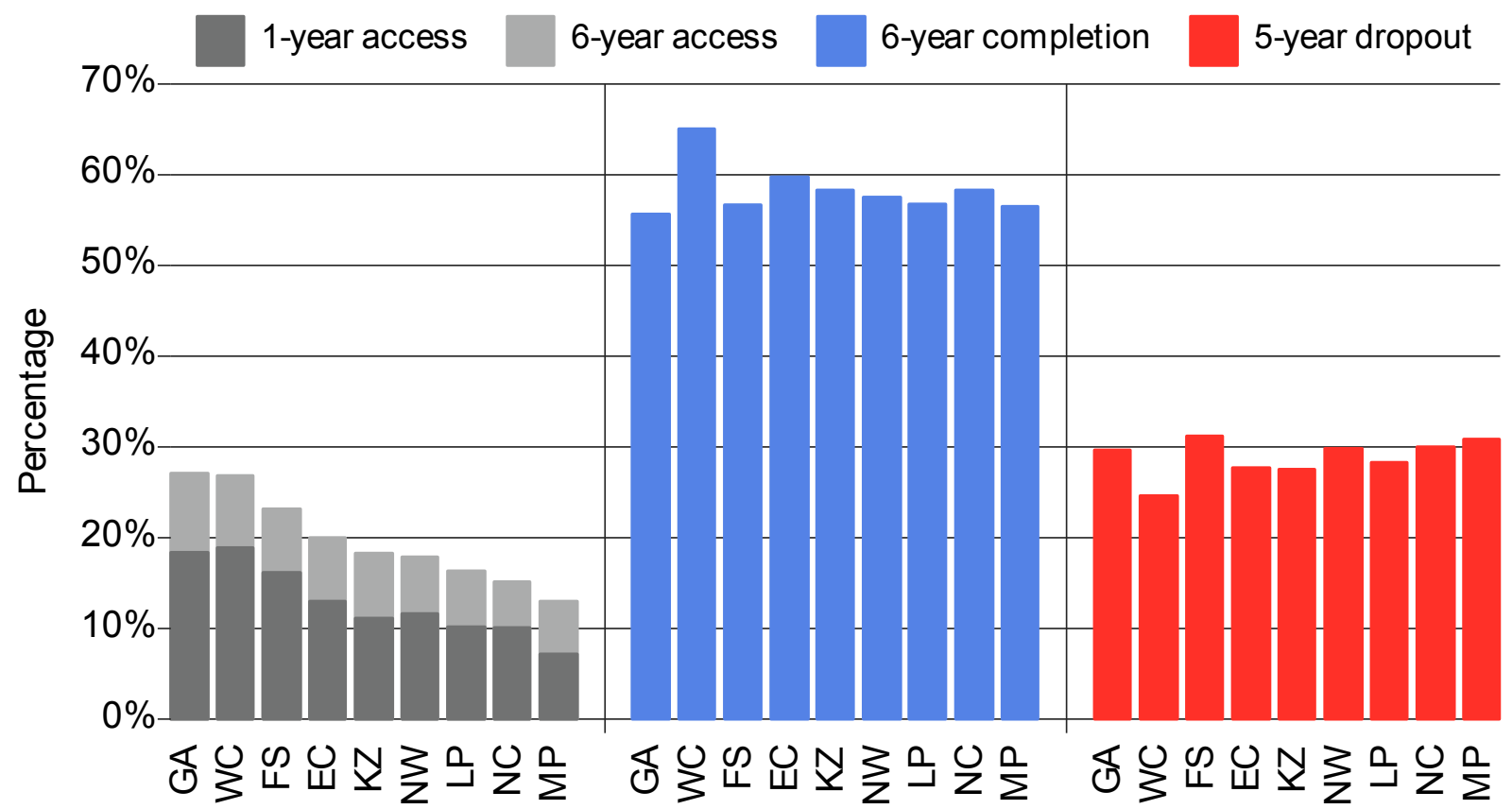

NOTES: Bars represent the estimated 1-year access, 6-year access, 6-year completion, and 5-year dropout rates for 2008 matric cohort candidates, by school province. Completion and dropout rates are estimated only for those learners from each NSC subgroup who enrolled in undergraduate studies for the first time in 2009. Access, completion, and dropout rates are cumulative. 
As expected, the provincial 1-year and six-year access rates broadly reflect provincial matric performance patterns. For example, while Gauteng and the Western Cape have the highest access rates, Limpopo and Mpumalanga have the lowest. There are some exceptions, however. Learners from the Eastern Cape had the fourth highest university access rates, on average, despite the fact that the province performed comparatively poorly in terms of achieving Bachelor level passes in 2008. The large differences in access rates between the provinces should be noted. Gauteng and the Western Cape had the highest six-year access rate, at around 27\%. This contrasts sharply with rates as low as 13\% (Mpumalanga) and 15.2\% (Northern Cape).

In terms of university success, the performance of learners from the Western Cape is striking, though not surprising, given the superior performance of the Western Cape in the NSC examinations. Of those from the 2008 Western Cape matric cohort who enrolled in university, 58\% (15.5\% of the original Western Cape cohort) had successfully completed an undergraduate qualification by the end of 2014 and only $26 \%$ of university participants (7\% of the original Western Cape matric cohort) had dropped out without obtaining any qualification by the end of 2014. What is surprising is the university completion rates of learners from Gauteng and Eastern Cape, given the NSC performance of learners from these provinces. Gauteng performed nearly on par with the Western Cape in the NSC examinations, yet learners from Gauteng achieved the second-lowest six-year completion rate of all the provinces, at 47\% (12.8\% of the original Gauteng cohort). Learners from the Eastern Cape, on the other hand, while performing very poorly relative to the other provinces in the NSC, achieved the second-highest six-year completion rate, at 53\% (10.6\% of the original Eastern Cape cohort). Differences in dropout rates between the provinces share the same surprising trend: Gauteng had the highest six-year dropout rate, at 33\% (9\% of the original Gauteng cohort), while the Eastern Cape and Limpopo had the lowest and second lowest dropout rates respectively, both at about at $29 \%$ (that is, $5.7 \%$ of the original Eastern Cape cohort and 5\% of the original Limpopo cohort).

The superior university access, completion, and dropout performance of learners from the Western Cape may be explained by the fact that the province had a much higher Bachelor pass rate than other provinces. Figure 2.4 replicates Figure 2.3, but considers only those learners who had achieved Bachelor passes.

Figure 2.4 shows a fair amount of variation in university access between provinces, even when considering only learners who achieved Bachelor passes. For example, the one-year access rate for the Eastern Cape exceeded $60 \%$, while it was only just above $40 \%$ in the Northern Cape and Limpopo. The Northern Cape and Mpumalanga - the two provinces without universities until 2014 - still had the lowest university access rates among the provincial cohorts, even when only Bachelor passers are considered. Very different results now emerge regarding the provinces with the highest access rates. When considering the entire 2008 matric cohort, the Eastern Cape had the highest one-year and six-year access rates when considering only learners who had achieved Bachelor passes, and Limpopo the second-highest.

In terms of university success, the Western Cape still had the highest six-year completion rate and the lowest five-year dropout rate among provincial cohorts, even when considering only learners who had achieved Bachelor passes. However, it is important to remember that the completion and dropout rates in the figure only 
apply to those learners from the 2008 matric cohort who entered undergraduate studies in 2009. Since on-time entry into university is associated with better performance in secondary school, when considering only those with Bachelor passes who enrolled in university in 2009 (i.e. without any delay), it is essentially only the topperforming learners from the 2008 matric cohort that are being considered. These completion and dropout rates are therefore unlikely to be reflective of what completion and dropout rates would look like if university access were to be expanded to include learners lower on the matric performance distribution.

Figure 2.4: Provincial university access, completion, and dropout rates (\%) for learners who achieved Bachelor passes in the 2008 NSC

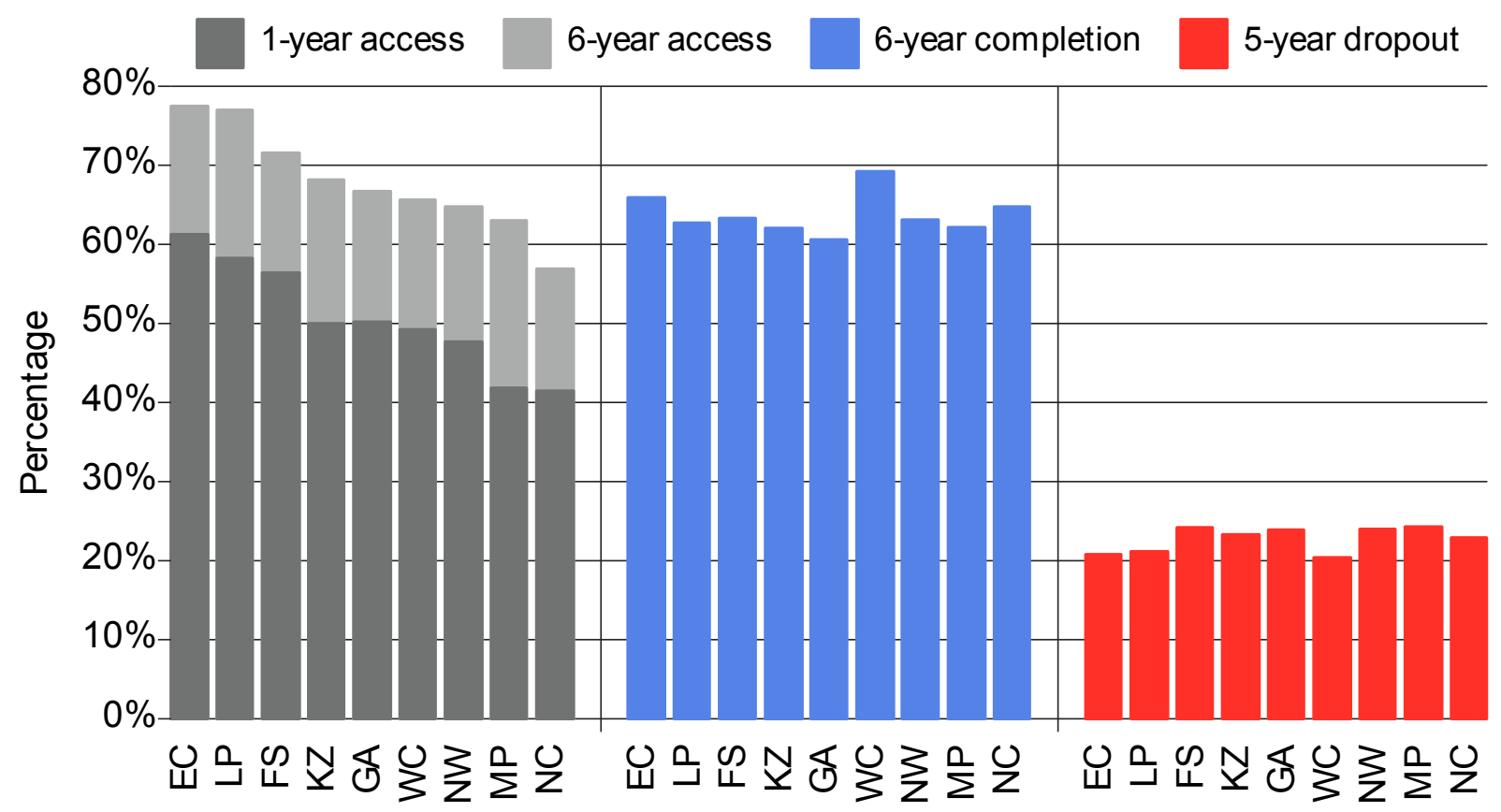

NOTES: Figures are only estimated for learners from the 2008 provincial matric cohorts who achieved Bachelor passes. Bars represent the estimated 1-year access, 6-year access, 6-year completion, and 5-year dropout rates for each group from the 2008 matric cohort. Completion and dropout rates are estimated only for those learners from each NSC subgroup who enrolled in undergraduate studies for the first time in 2009. Access, completion, and dropout rates are cumulative.

\subsection{School district}

Tables A6 - A14 in the Appendix report the Bachelor pass, access, completion and dropout rates for each school district in the country by province. These results are not discussed here since the geographic location of a district does not reveal much about the socio-economic status of the school. Nevertheless, Figure 2.5 shows the percentage of matric candidates in each school district that achieved Bachelor passes in the 2008 NSC exams. Given the apparent differences in overall performance between school districts, it is reasonable to expect that university access rates for the 2008 matric cohort would also have differed between districts. Figure 2.6, which shows the six-year university access rates for the 2008 matric cohort by school district, indicates that this was indeed the case. Though there are exceptions, districts with higher Bachelor pass rates generally also had higher university access rates. However, Figure 2.7 shows that the pattern of university access rate differences between school districts changes considerably when one considers only those candidates who achieved Bachelor passes in the 2008 NSC examinations. In this instance, there no longer 
appears to be a systematic association between the differences in university access rates and the differences in NSC exam performance between school districts.

Figure 2.5: Bachelor pass rates (\%) by school district for the 2008 matric cohort
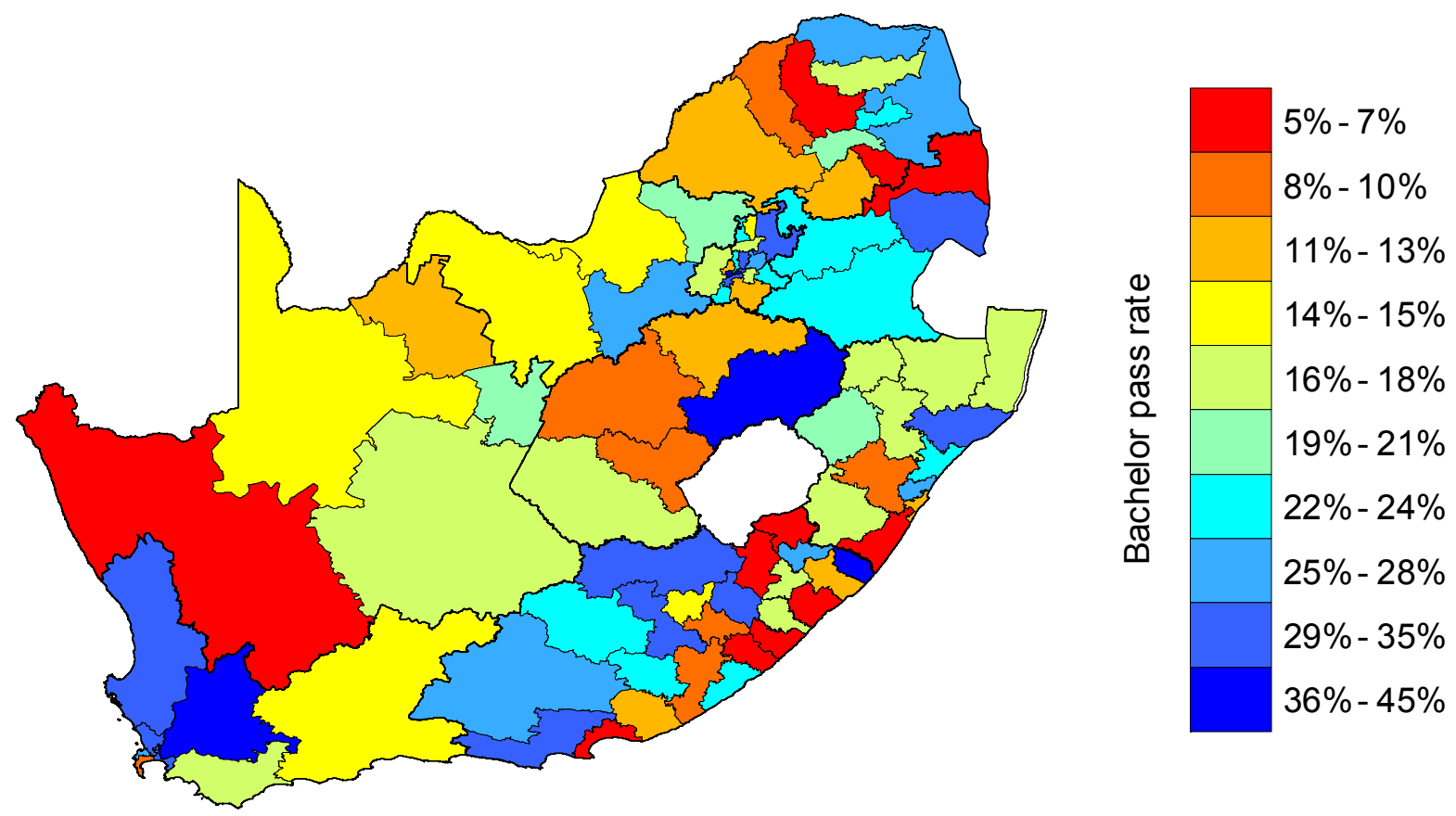

NOTES: Colours reflect the percentage of 2008 NSC candidates who achieved Bachelor passes for each school district.

Figure 2.6: Six-year university access rates (\%) for the 2008 matric cohort, by school district
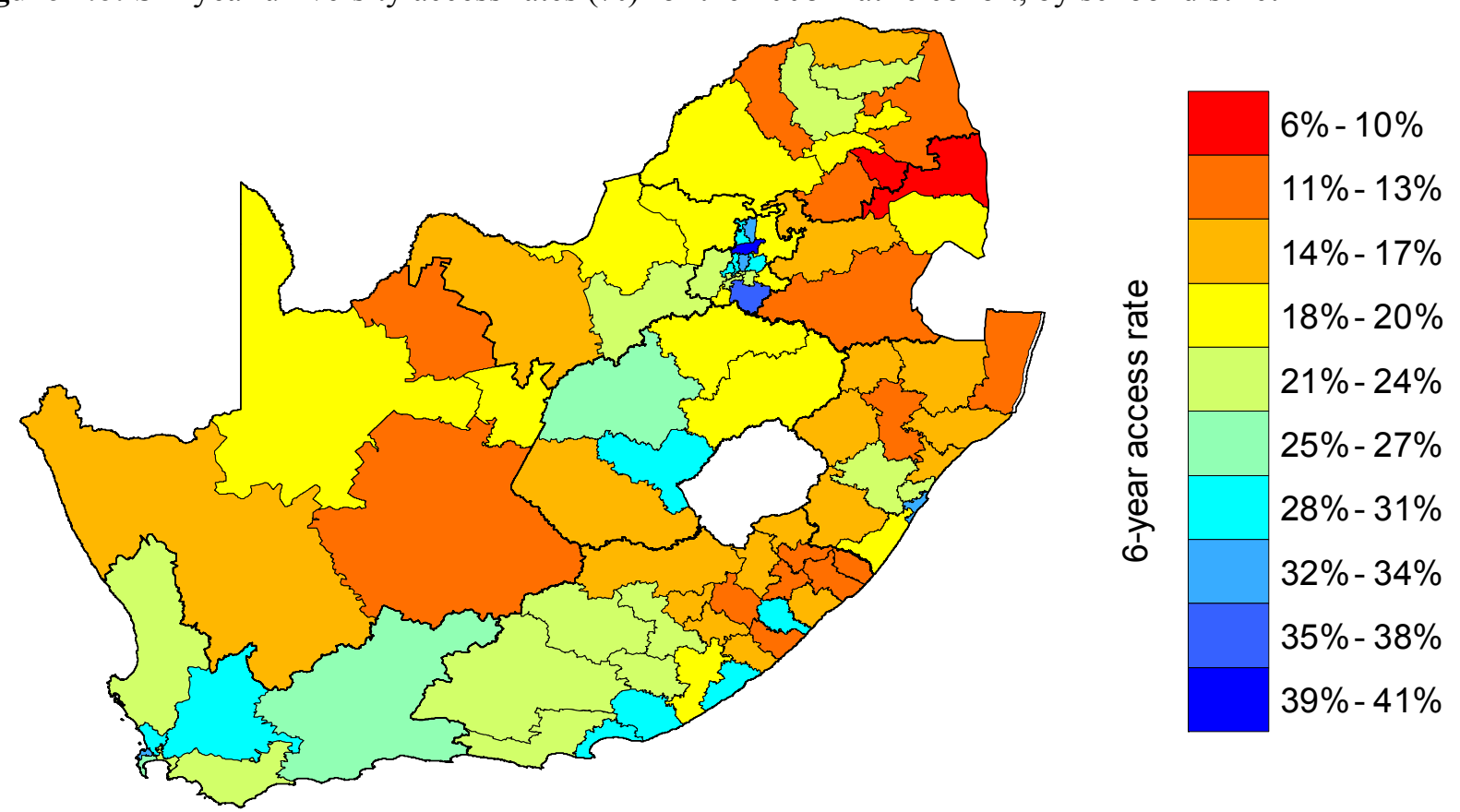

NOTES: Colours reflect the percentage of 2008 NSC candidates in each school district who enrolled in undergraduate studies in the public university system at some stage between 2009 and 2014. 
Figure 2.7: Six-year university access rates (\%) for Bachelor pass candidates from the 2008 matric cohort,by school district
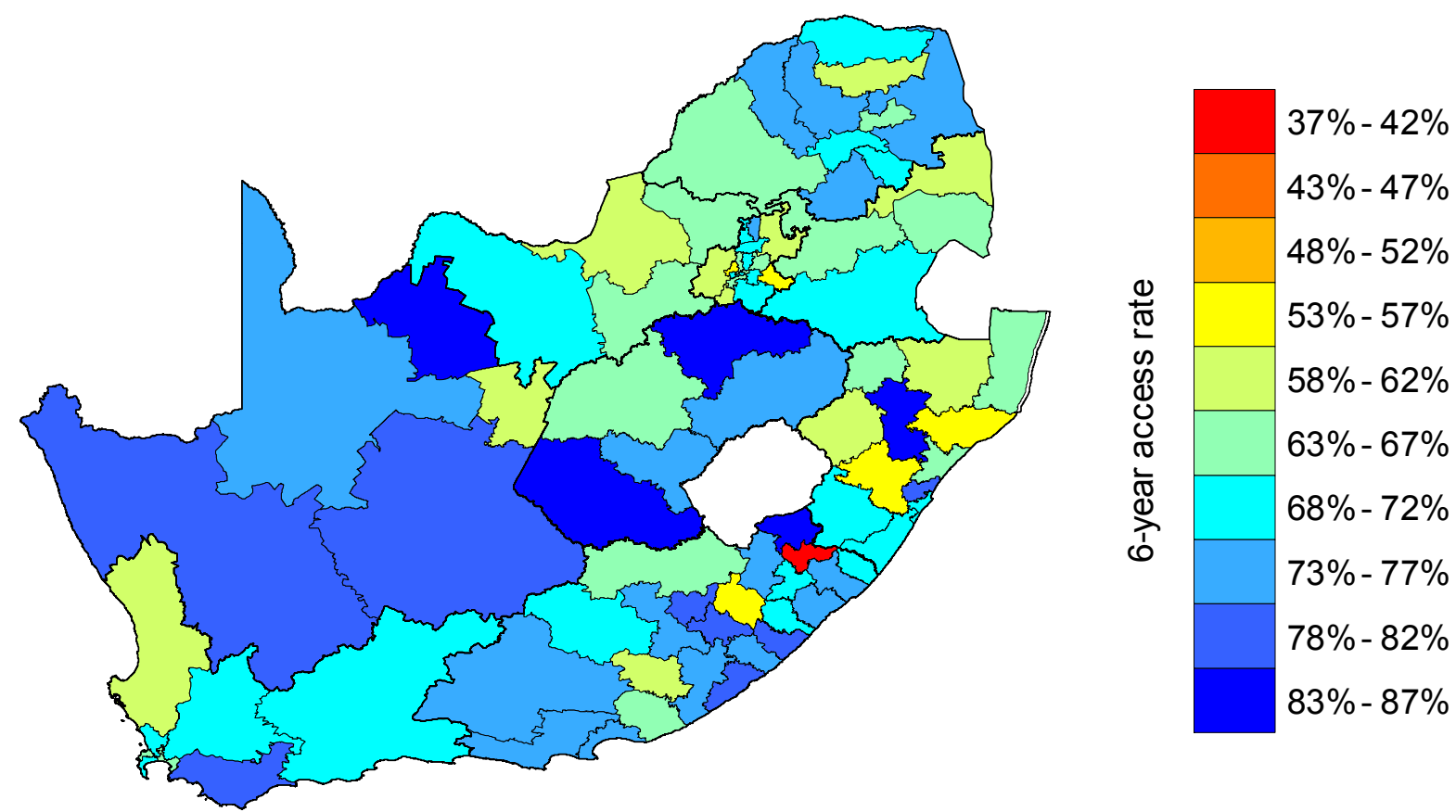

NOTES: Colours reflect the percentage of 2008 NSC Bachelor pass candidates in each school district who enrolled in undergraduate studies in the public university system at some stage between 2009 and 2014. 2.3. Where do learners go to study.

Tables 2.1 and 2.2 provide information about where learners from the 2008 matric cohort who enrolled in undergraduate studies between 2009 and 2014 went to study. Where Table 2.1 looks at the specific universities that students from the cohort attended, Table 2.2 considers the provinces where students chose to study.

The majority of learners who entered the public university system after matriculation enrolled at universities in the same provinces where they went to school. For example, Table 2.6 shows that $88.9 \%$ of Western Cape learners who enrolled in undergraduate studies between 2009 and 2014 attended CPUT (34.4\%), US (21.7\%), UWC (20.4\%), and/or UCT (12.4\%). Similarly, $68.6 \%$ of Eastern Cape learners enrolled in undergraduate studies at NMMU (30.0\%), WSU (28.5\%), or UFH (10.1\%); 66.6\% of Free State learners attended CUT (34.8\%) or UFS (31.8\%); $63.5 \%$ of KwaZulu Natal learners attended UKZN (24.6\%), DUT (20.3\%), UZ (9.4\%), or MUT (9.2\%); and 69\% of Gauteng learners attended UJ (28.3\%), UP (16.9\%), TUT (13.0\%), or WITS $(10.8 \%)$. The exception to this rule is those provinces with few or no universities, namely the Northern Cape, North West, Limpopo and Mpumalanga.

Despite the significant trend of studying in one's own school province, there is clearly a fair share of students who do their undergraduate studies in a different province from the one in which they may have gone to secondary school. In this regard, it is notable that large numbers of learners from North West, Mpumalanga, and Limpopo attended universities in Gauteng between 2009 and 2014. The more universities there are in a learner's province of matriculation, the more likely the learner is to remain in that province for undergraduate studies. 
Table 2.1: Universities attended by university participants from the 2008 matric cohort, by school province

\begin{tabular}{|c|c|c|c|c|c|c|c|c|c|}
\hline & WC & EC & NC & FS & KZ & NW & GA & MP & $\mathbf{L P}$ \\
\hline CPUT & 34.4 & 7.5 & 7.6 & 0.8 & 0.5 & 0.6 & 0.4 & 0.8 & 0.8 \\
\hline UCT & 12.4 & 2.2 & 1.1 & 0.9 & 2.0 & 0.8 & 1.1 & 0.8 & 1.0 \\
\hline CUT & 0.3 & 1.2 & 12.1 & 34.8 & 0.1 & 2.5 & 0.2 & 0.4 & 0.4 \\
\hline DUT & 0.1 & 1.6 & 0.1 & 0.5 & 20.3 & 0.1 & 0.2 & 1.5 & 0.3 \\
\hline UFH & 0.2 & 10.1 & 0.3 & 0.1 & 0.2 & 0.1 & 0.1 & 0.1 & 0.1 \\
\hline UFS & 0.7 & 2.9 & 24.0 & 31.8 & 2.1 & 3.1 & 0.8 & 1.2 & 1.1 \\
\hline UJ & 0.3 & 3.1 & 2.9 & 5.9 & 3.6 & 14.9 & 28.3 & 12.3 & 15.9 \\
\hline UKZN & 0.1 & 0.8 & 0.2 & 0.4 & 24.6 & 0.1 & 0.3 & 1.8 & 0.5 \\
\hline UL & 0.0 & 0.1 & 0.1 & 0.2 & 0.2 & 1.3 & 1.0 & 5.4 & 16.7 \\
\hline NMMU & 2.8 & 30.0 & 0.8 & 0.5 & 0.8 & 0.5 & 0.5 & 0.6 & 0.6 \\
\hline NWU & 1.5 & 0.7 & 22.1 & 8.7 & 1.1 & 36.1 & 6.6 & 5.5 & 1.7 \\
\hline UP & 0.6 & 1.2 & 2.8 & 2.7 & 1.8 & 8.2 & 16.9 & 11.9 & 5.3 \\
\hline RHODES & 0.8 & 4.0 & 1.0 & 0.3 & 0.7 & 0.3 & 0.6 & 0.3 & 0.4 \\
\hline UNISA & 14.0 & 10.5 & 13.8 & 9.7 & 28.3 & 20.0 & 26.8 & 22.1 & 22.7 \\
\hline US & 21.7 & 2.3 & 6.3 & 0.9 & 0.5 & 0.6 & 1.0 & 0.8 & 0.3 \\
\hline TUT & 0.3 & 1.5 & 2.9 & 3.6 & 2.9 & 14.0 & 13.0 & 31.5 & 24.7 \\
\hline UNIVEN & 0.0 & 0.0 & 0.0 & 0.0 & 0.0 & 0.1 & 0.1 & 1.8 & 7.9 \\
\hline VUT & 0.1 & 0.6 & 8.0 & 7.0 & 0.6 & 6.6 & 5.7 & 7.6 & 9.4 \\
\hline WSU & 0.7 & 28.5 & 0.3 & 0.2 & 1.3 & 0.1 & 0.3 & 0.1 & 0.1 \\
\hline UWC & 20.4 & 2.8 & 4.1 & 0.3 & 0.5 & 0.3 & 0.3 & 0.4 & 0.3 \\
\hline WITS & 0.3 & 1.2 & 1.7 & 1.6 & 2.1 & 4.1 & 10.8 & 3.8 & 4.4 \\
\hline $\mathrm{UZ}$ & 0.0 & 0.1 & 0.0 & 0.1 & 9.4 & 0.1 & 0.1 & 1.5 & 0.1 \\
\hline SPU & 0.0 & 0.0 & 0.1 & 0.0 & 0.0 & 0.0 & 0.0 & 0.0 & 0.0 \\
\hline UM & 0.0 & 0.0 & 0.0 & 0.0 & 0.0 & 0.0 & 0.0 & 0.0 & 0.0 \\
\hline MUT & 0.0 & 0.9 & 0.0 & 0.1 & 9.2 & 0.0 & 0.1 & 0.5 & 0.2 \\
\hline
\end{tabular}

NOTES: Figures reflect the percentage of 2008 matric cohort university participants for each school province who enrolled in undergraduate studies at the specified university at some stage between 2009 and 2014 . The percentages in each column may sum to more than $100 \%$ as it would have been possible for students to register at more than one university between 2009 and 2014.

Large numbers of students from all provinces enrol at UNISA for undergraduate studies at some stage after leaving high school, though the prevalence of this also varies between provinces. For example, in KwaZulu Natal, Gauteng, Mpumalanga, and Limpopo UNISA either accounted for the largest or second largest share of undergraduate enrolments from the 2008 matric cohort. 
Table 2.2: Province of university attended by university participants from the 2008 matric cohort, by school province $(\%)$

\begin{tabular}{lccccccccc}
\hline & WC & EC & NC & FS & KZ & NW & GA & MP & LP \\
\hline WC HEI & 84.3 & 14.3 & 18.2 & 2.8 & 3.4 & 2.2 & 2.8 & 2.6 & 2.3 \\
EC HEI & 4.5 & 69.5 & 2.5 & 1.1 & 3.0 & 1.0 & 1.5 & 1.1 & 1.1 \\
NC HEI & 0.0 & 0.0 & 0.1 & 0.0 & 0.0 & 0.0 & 0.0 & 0.0 & 0.0 \\
FS HEI & 0.9 & 4.0 & 35.5 & 64.6 & 2.2 & 5.5 & 1.0 & 1.6 & 1.4 \\
KZ HEI & 0.2 & 3.4 & 0.3 & 1.1 & 60.5 & 0.3 & 0.7 & 5.1 & 1.1 \\
NW HEI & 1.5 & 0.7 & 22.1 & 8.7 & 1.1 & 36.1 & 6.6 & 5.5 & 1.7 \\
GA HEI & 1.6 & 7.1 & 18.1 & 19.7 & 10.6 & 44.9 & 70.6 & 63.7 & 55.7 \\
MP HEI & 0.0 & 0.0 & 0.0 & 0.0 & 0.0 & 0.0 & 0.0 & 0.0 & 0.0 \\
LP HEI & 0.0 & 0.1 & 0.1 & 0.2 & 0.2 & 1.4 & 1.1 & 7.2 & 24.3 \\
UNISA & 14.0 & 10.5 & 13.8 & 9.7 & 28.3 & 20.0 & 26.8 & 22.1 & 22.7 \\
\hline
\end{tabular}

NOTES: Figures reflect the percentage of 2008 matric cohort university participants for each school province who enrolled in undergraduate studies at a university located in specific provinces at some stage between 2009 and 2014 . The percentages in each column may sum to more than $100 \%$ as it would have been possible for students to register at more than one university between 2009 and 2014. UNISA has been included as its own category given that it is a distance-learning university and, therefore, not physically bound to a particular province.

\section{Higher education institutions}

\subsection{Enrolment and graduation by university}

The findings of Van Broekhuizen (2016: 28) suggest that patterns of university access and success are likely to differ by university. This section considers to what extent access, completion, dropout and throughput rates are associated with the specific university at which candidates from the 2008 matric cohort enrolled.

Tables 3.1 and 3.2 jointly summarise university enrolments and graduations for the 2008 matric cohort by university. Table 3.1 shows the numbers of specific enrolments and graduations per university, while Table 3.2 expresses these numbers as a percentage (for each university) of the total number of specific enrolment and graduations under consideration. UJ accounted for by far the largest share (12.5\%) of the 2009 first-time entering undergraduate enrolment (FTEN) intake from the 2008 matric cohort, followed by TUT (8.3\%), UP (7.8\%), and UNISA (7.6\%). ${ }^{12}$ Collectively, these four institutions accounted for $36.2 \%$ of all students from the 2008 matric cohort who entered undergraduate studies immediately after writing the NSC examinations.

A comparison of columns 2 and 3 in both Tables 3.1 and 3.2 shows that delayed university entry differed considerably across institutions. While the extent of delayed entry at WITS university was fairly limited, for example, the number of first-time undergraduate enrolments from the 2008 matric cohort at UNISA increased from 5566 in 2009 to 18500 by 2014. These differences in delayed entry means that the shares of FTEN change considerably over time. While UNISA accounted for $7.6 \%$ of the 2009 FTEN from the 2008 matric cohort, it accounted for $16.5 \%$ of FTEN from this cohort between 2009 and 2014. Collectively, UJ, UNISA,

\footnotetext{
${ }^{12}$ In the current context, students are only deemed to be first-time entering undergraduate enrolment (FTEN) students if they have never before enrolled in undergraduate studies at any public university in South Africa prior to the year or period under consideration. See the Important definitions and caveats section at the end of this report for more information.
} 
UP, and TUT accounted for 42.3\% of all FTEN from the 2008 matric cohort between 2009 and 2014. The tables, as well as Figure 3.1 below, also indicate that degree versus non-degree enrolments differ markedly between universities.

A comparison of columns 3 and 4 in tables 3.1 and 3.2 provides an indication of the extent to which students from the 2008 matric cohort moved to other universities after first enrolment. Most notable is the extent of apparent transfer to UNISA after having been enrolled at another university. While more than a fifth (21.5\%) of the learners from the 2008 matric cohort who enrolled in undergraduate studies between 2009 and 2014 enrolled at UNISA at some stage over the period, only $76.4 \%$ of this "UNISA" group did so when first entering the public university system (their FTEN year).

Transfer to UNISA could be due to one, or a combination, of factors. It could be that many students who first enrol for undergraduate programmes at contact universities transfer to UNISA to complete those programmes, or that students who fail to complete their undergraduate programmes at contact universities re-enrol for similar programmes at UNISA, or that students complete a first qualification at a contact university and enrol at UNISA for a second undergraduate qualification. 
Table 3.1: University enrolments and graduations for the 2008 matric cohort (2009 - 2014), by university

\begin{tabular}{|c|c|c|c|c|c|c|c|}
\hline University & $\begin{array}{c}\text { Undergraduate } \\
\text { FTEN (2009 only) }\end{array}$ & $\begin{array}{c}\text { Undergraduate } \\
\text { FTEN }\end{array}$ & UG enrolments & $\begin{array}{c}\text { Undergraduate } \\
\text { degree enrolments }\end{array}$ & $\begin{array}{c}\text { Postgraduate } \\
\text { enrolments }\end{array}$ & $\begin{array}{c}\text { Undergraduate } \\
\text { graduations }\end{array}$ & $\begin{array}{c}\text { Undergraduate } \\
\text { degree graduations }\end{array}$ \\
\hline CPUT & 2948 & 4899 & 5589 & 1754 & 43 & 2867 & 1140 \\
\hline UCT & 2345 & 2727 & 2877 & 2835 & 835 & 1865 & 1846 \\
\hline CUT & 2049 & 2850 & 3115 & 1077 & 152 & 1352 & 571 \\
\hline DUT & 3366 & 5065 & 5783 & 1011 & 36 & 2969 & 620 \\
\hline UFH & 683 & 1155 & 1372 & 1361 & 332 & 753 & 750 \\
\hline UFS & 2452 & 3870 & 4191 & 4111 & 799 & 2144 & 2139 \\
\hline UJ & 9070 & 12068 & 13242 & 7741 & 1163 & 6050 & 3783 \\
\hline UKZN & 5105 & 6294 & 6869 & 6844 & 1478 & 4081 & 4068 \\
\hline UL & 1807 & 2807 & 3229 & 3218 & 452 & 1894 & 1885 \\
\hline NMMU & 3153 & 4100 & 4524 & 2542 & 459 & 2298 & 1447 \\
\hline NWU & 4082 & 5470 & 5988 & 5575 & 1354 & 3611 & 3504 \\
\hline UP & 5689 & 6901 & 7431 & 7381 & 1575 & 4295 & 4256 \\
\hline RHODES & 867 & 992 & 1063 & 1063 & 300 & 572 & 572 \\
\hline UNISA & 5566 & 18500 & 24212 & 12867 & 1988 & 2762 & 1437 \\
\hline US & 2898 & 3412 & 3544 & 3536 & 1131 & 2430 & 2413 \\
\hline TUT & 6035 & 10086 & 11292 & 2068 & 77 & 4617 & 989 \\
\hline UNIVEN & 747 & 1127 & 1320 & 1305 & 107 & 733 & 725 \\
\hline VUT & 2659 & 4100 & 4614 & 643 & 12 & 1990 & 444 \\
\hline WSU & 2086 & 3740 & 3979 & 1215 & 110 & 1878 & 679 \\
\hline UWC & 2191 & 2791 & 3122 & 3091 & 436 & 1379 & 1363 \\
\hline WITS & 4017 & 4624 & 4822 & 4815 & 833 & 2202 & 2195 \\
\hline $\mathrm{UZ}$ & 1647 & 2457 & 2623 & 1944 & 213 & 1485 & 1102 \\
\hline SPU & 0 & 1 & 1 & - & - & - & - \\
\hline UM & 0 & 0 & 2 & 1 & - & - & - \\
\hline MUT & 1298 & 2366 & 2603 & 94 & - & 1264 & 66 \\
\hline $\mathrm{All}^{\mathbf{a}}$ & 72760 & 112402 & 112402 & 70632 & 13466 & 55721 & 38229 \\
\hline
\end{tabular}

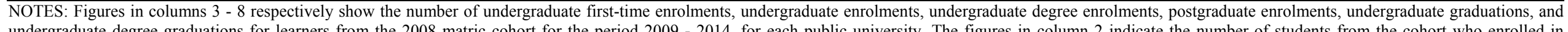

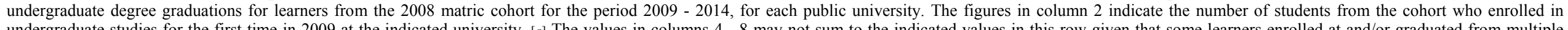

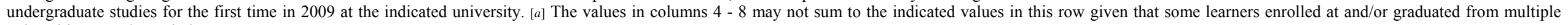
universities over the period. 
Table 3.2: Share of university enrolments and graduations for the 2008 matric cohort (2009 - 2014), by university

\begin{tabular}{|c|c|c|c|c|c|c|c|}
\hline University & $\begin{array}{l}\text { Undergraduate } \\
\text { FTEN (2009 only) }\end{array}$ & $\begin{array}{c}\text { Undergraduate } \\
\text { FTEN }\end{array}$ & UG enrolments & $\begin{array}{c}\text { Undergraduate } \\
\text { degree enrolments }\end{array}$ & $\begin{array}{c}\text { Postgraduate } \\
\text { enrolments }\end{array}$ & $\begin{array}{l}\text { Undergraduate } \\
\text { graduations }\end{array}$ & $\begin{array}{c}\text { Undergraduate } \\
\text { degree graduations }\end{array}$ \\
\hline CPUT & 4.1 & 4.4 & 5.0 & 2.5 & 0.3 & 5.1 & 3.0 \\
\hline UCT & 3.2 & 2.4 & 2.6 & 4.0 & 6.2 & 3.3 & 4.8 \\
\hline CUT & 2.8 & 2.5 & 2.8 & 1.5 & 1.1 & 2.4 & 1.5 \\
\hline DUT & 4.6 & 4.5 & 5.1 & 1.4 & 0.3 & 5.3 & 1.6 \\
\hline UFH & 0.9 & 1.0 & 1.2 & 1.9 & 2.5 & 1.4 & 2.0 \\
\hline UFS & 3.4 & 3.4 & 3.7 & 5.8 & 5.9 & 3.8 & 5.6 \\
\hline UJ & 12.5 & 10.7 & 11.8 & 11.0 & 8.6 & 10.9 & 9.9 \\
\hline UKZN & 7.0 & 5.6 & 6.1 & 9.7 & 11.0 & 7.3 & 10.6 \\
\hline UL & 2.5 & 2.5 & 2.9 & 4.6 & 3.4 & 3.4 & 4.9 \\
\hline NMMU & 4.3 & 3.6 & 4.0 & 3.6 & 3.4 & 4.1 & 3.8 \\
\hline NWU & 5.6 & 4.9 & 5.3 & 7.9 & 10.1 & 6.5 & 9.2 \\
\hline UP & 7.8 & 6.1 & 6.6 & 10.4 & 11.7 & 7.7 & 11.1 \\
\hline RHODES & 1.2 & 0.9 & 0.9 & 1.5 & 2.2 & 1.0 & 1.5 \\
\hline UNISA & 7.6 & 16.5 & 21.5 & 18.2 & 14.8 & 5.0 & 3.8 \\
\hline US & 4.0 & 3.0 & 3.2 & 5.0 & 8.4 & 4.4 & 6.3 \\
\hline TUT & 8.3 & 9.0 & 10.0 & 2.9 & 0.6 & 8.3 & 2.6 \\
\hline UNIVEN & 1.0 & 1.0 & 1.2 & 1.8 & 0.8 & 1.3 & 1.9 \\
\hline VUT & 3.7 & 3.6 & 4.1 & 0.9 & 0.1 & 3.6 & 1.2 \\
\hline WSU & 2.9 & 3.3 & 3.5 & 1.7 & 0.8 & 3.4 & 1.8 \\
\hline UWC & 3.0 & 2.5 & 2.8 & 4.4 & 3.2 & 2.5 & 3.6 \\
\hline WITS & 5.5 & 4.1 & 4.3 & 6.8 & 6.2 & 4.0 & 5.7 \\
\hline UZ & 2.3 & 2.2 & 2.3 & 2.8 & 1.6 & 2.7 & 2.9 \\
\hline SPU & 0.0 & 0.0 & 0.0 & - & - & - & - \\
\hline UM & 0.0 & 0.0 & 0.0 & 0.0 & - & - & - \\
\hline MUT & 1.8 & 2.1 & 2.3 & 0.1 & - & 2.3 & 0.2 \\
\hline $\mathrm{All}^{\mathrm{a}}$ & 100.0 & 100.0 & 100.0 & 100.0 & 100.0 & 100.0 & 100.0 \\
\hline
\end{tabular}

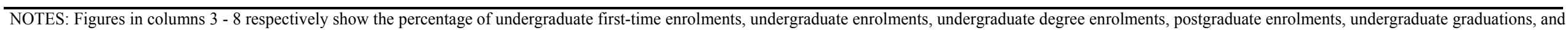

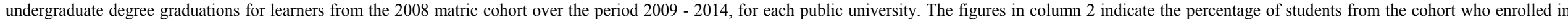
undergraduate studies for the first time in 2009 at the indicated university. 
Figure 3.1 shows enrolment of the 2008 matric cohort in undergraduate degree as opposed to undergraduate non-degree programmes at specific universities between 2009 and 2014. Degree programmes accounted for more than $99 \%$ of all undergraduate enrolments at RHODES, WITS, US, UL, UKZN, UP, UFH, UWC, UNIVEN, UCT, and UFS. By contrast, less than $50 \%$ of the undergraduate enrolments for the cohort at CUT, CPUT, WSU, TUT, DUT, VUT, and MUT were in degree programmes. Note that only just over half (53.1\%) of the learners from the 2008 matric cohort who enrolled in undergraduate studies at UNISA between 2009 and 2014 enrolled in degree programmes. Despite this, the institution's relative size meant that it still accounted for $18.2 \%$ (See Table 3.2) of all enrolments in undergraduate degree programmes among the 2008 matric cohort.

Figure 3.1: Undergraduate degree enrolments as percentage of all undergraduate enrolments in a university for the 2008 matric cohort (2009 - 2014)

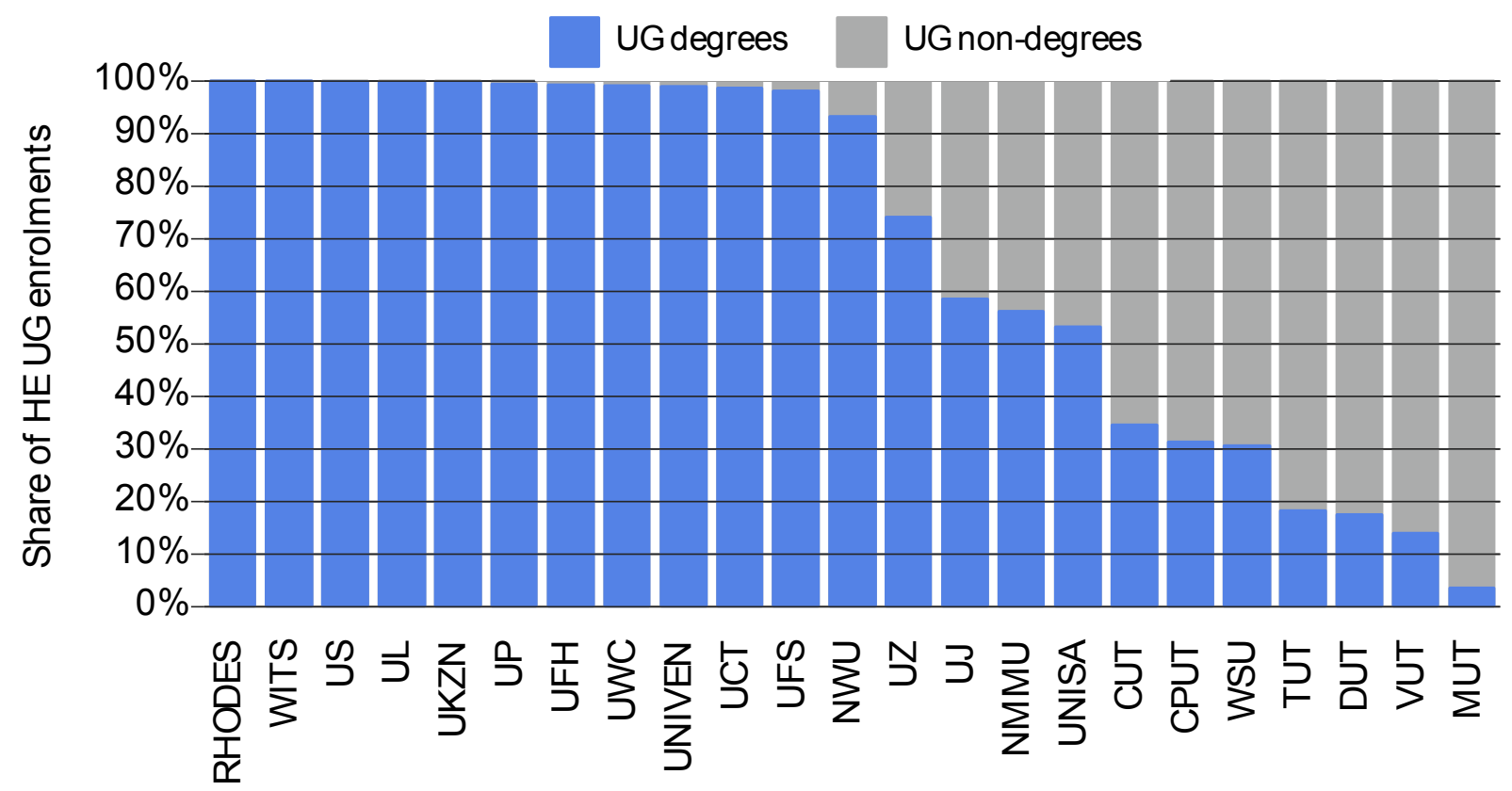

NOTES: Bars show the percentages of undergraduate enrolments among the 2008 matric cohort at each university between 2009 and 2014 that were enrolments in undergraduate degree rather than undergraduate non-degree programmes.

Figure 3.2 provides an indication of the extent to which undergraduate enrolments among the 2008 matric cohort at specific universities were converted into undergraduate graduations between 2009 and 2014. The same information can be gleaned by comparing columns 3 and 6 of Tables 3.1 and 3.2. The figure shows a fair amount of variation between universities in terms of graduation rates. ${ }^{13}$ For example, nearly $70 \%$ of the NSC candidates who enrolled in undergraduate programmes at US between 2009 and 2014 also completed undergraduate programmes over that period. On the lower end of the spectrum, only just above $40 \%$ of the candidates who enrolled in undergraduate programmes at TUT had completed undergraduate programmes by the end of 2014. UNISA is the clear outlier among the group. As the only distance-learning institution among South Africa's public universities, this is perhaps not wholly surprising. Nonetheless, it is striking that only

\footnotetext{
${ }^{13}$ The graduation rate normally expresses the number of graduations in a particular year as the percentage of enrolments in that year. In the current context, it expresses the total number of undergraduate graduations for the 2008 matric cohort between 2009 and 2014 as a percentage of the total number of undergraduate enrolments for the cohort over that period.
} 
about $11.4 \%$ of the learners from the 2008 matric cohort who enrolled in undergraduate studies at UNISA between 2009 and 2014 had completed undergraduate qualifications by the end of the period.

Figure 3.2: Undergraduate graduations as a percentage of undergraduate enrolments for the 2008 matric cohort (2009 - 2014), by university

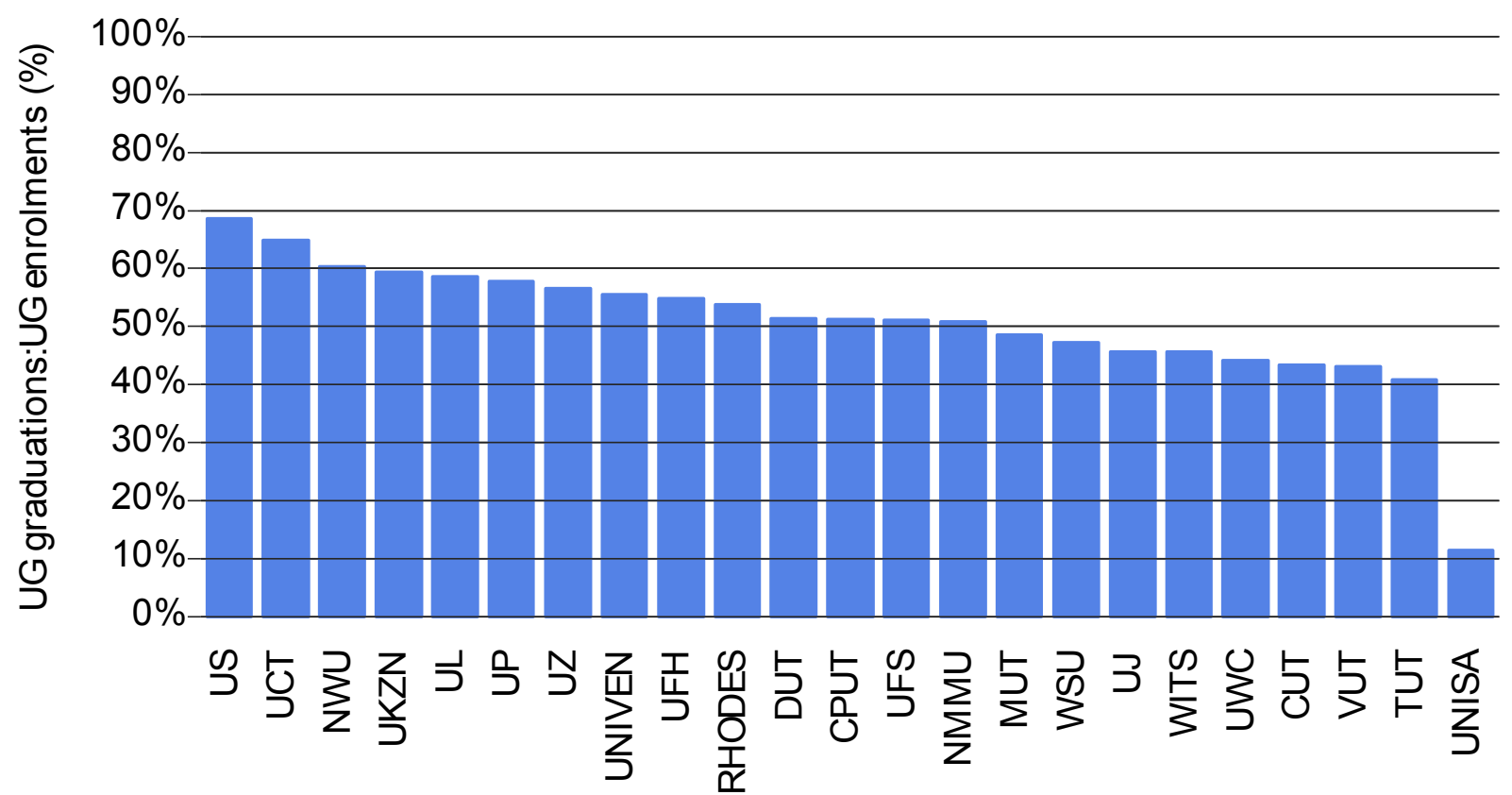

NOTES: Bars express the total number of learners from the 2008 matric cohort who completed undergraduate qualifications at a particular university between 2009 and 2014 as a percentage of the number of learners from the cohort who enrolled in undergraduate studies at that university.

Figure 3.2 provides only a crude indication of university throughput at different universities for the 2008 matric cohort since universities that were subject to a greater extent of delayed university entry would necessarily have had less opportunity to convert enrolments into graduation. In addition, the estimates in the figure group undergraduate degree and undergraduate non-degree graduations together. To overcome the first of these limitations, Figure 3.3 summarises the undergraduate completion rates only for students from the 2008 matric cohort who entered undergraduate studies in 2009. The same information presented in Table A15 of the Appendix. The figure shows that, similar to the case in Figure 3.2, there is a fair amount of variation in the sixyear undergraduate completion rates across universities. UFH, UL, US, NWU, UNIVEN, UKZN, and UCT all had six-year completion rates that were above or very near to $70 \%$. By contrast, CUT TUT and WITS had sixyear completion rates than were around $50 \%$. Yet again, UNISA is the outlier in terms of six-year completion rates. Only around $26 \%$ of the 2008 NSC candidates who had enrolled in undergraduate studies at UNISA in 2009 managed to complete undergraduate qualifications by the end of 2014 .

Another interesting finding that emerges from Figure 3.3 is that, for most universities, there is a substantial difference between four-year and six-year completion rates. On average, there was a 22 percentage point difference between the 4-year and 6-year completion rates across the institutions considered. This finding is of particular significance given that the vast majority of undergraduate programmes at South Africa universities have, at most, a 4-year minimum study time requirement for completion. Yet, there is clearly a significant share of students who only complete their qualifications after 5 or 6 years. This is even more disconcerting in light of the fact that $76.8 \%$ of the learners from the 2008 matric cohort who entered 
undergraduate studies in 2009 actually enrolled in programmes that had a minimum completion time requirement of three years or less. And yet, not a single university had a 3-year undergraduate completion rate of above $30 \%$.

Figure 3.3: Undergraduate completion rates for 2009 FTEN students from the 2008 matric cohort (2009 2014), by university of first enrolment

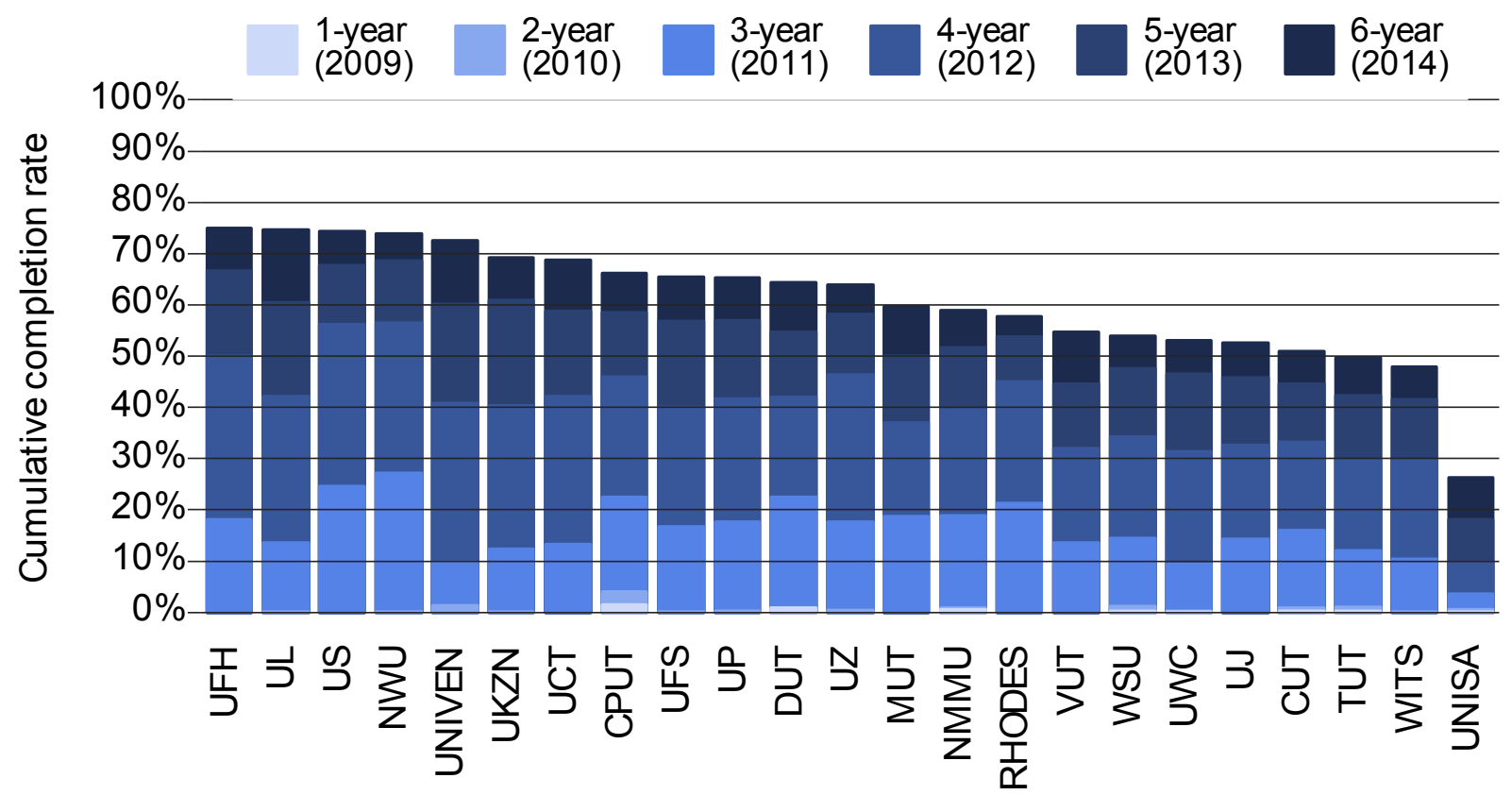

NOTES: Bars reflect the cumulative percentage of 2009 FTEN undergraduate students from the 2008 matric cohort who successfully completed undergraduate qualifications after a certain number of years, by the university of FTEN. Note that this implies that all completers who commenced with their undergraduate studies at a given university would contribute to the completion rate for that university, even if they ended up completing their undergraduate qualifications at other universities.

As mentioned above, one potential problem with the estimates in Figure 3.3 is that they cover both degree and non-degree undergraduate programmes. Figure 3.4 summarises the undergraduate degree completion rates for students from the 2008 matric cohort who entered undergraduate degree programmes in 2009 by the university of first-time entering enrolment. The same information is presented in Table A16 of the Appendix.

The rank-ordering in Figure 3.4 is different from that in Figure 3.3, with DUT, CPUT, and TUT now appearing to perform best in terms of the six-year undergraduate degree completion rate for the 2008 matric cohort. This constitutes an interesting result, considering these institutions all ranked roughly in the middle of the distribution when degree and non-degree completion rates were considered together. However, it should be noted that the undergraduate degree enrolments at these universities in 2009 among the 2008 matric cohort learners was very limited. For example, only 66 learners from the 2008 matric cohort entered undergraduate degree programmes at DUT in 2009. Nonetheless, of these, 60 had completed undergraduate degrees by the end of 2014. This is an exceptional result, and DUT clearly stands out from the other universities in this regard. It is further interesting to note that UFH, UL, US, NWU and UNIVEN all still have six-year completion rates of above $70 \%$, even when only undergraduate degrees are considered. This suggests large proportions of these institutions' overall six-year completion rates are attributable to undergraduate degree graduations. 
Figure 3.4: Undergraduate degree completion rates for 2009 FTEN students from the 2008 matric cohort (2009 - 2014), by university of first enrolment

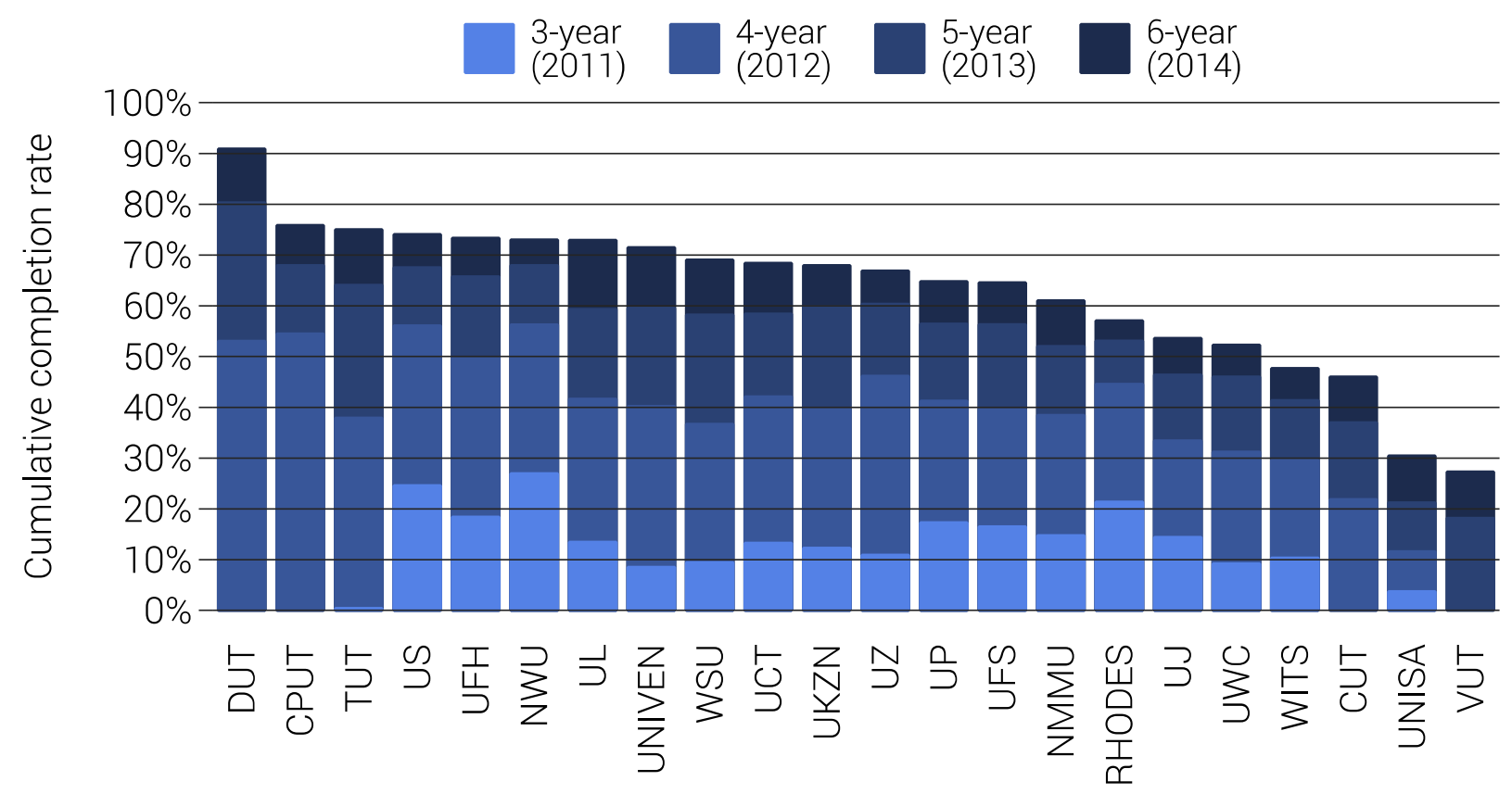

NOTES: Bars reflect the cumulative percentage of 2009 FTEN undergraduate degree students from the 2008 matric cohort who success- fully completed undergraduate degrees after a certain number of years, by the university of FTEN. Note that this implies that all completers who commenced with their undergraduate degrees at a given university would contribute to the completion rate for that university, even if they ended up completing their undergraduate degrees at another university.

Lastly, Figure 3.5 summarises the undergraduate dropout rates for students from the 2008 matric cohort who entered undergraduate programmes in 2009 by the university of first-time entering enrolment. The same information can be found in Table A17 of the Appendix.

Figure 3.5: Undergraduate dropout rates for 2009 FTEN students from the 2008 matric cohort (2009 - 2014), by university of first enrolment

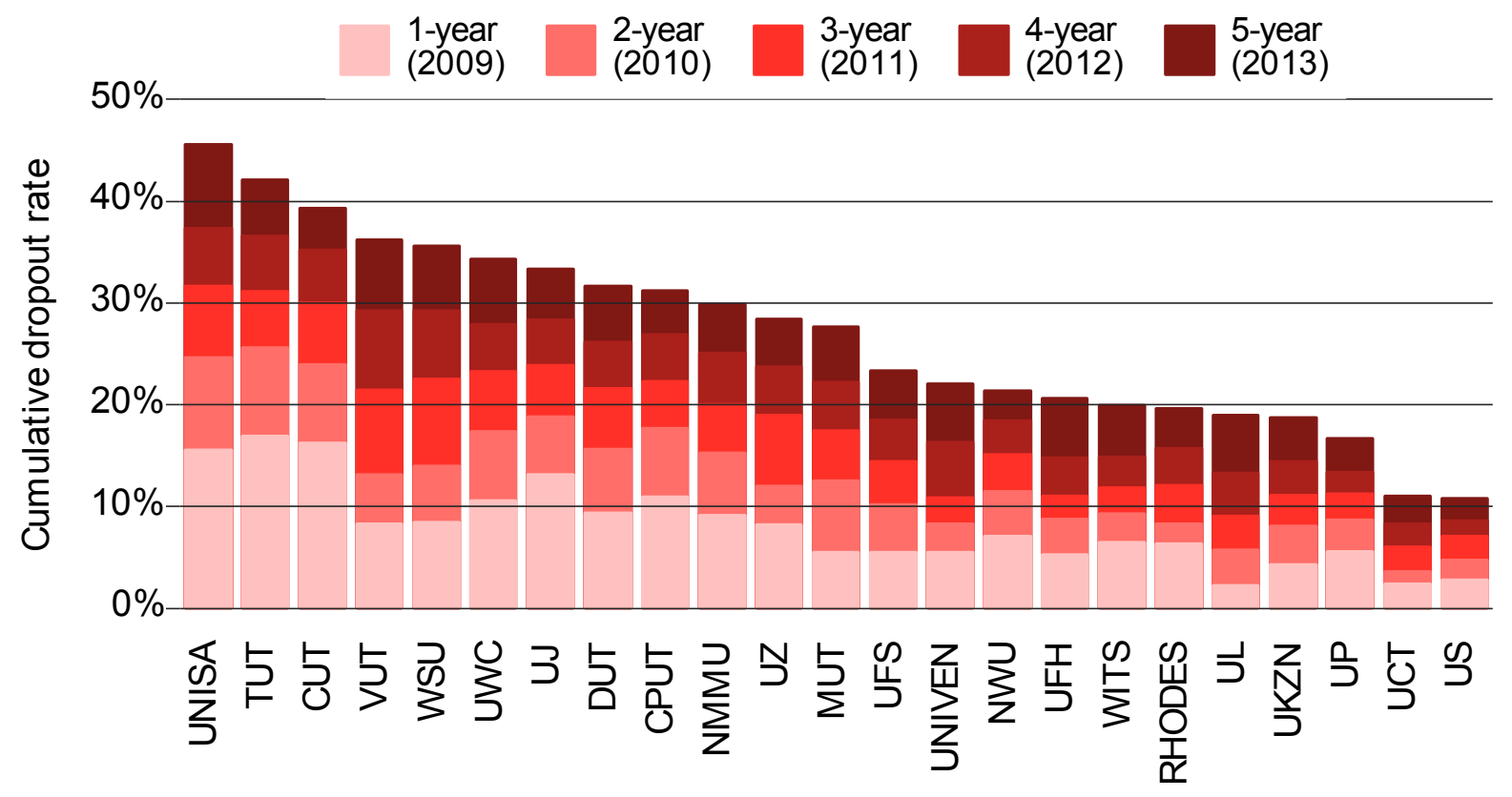

NOTES: Bars reflect the cumulative percentage of 2009 FTEN undergraduate students from the 2008 matric cohort who were no longer enrolled in university in 2014 without having completed any undergraduate qualifications before exiting the public university system. 
While the 5-year dropout rate rank-ordering indicated in Figure 3.5 seems to nearly be the inverse of the 6year undergraduate completion rate rank-ordering in Figure $\underline{3.3}$, note that the dropout rate is not simply the complement of the completion rate since the dropout rate is also a function of the extent of retention among non-completers. Not completing could also mean a candidate remains in the university system after six years of enrolling, without successfully obtaining an undergraduate qualification. Nevertheless, Figure 3.5 suggests that dropout rates seem to be highest at those universities with lower completion rates. The case of UNISA constitutes the most extreme manifestation of this pattern, the university having the lowest six-year undergraduate completion rate as well as the highest five-year undergraduate dropout rate of any public university in South Africa.

\subsection{Selection into universities}

As suggested by Tables 3.1 and 3.2, selection into specific universities among the 2008 matric cohort was nonrandom, i.e. there may be some association between certain characteristics of learners from the cohort and where they enrolled for further studies. To investigate the extent of apparent selection into universities on the basis of academic ability, Figure 3.6 shows how the matric average achievement distribution for learners from the 2008 matric cohort who entered undergraduate studies in 2009 differed by the universities where they enrolled as first-years.

It is striking that universities with relatively high completion rates and low dropout rates tended to have student intakes drawn from the upper end of the matric achievement distribution. The extent of the differences is matric average performance across universities is also remarkable. The learners from the 2008 matric cohort who enrolled at UCT or US in 2009, for example, had average matric achievement levels of around $75 \%$. Learners from the same cohort who enrolled at UZ, TUT, CUT, or VUT achieved closer to 55\% in matric, on average.

Figure 3.7 considers only those learners from the cohort who enrolled in undergraduate degree programmes in 2009. Insofar as matric average achievement is positively related to the likelihood of university completion, the differences outlined above imply that universities do not always compete on equal footing. Consequently, it is necessary to control for differences like these when assessing the relative performance of different universities. 
Figure 3.6: Matric average distributions for the 2009 FTEN undergraduate students from the 2008 matric cohort (2009 - 2014), by university of first enrolment

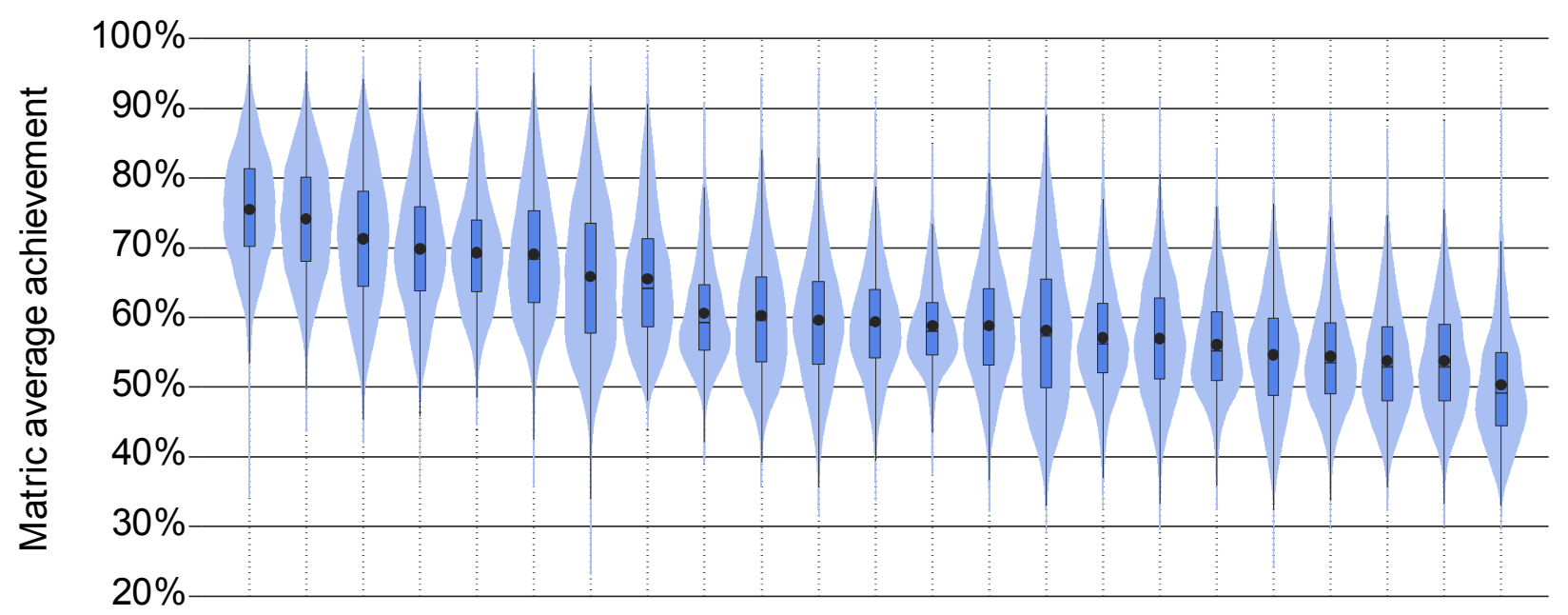

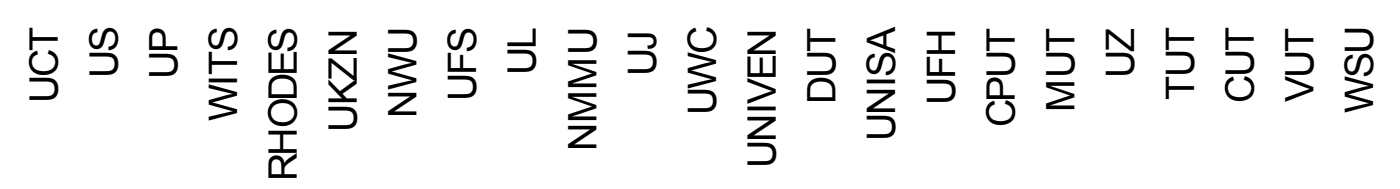

NOTES: Each violin plot shows the entire matric average distribution for a particular university's 2009 FTEN undergraduate intake from the 2008 matric cohort. The superimposed box plots furthermore show the 25th, 50th, and 75th percentiles of performance, with each dot indicating the average level of matric achievement for the university in question. Note that the sample includes only those learners from the 2008 matric cohort who enrolled in undergraduate studies at the specified universities in 2009.

Figure 3.7: Matric average distributions for the 2009 FTEN undergraduate degree students from the 2008 matric cohort (2009 - 2014), by university of first enrolment

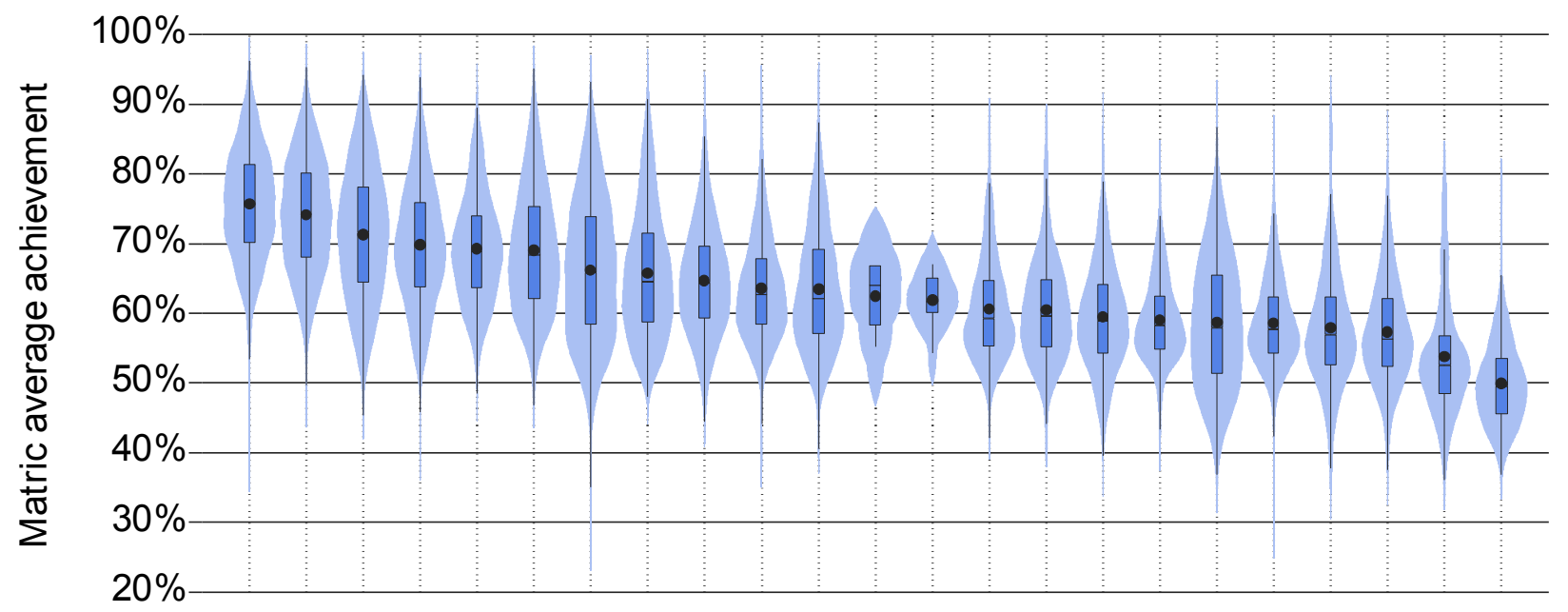

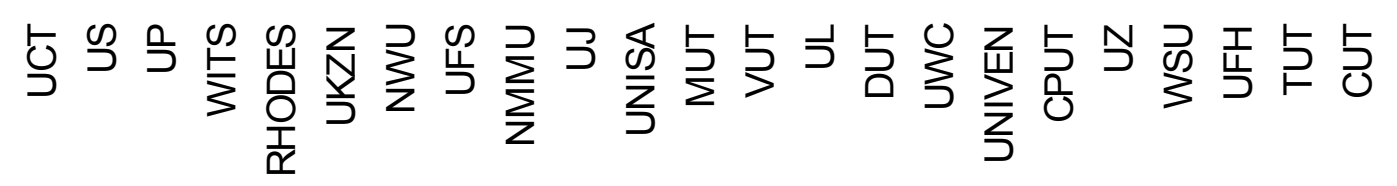

NOTES: Each violin plot shows the entire matric average distribution for a particular university's 2009 FTEN undergraduate degree intake from the 2008 matric cohort. The superimposed box plots furthermore show the 25 th, 50 th, and 75 th percentiles of performance, with the each dot indicating the average level of matric achievement for the university in question. Note that the sample includes only those learners from the 2008 matric cohort who enrolled in undergraduate degree programmes at the specified universities in 2009. 


\section{Qualification type and field of study}

This section reports on the association between qualification type and field of study on the one hand, and university access and success on the other.

Table 4.1 summarises the university enrolments for the 2008 matric cohort by broad qualification type and field of study. The table shows that enrolment in undergraduate degree programmes exceeded enrolment in non-degree studies. About $12.5 \%$ of the matric cohort enrolled in undergraduate degrees at some stage between 2009 and 2014, as against 9.6\% in diploma or certificate programmes. In terms of the popularity of fields of study, there appears to have been a fairly even spread across the Business, Commerce and Management (BCM), Humanities and Social Sciences (HSS), and Science, Engineering, and Technology (SET) qualifications in terms of enrolments from the cohort, though HSS programmes seemed to be least popular among those enrolling for diploma or certificate studies and most popular among those enrolling for undergraduate degrees.

Table 4.1: University enrolments for the 2008 matric cohort, by qualification level and broad field of study

\begin{tabular}{|c|c|c|c|c|}
\hline & BCM & HSS & SET & Any field \\
\hline UG non-degree & 23278 & 12569 & 21543 & 53896 \\
\hline$\%$ of students ${ }^{\mathrm{a}}$ & 20.7 & 11.2 & 19.2 & 47.9 \\
\hline$\%$ of learners ${ }^{b}$ & 4.1 & 2.2 & 3.8 & 9.6 \\
\hline UG degree & 22503 & 32788 & 25144 & 70453 \\
\hline$\%$ of students ${ }^{\mathrm{a}}$ & 20.0 & 29.2 & 22.4 & 62.7 \\
\hline$\%$ of learners ${ }^{b}$ & 4.0 & 5.8 & 4.5 & 12.5 \\
\hline PG qualification & 4796 & 4826 & 4009 & 13379 \\
\hline$\%$ of students ${ }^{\mathrm{a}}$ & 4.3 & 4.3 & 3.6 & 11.9 \\
\hline$\%$ of learners ${ }^{b}$ & 0.9 & 0.9 & 0.7 & 2.4 \\
\hline Any UG qualification & 42822 & 44471 & 42231 & 112402 \\
\hline$\%$ of students ${ }^{\mathrm{a}}$ & 38.1 & 39.6 & 37.6 & 100.0 \\
\hline$\%$ of learners ${ }^{b}$ & 7.6 & 7.9 & 7.5 & 20.0 \\
\hline
\end{tabular}

NOTES: Figures printed in black reflect the numbers of learners from the 2008 matric cohort who enrolled in a specific qualification type and broad field of study at some stage between 2009 and 2014. Since it would have been possible to enrol in multiple programmes over the period, figures may not some to the column and/or row totals. ${ }^{[a]}$ Expresses the number of learners who enrolled in a specific qualification type and broad field of study as a percentage of the number of learners from the cohort who enrolled in undergraduate studies between 2009 and $\left.2014 .{ }^{b}\right]$ Expresses the number of learners who enrolled in a specific qualification type and broad field of study as a percentage of the number of learners in the 2008 matric cohort.

Table 4.2 summarises university graduations (i.e. successful programme completions) for the 2008 matric cohort over the period 2009 - 2014, disaggregated by broad undergraduate qualification type and field of study. The table shows that by the end of 2014, around half of all learners from the cohort who enrolled in university, and roughly $10 \%$ of the cohort overall, had completed at least one undergraduate qualification. The share of students who completed their undergraduate qualifications by the end of 2014 is much greater among those who enrolled for degrees than those who enrolled in non-degree programmes: about $54 \%$ of learners who enrolled in degree programmes over the period completed their programmes, while only about $39 \%$ of nondegree entrants did so. The estimates in Table 4.2 also suggest that throughput rates for postgraduate qualifications are particularly high. This is hardly surprising considering the fact that learners who were able 
to enrol for postgraduate programmes could only have done so by virtue of already having successfully completed undergraduate degrees.

Table 4.2: University graduations for the 2008 matric cohort who enrolled in undergraduate studies over the period 2009 - 2014, by qualification type and broad field of study

\begin{tabular}{|c|c|c|c|c|}
\hline & BCM & HSS & SET & Any field \\
\hline UG non-degree & 8456 & 4418 & 8150 & 20977 \\
\hline$\%$ of students ${ }^{\mathrm{a}}$ & 36.3 & 35.1 & 37.8 & 38.9 \\
\hline$\%$ of learners ${ }^{b}$ & 1.5 & 0.8 & 1.5 & 3.7 \\
\hline UG degree & 10943 & 14442 & 12637 & 37962 \\
\hline$\%$ of students ${ }^{\mathrm{a}}$ & 48.6 & 44.0 & 50.3 & 53.9 \\
\hline$\%$ of learners ${ }^{\mathrm{b}}$ & 1.9 & 2.6 & 2.2 & 6.8 \\
\hline PG qualification & 3472 & 3410 & 2888 & 9645 \\
\hline$\%$ of students ${ }^{\mathrm{a}}$ & 72.4 & 70.7 & 72.0 & 72.1 \\
\hline$\%$ of learners ${ }^{\mathrm{b}}$ & 0.6 & 0.6 & 0.5 & 1.7 \\
\hline Any UG qualification & 18328 & 19231 & 19684 & 55721 \\
\hline$\%$ of students ${ }^{\mathrm{a}}$ & 42.8 & 43.2 & 46.6 & 49.6 \\
\hline$\%$ of learners ${ }^{\mathrm{b}}$ & 3.3 & 3.4 & 3.5 & 9.9 \\
\hline
\end{tabular}
NOTES: Figures printed in black reflect the numbers of learners from the 2008 matric cohort who enrolled in, and successfully completed a specific
qualification type and broad field of study at some stage between 2009 and 2014 . Since it would have been possible to complete multiple qualifications over the period, figures may not sum to the column and/or row totals. ${ }^{[a]}$ Expresses the number of students who completed a qualification of specific qualification type and broad field of study as a percentage of the number of learners from the cohort who enrolled in undergraduate studies between 2009 and 2014. ${ }^{[\mathrm{b}]}$ Expresses the number of learners who completed a qualification of specific qualification type and broad field of study as a percentage of the number of learners in the 2008 NSC cohort.

Figure 4.1 compares the cumulative matric average achievement distributions for students from the 2008 matric cohort by broad undergraduate qualification type and field of study. It is clear from the figure that learners who enrolled in undergraduate degree programmes tended to perform significantly better in the NSC examinations than those who enrolled in undergraduate diploma or certificate programmes in their first year of university studies. The figure further suggests that there is some association between matric performance and choice of qualification field. On average, learners who enrolled in SET programmes performed better in matric than those who enrolled in BCM programmes. Learners who enrolled in BCM programmes, in turn, generally performed better in matric than learners who enrolled in HSS programmes. This can be seen in the fact that the matric average distribution for students who enrolled in BCM programmes lies to the right of the distribution for those who enrolled in HSS programmes, with the distribution for students who enrolled in SET programmes lying even further to the right. This relative difference in matric performance across broad fields of study appears to hold both when looking at learners who enrolled in undergraduate non-degrees and learners who enrolled in undergraduate degree programmes

Figure 4.2 replicates Figure 4.1, but this time only considers students from the 2008 matric cohort who completed some undergraduate qualification between 2009 and 2014. A comparison between Figures 4.1 and 4.2 reveals that learners who completed programmes in this time frame had, on average, better matric achievement levels than those who did not. For example, the median matric average of first years enrolled in SET degree programmes was roughly $68 \%$, compared to roughly $71 \%$ for those who completed SET egrees. This appears to be the case regardless of broad field of study or qualification type, albeit to varying extents. 
Figure 4.1: Cumulative matric average achievement distribution for first-year students from the 2008 matric cohort (2009 - 2014), by undergraduate qualification level and broad field of study

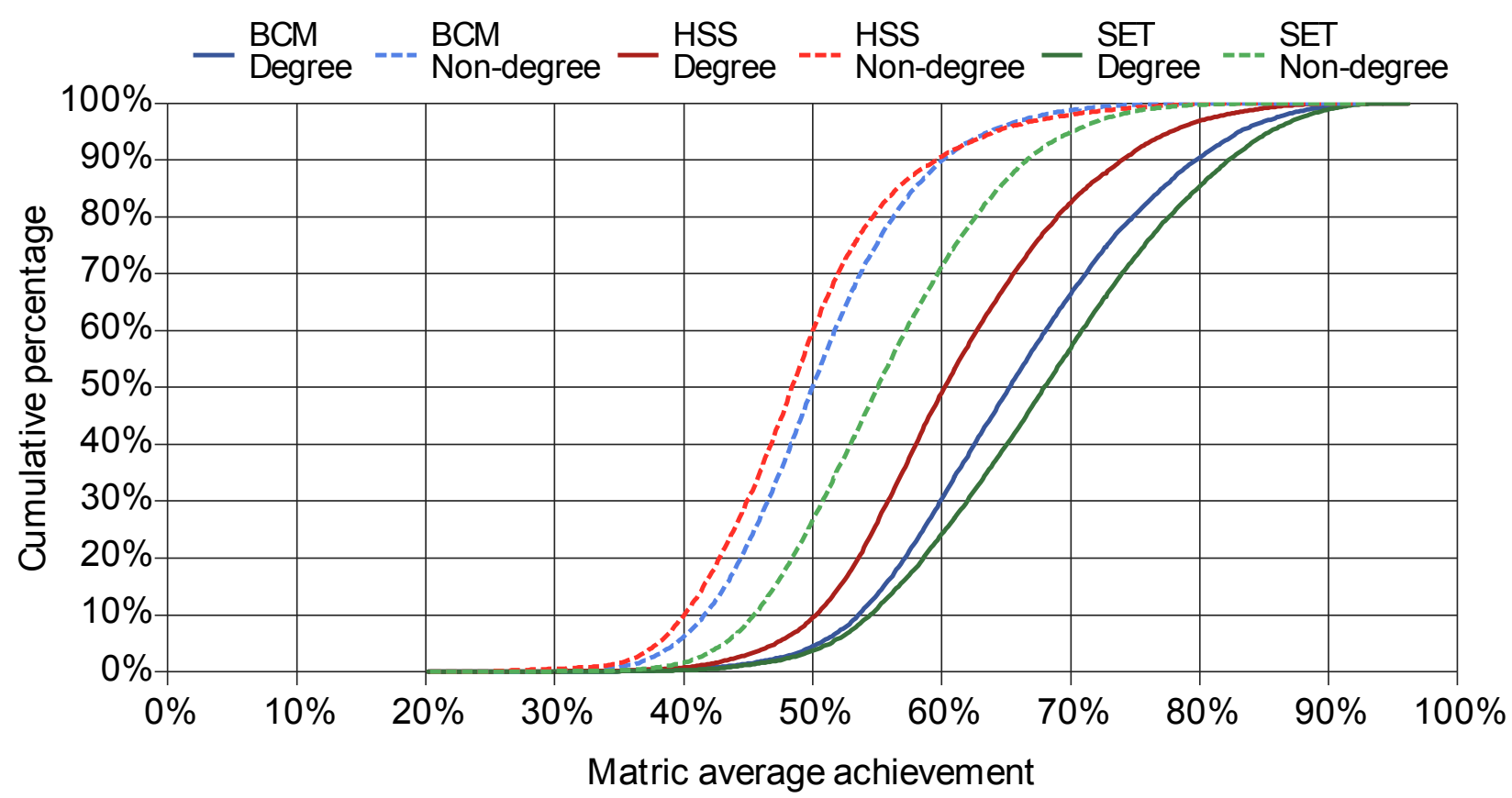

NOTES: Lines represent the cumulative percentage of a group that performed below a given level of 2008 matric average achievement. Each line is drawn only for those learners from the cohort who entered undergraduate programmes of the indicated qualification type and broad field of study during their first year at university between 2009 and 2014.

Moving on to differences in completion rates by qualification type, Table 4.3 shows the different completion rates for students enrolled in BCM, HSS and SET degree and non-degree programmes for the period 20092014. Only those learners who enrolled in university in the year immediately following their matric exams are considered in order to exclude differences in completion rates that are due to delayed entry into university.

The table shows that in general, the completion rate for undergraduate degrees was higher (roughly $62 \%$ ) than for non-degree programmes (49\%) in the period 2009-2014. ${ }^{14}$ Within the non-degree group, BCM students had a slightly higher six-year completion rate than their SET counterparts, at $46 \%$ as opposed to $44 \%$.

It is interesting to note the higher completion rate of BCM non-degree students, since they performed worse, on average, in matric than SET non-degree students. This might be indicative of differences in the relative difficulty of these two qualification types. In other words, judging by completion rates alone, non-degree SET programmes may be more difficult than non-degree BCM programmes. Furthermore, it is interesting that the three-year completion rate of HSS non-degree programmes is higher than that of the other two qualification types (20.2\% compared with $19.9 \%$ and $11.7 \%$ ), when it is lower than both other types after five or six years since matriculation. This might be indicative of the structure of HSS non-degree programmes, specifically that they have a lower minimum completion time than the other two types of qualifications.

\footnotetext{
${ }^{14}$ Some learners from the cohort enrolled in undergraduate degree programmes in 2009, but subsequently switched to undergraduate certificate or diploma programmes. For obvious reasons, these "switchers" could not add to the number of degree completers, even if they ultimately completed their undergraduate non-degree programmes. In such instances, they could still contribute to the overall undergraduate completion rate for the cohort, but not to the completion rate for undergraduate degree students. A similar logic holds for students who switched between broad fields of study. In other words, while switches between undergraduate programme types and fields should not affect the overall undergraduate completion rate, they are likely to affect the programme type and field-specific completion rates for the cohort,
} 
Figure 4.2: Cumulative matric average achievement distribution for completers from the 2008 matric cohort (2009 - 2014), by undergraduate qualification level and broad field of study

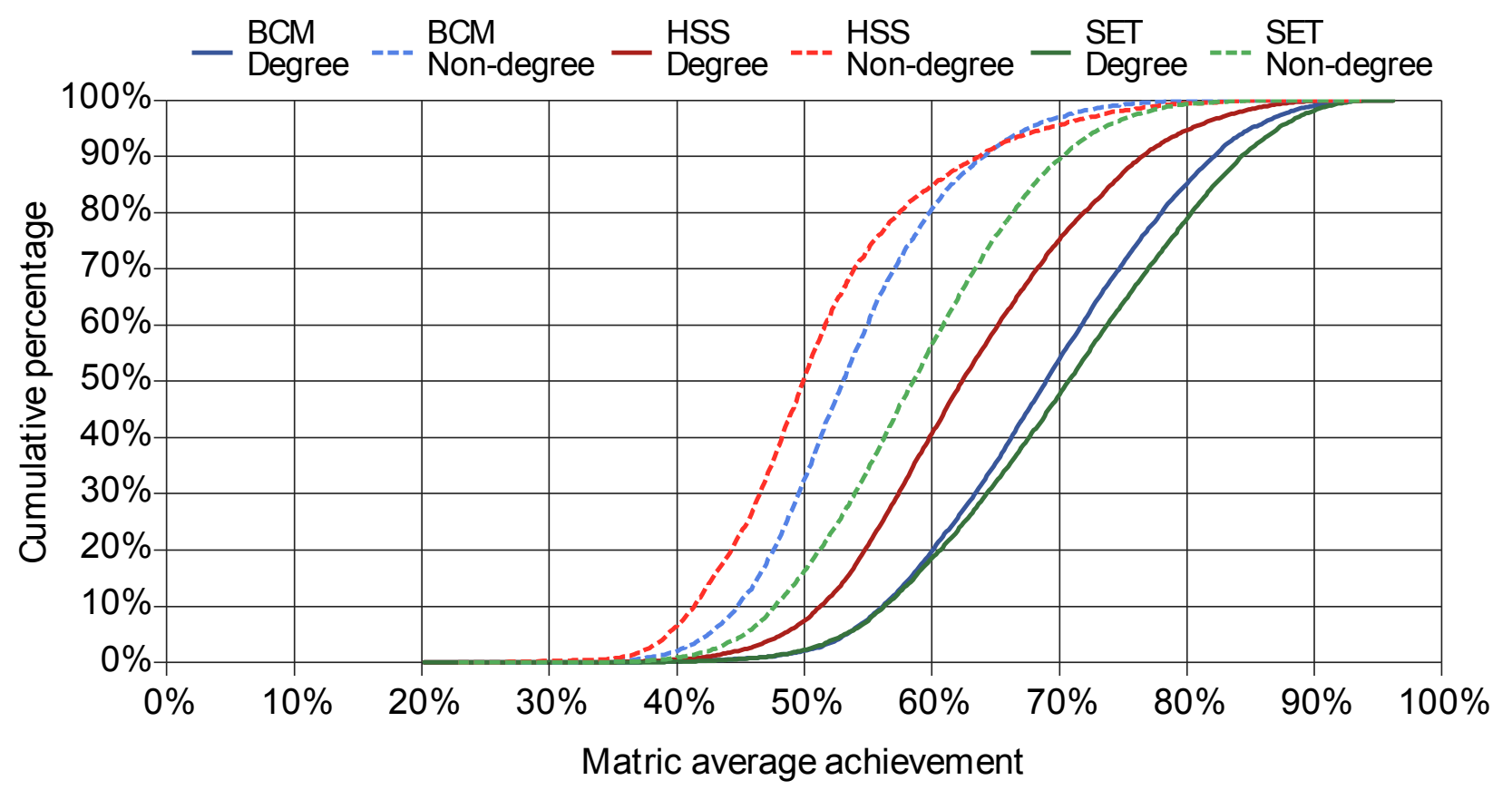

NOTES: Lines represent the cumulative percentage of a group that performed below a given level of 2008 matric average achievement. Each line is drawn only for those learners from the cohort who completed undergraduate programmes of the indicated qualification type and broad field of study between 2009 and 2014.

Table 4.3: University completion rates for 2009 FTEN students from the 2008 matric cohort (2009 - 2014), by broad qualification type and field of study

\begin{tabular}{lcccccc}
\hline & $\begin{array}{r}\text { 1 year } \\
(2009)\end{array}$ & $\begin{array}{c}\text { 2 years } \\
(2010)\end{array}$ & $\begin{array}{c}\text { 3 years } \\
(2011)\end{array}$ & $\begin{array}{c}\text { 4 years } \\
(2012)\end{array}$ & $\begin{array}{r}\text { 5 years } \\
(2013)\end{array}$ & $\begin{array}{c}\text { 6 years } \\
(2014)\end{array}$ \\
\cline { 2 - 7 } UG non-degrees & 0.6 & 2.1 & 18.2 & 33.6 & 43.3 & 48.8 \\
- BCM & 0.0 & 2.6 & 19.9 & 34.7 & 42.5 & 46.1 \\
- HSS & 1.0 & 1.8 & 20.2 & 31.1 & 36.6 & 39.1 \\
- SET & 1.0 & 1.4 & 11.7 & 26.0 & 37.0 & 44.4 \\
UG degree & 0.0 & 0.0 & 14.8 & 39.4 & 54.0 & 61.8 \\
- BCM & 0.0 & 0.0 & 20.6 & 40.6 & 51.8 & 57.0 \\
- HSS & 0.0 & 0.0 & 10.8 & 35.6 & 45.9 & 50.6 \\
- SET & 0.0 & 0.0 & 10.6 & 30.1 & 45.0 & 54.5 \\
\hline
\end{tabular}

NOTES: Figures reflect the broad qualification type- and field of study specific completion rates for learners from the 2008 matric cohort who enrolled in the specified undergraduate qualification types and fields of study for the first time in 2009. The completion rate for BCM degrees, for example, reflects the cumulative percentage of student who enrolled in BCM undergraduate degrees in 2009 and subsequently completed some BCM undergraduate degree between 2009 and 2014. Completion rates are cumulative.

Roughly the same broad patterns can be observed for degree qualifications. BCM degree programmes also had the highest six-year completion rate, at $57.0 \%$, while HSS and SET degree completion rates were $50.6 \%$ and $54.5 \%$ respectively. Once again, the higher completion rate of BCM degree participants relative to SET students is interesting given their lower average levels of matric performance, which again may point to greater difficulty levels for SET programmes. It is also interesting to note the large difference in four-year completion rates between BCM and SET degree students: the estimated four-year completion rate for the former is almost 10 percentage points higher than that of the latter. This difference decreases to just under 3 percentage points by the time six years have passed since matriculation. The results in Table 4.3 are illustrated visually in Figure 4.3. 
Figure 4.3: University completion rates for the 2009 undergraduate intake from the 2008 matric cohort (2009 -2014), by broad qualification type and field of study

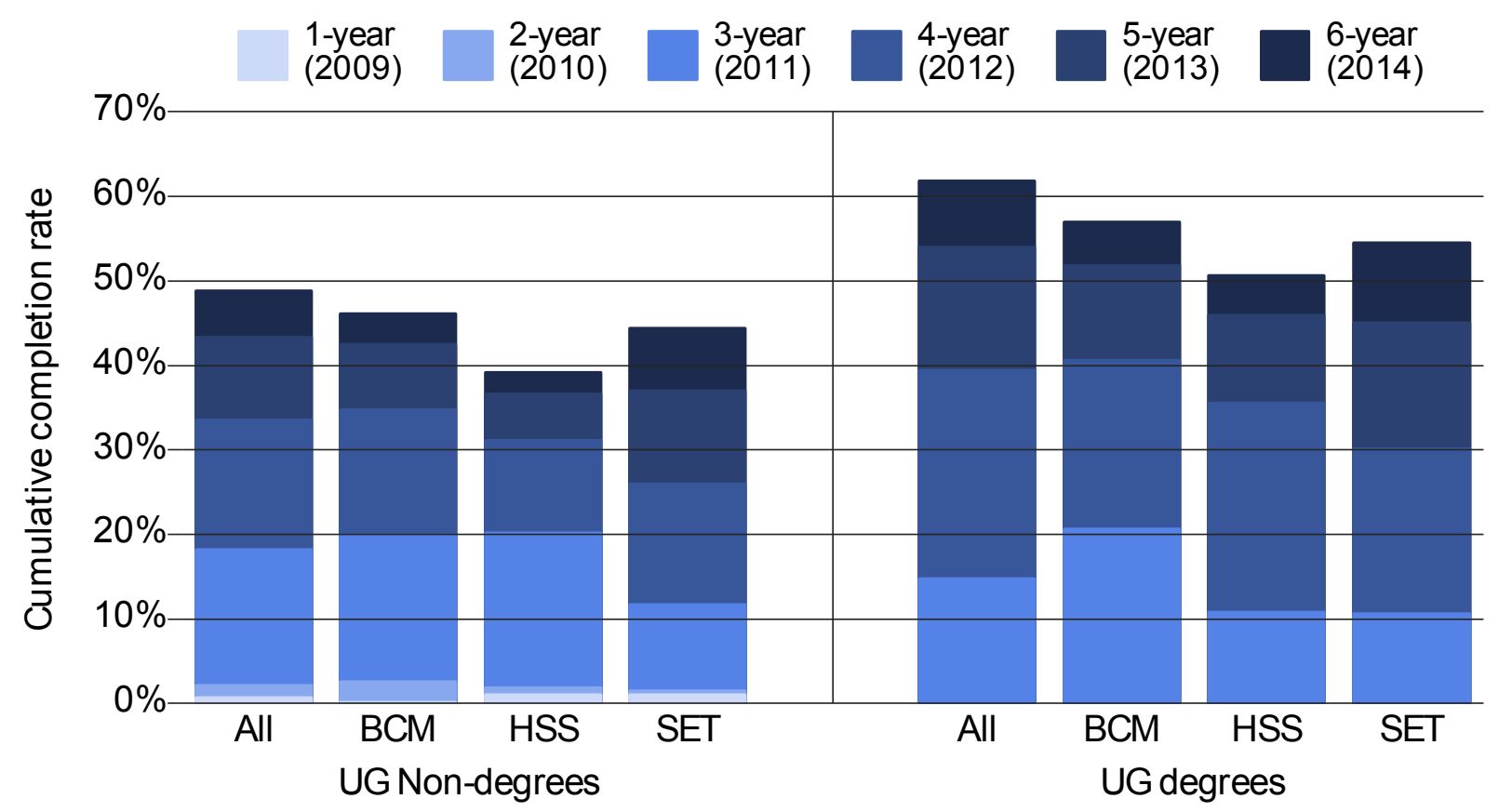

NOTES: Bars reflect the completion rates presented in Table 4.3 .

\section{Age}

Whether or not learners are of the appropriate age in Grade 12 conveys important underlying information about their entry into and pathways through the schooling system (Van Broekhuizen, 2016: 31). For example, if learners are over-aged in Grade 12 (that is, if they are 19 years of age or older by the end of the 31st of December in the year in which they wrote the NSC examinations) this may be because they entered the schooling system later than their peers, because they repeated one or more grades, or a combination of these two factors. Since these factors are likely to affect university access and success, it is instructive to investigate whether an association exists between age in Grade 12 and university access and success.

Table 5.1 summarises the NSC exam results by age for the 2008 matric cohort. Just about half of the learners in the 2008 matric cohort were overage in Grade 12, while only $0.8 \%$ were underage. There are clear differences in matric academic achievement between age groups. $79 \%$ and $78 \%$ of appropriate age and underage learners respectively passed the NSC exams, while only $46 \%$ of overage learners followed suit. The quality of matric passes among underage and appropriate age learners was also better than among overage learners: $33 \%$ and $32 \%$ of appropriate age and underage learners respectively achieved Bachelor passes, while this proportion was only $7 \%$ for overage learners. 
Table 5.1: NSC examination results for the 2008 matric cohort, by age group

\begin{tabular}{crrrr}
\hline & \multicolumn{1}{c}{ All } & Appropriate age & Under-aged & Over-aged \\
\cline { 2 - 4 } Candidates & 561722 & 274506 & 4381 & 282835 \\
row \% & 100.0 & 48.9 & 0.8 & 50.4 \\
column \% & 100.0 & 100.0 & 100.0 & 100.0 \\
Did not achieve & 210857 & 58081 & 960 & 151816 \\
row \% & 100.0 & 27.5 & 0.5 & 72.0 \\
column \% & 37.5 & 21.2 & 21.9 & 53.7 \\
Passed (all) & 350865 & 216425 & 3421 & 131019 \\
row \% & 100.0 & 61.7 & 1.0 & 37.3 \\
column \% & 62.5 & 78.8 & 78.1 & 46.3 \\
- SNE/NSC & 299 & 68 & 2 & 229 \\
row \% & 100.0 & 22.7 & 0.7 & 76.6 \\
column \% & 0.1 & 0.0 & 0.0 & 0.1 \\
- Higher Certificate & 108253 & 46811 & 819 & 60623 \\
row \% & 100.0 & 43.2 & 0.8 & 56.0 \\
column \% & 19.3 & 17.1 & 18.7 & 21.4 \\
- Diploma & 130633 & 78322 & 1200 & 51111 \\
row \% & 100.0 & 60.0 & 0.9 & 39.1 \\
column \% & 23.3 & 28.5 & 27.4 & 18.1 \\
- Bachelor & 111680 & 91224 & 1400 & 19056 \\
row \% & 100.0 & 81.7 & 1.3 & 17.1 \\
column \% & 19.9 & 33.2 & 32.0 & 6.7 \\
\hline
\end{tabular}

NOTES: Figures printed in black reflect the numbers of learners who wrote and achieved particular pass results in the NSC exams for the 2008 matric cohort, by age group. Row percentages are printed in grey and express the number of learners in a particular age group as a percentage of the number of candidates who achieved a particular pass result. Column percentages are also printed in grey and express the number of learners who achieved a particular pass result as a percentage of the number of candidates in each age group.

Table 5.2 shows that very few overage learners gained access to university. By the end of 2014, that is, six years following their NSC examinations, fewer than $8 \%$ of overage learners from the 2008 matric cohort had gained access to public universities. By contrast, about $32 \%$ of appropriate age and underage learners had gained access at some stage between 2009 and 2014.

University success was also clearly associated with age: by the start of 2014 , roughly $44 \%$ of appropriate and of underage learners from the cohort who entered universities had successfully completed undergraduate qualifications in the five years following matriculation, while $28 \%$ had dropped out of university without completing any qualification. Overage learners performed worse, with only $31 \%$ of university participants successfully completing an undergraduate qualification by the start of 2014 . As many as $42 \%$ of overage university participants from the 2008 matric cohort dropped out of university in the period 2009-2014 without completing any qualification. 
Table 5.2: University enrolment, exit, and completion for the 2008 matric cohort (2009 - 2014), by age group in Grade 12

\begin{tabular}{|c|c|c|c|c|c|c|}
\hline & 2009 & 2010 & 2011 & 2012 & 2013 & 2014 \\
\hline & \multicolumn{6}{|c|}{ Percentage of appropriate or under-aged learners ${ }^{1}$} \\
\hline Enrolled & 21.7 & 24.7 & 24.8 & 22.9 & 18.1 & 13.2 \\
\hline - First-time entering & 21.7 & 5.8 & 2.1 & 1.2 & 0.8 & 0.6 \\
\hline - Non-entering undergraduate & - & 18.9 & 22.7 & 20.2 & 15.0 & 10.3 \\
\hline - Non-entering postgraduate & - & - & 0.0 & 1.5 & 2.2 & 2.4 \\
\hline Not enrolled & 78.3 & 75.3 & 75.2 & 77.1 & 81.9 & 86.8 \\
\hline -Non-participants & 78.3 & 72.4 & 70.3 & 69.2 & 68.3 & 67.7 \\
\hline - Exit HE - Completers ${ }^{\mathrm{a}}$ & - & 0.0 & 0.0 & 1.0 & 5.1 & 10.1 \\
\hline - Exit HE - Non-Completers ${ }^{\mathrm{a}}$ & - & 1.8 & 3.5 & 5.3 & 6.9 & 9.0 \\
\hline Completers $^{\mathrm{a}}$ & 0.0 & 0.1 & 3.6 & 9.4 & 14.0 & 16.9 \\
\hline - Completers (non-cumulative) & 0.0 & 0.1 & 3.5 & 5.8 & 4.6 & 3.0 \\
\hline Dropouts $^{\mathrm{a}}$ & 1.8 & 3.5 & 5.3 & 6.9 & 9.0 & - \\
\hline \multirow[t]{2}{*}{ - Dropouts (non-cumulative) } & 1.8 & 1.8 & 1.7 & 1.6 & 2.1 & - \\
\hline & \multicolumn{6}{|c|}{ Percentage of over-aged learners ${ }^{2}$} \\
\hline Enrolled & 4.3 & 5.2 & 5.2 & 4.8 & 4.0 & 2.9 \\
\hline - First-time entering & 4.3 & 1.8 & 0.8 & 0.5 & 0.3 & 0.2 \\
\hline - Non-entering undergraduate & - & 3.4 & 4.5 & 4.2 & 3.4 & 2.4 \\
\hline - Non-entering postgraduate & - & - & - & 0.1 & 0.2 & 0.3 \\
\hline Not enrolled & 95.7 & 94.8 & 94.8 & 95.2 & 96.0 & 97.1 \\
\hline -Non-participants & 95.7 & 93.9 & 93.1 & 92.7 & 92.3 & 92.1 \\
\hline - Exit HE - Completers ${ }^{\mathrm{a}}$ & - & 0.0 & 0.0 & 0.2 & 0.9 & 1.7 \\
\hline - Exit HE - Non-Completers ${ }^{\mathrm{a}}$ & - & 0.6 & 1.3 & 1.9 & 2.5 & 3.2 \\
\hline Completers $^{\mathrm{a}}$ & 0.0 & 0.0 & 0.5 & 1.5 & 2.4 & 3.0 \\
\hline - Completers (non-cumulative) & 0.0 & 0.0 & 0.5 & 1.0 & 0.9 & 0.6 \\
\hline Dropouts $^{\mathrm{a}}$ & 0.6 & 1.3 & 1.9 & 2.5 & 3.2 & - \\
\hline - Dropouts (non-cumulative) & 0.6 & 0.7 & 0.6 & 0.6 & 0.7 & - \\
\hline
\end{tabular}

NOTES: ${ }^{[1]}$ Estimates are expressed as a percentage of the number of appropriate age and underage learners in the 2008 matric cohort. ${ }^{[2]}$ Estimates are expressed as a percentage of the number of overage learners in the 2008 matric cohort. Completers refer to students who successfully completed undergraduate qualifications between 2009 and 2014 whereas dropouts refer to students who left university prior to 2014 without having completed any undergraduate qualification. ${ }^{\text {a] }}$ Numbers are cumulative.

If overage learners are more likely to delay entry into university than appropriate age and underage learners, as Van Broekhuizen (2016: 31) reports, the lower completion rates of overage learners compared with underage and appropriate age learners observed in Table 5.2 may be affected by overage learners enrolling in undergraduate programmes later than their peers rather than solely due to weaker performance at university.

In order to gain a clearer understanding of the factors at play in this case, it is useful to consider only university participants from the 2008 matric cohort who enrolled in undergraduate studies for the first time in 2009 , that is, the year after they wrote their matric exams. Table 5.4 shows the completion, dropout and retention rates for such students. The table indicates that even when limiting the analysis to learners who enrolled in undergraduate studies in 2009 completion rates were far higher for appropriate age (and underage) university participants $(61 \%)$ than they were for overage participants $(46 \%)$. This implies that the difference in completion rates between appropriate age and overage learners cannot only be ascribed to overage learners 
entering university later than appropriate age learners. Similarly, the dropout rate among overage university participants from the cohort was substantially higher (41\%) than the dropout rate among appropriate age learners $(26 \%)$.

Table 5.3: University access, completion, dropout, and retention rates (\%) for the 2008 matric cohort (2009 2014), by age group in Grade 12

\begin{tabular}{|c|c|c|c|c|c|c|}
\hline & $\begin{array}{l}1 \text { year } \\
\text { (2009) }\end{array}$ & $\begin{array}{c}2 \text { years } \\
\text { (2010) }\end{array}$ & $\begin{array}{c}\text { 3 years } \\
(2011)\end{array}$ & $\begin{array}{c}4 \text { years } \\
\text { (2012) }\end{array}$ & $\begin{array}{c}5 \text { years } \\
(2013)\end{array}$ & $\begin{array}{c}6 \text { years } \\
(2014)\end{array}$ \\
\hline & \multicolumn{6}{|c|}{ Appropriate or under-aged learners ${ }^{1}$} \\
\hline Access rate & 21.7 & 27.6 & 29.7 & 30.8 & 31.7 & 32.3 \\
\hline Completion rate & 0.2 & 0.5 & 16.2 & 38.5 & 52.5 & 60.5 \\
\hline Dropout rate & 8.1 & 12.8 & 17.1 & 21.1 & 25.9 & - \\
\hline \multirow[t]{2}{*}{ Retention rate $^{\mathrm{a}}$} & 86.8 & 82.1 & 62.3 & 37.6 & 21.5 & - \\
\hline & \multicolumn{6}{|c|}{ Over-aged learners ${ }^{2}$} \\
\hline Access rate & 4.3 & 6.1 & 6.9 & 7.3 & 7.7 & 7.9 \\
\hline Completion rate & 0.2 & 0.6 & 11.6 & 28.8 & 39.8 & 46.1 \\
\hline Dropout rate & 14.8 & 23.1 & 29.3 & 35.0 & 41.1 & - \\
\hline Retention rate $^{\mathrm{a}}$ & 79.7 & 71.7 & 54.3 & 33.2 & 19.1 & - \\
\hline
\end{tabular}

Table 5.4: The 2008 matric cohort after six years (end of 2014), by age group in Grade 12

\begin{tabular}{lrrrr}
\hline & \multicolumn{1}{c}{ All } & $\begin{array}{c}\text { Appropriate } \\
\text { age }\end{array}$ & Under-aged & Over-aged \\
\hline Cohort & 561789 & 274532 & 4382 & 282875 \\
column \% & 100.0 & 100.0 & 100.0 & 100.0 \\
Enrolled in UG studies & 112402 & 88432 & 1595 & 22375 \\
column \% & 20.0 & 32.2 & 36.4 & 7.9 \\
Enrolled in UG degree & 70632 & 59168 & 946 & 10518 \\
column \% & 12.6 & 21.6 & 21.6 & 3.7 \\
Completed UG qualification & 55721 & 46363 & 884 & 8474 \\
column \% & 9.9 & 16.9 & 20.2 & 3.0 \\
Completed UG degree & 3829 & 33043 & 528 & 4658 \\
column \% & 6.8 & 12.0 & 12.0 & 1.6 \\
Enrolled in PG studies & 13466 & 11920 & 185 & 1361 \\
column \% & 2.4 & 4.3 & 4.2 & 0.5 \\
Completed PG qualification & 9727 & 8705 & 124 & 898 \\
column \% & 1.7 & 3.2 & 2.8 & 0.3 \\
Non-completers enrolled in 2014 & 22426 & 17361 & 305 & 4760 \\
column \% & 4.0 & 6.3 & 7.0 & 1.7 \\
Dropped-out before 2014 & 34163 & 24627 & 405 & 9131 \\
column \% & 6.1 & 9.0 & 9.2 & 3.2 \\
\hline Nolu & 42.0 & \\
\hline
\end{tabular}

NOTES: Figures printed in black reflect the numbers of learners from each of the 2008 matric cohort subgroups. Column percentages are printed in grey and express the number of learners in a particular row as a percentage of the number of candidates from the relevant subgroup.

Table 5.4 summarises university outcomes for the 2008 matric cohort, by age group in Grade 12 as well as the type of undergraduate programmes learners enrolled in. Appropriate or underage learners who accessed 
university were far more likely to enrol in degree programmes than overage learners. About $67 \%$ of appropriate age learners who attended public university at some stage between 2009 and 2014 enrolled in undergraduate degree programmes, as against only $47 \%$ of overage matriculants. Appropriate age learners from the 2008 matric cohort were also more than twice as likely to have completed postgraduate qualifications by 2014 as overage learners.

Table 5.5 presents the perhaps unexpected result that even when considering only learners who achieved Bachelor passes in 2008 (which constitutes a very small proportion of overage learners), there remains a significant difference in the proportions of appropriate age and overage learners with Bachelors passes who accessed university by 2014 (71\% and 57\%, respectively). Patterns of university success also differed: while $64 \%$ of appropriate age learners who achieved Bachelor passes successfully completed an undergraduate qualification by 2014 , the equivalent proportion for overage learners was only $54 \%$. Overage learners who achieved Bachelor passes also dropped out at a higher rate (31\%) in the five years following matriculation than their appropriate age counterparts $(21 \%)$.

Table 5.5: University access, completion, and dropout rate summaries for learners who achieved Bachelor passes in the 2008 NSC exams, by age group in Grade 12

\begin{tabular}{|c|c|c|c|}
\hline & Appropriate age & Underage & Overage \\
\hline Share of Bachelor passes & 81.7 & 1.3 & 17.1 \\
\hline 6-year access rate & 70.9 & 75.0 & 56.6 \\
\hline - UG degree ${ }^{a}$ & 58.7 & 58.1 & 43.2 \\
\hline 1-year access rate & 53.9 & 54.6 & 38.1 \\
\hline - UG degree ${ }^{b}$ & 46.0 & 42.3 & 29.8 \\
\hline 6-year completion rate & 64.4 & 68.2 & 54.0 \\
\hline - UG degree ${ }^{c}$ & 62.4 & 64.2 & 52.1 \\
\hline 5-year dropout rate & 21.4 & 19.0 & 31.4 \\
\hline - UG degree ${ }^{\mathrm{d}}$ & 18.6 & 15.4 & 27.2 \\
\hline
\end{tabular}

NOTES: Figures are only calculated for learners from the 2008 matric cohort who achieved Bachelor passes. Completion and dropout rates are determined only for those learners from each cohort subgroup who enrolled in undergraduate studies for the first time in 2009. ${ }^{\text {[a] }}$ Percentage of learners in each cohort subgroup who enrolled for an undergraduate degree programme at some stage between 2009 and 2014 . ${ }^{\text {b] }}$ Percentage of learners in each cohort subgroup who enrolled for an undergraduate degree programme in 2009. ${ }^{\text {c] }}$ Percentage of learners who enrolled for an undergraduate degree programme in 2009 from each cohort subgroup and successfully completed undergraduate degrees by the end of 2014 . $^{\text {[d] }}$ Percentage of learners who enrolled for an undergraduate degree programme in 2009 from each cohort subgroup, but dropped out of university before 2014 without completing any undergraduate qualification.

The information in Table 5.5 seems to suggest that the disadvantage of being over-aged with regards to university access, completion, and dropout is not purely because overage learners perform weaker in matric, as being over-aged remains a disadvantage even among learners who achieved Bachelor passes in matric. Similar results have been found in other studies. Van Broekhuizen (2016: 30) reports that most international studies of the relationship between age and university success find that younger students who enter university shortly after finishing secondary school are more likely to study successfully than older students. This is partly because younger students are often more accustomed to dealing with the academic demands of formal education, but also because older students tend to have significant additional responsibilities outside of their formal studies and are more inclined to drop out if they have to repeat a year or more at university. 


\section{Gender}

In South Africa, females account for a larger share of university enrolments than males and this share appears to be rising steadily over time (Van Broekhuizen, 2016: 32). This may seem surprising, considering that males and females generally appear to perform roughly similarly in the NSC exams, in terms of matric outcomes. This is certainly true of the 2008 matric cohort. But Table 6.1 also shows that many more girls wrote the 2008 NSC exams, due to higher repetition and dropout at school amongst boys. For example, 54\% of the 2008 matric cohort was female, and though about equal proportions of male and female matriculants passed matric overall, proportionally more females achieved bachelor passes (21\%) than males (19\%). As a result, females accounted for $56 \%$ of all learners achieving Bachelor passes in the 2008 NSC exams.

Table 6.1: NSC exam results for the 2008 matric cohort, by gender

\begin{tabular}{crrr}
\hline & All & Male & Female \\
\cline { 2 - 4 } Candidates & 561624 & 258238 & 303386 \\
row \% & 100.0 & 46.0 & 54.0 \\
column \% & 100.0 & 100.0 & 100.0 \\
Did not achieve & 210788 & 95005 & 115783 \\
row \% & 100.0 & 45.1 & 54.9 \\
column \% & 37.5 & 36.8 & 38.2 \\
Passed (all) & 350836 & 163233 & 187603 \\
row \% & 100.0 & 46.5 & 53.5 \\
column \% & 62.5 & 63.2 & 61.8 \\
- SNE/NSC & 299 & 167 & 132 \\
row \% & 100.0 & 55.9 & 44.1 \\
column \% & 0.1 & 0.1 & 0.0 \\
- Higher Certificate & 108.9 & 58366 \\
row \% & 246 & 49880 & 53.9 \\
column \% & 100.0 & 46.1 & 19.2 \\
- Diploma & 19.3 & 19.3 & 66719 \\
row \% & 130616 & 63897 & 51.1 \\
column \% & 100.0 & 48.9 & 22.0 \\
- Bachelor & 23.3 & 24.7 & 62386 \\
row \% & 111675 & 49289 & 55.9 \\
column \% & 100.0 & 44.1 & 20.6 \\
\hline
\end{tabular}

NOTES: Figures printed in black reflect the numbers of learners who wrote and achieved particular pass results in the NSC exams for the 2008 matric cohort, by gender. Row percentages are printed in grey and express the number of learners in a particular gender group as a percentage of the number of candidates who achieved a particular pass result. Column percentages are also printed in grey and express the number of learners who achieved a particular pass result as a percentage of the number of candidates in each gender group.

Since the 2008 NSC performance patterns are broadly similar for male and female learners, it is reasonable to expect broadly similar levels of university access, completion, and dropout among the two groups. However, Table 6.2 indicates that females slightly outperform males in relative terms in most of the measures reported. For example, slightly more females (21.2\%) gained access to university within the first six years of writing the NSC examinations than males (18.6\%). A difference in the extent of programme completion is also discernable: $11 \%$ of females learners successfully completed undergraduate qualifications in the period 20092014, compared to $8 \%$ of males, with the consequence that 33929 females from the cohort had completed 
undergraduate qualifications by the end of 2014 compared to 21792 males. In addition, slightly fewer females (5.9\%) dropped out of university during this period than males $(6.3 \%)$.

Table 6.2: University enrolment, exit, and completion for the 2008 matric cohort (2009 - 2014), by gender

\begin{tabular}{|c|c|c|c|c|c|c|}
\hline & 2009 & 2010 & 2011 & 2012 & 2013 & 2014 \\
\hline & \multicolumn{6}{|c|}{ Percentage of male learners ${ }^{1}$} \\
\hline Enrolled & 11.9 & 13.8 & 13.8 & 12.7 & 10.3 & 7.6 \\
\hline - First-time entering & 11.9 & 3.8 & 1.4 & 0.7 & 0.5 & 0.3 \\
\hline - Non-entering undergraduate & - & 10.1 & 12.4 & 11.3 & 8.8 & 6.1 \\
\hline - Non-entering postgraduate & - & - & - & 0.6 & 1.0 & 1.2 \\
\hline Not enrolled & 88.1 & 86.2 & 86.2 & 87.3 & 89.7 & 92.4 \\
\hline -Non-participants & 88.1 & 84.3 & 82.9 & 82.2 & 81.7 & 81.4 \\
\hline - Exit HE - Completers ${ }^{\mathrm{a}}$ & - & 0.0 & 0.0 & 0.4 & 2.2 & 4.7 \\
\hline - Exit HE - Non-Completers ${ }^{\mathrm{a}}$ & - & 1.2 & 2.5 & 3.7 & 4.8 & 6.3 \\
\hline Completers $^{\mathrm{a}}$ & 0.0 & 0.1 & 1.6 & 4.4 & 6.7 & 8.4 \\
\hline - Completers (non-cumulative) & 0.0 & 0.0 & 1.6 & 2.7 & 2.4 & 1.7 \\
\hline Dropouts $^{\mathrm{a}}$ & 1.2 & 2.5 & 3.7 & 4.8 & 6.3 & - \\
\hline \multirow[t]{2}{*}{ - Dropouts (non-cumulative) } & 1.2 & 1.3 & 1.2 & 1.1 & 1.4 & - \\
\hline & \multicolumn{6}{|c|}{ Percentage of female learners $^{2}$} \\
\hline Enrolled & 13.9 & 15.8 & 16.0 & 14.7 & 11.6 & 8.4 \\
\hline - First-time entering & 13.9 & 3.8 & 1.5 & 0.9 & 0.7 & 0.5 \\
\hline - Non-entering undergraduate & - & 12.0 & 14.5 & 12.9 & 9.5 & 6.5 \\
\hline - Non-entering postgraduate & - & - & 0.0 & 0.9 & 1.4 & 1.5 \\
\hline Not enrolled & 86.1 & 84.2 & 84.0 & 85.3 & 88.4 & 91.6 \\
\hline -Non-participants & 86.1 & 82.3 & 80.8 & 80.0 & 79.3 & 78.8 \\
\hline - Exit HE - Completers ${ }^{\mathrm{a}}$ & - & 0.0 & 0.0 & 0.7 & 3.6 & 6.9 \\
\hline - Exit HE - Non-Completers ${ }^{\mathrm{a}}$ & - & 1.2 & 2.3 & 3.5 & 4.6 & 5.9 \\
\hline Completers $^{\mathrm{a}}$ & 0.0 & 0.1 & 2.4 & 6.3 & 9.3 & 11.2 \\
\hline - Completers (non-cumulative) & 0.0 & 0.1 & 2.3 & 3.9 & 3.0 & 1.9 \\
\hline Dropouts $^{\mathrm{a}}$ & 1.2 & 2.3 & 3.5 & 4.6 & 5.9 & - \\
\hline - Dropouts (non-cumulative) & 1.2 & 1.2 & 1.2 & 1.1 & 1.4 & - \\
\hline
\end{tabular}

NOTES: ${ }^{[1]}$ Estimates are expressed as a percentage of the number of male learners in the 2008 matric cohort. ${ }^{[2]}$ Estimates are expressed as a percentage of the number of female learners in the 2008 matric cohort. Completers refer to students who successfully completed undergraduate qualifications between 2009 and 2014 whereas dropouts refer to students who left university prior to 2014 without having completed any undergraduate qualification.

${ }^{[a]}$ Numbers are cumulative.

Similar patterns are observable in Table 6.3, which shows the access, completion, dropout and throughput rates of only those university participants from the cohort who enrolled in undergraduate studies in 2009, i.e. the year immediately following matriculation, for males and females separately. The table reiterates the findings of Tables 6.2 above, with the added observation that the completion rate for females was substantially greater than that for males: by the end of 2009 , roughly $62 \%$ of the female university participants from the cohort who had enrolled in undergraduate studies in 2009 had completed undergraduate qualifications. For males, the figure was only $53 \%$. The dropout rate for this group was also greater among males than females: males dropped out at a rate of $32 \%$ in the five years following entrance into university, whereas the dropout rate for 
females was $26 \%$. As can be seen in Table 6.4, proportionally more females also enrolled in undergraduate degree programmes at $14 \%$, compared with the $11 \%$ of males who did the same.

Table 6.3: University access, completion, dropout, and retention rates (\%) for the 2008 matric cohort (2009 2014), by gender

\begin{tabular}{lcccccc}
\hline & $\begin{array}{c}\text { 1 year } \\
(2009)\end{array}$ & $\begin{array}{c}\text { 2 years } \\
(2010)\end{array}$ & $\begin{array}{c}\text { 3 years } \\
(2011)\end{array}$ & $\begin{array}{c}\text { 4 years } \\
(2012)\end{array}$ & $\begin{array}{c}\text { 5 years } \\
(2013)\end{array}$ & $\begin{array}{c}\text { 6 years } \\
(2014)\end{array}$ \\
\hline & \multicolumn{5}{c}{ Male learners } \\
Access rate & 11.9 & 15.7 & 17.1 & 17.8 & 18.3 & 18.6 \\
Completion rate & 0.2 & 0.4 & 13.3 & 32.1 & 44.9 & 53.1 \\
Dropout rate & 10.1 & 16.2 & 21.5 & 26.4 & 32.2 & - \\
Retention rate $^{\mathbf{a}}$ & 84.5 & 78.6 & 60.6 & 38.5 & 22.8 & - \\
\hline & & \multicolumn{7}{c}{ Female learners ${ }^{2}$} \\
Access rate & 13.9 & 17.7 & 19.2 & 20.0 & 20.7 & 21.2 \\
Completion rate & 0.2 & 0.6 & 16.9 & 40.3 & 54.3 & 61.8 \\
Dropout rate & 8.6 & 13.3 & 17.5 & 21.3 & 25.6 & - \\
Retention rate $^{\mathrm{a}}$ & 86.5 & 81.6 & 61.2 & 35.7 & 20.0 & - \\
\hline
\end{tabular}

NOTES: ${ }^{[1]}$ Access rates are calculated for male learners from the 2008 matric cohort while completion, dropout, and retention rates are only determined for students from this group who enrolled in undergraduate studies for the first time in 2009. : ${ }^{[2]}$ Access rates are calculated for female learners from the 2008 matric cohort while completion, dropout, and retention rates are only determined for students from this group who enrolled in undergraduate studies for the first time in 2009. Access, completion, and dropout rates are cumulative. ${ }^{\text {[a] }}$ The retention rate presented in the table reflects the percentage of students from the 2009 first-time entering group who had not yet completed any qualification, but were still enrolled in undergraduate studies in the following year.

Table 6.4: The 2008 matric cohort after six years (end of 2014), by gender

\begin{tabular}{lrrr}
\hline & All & Male & Female \\
\hline Cohort & 561667 & 258261 & 303406 \\
column \% & 100.0 & 100.0 & 100.0 \\
Enrolled in UG studies & 112402 & 48003 & 64399 \\
column \% & 20.0 & 18.6 & 21.2 \\
Enrolled in UG degree & 70632 & 28930 & 41702 \\
column \% & 12.6 & 11.2 & 13.7 \\
Completed UG qualification & 55721 & 21792 & 33929 \\
column \% & 9.9 & 8.4 & 11.2 \\
Completed UG degree & 38229 & 14373 & 23856 \\
column \% & 6.8 & 5.6 & 7.9 \\
Enrolled in PG studies & 13466 & 5253 & 8213 \\
column \% & 2.4 & 2.0 & 2.7 \\
Completed PG qualification & 9727 & 3658 & 6069 \\
column \% & 1.7 & 1.4 & 2.0 \\
Non-completers enrolled in 2014 & 22426 & 9994 & 12432 \\
column \% & 4.0 & 3.9 & 4.1 \\
Dropped-out before 2014 & 34163 & 16181 & 17982 \\
column \% & 6.1 & 6.3 & 5.9 \\
\hline
\end{tabular}

NOTES: Figures printed in black reflect the numbers of learners from each of the 2008 matric cohort subgroups. Column percentages are printed in grey and express the number of learners in a particular row as a percentage of the number of candidates from the relevant subgroup. 
Table 6.5 further emphasises the gender differences in university access and success, specifically in terms of undergraduate degrees. A much larger proportion of females (64.2\%) who had enrolled in degree programmes in 2009 had completed their qualifications successfully by 2014 than was the case for males (54.7\%).

Table 6.5: NSC pass type and university access, completion, and dropout rate summaries for the 2008 NSC, by gender

\begin{tabular}{|c|c|c|}
\hline & Male & Female \\
\hline Share of matric cohort & 46.0 & 54.0 \\
\hline Bachelor Pass & 19.1 & 20.6 \\
\hline 6-year access rate & 18.6 & 21.2 \\
\hline - UG degree ${ }^{\mathrm{a}}$ & 11.2 & 13.7 \\
\hline 1-year access rate & 11.9 & 13.9 \\
\hline - UG degree ${ }^{\mathrm{b}}$ & 8.1 & 10.1 \\
\hline 6-year completion rate & 53.1 & 61.8 \\
\hline - UG degree ${ }^{c}$ & 54.7 & 64.2 \\
\hline 5-year dropout rate & 32.2 & 25.6 \\
\hline - UG degree ${ }^{\mathrm{d}}$ & 22.6 & 17.8 \\
\hline
\end{tabular}

NOTES: Completion and dropout rates are calculated only for those learners from each 2008 NSC subgroup who enrolled in undergraduate studies for the first time in 2009. [a] Percentage of learners in each 2008 NSC subgroup who enrolled for an undergraduate degree programme at some stage between 2009 and 2014. ${ }^{[b]}$ Percentage of learners who enrolled for an undergraduate degree programme in 2009 from each 2008 NSC subgroup and successfully completed undergraduate degrees by the end of 2014. ${ }^{[c]}$ Percentage of learners who enrolled for an undergraduate degree programme in 2009 from each 2008 NSC subgroup, but dropped out of university before 2014 without completing any undergraduate qualification. [d] Percentage of learners who enrolled for an undergraduate degree programme in 2009 from each 2008 NSC subgroup, but dropped out of university before 2014 without completing any undergraduate qualification.

Table 6.6: University access, completion, and dropout rate summaries for learners who achieved Bachelor passes in the $2008 \mathrm{NSC}$, by gender

\begin{tabular}{lcc}
\hline & Male & Female \\
\hline Share of matric cohort $^{\text {Bachelor Pass }}$ & 44.1 & 55.9 \\
6-year access rate $^{\text {a }}$ & 66.9 & 69.8 \\
- UG degree $^{\mathrm{a}}$ & 52.4 & 59.0 \\
1-year access rate $^{\text {- }}$ & 48.9 & 53.0 \\
- UG degree $^{\text {b }}$ & 39.9 & 45.8 \\
6-year completion rate & 57.8 & 67.1 \\
- UG degree $^{\text {c }}$ & 55.6 & 65.1 \\
5-year dropout rate & 26.6 & 19.8 \\
- UG degree $^{\text {d }}$ & 22.5 & 17.6 \\
\hline
\end{tabular}

NOTES: Figures are only calculated for learners from the 2008 matric cohort who achieved Bachelor passes. Completion and dropout rates are determined only for those learners from each cohort subgroup who enrolled in undergraduate studies for the first time in 2009. ${ }^{[a]}$ Percentage of learners in each cohort subgroup who enrolled for an undergraduate degree programme at some stage between 2009 and 2014. ${ }^{[b]}$ Percentage of learners in each cohort subgroup who enrolled for an undergraduate degree programme in 2009. ${ }^{[c]}$ Percentage of learners who enrolled for an undergraduate degree programme in 2009 from each cohort subgroup and successfully completed undergraduate degrees by the end of 2014. ${ }^{\text {[d] }}$ Percentage of learners who enrolled for an undergraduate degree programme in 2009 from each cohort subgroup, but dropped out of university before 2014 without completing any undergraduate qualification.

One possible reason for the differential university performance of male and female learners from the cohort may be differential selection into university. Specifically, if more weak-performing male learners gained access to university than was the case for female learners, it would be reasonable to expect that the 
comparatively "stronger" female student group would outperform its comparatively "weaker" male counterpart. In order to test for this explanation, it is instructive to limit the analysis to learners in the cohort who performed relatively similarly in their matric examinations. This is done in Table 6.6 by considering only those learners from the 2008 matric cohort who achieved Bachelor passes. Amongst this more homogenous group in terms of matric performance, females still outperformed males in terms of the six-year access, the six-year completion and the five-year dropout rate. In fact, the 6-year completion rates for female learners who achieved Bachelor passes was almost 10 percentage points higher than for males - 67\% compared to $58 \%$. This result is very similar to the difference in the six-year completion rate between males and females for the full cohort (Table 6.4). This suggests that the difference in completion rates between males and females is unlikely to be due to differential selection into university between males and females.

Van Broekhuizen (2016: 32) notes that the international evidence suggests it is quite common for females to perform better than males in terms of university throughput and retention. The findings regarding gender differences in university access and success for the 2008 matric cohort therefore conform to patterns observed elsewhere.

\section{Race}

Race remains perhaps the single most prominent demographic correlate of university access and success in South Africa. In order to investigate the association between race and university outcomes for the 2008 matric cohort, it is useful to first consider differences in matric performance between different race groups. Table 7.1 shows the 2008 cohort's matric exam results by race.

Black learners accounted for the bulk (82.5\%) of 2008 NSC candidates with white (7.7\%), coloured (6.8\%), and Asian $(2.9 \%)$ candidates collectively constituting the rest of the cohort. It is evident that there are staggering differences in matric pass rates across race groups. Only about $57 \%$ of black learners passed the 2008 NSC exams, compared with $80 \%, 90 \%$, and 99\% of coloured, Asian, and white learners respectively. There are also large differences in the types of passes achieved. For example, among white learners who passed matric, 71\% achieved Bachelor passes, and amongst Asians 60\%, while these proportions were much lower amongst coloured and black learners at only $30 \%$ and $24 \%$ respectively. 
Table 7.1: NSC exam results for the 2008 matric cohort, by race

\begin{tabular}{lrrrrr}
\hline & \multicolumn{1}{c}{ All } & Black & Coloured & Asian & White \\
\hline Candidates & 560878 & 462637 & 38399 & 16440 & 43402 \\
row \% & 100.0 & 82.5 & 6.8 & 2.9 & 7.7 \\
column \% & 100.0 & 100.0 & 100.0 & 100.0 & 100.0 \\
Did not achieve & 210735 & 200818 & 7870 & 1727 & 320 \\
row \% & 100.0 & 95.3 & 3.7 & 0.8 & 0.2 \\
column \% & 37.6 & 43.4 & 20.5 & 10.5 & 0.7 \\
Passed (all) & 350143 & 261819 & 30529 & 14713 & 43082 \\
row \% & 100.0 & 74.8 & 8.7 & 4.2 & 12.3 \\
column \% & 62.4 & 56.6 & 79.5 & 89.5 & 99.3 \\
- SNE/NSC & 299 & 256 & 10 & 4 & 29 \\
row \% & 100.0 & 85.6 & 3.3 & 1.3 & 9.7 \\
column \% & 0.1 & 0.1 & 0.0 & 0.0 & 0.1 \\
- Higher Certificate & 108 199 & 97845 & 7778 & 1575 & 1001 \\
row \% & 100.0 & 90.4 & 7.2 & 1.5 & 0.9 \\
column \% & 19.3 & 21.1 & 20.3 & 9.6 & 2.3 \\
- Diploma & 130392 & 100979 & 13589 & 4259 & 11565 \\
row \% & 100.0 & 77.4 & 10.4 & 3.3 & 8.9 \\
column \% & 23.2 & 21.8 & 35.4 & 25.9 & 26.6 \\
- Bachelor & 111253 & 62739 & 9152 & 8875 & 30487 \\
row \% & 100.0 & 56.4 & 8.2 & 8.0 & 27.4 \\
column \% & 19.8 & 13.6 & 23.8 & 54.0 & 70.2 \\
\hline
\end{tabular}

NOTES: Figures printed in black reflect the numbers of learners who wrote and achieved particular pass results in the NSC exams for the 2008 matric cohort, by race group. Row percentages are printed in grey and express the number of learners in a particular age group as a percentage of the number of candidates who achieved a particular pass result. Column percentages are also printed in grey and express the number of learners who achieved a particular pass result as a percentage of the number of candidates in each race group.

Figure 7.1 compares the cumulative matric average achievement distributions for the 2008 matric cohort by race. Once again, stark differences in academic achievement are immediately obvious. One way of comparing performances between the race groups is to consider their respective median matric averages: among black, coloured, Asian, and white learners, the average matric marks at the median (i.e. the middle value amongst all candidates) were $38 \%, 44 \%, 55 \%$, and $63 \%$ respectively. Another way to compare performances is to look at the proportion of learners that achieved above a certain mark. Again, the differences between race groups are stark: while more than $85 \%$ of white learners from the cohort scored a matric average above $50 \%$, roughly $61 \%$ of Asian learners, $30 \%$ of coloured learners, and fewer than $20 \%$ of the black learners from the cohort did so. 
Figure 7.1: Cumulative matric average achievement distribution for the 2008 matric cohort, by race

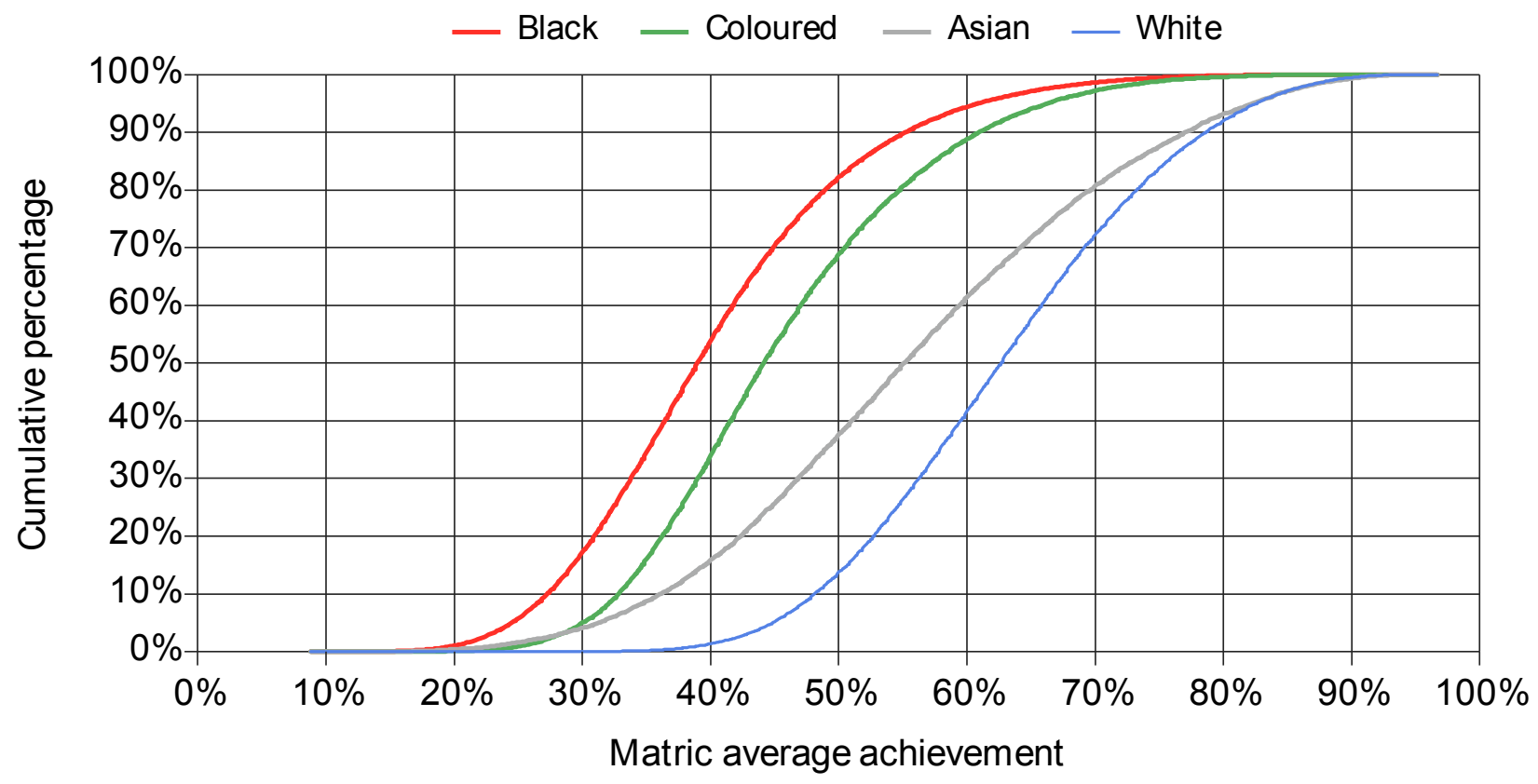

NOTES: Each line represents the cumulative percentage of a particular race group that performed below a given level of 2008 NSC matric average achievement.

It is to be expected that the large racial differences in matric performance among the 2008 matric cohort would have subsequently translated into large differences in post-matric outcomes. Table 7.2 summarises university enrolment, exit, and completion for each race group from the 2008 matric cohort in turn.

Table 7.2: University enrolment, exit, and completion for the 2008 matric cohort (2009 - 2014), by race

\begin{tabular}{|c|c|c|c|c|c|c|}
\hline & 2009 & 2010 & 2011 & 2012 & 2013 & 2014 \\
\hline & \multicolumn{6}{|c|}{ Percentage of black learners $^{1}$} \\
\hline Enrolled & 10.0 & 11.9 & 12.1 & 11.2 & 9.2 & 6.8 \\
\hline - First-time entering & 9.9 & 3.5 & 1.4 & 0.8 & 0.6 & 0.4 \\
\hline - Non-entering undergraduate & - & 8.4 & 10.7 & 10.1 & 8.0 & 5.6 \\
\hline - Non-entering postgraduate & - & - & - & 0.3 & 0.6 & 0.8 \\
\hline Not enrolled & 90.0 & 88.1 & 87.9 & 88.8 & 90.8 & 93.2 \\
\hline -Non-participants & 90.1 & 86.6 & 85.2 & 84.4 & 83.8 & 83.4 \\
\hline - Exit HE - Completers ${ }^{\mathrm{a}}$ & - & 0.0 & 0.0 & 0.4 & 2.0 & 4.3 \\
\hline - Exit HE - Non-Completers ${ }^{\mathrm{a}}$ & - & 1.0 & 2.0 & 3.1 & 4.2 & 5.5 \\
\hline Completers $^{\mathrm{a}}$ & 0.0 & 0.1 & 1.3 & 3.7 & 5.9 & 7.5 \\
\hline - Completers (non-cumulative) & 0.0 & 0.1 & 1.2 & 2.4 & 2.2 & 1.6 \\
\hline Dropouts $^{\mathrm{a}}$ & 1.0 & 2.0 & 3.1 & 4.2 & 5.5 & - \\
\hline \multirow{2}{*}{ - Dropouts (non-cumulative) } & 1.0 & 1.1 & 1.1 & 1.1 & 1.3 & - \\
\hline & \multicolumn{6}{|c|}{ Percentage of coloured learners ${ }^{2}$} \\
\hline Enrolled & 14.1 & 14.9 & 14.1 & 12.6 & 9.6 & 7.0 \\
\hline - First-time entering & 13.9 & 3.3 & 1.1 & 0.6 & 0.5 & 0.4 \\
\hline - Non-entering undergraduate & - & 11.6 & 13.0 & 11.4 & 8.0 & 5.5 \\
\hline - Non-entering postgraduate & - & - & - & 0.6 & 1.1 & 1.1 \\
\hline Not enrolled & 85.9 & 85.1 & 85.9 & 87.4 & 90.4 & 93.0 \\
\hline -Non-participants & 86.1 & 82.8 & 81.7 & 81.1 & 80.6 & 80.2 \\
\hline - Exit HE - Completers ${ }^{\mathrm{a}}$ & - & 0.0 & 0.0 & 0.7 & 3.3 & 6.0 \\
\hline
\end{tabular}




\begin{tabular}{|c|c|c|c|c|c|c|}
\hline - Exit HE - Non-Completers ${ }^{\mathrm{a}}$ & - & 1.8 & 3.4 & 4.7 & 5.7 & 6.9 \\
\hline Completers $^{\mathrm{a}}$ & 0.1 & 0.2 & 2.0 & 5.4 & 7.8 & 9.4 \\
\hline - Completers (non-cumulative) & 0.1 & 0.2 & 1.8 & 3.4 & 2.5 & 1.5 \\
\hline Dropouts $^{\mathrm{a}}$ & 1.8 & 3.4 & 4.7 & 5.7 & 6.9 & - \\
\hline \multirow[t]{2}{*}{ - Dropouts (non-cumulative) } & 1.8 & 1.6 & 1.3 & 1.0 & 1.2 & - \\
\hline & \multicolumn{6}{|c|}{ Percentage of Asian learners ${ }^{3}$} \\
\hline Enrolled & 35.3 & 34.9 & 33.8 & 30.7 & 24.3 & 17.3 \\
\hline - First-time entering & 36.2 & 4.1 & 1.3 & 0.7 & 0.5 & 0.4 \\
\hline - Non-entering undergraduate & - & 31.1 & 32.5 & 27.2 & 19.7 & 12.5 \\
\hline - Non-entering postgraduate & - & - & - & 2.8 & 4.1 & 4.4 \\
\hline Not enrolled & 64.7 & 65.1 & 66.2 & 69.3 & 75.7 & 82.7 \\
\hline -Non-participants & 63.8 & 59.7 & 58.4 & 57.7 & 57.1 & 56.7 \\
\hline - Exit HE - Completers ${ }^{\mathrm{a}}$ & - & 0.0 & 0.0 & 1.2 & 7.0 & 14.4 \\
\hline - Exit HE - Non-Completers ${ }^{\mathrm{a}}$ & - & 2.7 & 4.9 & 6.9 & 8.6 & 10.9 \\
\hline Completers $^{\mathrm{a}}$ & 0.0 & 0.0 & 5.3 & 13.5 & 20.4 & 24.3 \\
\hline - Completers (non-cumulative) & 0.0 & 0.0 & 5.2 & 8.2 & 6.9 & 3.9 \\
\hline Dropouts $^{\mathrm{a}}$ & 2.7 & 4.9 & 6.9 & 8.6 & 10.9 & - \\
\hline \multirow[t]{2}{*}{ - Dropouts (non-cumulative) } & 2.7 & 2.2 & 2.0 & 1.7 & 2.3 & - \\
\hline & \multicolumn{6}{|c|}{ Percentage of white learners ${ }^{4}$} \\
\hline Enrolled & 35.6 & 38.9 & 39.0 & 35.8 & 26.1 & 18.2 \\
\hline - First-time entering & 35.5 & 7.0 & 2.3 & 1.1 & 0.9 & 0.5 \\
\hline - Non-entering undergraduate & - & 32.0 & 36.7 & 29.4 & 18.8 & 11.9 \\
\hline - Non-entering postgraduate & - & - & 0.0 & 5.2 & 6.4 & 5.8 \\
\hline Not enrolled & 64.4 & 61.1 & 61.0 & 64.2 & 73.9 & 81.8 \\
\hline -Non-participants & 64.5 & 57.5 & 55.2 & 54.0 & 53.1 & 52.6 \\
\hline - Exit HE - Completers ${ }^{\mathrm{a}}$ & - & 0.0 & 0.0 & 1.7 & 10.9 & 19.3 \\
\hline - Exit HE - Non-Completers ${ }^{a}$ & - & 2.3 & 4.5 & 6.5 & 7.9 & 9.8 \\
\hline Completers $^{\mathrm{a}}$ & 0.0 & 0.1 & 8.7 & 20.2 & 26.8 & 30.3 \\
\hline - Completers (non-cumulative) & 0.0 & 0.1 & 8.7 & 11.5 & 6.6 & 3.5 \\
\hline Dropouts $^{\mathrm{a}}$ & 2.3 & 4.5 & 6.5 & 7.9 & 9.8 & - \\
\hline - Dropouts (non-cumulative) & 2.3 & 2.2 & 2.0 & 1.5 & 1.9 & - \\
\hline
\end{tabular}

As black learners represent by far the largest share of 2008 NSC candidates, figures for this group are broadly reflective of the overall university outcomes. Table 7.2 shows that by the end of 2014 only $16.6 \%$ of black learners had gained access to public universities. Of these, only $60 \%$ (9.9\% of black learners in the original 2008 matric cohort) enrolled in undergraduate studies in the year immediately following the writing of their matric exams. Furthermore, $45 \%$ of black university participants $(7.5 \%$ of black learners from the original cohort) had completed undergraduate qualifications by the end of 2014 , while $33 \%$ (5.5\% of the original cohort) had dropped out by the end of 2013. About $10 \%$ of black learners who enrolled in undergraduate programmes $(1.7 \%$ of the cohort) proceeded to enrol in postgraduate programmes by the end of 2014 .

Although slightly better than the equivalent outcomes for black learners, the figures for coloured learners still constitute rather poor performance in terms of the university outcomes considered. For example, just under 
$20 \%$ of coloured learners from the cohort accessed university during the period 2009-2014. The proportion of university participants who enrolled in university in the year immediately after matric was higher than that for black learners, at $70 \%$ (compared with $60 \%$ ). In terms of programme completion, $47.5 \%$ of coloured university participants (9.4\% of coloured learners from the original 2008 matric cohort) had successfully completed undergraduate programmes by the end of 2014. Interestingly, coloured university participants performed marginally worse than their black counterparts in terms of dropout: by 2014 , nearly $35 \%$ of coloured university participants had dropped out of university ( $6.9 \%$ for the original cohort of coloured learners). It is also perhaps unexpected that black learners outperformed coloured learners in terms of the proportion of university participants who had enrolled in postgraduate programmes by the end of 2014: for coloured university participants, this proportion was only $5.5 \%$ (1.1\% of the original cohort) whereas the rate for black university participants was nearly double that at $10.2 \%$.

Asian learners performed markedly better than black and coloured learners with about $43 \%$ gaining access to university, of which roughly 56\% (24\% of the original 2008 matric cohort) completed undergraduate programmes by the end of 2014. About $84 \%$ of Asian university participants (roughly $36 \%$ of the original 2008 matric cohort) enrolled in undergraduate studies in the year immediately after matriculating. Interestingly, while Asian learners outperformed their black counterparts on every other university outcome reported in Table 7.2, the proportion of Asian and black university participants who had enrolled in postgraduate programmes by the end of 2014 was similar at roughly $10 \%$.

White learners from the 2008 matric cohort performed significantly better than all three other race groups in almost all the university outcomes measured in Table 7.2. By 2014, nearly half of white learners from the 2008 matric cohort had entered undergraduate studies in the public university system at some stage. Of these, roughly $64 \%$ (30\% of white learners from the original 2008 matric cohort) had successfully completed undergraduate qualifications by the end of 2014 . About $75 \%$ of white university participants (36\% of the original cohort) entered university in the year immediately following matriculation. $21 \%$ (10\% of the original cohort) had dropped out by the end of 2013. This means that there were three times as many white learners who completed undergraduate qualifications by the end of 2014 as there were white learners who had dropped out during this time. $12 \%$ of white university participants ( $6 \%$ of white learners from the original cohort) had entered postgraduate programmes by the end of 2014.

Once again, it is likely that the observed differences in completion and dropout rates between learners from different race groups may be due, at least partially, to differences in the timing of university access. This is especially problematic considering that the rates of delayed entry into university differed considerably by race: $40 \%$ of black learners who accessed university at some point during 2009-2014 did so two or more years after matriculation, as against $30 \%$ for coloureds, $14 \%$ for Asians and $25 \%$ for whites. In order to account for the effect of differences in timing of university entry on dropout and completion rates, it is once again instructive to limit the analysis to university participants who enrolled in undergraduate programmes in 2009.

Table 7.3 compares university access, completion, dropout, and retention rates between learners from different race groups who entered in university in 2009. Even when limiting the sample to only those who enrolled in 
2009 , significant differences between the race groups remain. While roughly $72 \%$ of white university participants who enrolled in 2009 had successfully completed their undergraduate qualifications by the end of 2014, this proportion was slightly lower for Asian learners, at 62\%, and lower still for black and coloured learners, for whom the proportion was roughly equal at 54\%. Dropout rates among 2009 first-time entrants also differed markedly by race: $18 \%$ of white 2009 first-time entrants had dropped out of university by the end of 2013 without completing any qualification, whereas this proportion was higher for Asian, coloured and black 2009 first-time entrants, at roughly $23 \%, 34 \%$ and $32 \%$ respectively. The fact that the observed racial differences in terms of university completion and dropout rates remain even after restricting the sample to only those who enrolled in university in 2009 indicates that these differences cannot be ascribed solely to differences in timing of entry into university.

Table 7.3: University access, completion, dropout, and retention rates (\%) for black learners from the 2008 matric cohort (2009 - 2014)

\begin{tabular}{|c|c|c|c|c|c|c|}
\hline & $\begin{array}{l}1 \text { year } \\
\text { (2009) }\end{array}$ & $\begin{array}{c}2 \text { years } \\
(2010)\end{array}$ & $\begin{array}{c}3 \text { years } \\
(2011)\end{array}$ & $\begin{array}{c}4 \text { years } \\
(2012)\end{array}$ & $\begin{array}{c}5 \text { years } \\
(2013)\end{array}$ & $\begin{array}{c}6 \text { years } \\
(2014)\end{array}$ \\
\hline & \multicolumn{6}{|c|}{ Black learners ${ }^{1}$} \\
\hline Access rate & 9.9 & 13.4 & 14.8 & 15.6 & 16.2 & 16.6 \\
\hline Completion rate & 0.2 & 0.6 & 12.7 & 31.8 & 45.3 & 53.5 \\
\hline Dropout rate & 9.9 & 15.7 & 21.0 & 26.2 & 32.0 & - \\
\hline \multirow[t]{2}{*}{ Retention rate $^{\mathrm{a}}$} & 84.7 & 78.9 & 61.5 & 38.8 & 22.6 & - \\
\hline & \multicolumn{6}{|c|}{ Coloured learners $^{2}$} \\
\hline Access rate & 13.9 & 17.2 & 18.3 & 18.9 & 19.4 & 19.8 \\
\hline Completion rate & 0.4 & 1.3 & 14.0 & 34.9 & 46.9 & 53.8 \\
\hline Dropout rate & 12.7 & 19.8 & 25.2 & 29.4 & 33.8 & - \\
\hline \multirow[t]{2}{*}{ Retention rate $^{\mathrm{a}}$} & 83.3 & 74.7 & 57.1 & 33.8 & 19.9 & - \\
\hline & \multicolumn{6}{|c|}{ Asian learners $^{3}$} \\
\hline Access rate & 36.2 & 40.3 & 41.6 & 42.3 & 42.9 & 43.3 \\
\hline Completion rate & 0.1 & 0.1 & 14.5 & 36.0 & 53.1 & 62.1 \\
\hline Dropout rate & 7.4 & 11.6 & 15.3 & 18.3 & 22.8 & - \\
\hline \multirow[t]{2}{*}{ Retention rate $^{\mathrm{a}}$} & 85.7 & 81.7 & 63.9 & 42.1 & 23.1 & - \\
\hline & \multicolumn{6}{|c|}{ White learners ${ }^{4}$} \\
\hline Access rate & 35.5 & 42.5 & 44.8 & 46.0 & 46.9 & 47.4 \\
\hline Completion rate & 0.0 & 0.2 & 24.4 & 52.7 & 65.3 & 71.6 \\
\hline Dropout rate & 6.5 & 10.2 & 13.1 & 15.3 & 18.1 & - \\
\hline Retention rate $^{\mathrm{a}}$ & 90.0 & 86.9 & 59.9 & 30.6 & 16.6 & - \\
\hline
\end{tabular}

NOTES: Access rates are calculated for black ${ }^{[1]}$, coloured ${ }^{[2]}, \mathrm{Asian}^{[3]}$, and white ${ }^{[4]}$ learners from the 2008 matric cohort while completion, dropout, and retention rates are only determined for students from this group who enrolled in undergraduate studies for the first time in 2009. Access, completion, and dropout rates are cumulative. ${ }^{[a]}$ The retention rate presented in the table reflects the percentage of students from the 2009 first-time entering group who had not yet completed any qualification, but were still enrolled in undergraduate studies in the following year.

Table 7.4 summarises university outcomes for the 2008 matric cohort after six years, by race. While the table reflects much of the same information as the preceding tables, it furthermore indicates that only $4 \%$ of black learners from the cohort had completed undergraduate degrees by the end of 2014 with $1 \%$ furthermore completing postgraduate programmes. By the end of 2014, a greater percentage of black learners had dropped out of university without completing any undergraduate qualification (roughly 6\%) than had completed 
undergraduate degrees $(4 \%)$. By contrast, $28 \%$ of white learners had completed undergraduate programmes over the same period and $10 \%$ post-graduate qualifications.

Stark differences in the proportions of learners enrolled in undergraduate degree programmes can also be gleaned from Table 7.4. At the end of 2014, white learners had the highest access rate in undergraduate degrees, at $43 \%$. The corresponding proportion for Asian learners was 36\%, 14\% for coloured learners and 9\% for black learners. Unsurprisingly, completion of undergraduate degrees followed the same pattern: white learners had the highest extent of degree completion, at 28\%, followed by Asian learners at $21 \%$. The corresponding proportions for coloured and black learners were once again much lower, at $7 \%$ and $4 \%$ respectively. It is interesting to note that nearly half (47\%) of black learners enrolled in undergraduate programmes were enrolled in non-degree programmes. This is far more than for any other race group: the corresponding proportions for coloured, Asian and white students were 28\%,16\% and 10\% respectively. Unsurprisingly, numbers of degree completions as percentages of all undergraduate qualifications followed a very similar pattern.

Table 7.4: The 2008 matric cohort after six years (end of 2014), by race group

\begin{tabular}{lrrrrr}
\hline & \multicolumn{1}{c}{ All } & Black & Coloured & \multicolumn{1}{c}{ Asian } & White \\
\hline Cohort & 560921 & 462680 & 38399 & 16440 & 43402 \\
column \% & 100.0 & 100.0 & 100.0 & 100.0 & 100.0 \\
Enrolled in UG studies & 112092 & 76767 & 7616 & 7120 & 20589 \\
column \% & 20.0 & 16.6 & 19.8 & 43.3 & 47.4 \\
Enrolled in UG degree & 70393 & 40490 & 5471 & 5972 & 18460 \\
column \% & 12.5 & 8.8 & 14.2 & 36.3 & 42.5 \\
Completed UG qualification & 55536 & 34817 & 3595 & 3994 & 13130 \\
column \% & 9.9 & 7.5 & 9.4 & 24.3 & 30.3 \\
Completed UG degree & 38070 & 19811 & 2695 & 3468 & 12096 \\
column \% & 6.8 & 4.3 & 7.0 & 21.1 & 27.9 \\
Enrolled in PG studies & 13417 & 6071 & 780 & 1354 & 5212 \\
column \% & 2.4 & 1.3 & 2.0 & 8.2 & 12.0 \\
Completed PG qualification & 9688 & 3878 & 593 & 987 & 4230 \\
column \% & 1.7 & 0.8 & 1.5 & 6.0 & 9.7 \\
Non-completers enrolled in & 22396 & 16595 & 1371 & 1268 & 3162 \\
column \% & 4.0 & 3.6 & 3.6 & 7.7 & 7.3 \\
Dropped-out before 2014 & 34089 & 25389 & 2645 & 1794 & 4261 \\
column \% & 6.1 & 5.5 & 6.9 & 10.9 & 9.8 \\
\hline
\end{tabular}

NOTES: Figures printed in black reflect the numbers of learners from each of the 2008 matric cohort subgroups. Column percentages are printed in grey and express the number of learners in a particular row as a percentage of the number of candidates from the relevant subgroup.

Figure 7.2 summarises the access rates of the 2008 matric cohort, as well as the completion and dropout rates for those learners from the cohort who enrolled in undergraduate studies in 2009. 
Figure 7.2: University access, completion, and dropout rates (\%) for the 2008 matric cohort (2009 - 2014), by race

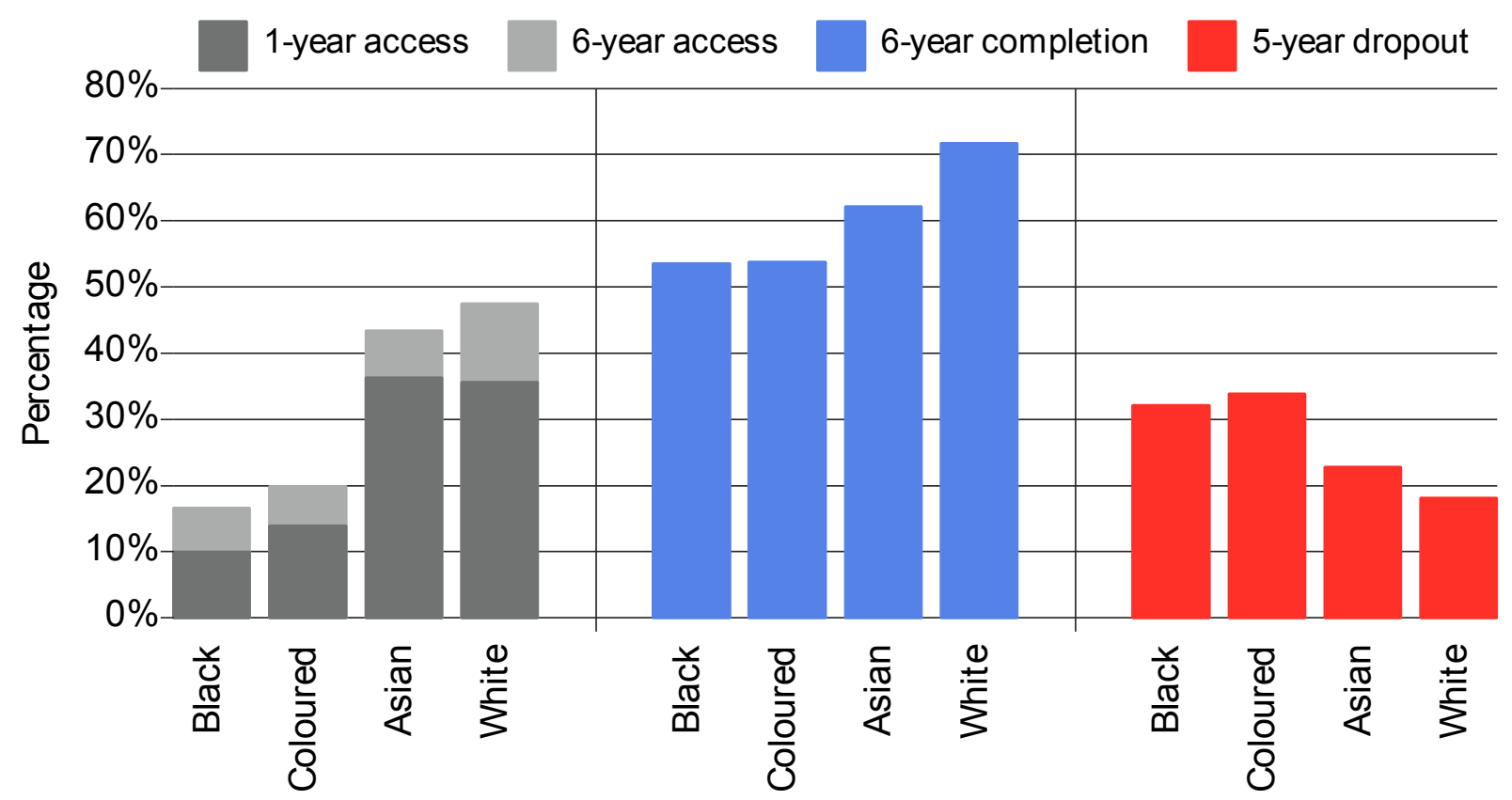

NOTES: Bars represent the 1-year access, 6-year access, 6-year completion, and 5-year dropout rates for each race group from the 2008 matric cohort. Completion and dropout rates are shown only for those learners from each NSC subgroup who enrolled in undergraduate studies for the first time in 2009. Access, completion, and dropout rates are cumulative.

Clearly, university outcomes for the 2008 matric cohort are highly inequitable. To the extent that university outcomes are affected by performance in secondary school, it is helpful to consider only learners who performed similarly in matric in order to untangle the causes of these racial differences in university outcomes. To do this, Table 7.5 depicts access, completion and dropout rates for only those learners from the 2008 matric cohort who achieved Bachelor passes in matric. An interesting and surprising result emerges, namely that sixyear university access rate for black learners who achieved Bachelor passes is substantially higher (71\%) than the rates for coloured (63\%) and white (63\%) learners who had also achieved Bachelor passes. Similarly, the 6-year completion rates for black learners who achieved Bachelor passes was higher (59\%) than when considering all black learners from the cohort (roughly 53.5\%). The five-year dropout rate for black Bachelor pass learners was also lower (25\%) than the dropout rate of black learners overall (33\%).

Despite these encouraging signs, however, limiting the analysis to learners who achieved Bachelor passes does not remove disparities in university outcomes between race groups. For example, white learners who achieved Bachelor passes remain significantly more likely to enrol in undergraduate degree programmes (59\%) than comparable black (53.7\%) or coloured (53.3\%) learners. Completion rates of black learners relative to Asian and white learners also remain relatively low while dropout rates remain relatively high. For example, the proportion of black university participants who achieved Bachelor passes and went on to complete undergraduate qualifications within six years of matriculating was only $59 \%$, which is much lower than the equivalent proportion of white learners, namely $73 \%$. 
Table 7.5: University access, completion, and dropout rate summaries for learners who achieved Bachelor passes in the $2008 \mathrm{NSC}$, by race group

\begin{tabular}{|c|c|c|c|c|}
\hline & Black & Coloured & Asian & White \\
\hline Share of Bachelor Passes (\%) & 56.4 & 8.2 & 8.0 & 27.4 \\
\hline 6-year access rate & 71.2 & 63.1 & 72.8 & 63.4 \\
\hline - UG degree ${ }^{\mathrm{a}}$ & 53.7 & 53.3 & 66.1 & 59.0 \\
\hline 1-year access rate & 51.3 & 47.5 & 62.9 & 48.7 \\
\hline - UG degree ${ }^{b}$ & 40.0 & 41.1 & 57.8 & 46.2 \\
\hline 6-year completion rate & 58.9 & 58.7 & 64.6 & 73.1 \\
\hline - UG degree ${ }^{c}$ & 55.0 & 56.5 & 63.4 & 72.7 \\
\hline 5-year dropout rate & 25.2 & 28.2 & 20.2 & 16.6 \\
\hline - UG degree ${ }^{d}$ & 21.5 & 25.6 & 18.1 & 15.2 \\
\hline
\end{tabular}

NOTES: Figures are only calculated for learners from the 2008 matric cohort who achieved Bachelor passes. Completion and dropout rates are determined only for those learners from each cohort subgroup who enrolled in undergraduate studies for the first time in 2009. ${ }^{[a]}$ Percentage of learners in each cohort subgroup who enrolled for an undergraduate degree programme at some stage between 2009 and 2014. ${ }^{[b]}$ Percentage of learners in each cohort subgroup who enrolled for an undergraduate degree programme in 2009. ${ }^{[c]}$ Percentage of learners who enrolled for an undergraduate degree programme in 2009 from each cohort subgroup and successfully completed undergraduate degrees by the end of 2014. ${ }^{\text {[d] }}$ Percentage of learners who enrolled for an undergraduate degree programme in 2009 from each cohort subgroup, but dropped out of university before 2014 without completing any undergraduate qualification.

The fact that large differences in university outcomes remain even when limiting the sample to learners who achieved Bachelor passes in matric suggests that racial differences in university outcomes persist, even when attempting to account for the impact of matric performance on these outcomes. In other words, differentials remain between race groups even when the differences in matric performance have partially been controlled for.

The data presented in the preceding tables point to a clear association between matric performance (as measured by Bachelor passes) and university access, completion and dropout rates. In order to examine this association more explicitly, expected access, completion and dropout rates are presented as functions of average matric achievement in Figures 7.3-7.6 for the four race groups.

As expected, the figures show clear associations between matric average marks and university access, completion and dropout rates for all race groups, but the nature of these associations differs quite substantially by race. For example, $73 \%$ of black learners who had achieved an average mark of $60 \%$ in matric accessed university within the first six years following matriculation. By contrast, only $40 \%$ of white learners achieving $60 \%$ in matric accessed university some time by the end of 2014. Similar differences are apparent at lower levels of matric achievement: roughly $35 \%$ of black learners who achieved $50 \%$ in matric accessed university in the period 2009-2014, while only $11 \%$ of white learners achieving the same grade in matric did so. The association between matric performance and access rates therefore differs quite substantially between black and white learners.

The same appears to be true for the association between matric performance and dropout rates. While white learners who achieved $60 \%$ in matric had an expected five-year dropout rate of roughly $38 \%$, the corresponding rate for black learners was much lower, at about $28 \%$. White learners who achieved $50 \%$ in matric had an expected five-year dropout rate of roughly $59 \%$, which is much higher than the dropout rate of $42 \%$ for black 
learners achieving the same grade in matric. Clearly, university dropout was much higher among white learners who performed at a certain level in matric, compared with their black counterparts who performed similarly in matric.

Figure 7.3: Expected 1-year access rates for the 2008 matric cohort by race and matric average achievement (\%) (2009)

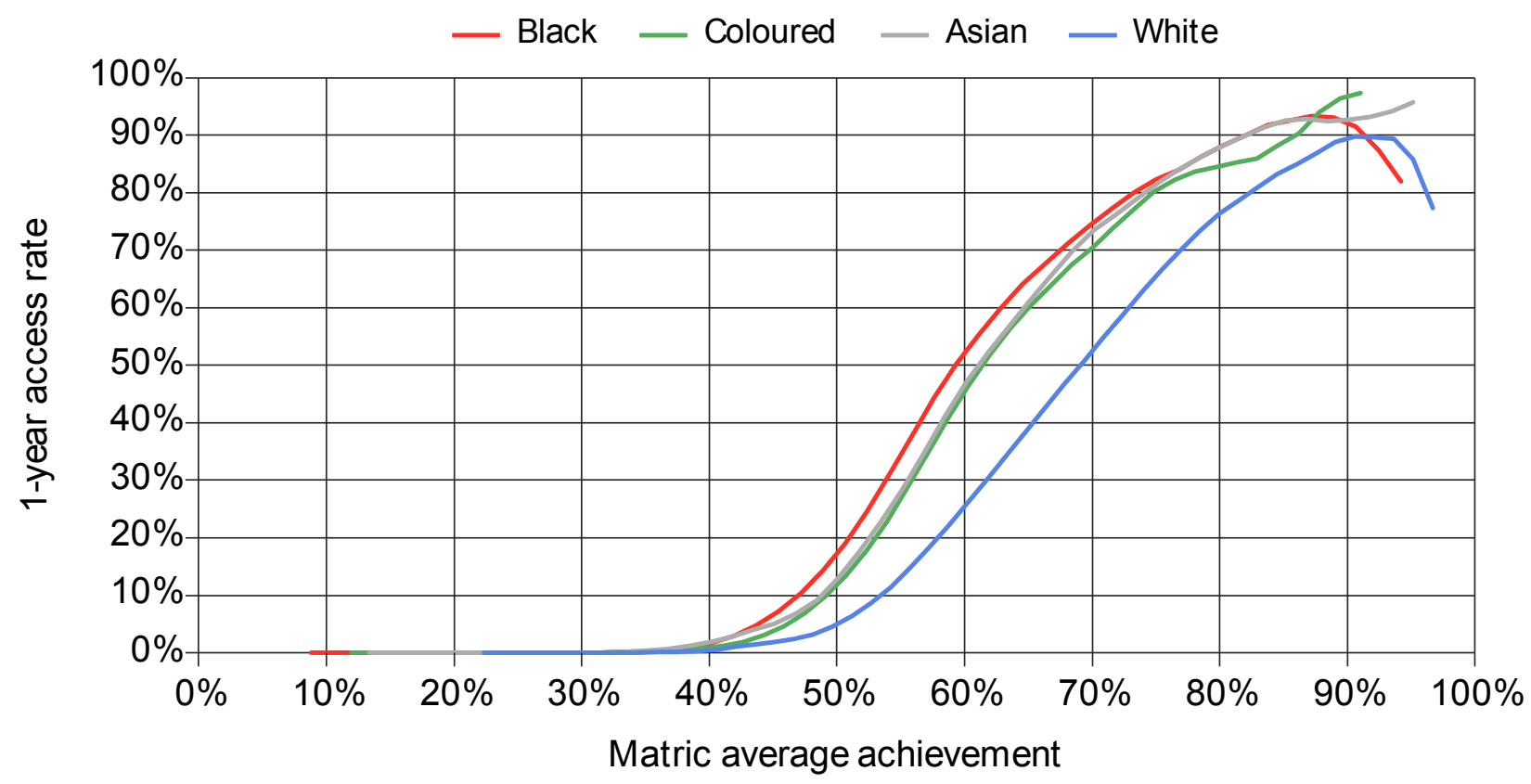

NOTES: Lines represent the expected 1-year university access rates for learners from the 2008 matric cohort, by race and conditional on matric average achievement. All lines were estimated via local polynomial regression.

Figure 7.4: Expected 6-year access rates for the 2008 matric cohort by race and matric average achievement (\%) (2009)

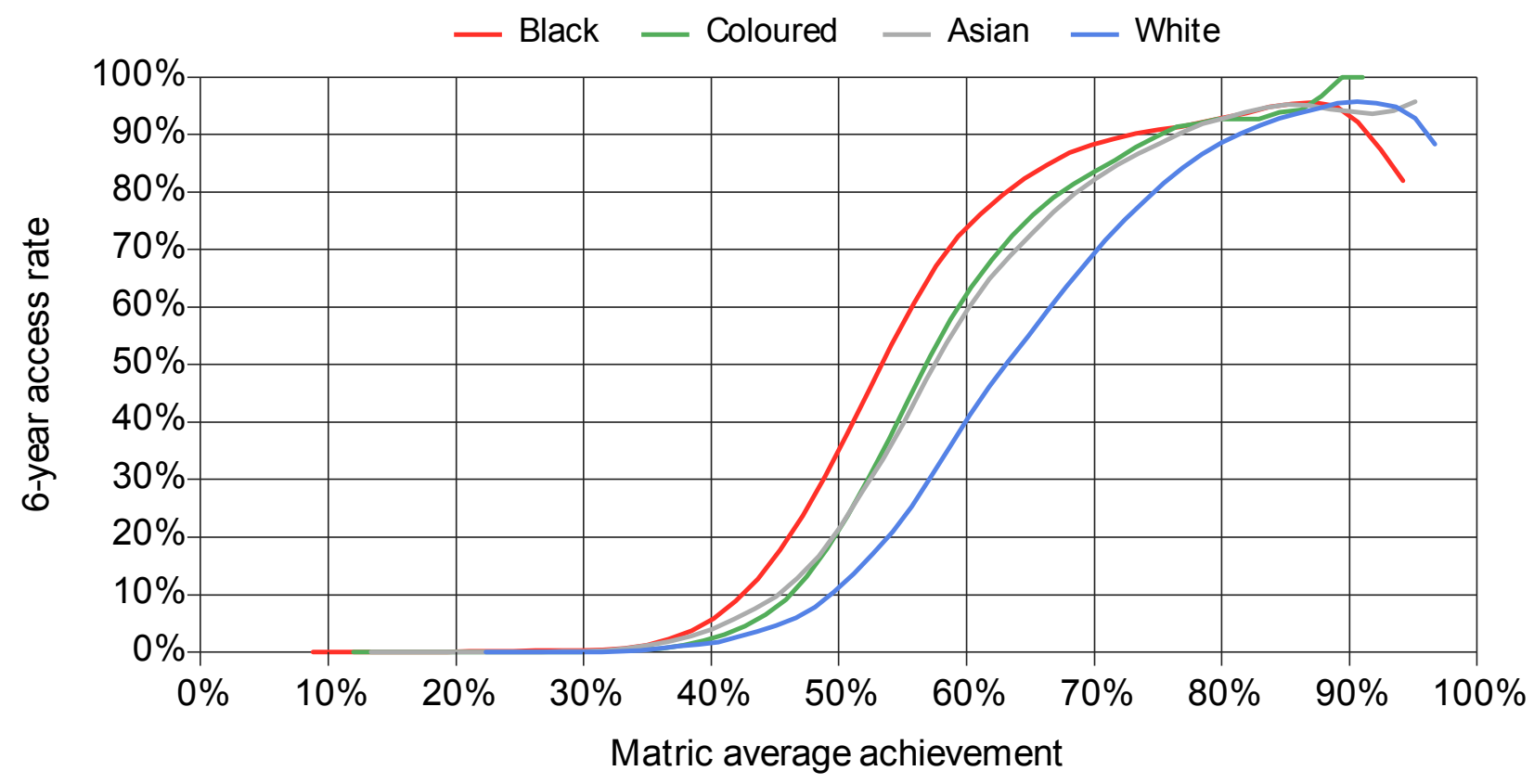

NOTES: Lines represent the expected 6-year university access rates for learners from the 2008 matric cohort, by race and conditional on matric average achievement. All lines were estimated via local polynomial regression. 
Figure 7.5: Expected 6-year completion rates for learners from the 2008 matric cohort who enrolled in university in 2009 by race and matric average achievement (\%) (2009 - 2014)

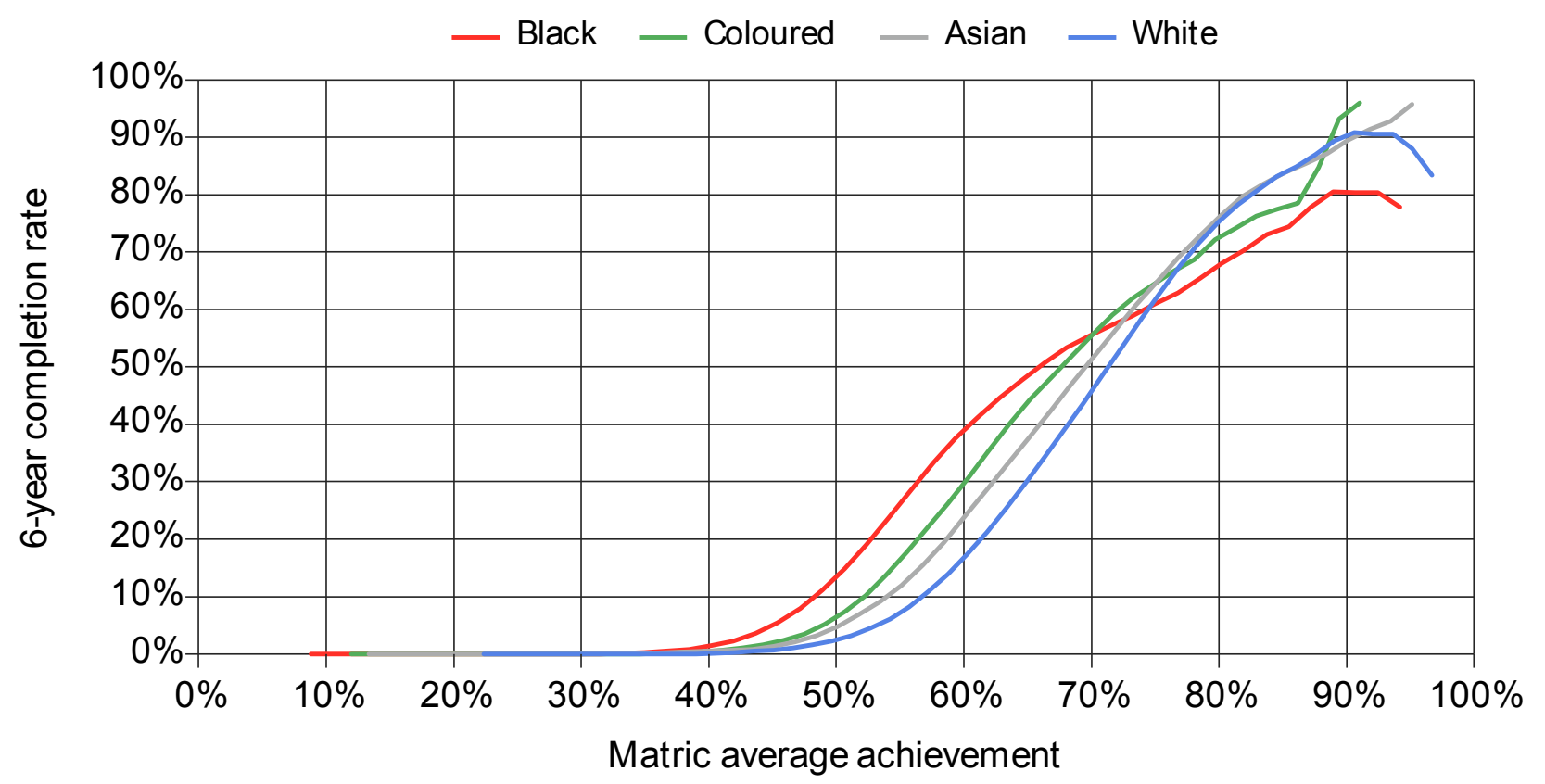

NOTES: Lines represent the expected 6-year undergraduate university completion rates for learners from the 2008 matric cohort who enrolled in undergraduate studies for the first time in 2009, by race and conditional on matric average achievement. All lines were estimated via local polynomia] regression.

Figure 7.6: Expected 5-year dropout rates for learners from the 2008 matric cohort who enrolled in university in 2009 by race and matric average achievement (\%) $(2009$ - 2014)

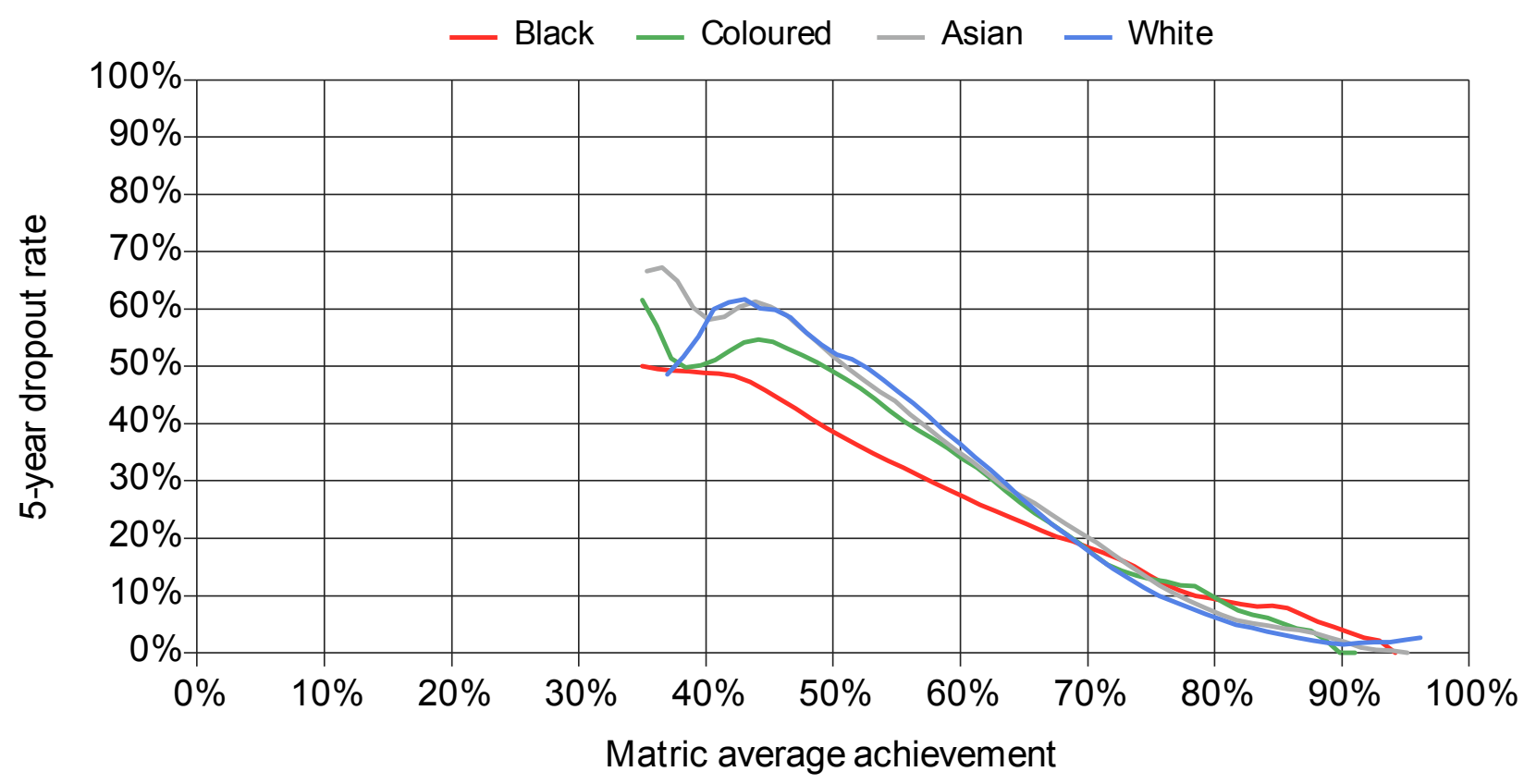

NOTES: Lines represent the expected 5-year university dropout rates for learners from the 2008 matric cohort who enrolled in undergraduate studies for the first time in 2009, by race and conditional on matric average achievement. All lines were estimated via local polynomial regression. 


\section{Gateway subjects}

\subsection{Gateway subject participation}

In this section, four specific so-called 'gateway subjects' are considered, namely Mathematics, Mathematical Literacy, Physical Sciences, and English First Additional Language, to determine whether offering these as matric subjects and performance in them are associated with university access and success.

Table 8.1: Participation in gateway NSC subjects among the 2008 matric cohort, by undergraduate sub-group

\begin{tabular}{|c|c|c|c|c|c|}
\hline & Mathematics & $\begin{array}{l}\text { Maths } \\
\text { literacy }\end{array}$ & $\begin{array}{l}\text { Physical } \\
\text { Sciences }\end{array}$ & English FAL & Total \\
\hline Non-participants in university & 223330 & 225993 & 159790 & 397925 & 449390 \\
\hline row $\%$ & 49.7 & 50.3 & 35.6 & 88.5 & 100.0 \\
\hline column $\%$ & 74.9 & 85.7 & 73.9 & 85.1 & 80.0 \\
\hline Non-degree non-completers & 18941 & 13657 & 15057 & 22892 & 32597 \\
\hline row $\%$ & 58.1 & 41.9 & 46.2 & 70.2 & 100.0 \\
\hline column $\%$ & 6.4 & 5.2 & 7.0 & 4.9 & 5.8 \\
\hline Non-degree completers & 14344 & 6999 & 10705 & 14441 & 21343 \\
\hline row $\%$ & 67.2 & 32.8 & 50.2 & 67.7 & 100.0 \\
\hline column \% & 4.8 & 2.7 & 5.0 & 3.1 & 3.8 \\
\hline Degree non-completers & 20859 & 11544 & 15873 & 18925 & 32403 \\
\hline row $\%$ & 64.4 & 35.6 & 49.0 & 58.4 & 100.0 \\
\hline column \% & 7.0 & 4.4 & 7.3 & 4.0 & 5.8 \\
\hline Degree completers & 29241 & 8988 & 21597 & 20768 & 38229 \\
\hline row $\%$ & 76.5 & 23.5 & 56.5 & 54.3 & 100.0 \\
\hline column $\%$ & 9.8 & 3.4 & 10.0 & 4.4 & 6.8 \\
\hline Total (Matric 2008 cohort) & 298083 & 263643 & 216235 & 467463 & 561792 \\
\hline row $\%$ & 53.1 & 46.9 & 38.5 & 83.2 & 100.0 \\
\hline column $\%$ & 100.0 & 100.0 & 100.0 & 100.0 & 100.0 \\
\hline
\end{tabular}

NOTES: Figures printed in black reflect the numbers of candidates in each sub-category for learners from the 2008 matric cohort. Row percentages are printed in grey and express the number of learners from a particular subgroup who offered the indicated gateway subject in the NSC exams as a percentage of the total number of learners in that subgroup. Column percentages are also printed in grey and express the number of learners from a particular subgroup who offered the indicated gateway subject as a percentage of the total number of learners from the cohort who offered that subject in the NSC exams.

It is plausible that gateway subject participation may in itself be associated with the likelihood of accessing university and successfully completing university studies. Table 8.1 provides a breakdown of gateway subject participation among learners from the 2008 matric cohort for various university participation and throughput subgroups. Of the 561792 candidates who wrote matric in 2008, 53\% offered Mathematics, 47\% Mathematical literacy, 39\% Physical Sciences, and 83\% English First Additional Language. Participation in Mathematics and Physical Sciences was much higher among learners who later enrolled in undergraduate studies between 2009 and 2014 than those who did not, and higher still among those who subsequently completed undergraduate qualifications over the period. For example, $77 \%$ of 2008 matrics who completed undergraduate degrees between 2009 and 2014 offered Mathematics as a subject in the NSC exams. By implication, less than a quarter of degree completers had offered Mathematical Literacy instead. The decrease in English First Additional Language participation as one moves down the rows of Table 8.1 is due to the fact that learners 
who offered English Home Language than rather than English First Additional Language generally performed better at school and also at university.

The table therefore provides evidence of an association between participation in certain gateway subjects and university outcomes. Specifically, it suggests that there may be a positive association between access and success in university and participation in Mathematics and Physical Sciences, and a negative association with participation in Mathematical Literacy and English First Additional Language.

\subsection{Gateway subject performance}

The association between gateway subject performance and university access, completion, and dropout can only be investigated for learners who offered the particular gateway subject(s) in question in the NSC examinations.

\subsubsection{Mathematics}

Figure 8.1 illustrates the cumulative NSC Mathematics performance distribution for learners from the 2008 matric cohort for the same university participation and throughput subgroups as those in Table 8.1. The first thing to note is the very poor performance in mathematics of learners who did not enrol in any sort of university programme: only about $3 \%$ of such learners who took Mathematics at school achieved a grade of $60 \%$ or higher. Those who entered non-degree programmes at university and had offered Mathematics at school had performed significantly better in Mathematics, with about 30\% achieving a grade of $60 \%$ or higher. School Mathematics performance was even better for those who completed non-degree programmes, even better for those who entered degree programmes, and best for the subgroup that both entered and completed degree programmes: $67 \%$ of such degree completers in the period 2009-2014 who offered Mathematics achieved a Mathematics grade of $60 \%$ or higher in matric.

These findings imply that Mathematics performance is fairly predictive of university access and success. In addition, there were learners who, although never having enrolled in undergraduate degree programmes between 2009 and 2014, performed well enough in Mathematics to have conceivably completed undergraduate degrees. Although this group constitutes a small minority of matriculants, this again suggests performance in Mathematics is not perfectly predictive of university access, either.

Another way of gauging the strength of the association between NSC Mathematics performance and undergraduate degree enrolment and completion is to determine the extent of undergraduate degree enrolment and completion among the 2008 matric cohort for each given level of NSC Mathematics performance. This is represented graphically in Figure 8.2. The figure shows clear differences in degree enrolment patterns by Mathematics performance in matric. Very few candidates who took Mathematics but scored below $50 \%$ in the subject enrolled in undergraduate degree programmes between 2009 and 2014. By contrast, 50\% of learners who achieved $60 \%$ in Mathematics enrolled in undergraduate degrees over the period. This percentage rises to nearly $70 \%$ for learners who achieved $70 \%$ in Mathematics and roughly $90 \%$ for learners who had achieved $90 \%$ in Mathematics. 
Figure 8.1: Cumulative NSC Mathematics performance distribution for the 2008 matric cohort by enrolment and completion of undergraduate programmes between 2009 and 2014

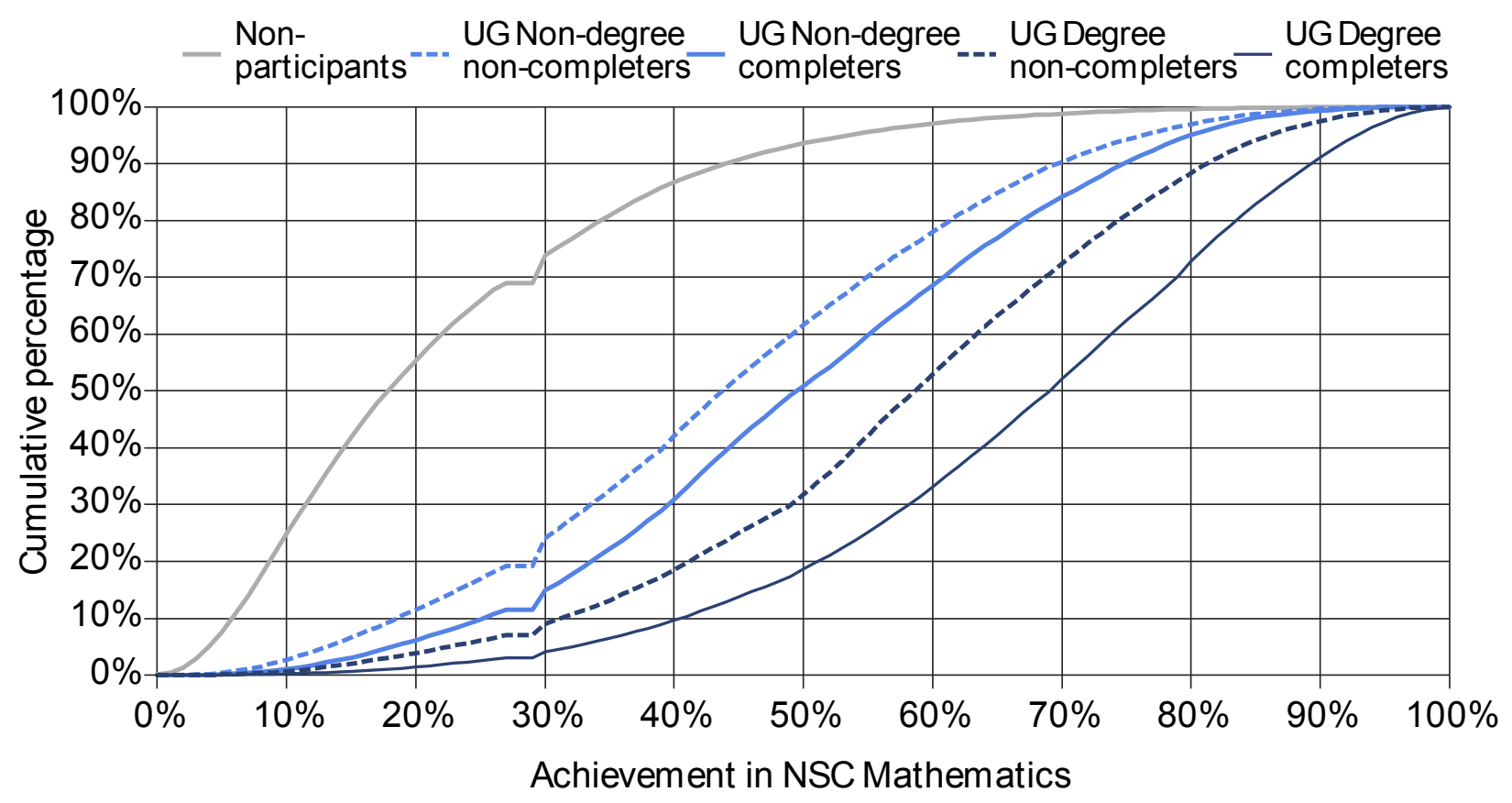

NOTES: Each line represents the cumulative percentage of a group that performed below a given level of 2008 NSC Mathematics achievement.

Figure 8.2: Enrolment in and completion of undergraduate degree programmes for the 2008 matric cohort (2009 - 2014), by NSC Mathematics achievement

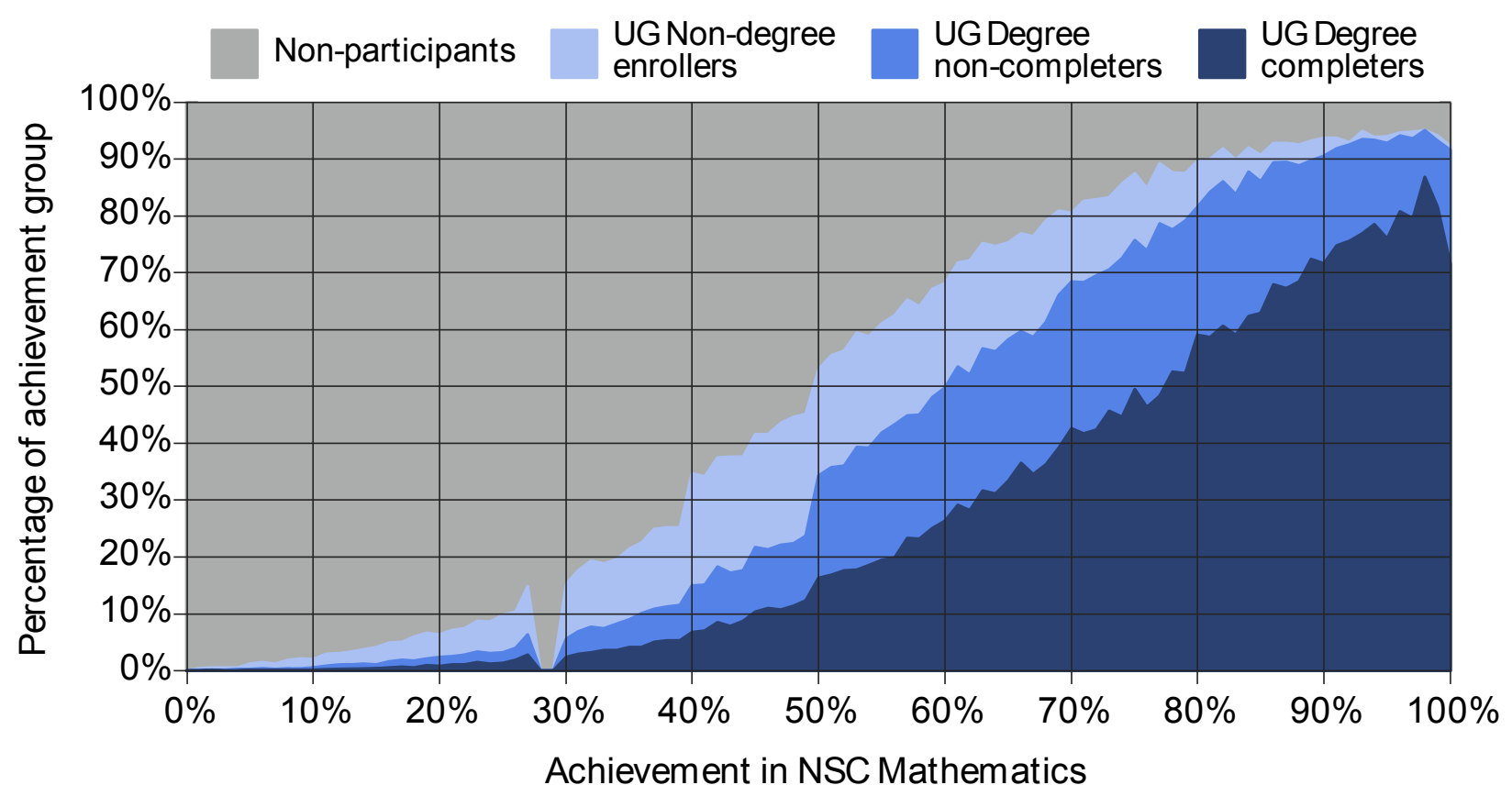

NOTES: Figure shows the percentage of learners from the 2008 matric cohort at each point of the NSC Mathematics performance distribution that respectively did not enrol in undergraduate studies, enrolled only in undergraduate non-degree programmes, enrolled in undergraduate degree programmes without completing those programmes, and completed undergraduate degree programmes between 2009 and 2014 . Note that students were only classified as "UG Non-degree enrollers" if they enrolled in undergraduate non-degree programmes, but did not also enrol in undergraduate degree studies at some other stage over the period under consideration.

From Figure 8.2 it is clear that better performance in Mathematics is also associated with higher degree completion rates. This can also be seen in Figure 8.3 below. Fewer than half of the undergraduate degree students from the cohort who scored $50 \%$ in Mathematics completed their qualifications before the end of 2014. By contrast, of the undergraduate degree students from the cohort who scored around $70 \%$ in 
Mathematics, $60 \%$ completed their programmes, before 2014 and of those who scored $80 \%$ in Mathematics, roughly $70 \%$ completed.

Figure 8.3: Percentage of undergraduate degree students from the 2008 matric cohort who completed undergraduate degrees between 2009 and 2014, by NSC Mathematics performance

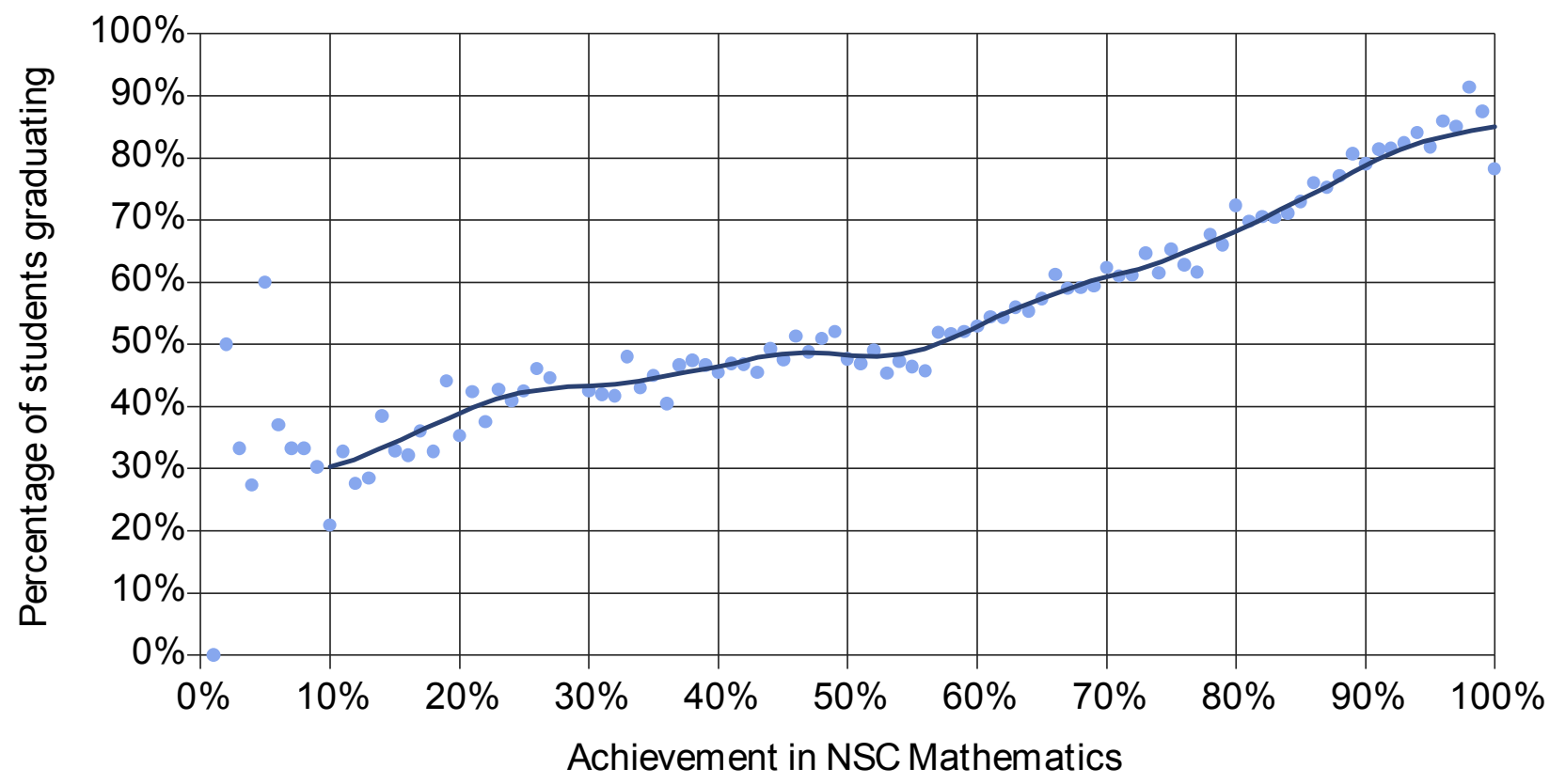

NOTES: Dots show the percentage of 2009 - 2014 undergraduate students from the 2008 matric cohort who completed undergraduate degrees over the period for different levels of NSC mathematics achievement. The smoothed line through the dots was estimated using weighted local polynomial regression.

Figure 8.4: Expected access, completion, and dropout rates for learners from the 2008 matric cohort (20092014), by NSC Mathematics achievement

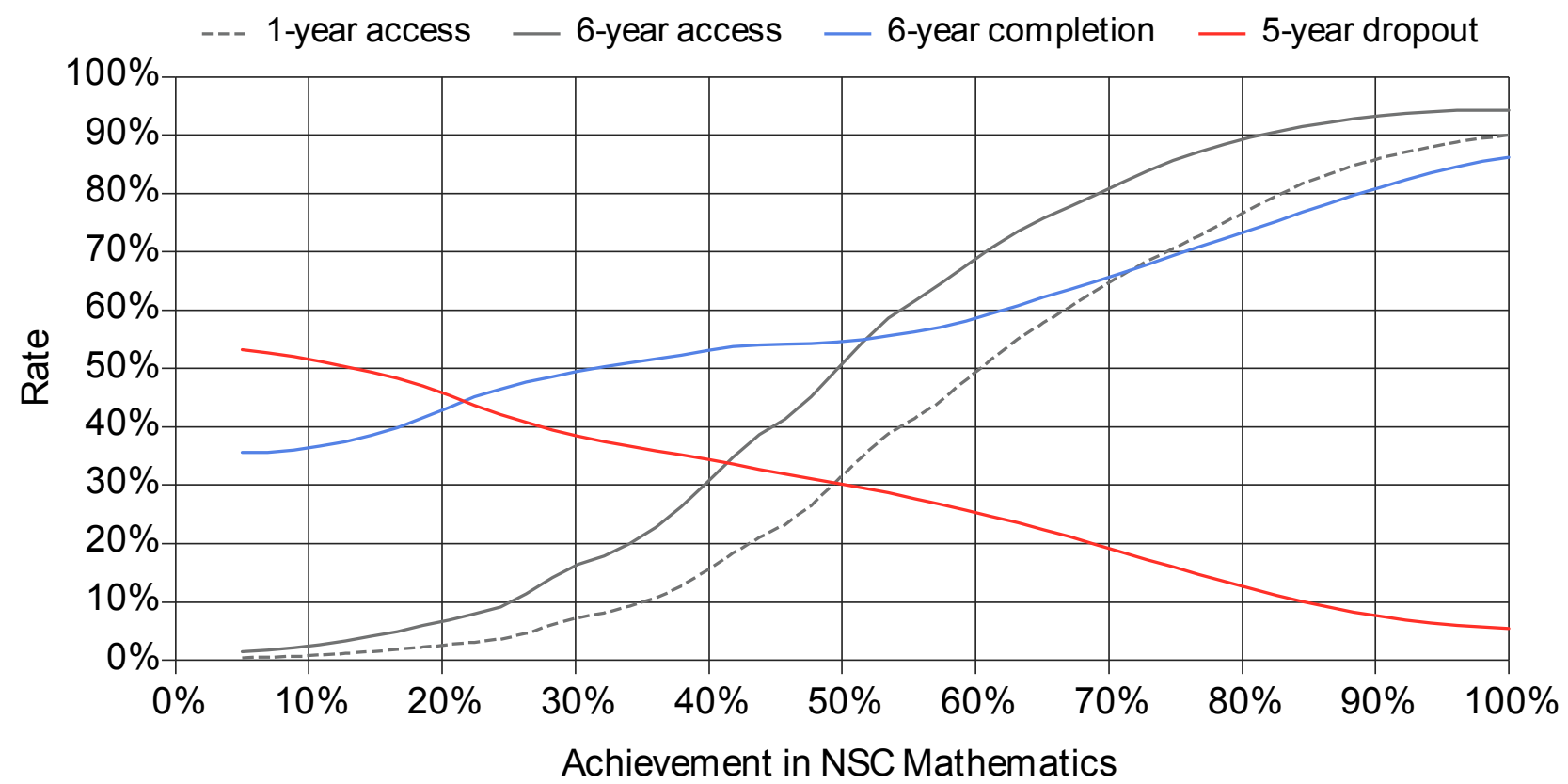

NOTES: Lines represent the expected 6-year access, 1-year access, 6-year completion, and 5-year dropout rates conditional on NSC Mathematics achievement for learners from the 2008 matric cohort and were drawn using local polynomial regression. The curves for completion and dropout are only drawn for those learners from the cohort who enrolled in undergraduate studies for the first time in 2009. 
Figure 8.4 provides a more general picture of the relationship between university outcomes and matric Mathematics achievement. The figure shows the expected 1-year access, 6-year access, 6-year completion, and 5-year dropout rates for learners from the 2008 matric cohort (2009 - 2014), by NSC Mathematics achievement. It confirms that university access and completion are positively associated with matric performance in Mathematics, and adds the further insight that better Mathematics performance is associated with lower university dropout rates. The figure further suggests that increases in Mathematics performance are more closely associated with increases in university access rates than completion rates, hence the flatter curve for the latter measure. This is similar to the findings of Van Broekhuizen (2016: 46) that subject-specific performance in secondary school is a stronger predictor of university access than it is of throughput.

\subsubsection{Mathematical literacy}

Figure 8.5 illustrates the cumulative NSC Mathematical Literacy performance distribution for learners from the 2008 matric cohort according to university sub-group. About 82\% of learners who did not enrol in university between 2009 and 2014 and who offered Mathematical Literacy in the NSC exams achieved a grade of less than $60 \%$ in the subject. By contrast, only just over half of those who enrolled for non-degree programmes without complete those programmes attained a grade of less than $60 \%$ for Mathematical Literacy. Among degree completers, only $18 \%$ achieved $60 \%$ or less for Mathematical Literacy. The entire Mathematical Literacy distribution for degree completers lies to the right of the Mathematical Literacy performance distribution for degree non-completers. The latter lies to the right of the performance distribution for non-degree participants, which in turn lies considerably to the right of the performance distribution of nonenrollers. Put differently, those learners in the 2008 matric cohort who enrolled in, and completed, degree programmes in the six years after matric performed considerably better in Mathematical Literacy than those who enrolled in degree programmes but did not complete them. The latter group, however, outperformed those who enrolled in non-degree programmes, and these, in turn, outperformed those who did not enrol in any sort of university programme.

Figure 8.6 presents undergraduate degree enrolment and completion for each given level of NSC Mathematical Literacy performance. The figure shows clear differences in degree enrolment patterns by Mathematical Literacy performance. Only about $5 \%$ of learners who scored $50 \%$ in Mathematical Literacy enrolled in undergraduate degree programmes between 2009 and 2014, as against 34\% who scored $80 \%$ and about half of those who achieved a Mathematical Literacy grade of $90 \%$. Note that these figures contrast sharply with the proportions of degree enrolments among learners who offered Mathematics in the NSC examinations. Consider, for example, that as many as $90 \%$ of learners who achieved $90 \%$ in Mathematics went on to enrol in undergraduate degrees.

Performance in Mathematical Literacy seems to be reasonably predictive of university access. This conclusion is drawn from the large gap in Mathematical Literacy performance observed between entrants into university and non-entrants, as well as the large gap in Mathematical Literacy performance observed between entrants into degree and non-degree programmes. It therefore seems likely that performance in Mathematical Literacy is a determinant of access to university for those learners who offer it as subject in the NSC exams. 
Figure 8.5: Cumulative NSC Mathematical Literacy performance distribution for the 2008 matric cohort by enrolment and completion of undergraduate degree programmes between 2009 and 2014

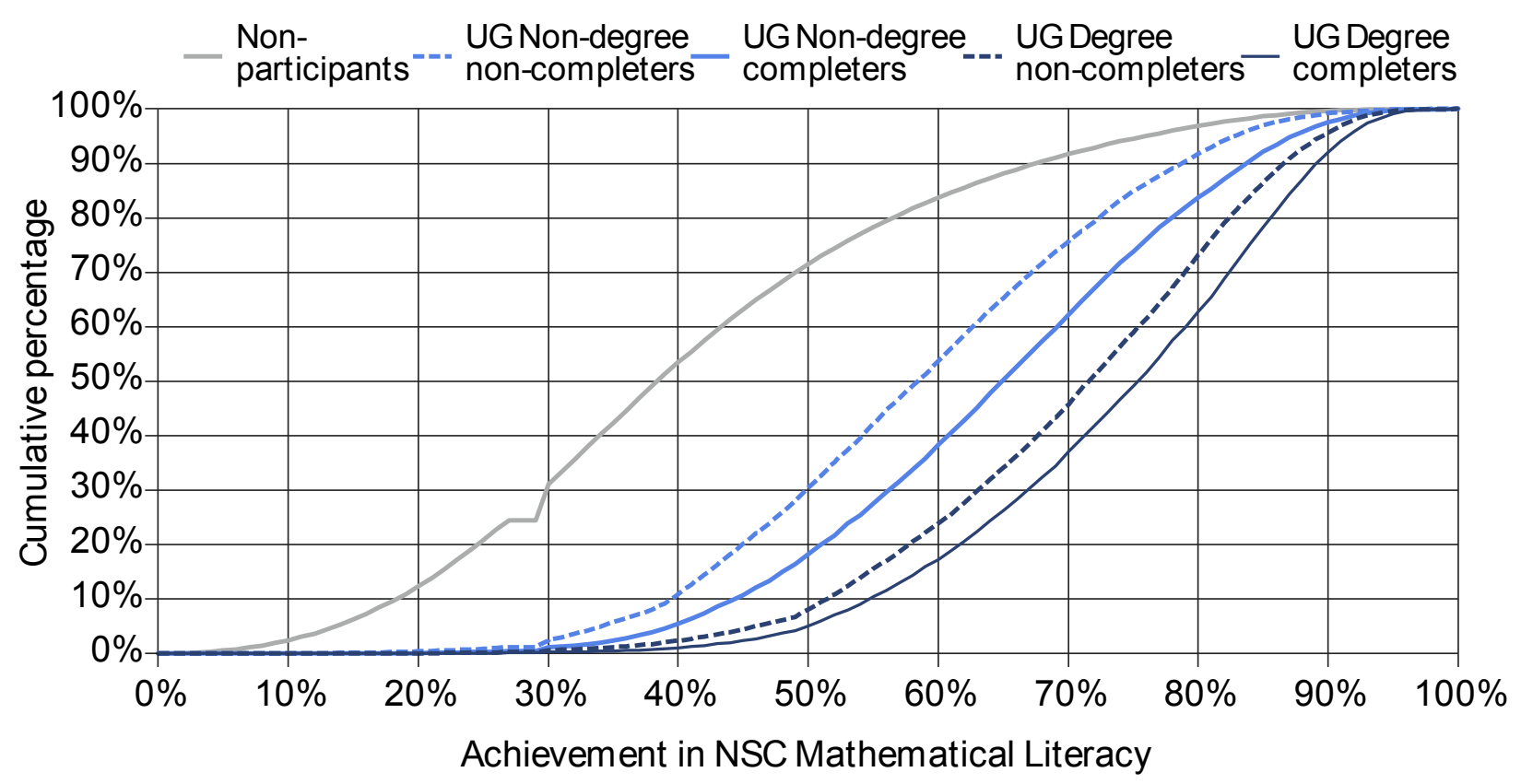

NOTES: Each line represents the cumulative percentage of a group that performed below a given level of 2008 NSC Mathematical Literacy achievement.

Figure 8.6: Enrolment in and completion of undergraduate degree programmes for the 2008 matric cohort (2009 - 2014), by NSC Mathematical Literacy achievement

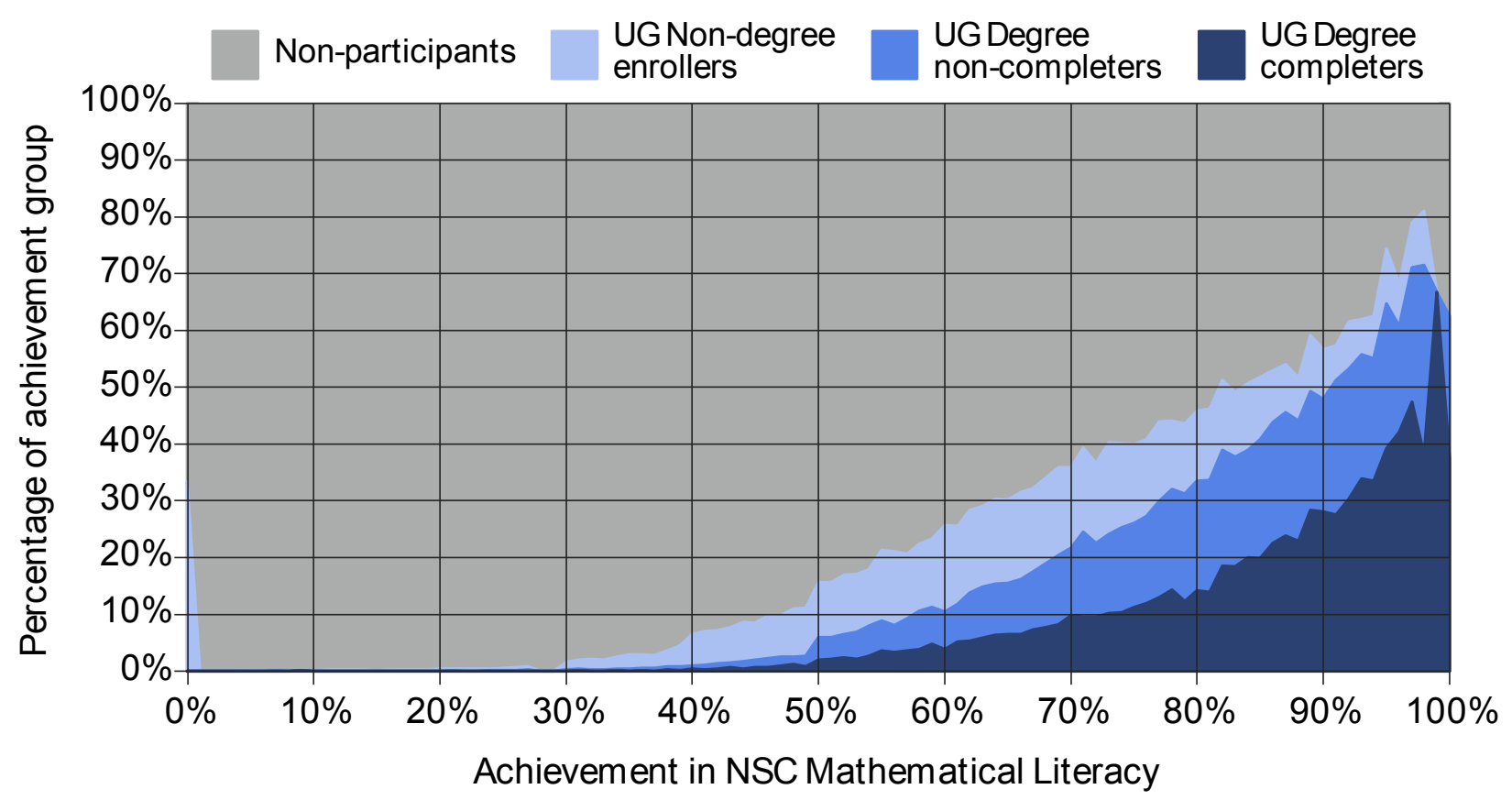

NOTES: Figure shows the percentage of learners from the 2008 matric cohort at each point of the NSC Mathematical Literacy performance distribution that respectively did not enrol in undergraduate studies, enrolled only in undergraduate non-degree programmes, enrolled in undergraduate degree programmes without completing those programmes, and completed undergraduate degree programmes between 2009 and 2014 . Note that students were only classified as "UG Non-degree enrollers" if they enrolled in undergraduate non-degree programmes, but did not also enrol in undergraduate degree studies at some other stage over the period under consideration.

Figure 8.6 shows that better performance in Mathematical Literacy, as was the case for Mathematics, is associated with higher degree completion. This can also be seen in Figure 8.7 below. The association appears to be much weaker (i.e. the graph's slope is much flatter), however, than the corresponding relationship between degree completion and performance in NSC Mathematics. For example, only about $15 \%$ of learners 
who scored $80 \%$ in Mathematical Literacy went on to complete undergraduate degrees, while the corresponding proportion for those who scored $80 \%$ in Mathematics was roughly $60 \%$. Even for those who achieved $90 \%$ in Mathematical Literacy, slightly fewer than 30\% went on to complete undergraduate degrees within six years. It therefore seems clear that achievement in Mathematical Literacy is less predictive of university success than achievement in Mathematics.

It is once again instructive to consider a more general picture of university outcomes by performance in Mathematical Literacy. Figure 8.8 confirms that university access and completion are positively associated with achievement in Mathematical Literacy in matric and adds the insight that better performance in Mathematical Literacy is associated with lower university dropout rates. Similar to the case for Mathematics, Figure 8.8 suggests that increases in Mathematical Literacy performance are associated with larger increases in university access than throughput. Also analogous to achievement in Mathematics, the figure suggests that overall, learners who perform better in NSC Mathematical Literacy are more likely to complete their qualifications and less likely to drop out of university study than those who perform at lower levels - even among the select group of learners who access undergraduate studies immediately after writing the NSC examinations.

It is interesting to note that a smaller proportion of degree completers achieved at least $60 \%$ in Mathematics (67\%) than in Mathematical Literacy (82\%). That is, among those learners who did enrol in undergraduate degrees, those who offered Mathematical Literacy in their NSC exams and scored above $60 \%$ in their final grade for this subject were more likely to complete their undergraduate degrees within six years than their counterparts who offered Mathematics in their NSC examinations and scored a grade of above $60 \%$. This result seems counterintuitive, since Table 8.1 above indicates that participation in Mathematical Literacy is negatively associated with degree completion, while participation in Mathematics is positively associated with degree completion.

A possible explanation for this finding lies in the fact learners who offer Mathematical Literacy in the NSC examinations are excluded from enrolling in certain undergraduate degree programmes, such as Bachelor of Commerce, Science, Medicine and Engineering programmes. This means that such learners can often only enrol in Bachelor of Arts, Social Science, Education, and Law programmes. The former group of undergraduate degrees have lower completion rates, in general, than the latter group. For example, Scott et al. (2007: 27) report that for the 2006 first-time entering undergraduate cohort, Bachelor of Commerce, Engineering and Science programmes had lower average record-time completion rates than Bachelor of Social Science and Education programmes. If one assumes similar trends in completion rates by undergraduate degree programmes hold for the 2009 first-time entering cohort, it seems that learners who offer Mathematical Literacy are excluded from studying degree programmes that generally have low completion rates relative to the degree programmes they can enrol for. This could explain why the six-year completion rate for degree entrants offering Mathematical Literacy may be higher than that of their counterparts offering Mathematics, simply by virtue of the fact that the former are excluded from enrolling in certain undergraduate degree programmes. 
Figure 8.7: Percentage of undergraduate degree students from the 2008 matric cohort who completed undergraduate degrees between 2009 and 2014, by NSC Mathematical Literacy performance

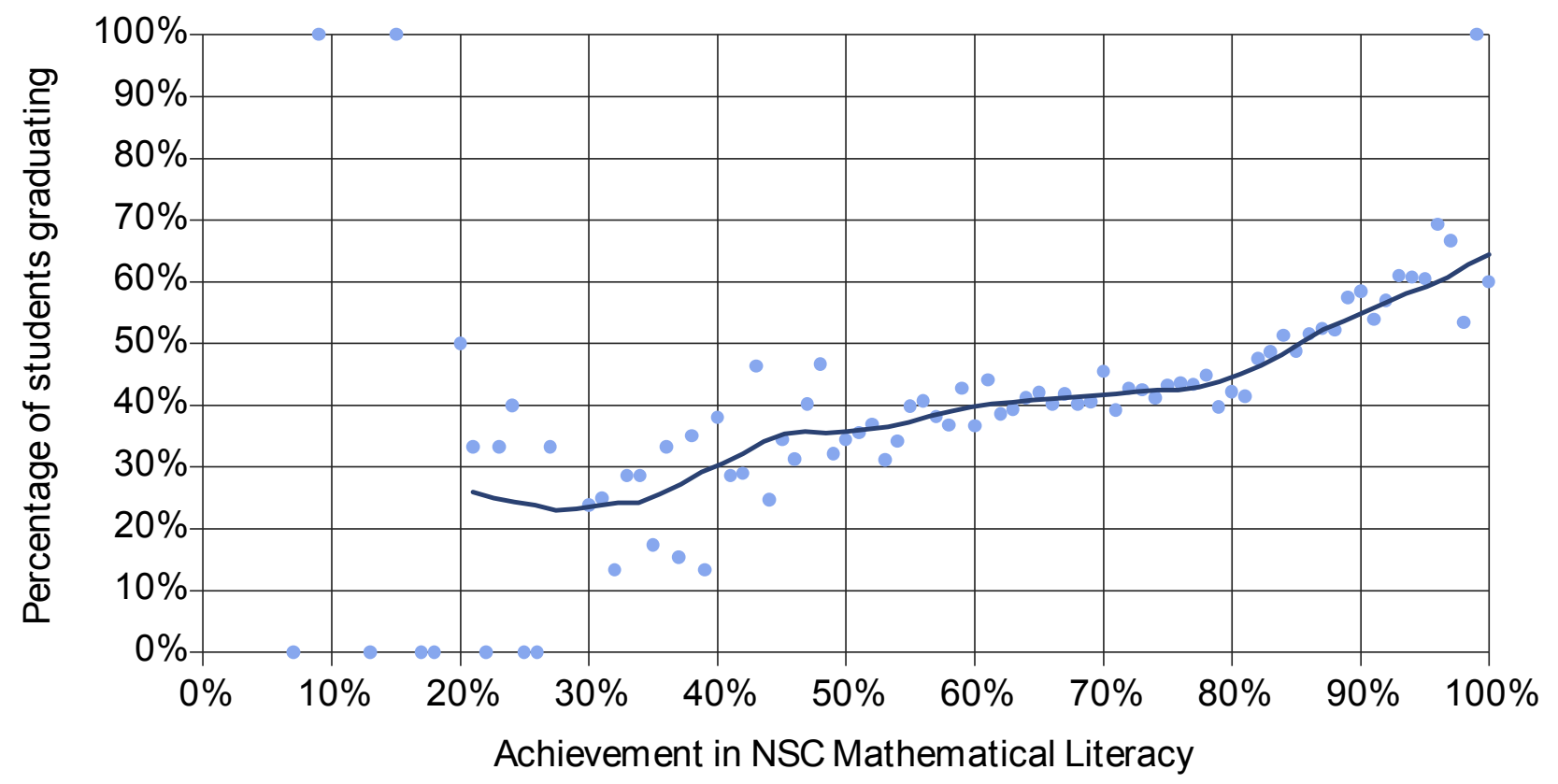

NOTES: Dots show the percentage of 2009 - 2014 undergraduate students from the 2008 matric cohort who completed undergraduate degrees over the period for different levels of NSC Mathematical Literacy achievement. The smoothed line through the dots was estimated using weighted local polynomial regression.

Figure 8.8: Expected access, completion, and dropout rates for learners from the 2008 matric cohort (2009 2014), by NSC Mathematical Literacy achievement

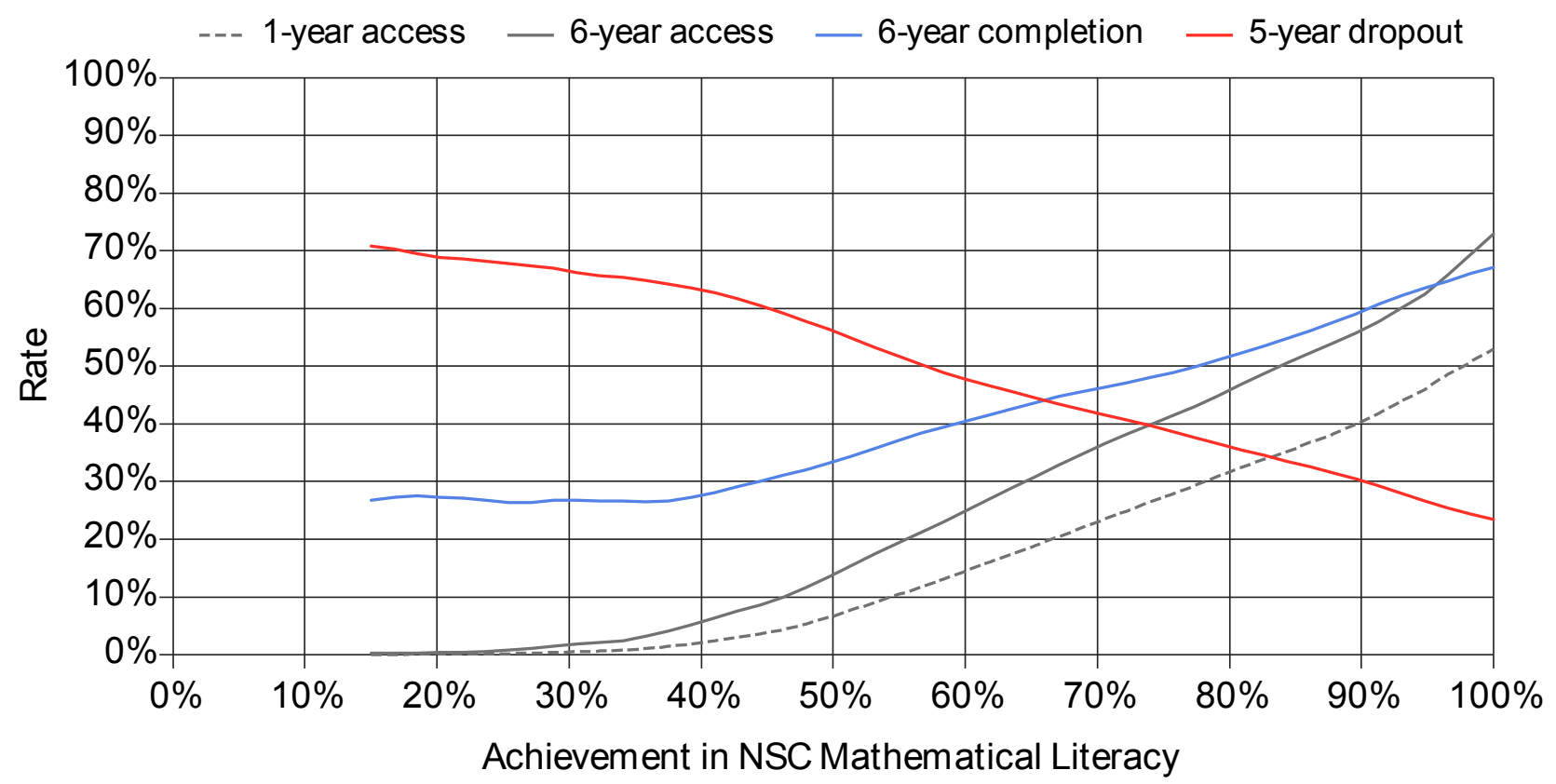

NOTES: Lines represent the expected 6-year access, 1-year access, 6-year completion, and 5-year dropout rates conditional on NSC Mathematical Literacy achievement for learners from the 2008 matric cohort and were drawn using local polynomial regression. The curves for completion and dropout are only drawn for those learners from the cohort who enrolled in undergraduate studies for the first time in 2009.

\subsubsection{Physical Sciences}

Figure 8.9 below shows the cumulative NSC Physical Sciences performance distribution for learners from the 2008 matric cohort. Achievement in this subject is significantly weaker than in both Mathematics and Mathematical Literacy: fewer than $1 \%$ of university non-participants achieved a grade of $60 \%$ or higher for 
Physical Sciences, whereas this proportion was only about $5 \%$ for non-degree enrollers, fewer than $25 \%$ for degree non-completers, and only about $47 \%$ for degree completers. Once again, a large gap exists between the distributions of Physical Science performance of non-enrollers and non-degree enrollers, suggesting that performance in Physical Sciences is predictive of access to university. However, since this gap is smaller than the corresponding gap in Mathematics performance, it seems that performance in Mathematics is more predictive of university access than performance in Physical Sciences. In terms of predicting university completion, performance in Physical Sciences seems fairly predictive: a relatively large gap exists between degree completers and non-completers in terms of their Physical Sciences grades. This predictive power is limited, however, since about $10 \%$ of degree completers achieved a grade of below $40 \%$ for Physical Sciences. This is a relatively poor grade, and it is surprising that a relatively large proportion of learners achieving such a grade managed to complete undergraduate degrees.

Figure 8.9: Cumulative NSC Physical Sciences performance distribution for the 2008 matric cohort by enrolment and completion of undergraduate degree programmes between 2009 and 2014

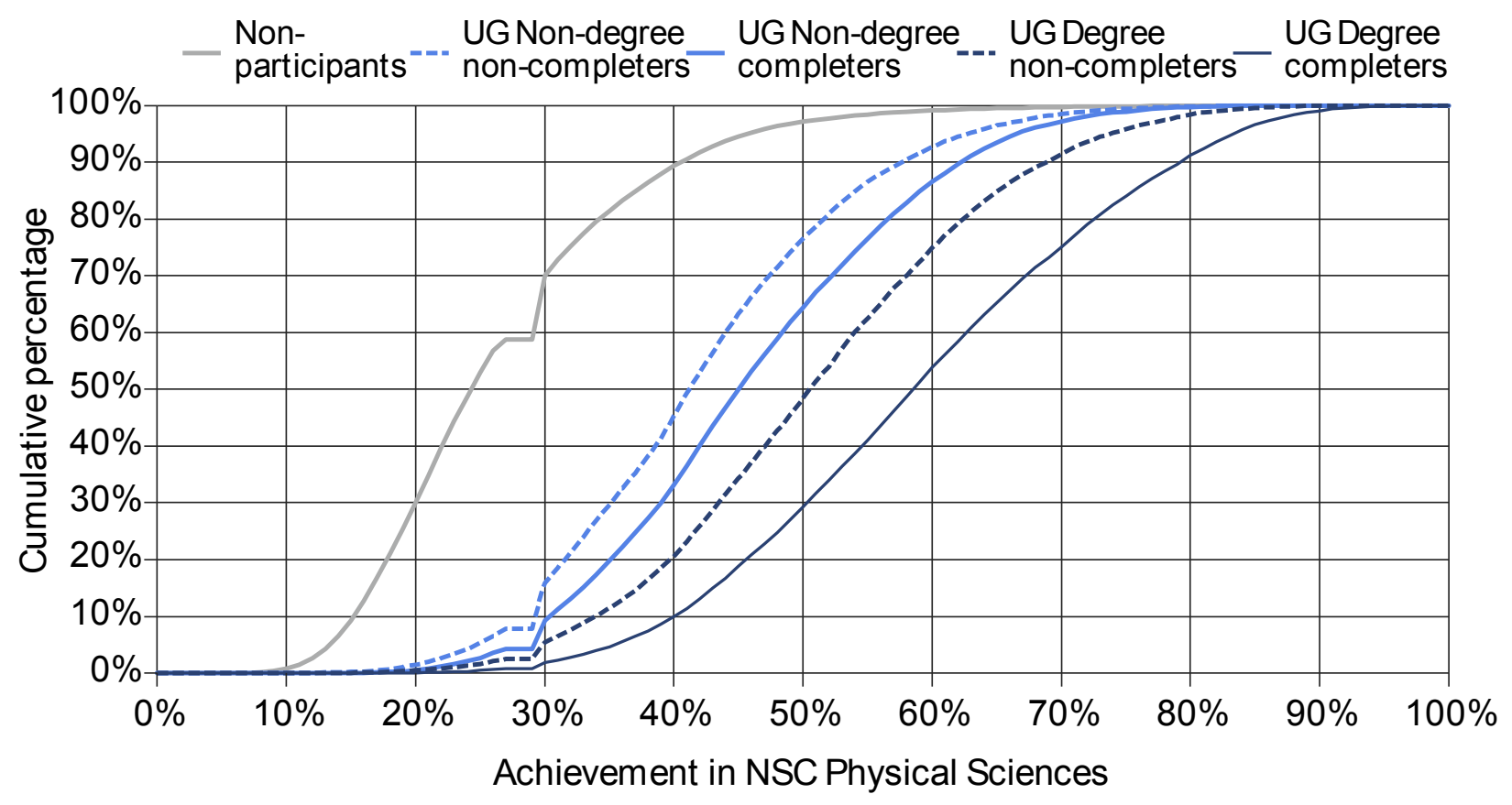

NOTES: Each line represents the cumulative percentage of a group that performed below a given level of 2008 NSC Physical Sciences achievement.

Figure 8.10 presents the extent of undergraduate degree enrolment and completion for each given level of NSC Physical Sciences performance. As was the case for both Mathematics and Mathematical Literacy, there are clear differences in degree enrolment patterns by Physical Sciences performance. Interestingly, better achievement in Physical Sciences is associated with much greater probabilities of accessing university than is the case for both Mathematics and Mathematical Literacy achievement. About 53\% of learners from the 2008 matric cohort who achieved 50\% in Physical Sciences went on to enrol in undergraduate degree programmes. This is much larger than the equivalent proportion of learners who achieved 50\% in Mathematics - only 35\% of those learners went on to enrol in undergraduate degree programmes. Astonishingly, roughly $95 \%$ of learners who achieved $80 \%$ in Physical Sciences went on to enrol in undergraduate degree programmes (compared with $80 \%$ of learners who achieved $80 \%$ in Mathematics who did so). By implication, performance 
in Physical Sciences seems to be highly correlated with the probability of enrolling in undergraduate degree programmes.

Figure 8.10: Enrolment in and completion of undergraduate degree programmes for the 2008 matric cohort (2009 - 2014), by NSC Physical Sciences achievement

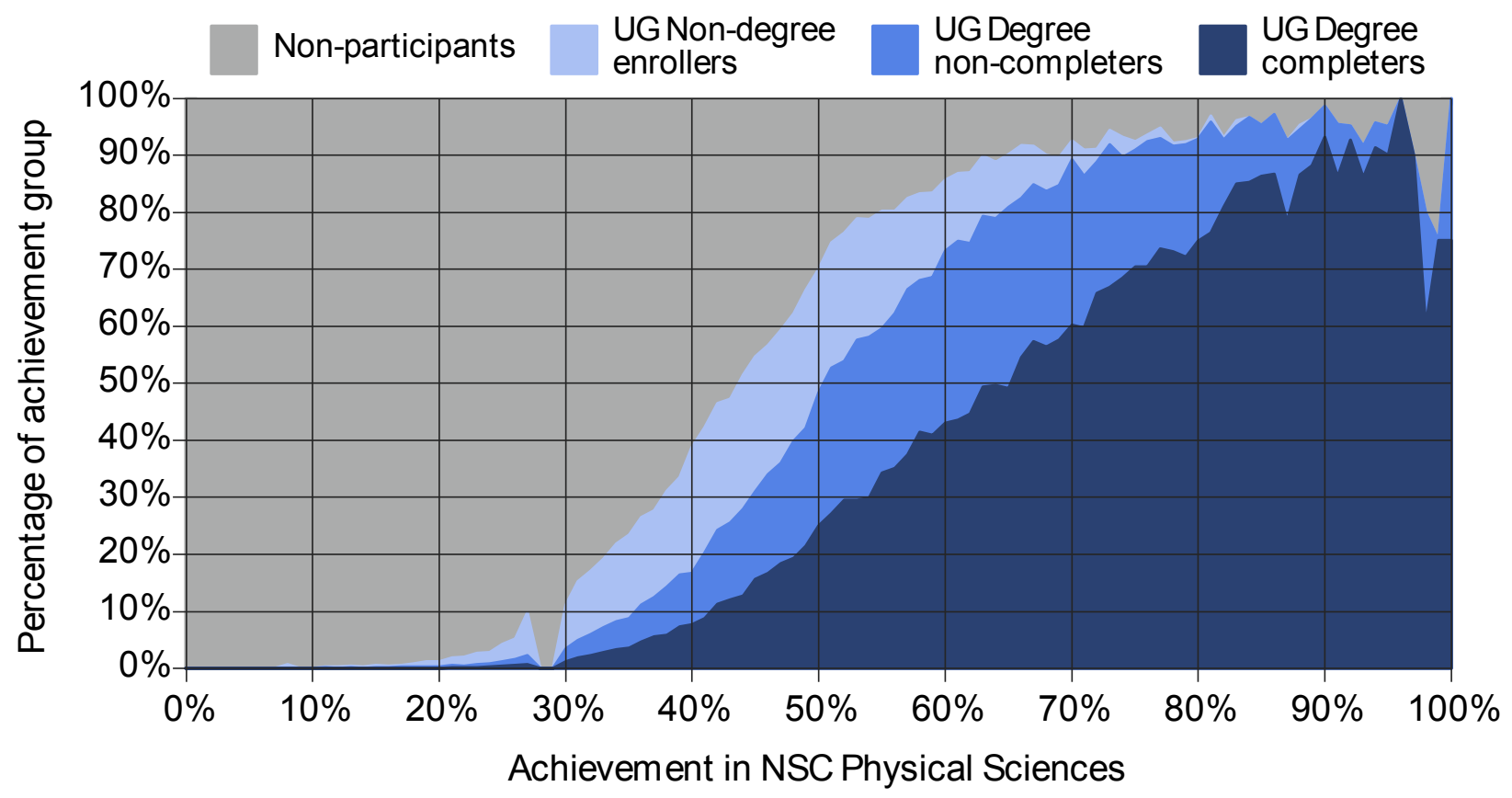

NOTES: Figure shows the percentage of learners from the 2008 matric cohort at each point of the NSC Physical Sciences performance distribution that respectively did not enrol in undergraduate studies, enrolled only in undergraduate non-degree programmes, enrolled in under- graduate degree programmes without completing those programmes, and completed undergraduate degree programmes between 2009 and 2014. Note that students were only classified as "UG Non-degree enrollers" if they enrolled in undergraduate non-degree programmes, but did not also enrol in undergraduate degree studies at some other stage over the period under consideration.

Figure 8.10 suggests that achievement in Physical Sciences is also strongly correlated with undergraduate degree completion rates. This can also be seen in Figure 8.11 below. Once again, this association is stronger than that between achievement in either NSC Mathematics or Mathematical Literacy and degree completion rates. According to the figure, $41 \%$ of learners who achieved a grade of $60 \%$ in NSC Physical Sciences and enrolled in undergraduate degree programmes between 2009 and 2014 would go on to complete undergraduate degrees during the period. $72 \%$ of those who achieved $80 \%$ in Physical Sciences, and roughly $91 \%$ of students who achieved $90 \%$, followed suit. In other words, for every 10 undergraduate degree students from the 2008 matric cohort who achieved $90 \%$ in NSC Physical Sciences, nine went on to complete their undergraduate degrees within six years. This constitutes a very strong association.

Figure 8.12 presents a more general picture of university outcomes by achievement in Physical Sciences. It shows that increases in Physical Sciences achievement is associated with larger increases in university access than completion rates. A similar trend was found for achievement in either Mathematics and Mathematical Literacy. This indicates that performance in Physical Sciences is a stronger predictor of university access than success, as also found by Van Broekhuizen (2016: 46). 
Figure 8.11: Percentage of undergraduate degree students from the 2008 matric cohort who completed undergraduate degrees between 2009 and 2014, by NSC Physical Sciences performance

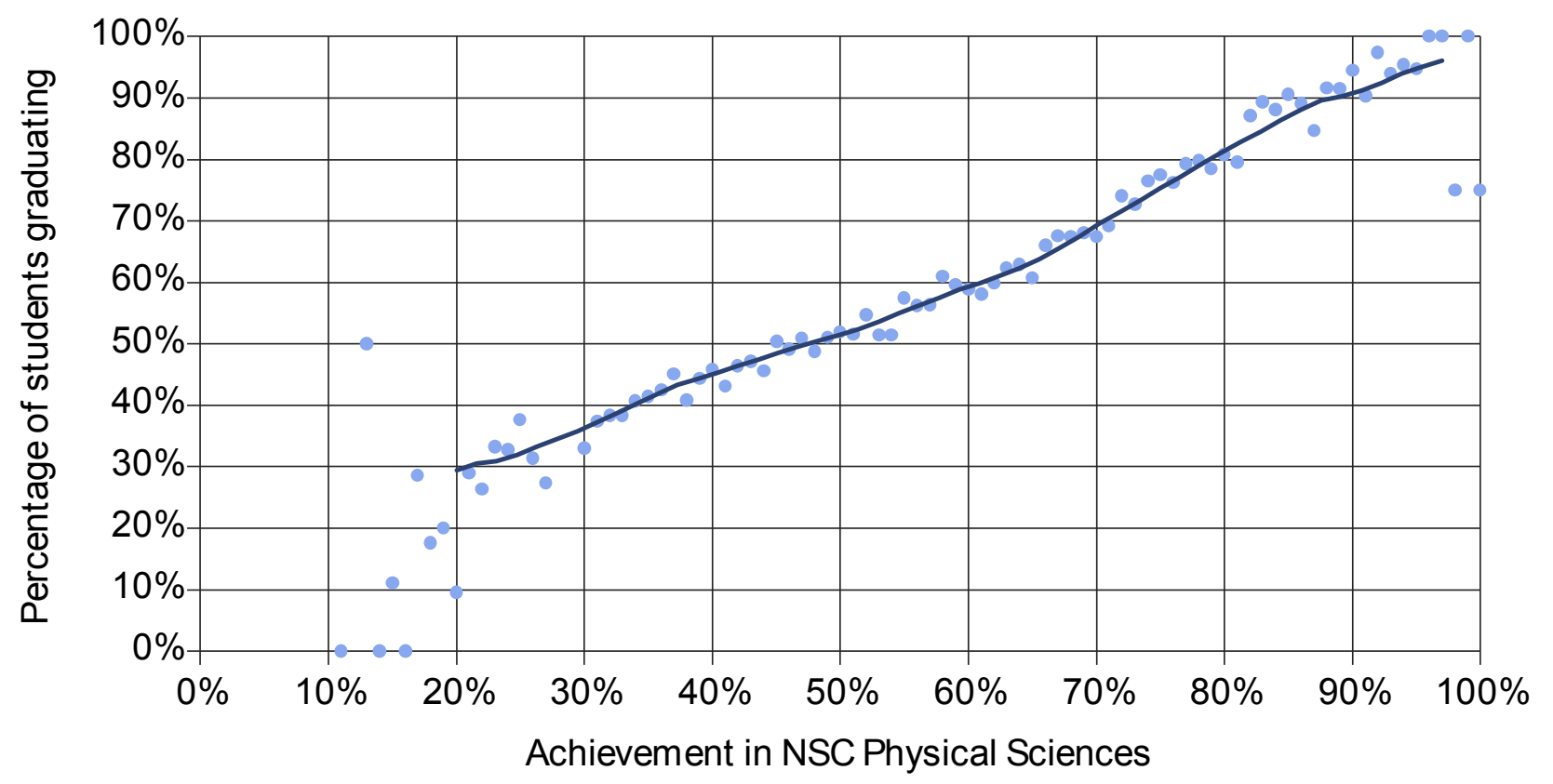

NOTES: Dots show the percentage of 2009 - 2014 undergraduate students from the 2008 matric cohort who completed undergraduate degrees over the period for different levels of NSC Physical Sciences achievement. The smoothed line through the dots was estimated using weighted local polynomial regression.

Figure 8.12: Expected access, completion, and dropout rates for learners from the 2008 matric cohort (20092014), by NSC Physical Sciences achievement

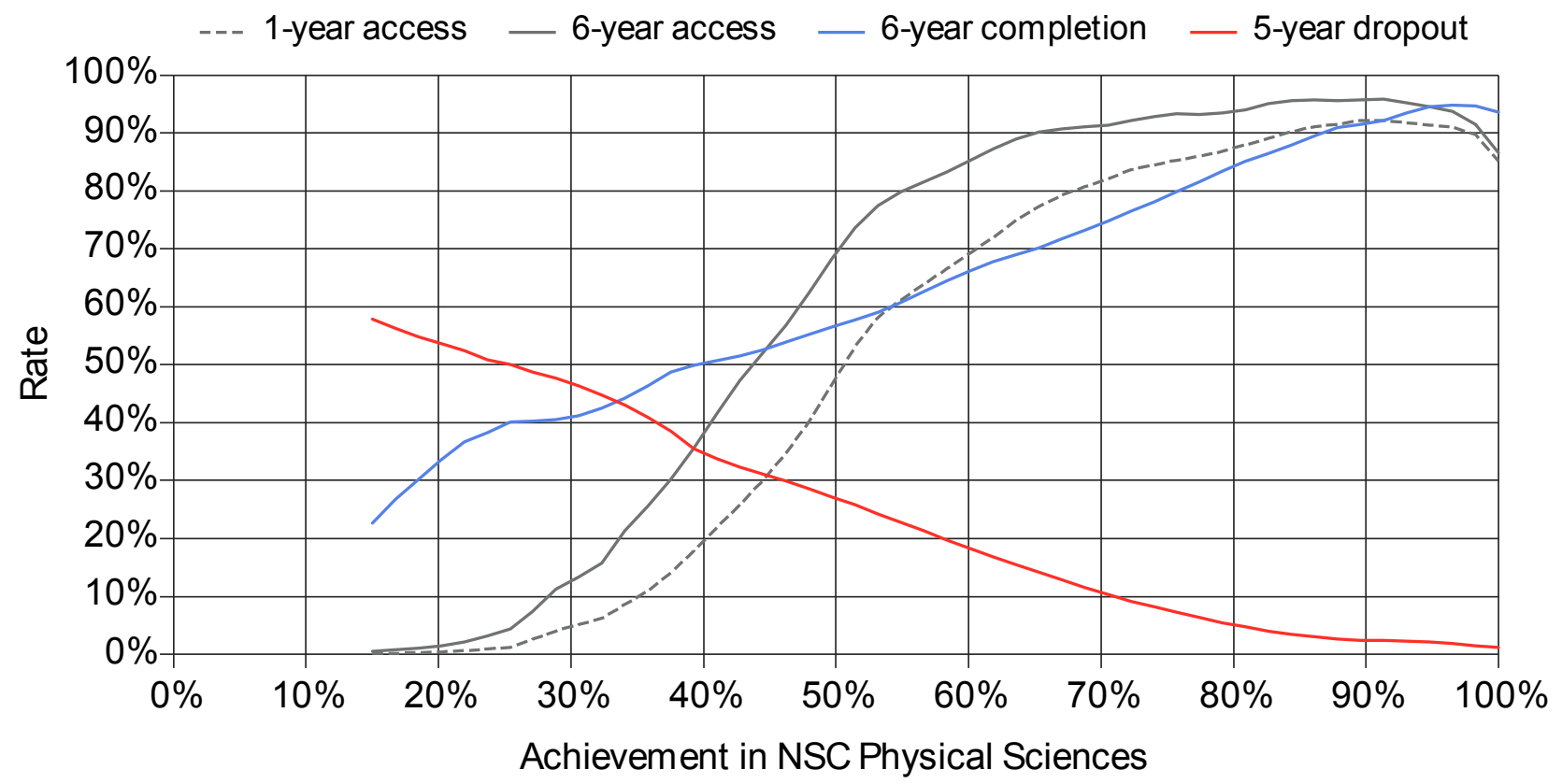

NOTES: Lines represent the expected 6-year access, 1-year access, 6-year completion, and 5-year dropout rates conditional on NSC Physical Sciences achievement for learners from the 2008 matric cohort and were drawn using local polynomial regression. The curves for completion and dropout are only drawn for those learners from the cohort who enrolled in undergraduate studies for the first time in 2009. 


\subsubsection{English First Additional Language}

Figure 8.13 below shows the cumulative NSC English FAL performance distribution for learners from the 2008 matric cohort. Once again, clear differences in achievement can be seen across different sub-groups, distinguished by their university access and completion status. Specifically, the distribution of English FAL performance of those learners who did not access university at all in this period lies far to the left of the distributions of those who did enrol in university at some point. Roughly $42 \%$ of learners who enrolled in undergraduate degrees without completing them and roughly $30 \%$ of those who completed undergraduate degrees within six years had attained a grade of $60 \%$ or higher for English FAL. Virtually none of the learners who achieved an English FAL grade of $40 \%$ or lower completed undergraduate degrees within six years of matriculating. Only about $4 \%$ of learners who achieved $40 \%$ or less in English FAL enrolled in university at all, while only about $1 \%$ of those who achieved this grade enrolled in undergraduate degrees. In other words, learners from this cohort who offered English FAL, but did not attain at least $40 \%$ in the subject, had an extremely small chance of enrolling in university within six years of matriculation, and virtually no chance of completing an undergraduate degree by the end of 2014. This indicates that weak performance in English FAL was fairly predictive of university access and success for the 2008 matric cohort.

Figure 8.13: Cumulative NSC English First Additional Language performance distribution for the 2008 matric cohort by enrolment and completion of undergraduate degree programmes between 2009 and 2014

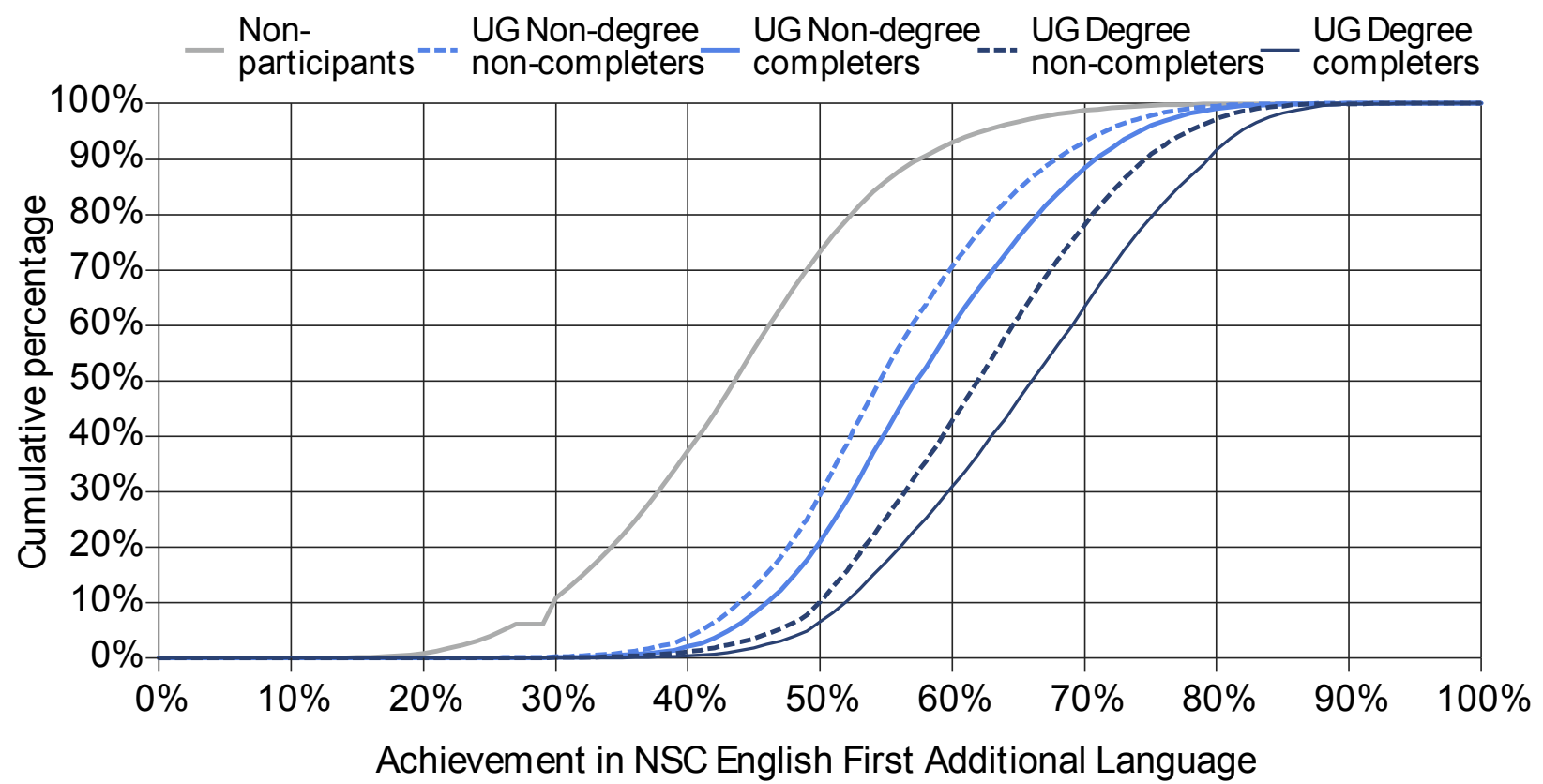

NOTES: Each line represents the cumulative percentage of a group that performed below a given level of 2008 NSC English First Additional Language achievement.

Figure 8.14 shows the undergraduate degree enrolment and completion for each given level of English FAL performance. University enrolment patterns clearly differ by English FAL achievement. Among learners who achieved $60 \%$ for English FAL, 36\% enrolled in undergraduate studies. Of these, about $56 \%$ (roughly $20 \%$ of the original cohort) enrolled in degree programmes. 
Figure 8.14: Enrolment in and completion of undergraduate degree programmes for the 2008 matric cohort (2009 - 2014), by NSC English FAL achievement

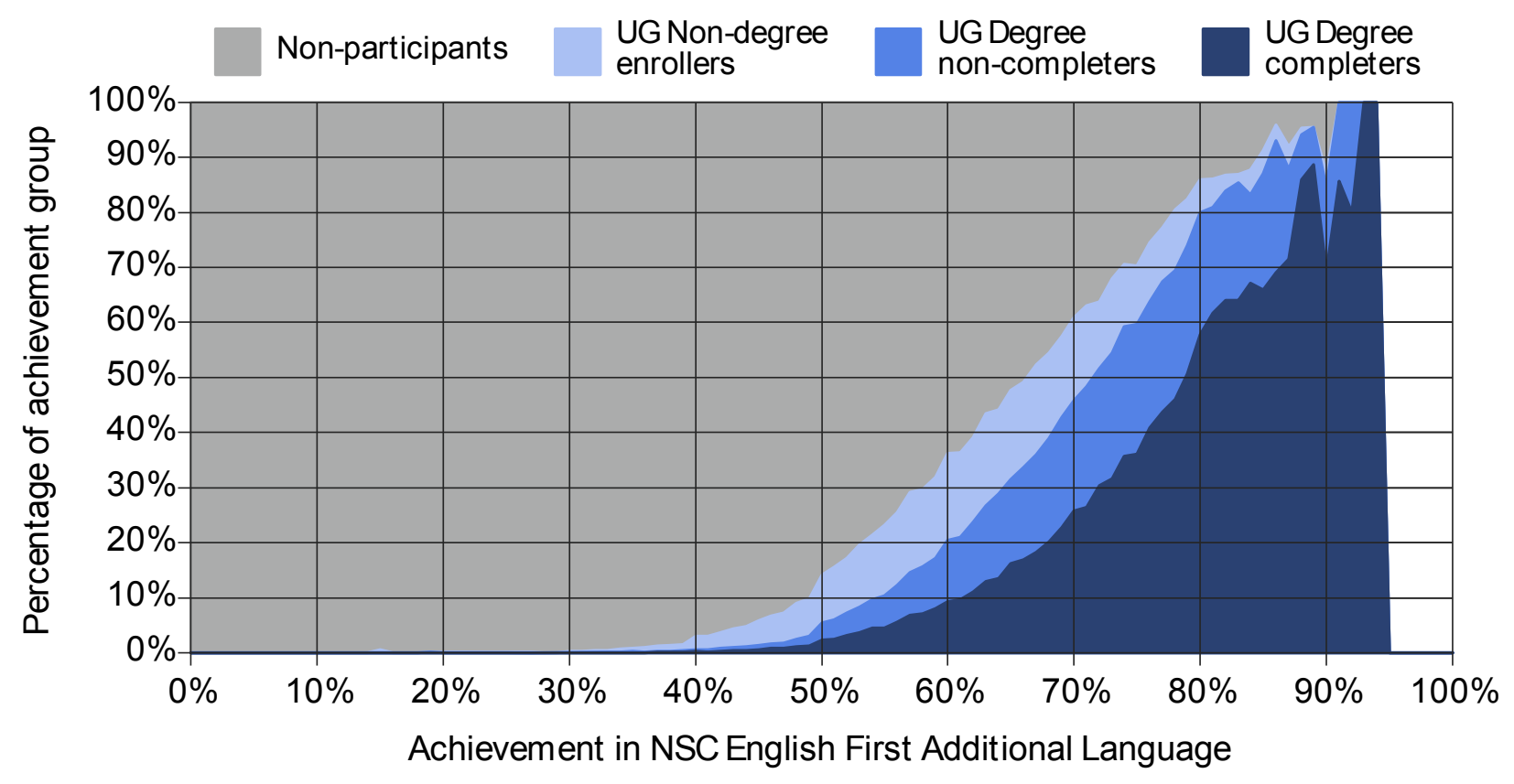

NOTES: Figure shows the percentage of learners from the 2008 matric cohort at each point of the NSC English FAL performance distribution that respectively did not enrol in undergraduate studies, enrolled only in undergraduate non-degree programmes, enrolled in undergraduate degree programmes without completing those programmes, and completed undergraduate degree programmes between 2009 and 2014 . Note that students were only classified as "UG Non-degree enrollers" if they enrolled in undergraduate non-degree programmes, but did not also enrol in undergraduate degree studies at some other stage over the period under consideration.

Figure 8.15 confirms that English FAL performance is associated with undergraduate degree completion. Interestingly, the strength of this association seems to increase at higher levels of English FAL achievement. For example, among those who achieved $60 \%$ for English FAL, only about half of those enrolled in undergraduate degrees $(10 \%$ of the original cohort) had completed their degrees by the end of 2014 . On the other hand, of those who achieved 80\% for English FAL and enrolled in undergraduate degrees, 75\% (roughly $60 \%$ of the original cohort) had completed their degrees by the end of 2014 . This suggests that higher achievement in English FAL is associated with a greater chance of completing one's undergraduate degree within six years.

Figure 8.16 shows the expected 1-year access, 6-year access, 6-year completion, and 5- year dropout rates for learners from the 2008 matric cohort (2009 - 2014), by NSC English FAL achievement. This figure provides a more general picture of the associations between performance in English FAL and university outcomes.

The figure confirms the positive association between English FAL performance and university access and completion rates, and illustrates a negative association between English FAL performance and university dropout rates. As is the case with Mathematics, Mathematical Literacy and Physical Sciences, increases in English FAL achievement are associated with larger increases in access rates than completion rates. This indicates that performance in English FAL, too, is a stronger predictor of university access than success. 
Figure 8.15: Percentage of undergraduate degree students from the 2008 matric cohort who completed undergraduate degrees between 2009 and 2014, by NSC English First Additional Language performance

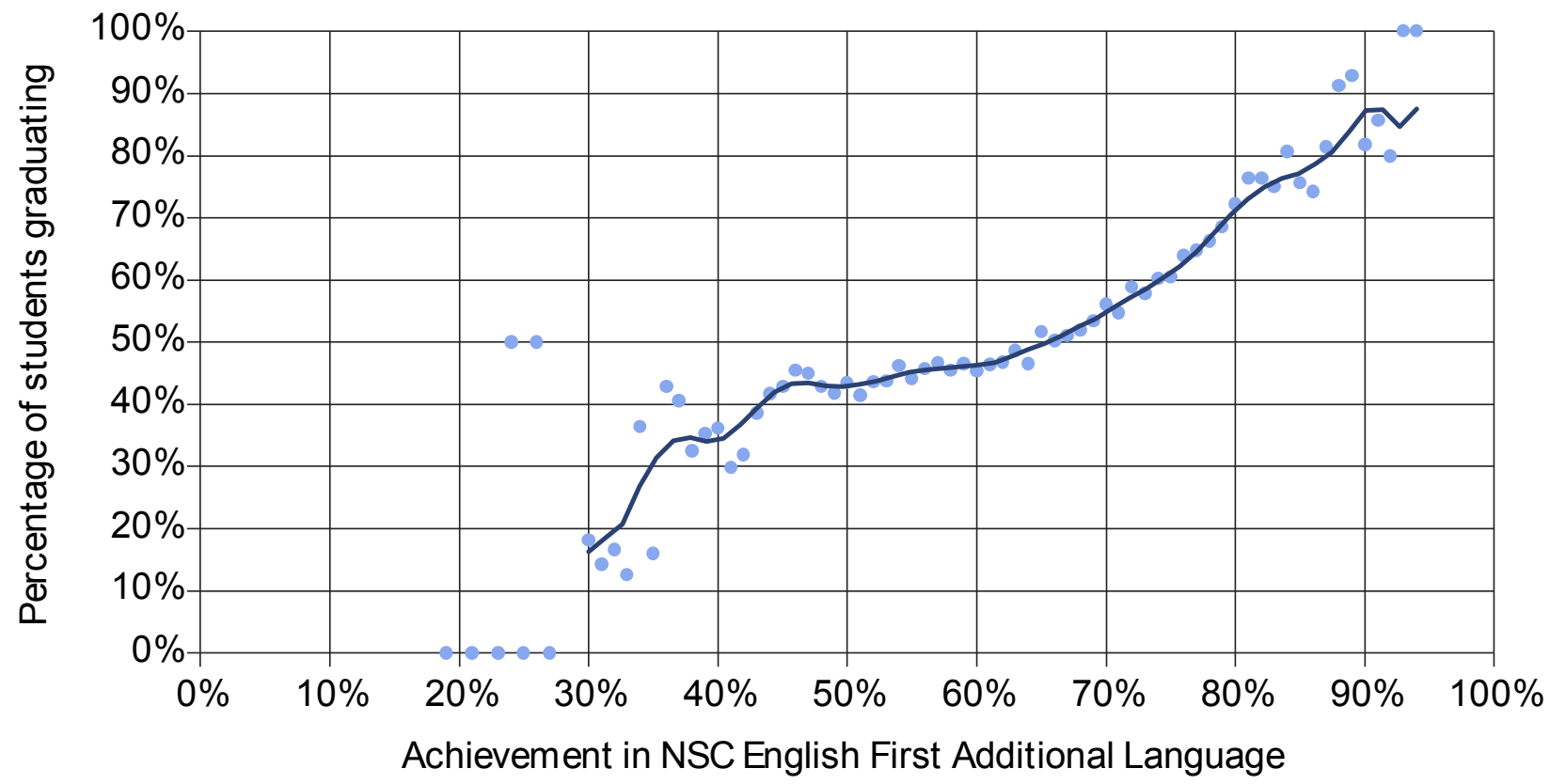

NOTES: Dots show the percentage of 2009 - 2014 undergraduate students from the 2008 matric cohort who completed undergraduate degrees over the period for different levels of NSC English FAL achievement. The smoothed line through the dots was estimated using weighted local polynomial regression.

Figure 8.16: Expected access, completion, and dropout rates for learners from the 2008 matric cohort (2009 - 2014), by NSC English First Additional Language achievement

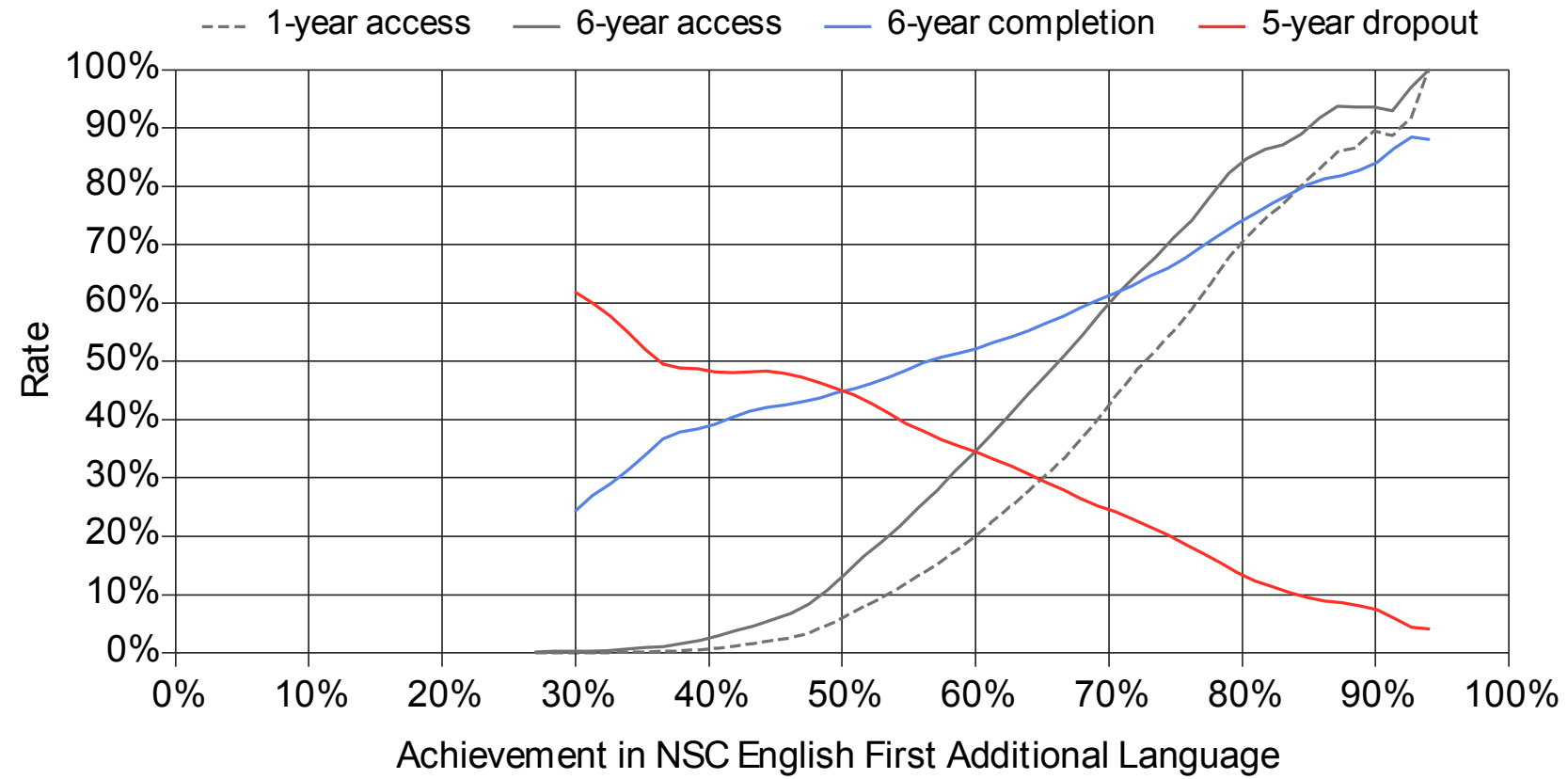

NOTES: Lines represent the expected 6-year access, 1-year access, 6-year completion, and 5-year dropout rates conditional on NSC English First Additional Language achievement for learners from the 2008 matric cohort and were drawn using local polynomial regression. The curves for completion and dropout are only drawn for those learners from the cohort who enrolled in undergraduate studies for the first time in 2009. 


\subsection{An articulation gap between school and university?}

The finding that performance in Mathematics, Mathematical Literacy, Physical Sciences and English FAL is a stronger predictor of university access than success supports the notion that there exists an articulation gap between secondary school and university in South Africa. This is the phenomenon whereby many learners who perform sufficiently well in matric to qualify for entrance into university and who find the means to actually attend university nevertheless do not successfully complete their undergraduate programmes within six years of enrolling (Van Broekhuizen, 2016: 41). This suggests that many who qualify for university studies are not adequately equipped to deal with the demands of university. In this sense, there exists a gap between the signal of ability provided by achievement in these four subjects, and actual ability to study with success. Achievement in gateway subjects signals readiness for university, but the limited association between this achievement and undergraduate completion rates indicates that this signal may not always be reliable. Learners who perform well in gateway subjects will not necessarily succeed in university, and conversely, those who perform poorly in gateway subjects may go on to succeed in university.

\section{School background}

\section{1. University performance by school quintile}

Table 9.1 summarises the NSC examination results of the 2008 cohort, by school poverty quintile. The table shows extreme gaps in the proportions of learners from each quintile achieving matric passes. For example, the proportion of learners from quintile 5 schools who passed matric is more than double (93\%) that of learners from quintile 1 schools (46\%). The table also makes clear that the gaps in matric pass rates between the quintiles are not equal. For example, the matric pass rates of quintiles 1,2 and 3 schools differed quite substantially, at $46 \%, 51.0 \%$ and $57 \%$, respectively. These differences are minor, however, in comparison with differences in matric pass rates between these quintiles, on the one hand, and quintile 4 and quintile 5 schools, on the other. The differences in matric pass rates between quintiles 1 and 2, and 2 and 3 schools, for example, are 5 and 6 percentage points respectively. By contrast, the gap in pass rates between quintile 3 and 4 schools is much higher than either of these, at 15 percentage points. The gap in pass rates between quintile 4 and 5 schools is even higher, at 20 percentage points. In terms of matric pass rate, it therefore is apparent that quintiles 1-3 schools perform roughly similarly, quintile 4 schools perform quite a lot better, and quintile 5 schools perform much better still.

The differences in matric pass type between the different quintiles follow a similar pattern: while 53\% of learners attending quintile 5 schools achieved bachelor passes, only $8 \%$ of learners from quintile 1 schools, $9.3 \%$ of learners from quintile 2 schools, $12 \%$ of those from quintile 3 schools, and $22 \%$ of learners from quintile 4 schools did so. 
Table 9.1: NSC exam results for the 2008 matric cohort, by school quintile

\begin{tabular}{crrrrrr}
\hline & \multicolumn{1}{c}{ All } & Quintile 1 & Quintile 2 & Quintile 3 & Quintile 4 & Quintile 5 \\
\cline { 2 - 6 } Candidates & 537542 & 107461 & 126893 & 135933 & 71188 & 96067 \\
row \% & 100.0 & 20.0 & 23.6 & 25.3 & 13.2 & 17.9 \\
column \% & 100.0 & 100.0 & 100.0 & 100.0 & 100.0 & 100.0 \\
Did not achieve & 204667 & 58191 & 62230 & 57986 & 19528 & 6732 \\
row \% & 100.0 & 28.4 & 30.4 & 28.3 & 9.5 & 3.3 \\
column \% & 38.1 & 54.2 & 49.0 & 42.7 & 27.4 & 7.0 \\
Passed (all) & 332875 & 49270 & 64663 & 77947 & 51660 & 89335 \\
row \% & 100.0 & 14.8 & 19.4 & 23.4 & 15.5 & 26.8 \\
column \% & 61.9 & 45.8 & 51.0 & 57.3 & 72.6 & 93.0 \\
- SNE/NSC & 216 & 93 & 86 & 28 & 7 & 2 \\
row \% & 100.0 & 43.1 & 39.8 & 13.0 & 3.2 & 0.9 \\
column \% & 0.0 & 0.1 & 0.1 & 0.0 & 0.0 & 0.0 \\
- Higher Certificate & 104934 & 22898 & 28524 & 30821 & 14366 & 8325 \\
row \% & 100.0 & 21.8 & 27.2 & 29.4 & 13.7 & 7.9 \\
column \% & 19.5 & 21.3 & 22.5 & 22.7 & 20.2 & 8.7 \\
- Diploma & 12434 & 18227 & 24243 & 30596 & 21374 & 29901 \\
row \% & 100.0 & 14.7 & 19.5 & 24.6 & 17.2 & 24.0 \\
column \% & 23.1 & 17.0 & 19.1 & 22.5 & 30.0 & 31.1 \\
- Bachelor & 103384 & 8052 & 11810 & 16502 & 15913 & 51107 \\
row \% & 100.0 & 7.8 & 11.4 & 16.0 & 15.4 & 49.4 \\
column \% & 19.2 & 7.5 & 9.3 & 12.1 & 22.4 & 53.2 \\
\hline
\end{tabular}

NOTES: Figures printed in black reflect the numbers of learners who wrote and achieved particular pass results in the NSC examinations for the 2008 matric cohort, by school quintile. Row percentages are printed in grey and express the number of learners in a particular age group as a percentage of the number of candidates who achieved a particular pass result. Column percentages are also printed in grey and express the number of learners who achieved a particular pass result as a percentage of the number of candidates in each race group.

Figure 9.1 compares the cumulative matric average achievement distributions for learners from the 2008 matric cohort by quintile of the school attended. The findings from Table 1 are reflected even more strongly in this graph. In terms of NSC performance, there again appears to be three distinct groups of schools: quintile 1 - 3 schools, quintile 4 schools, and quintile 5 schools. This can further be seen in the median matric average achievement levels for quintile 1 - 5 schools, which are respectively $36 \%, 385 \%, 39 \%, 43 \%$, and 56 . Figure 1 also shows that while more than $65 \%$ of quintile 5 learners achieved above $50 \%$ in the 2008 NSC examinations, fewer than $15 \%$ of quintile $1-3$ and $30 \%$ of quintile 4 learners did so.

Tables 9.2 compares the university enrolment, exit, and completion for learners from quintile 1 - 3, quintile 4, and quintile 5 schools from the 2008 matric cohort over the period 2009 to 2014 . The table shows clear differences in university access, completion and dropout rates between quintiles. While only about $12 \%$ of learners from quintile 1-3 schools enrolled in undergraduate programmes at some point between 2009 and 2014, the corresponding proportions for learners from quintile 4 and 5 schools were roughly $24 \%$ and $45 \%$ respectively. There are also vast differences in the extent of delayed entry into university between learners from different types of schools (in terms of poverty quintile). Only about $6 \%$ of learners from quintile $1-3$ 
schools enrolled in undergraduate studies in 2009 , the year immediately following matriculation, as against $15 \%$ and $34 \%$, respectively for quintile 4 and 5 schools.

Figure 9.1: Cumulative matric average achievement distribution for the 2008 matric cohort, by school quintile

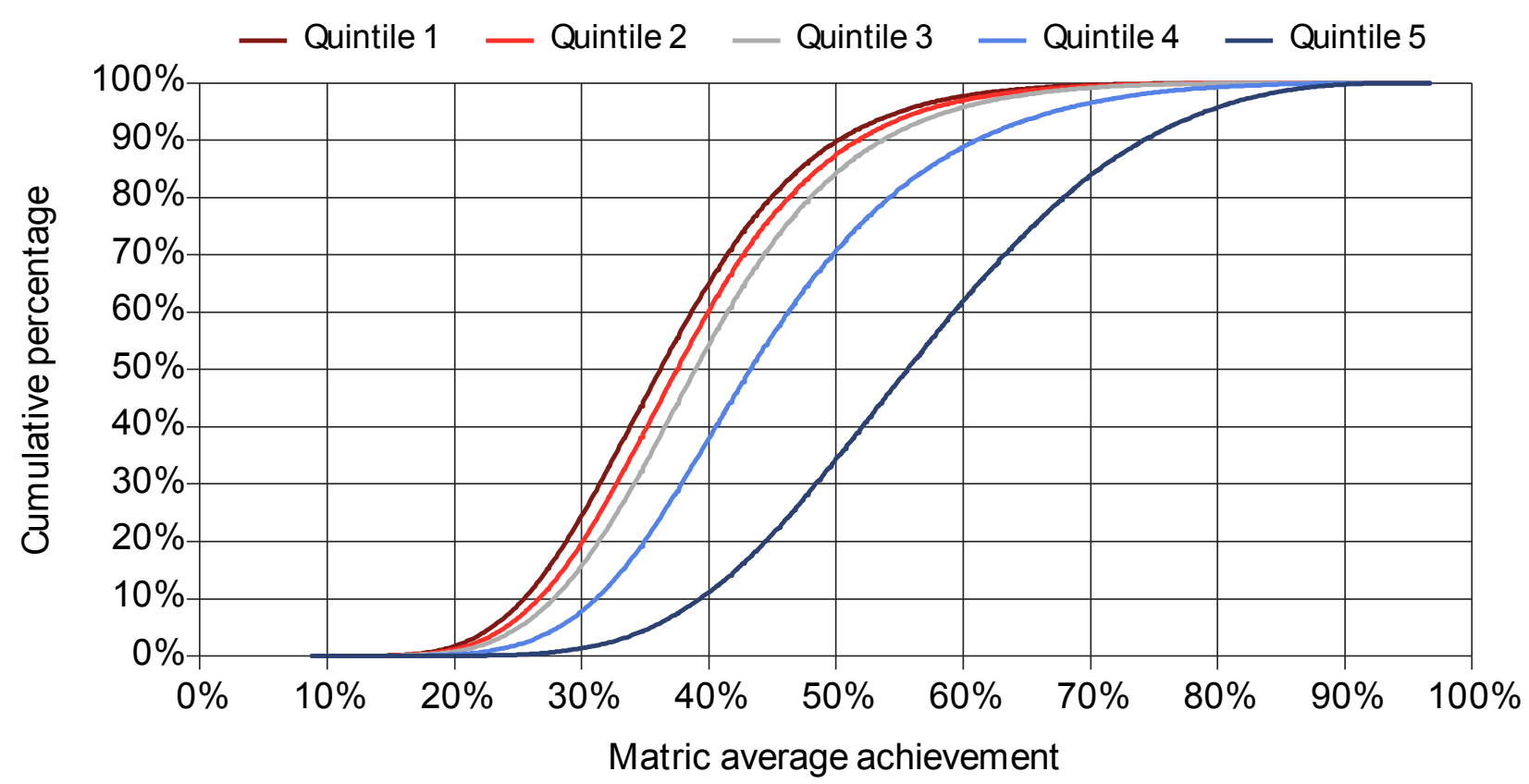

NOTES: Each line represents the cumulative percentage of a group that performed below a given level of 2008 NSC matric average achievement.

Learners from different quintiles also differ in terms of proportions enrolled in degree programmes. The proportions of learners enrolled in undergraduate degrees for learners from quintile 1, 2, 3, 4, and 5 schools were $4.4 \%, 5.5 \%, 7.4 \%, 13.7 \%$ and $34.9 \%$ respectively (see Table A18 in Appendix).

Interestingly, the differences in completion rates between learners from different quintiles are much smaller than the differences in access rates (see Table A18 in Appendix). Learners from quintile 1-3 schools performed only marginally worse in terms of completion rates than those from quintile 4 schools: $45 \%$ of learners from quintile 1-3 schools who had enrolled in undergraduate studies had completed undergraduate qualifications by the end of 2014, while the equivalent proportion of learners from quintile 4 schools was $46 \%$ and from quintile 5 schools $56 \%$. The gap in completion between university participants from quintile 1-3 schools and quintile 5 schools was also smaller than one might expect: $45 \%$ of university participants from quintile 1-3 schools had completed undergraduate qualifications by the end of 2014 , while $56 \%$ of learners from quintile 5 schools had done so. It should be noted, however, that the differences in the extent of undergraduate degree completion between leaners from different school quintiles were far larger. By the end of 2014, 49\% of university participants from quintile 5 schools had completed undergraduate degrees. By contrast, the comparable figure for university participants from quintile $1-3$ schools was only $24 \%$.

These are somewhat surprising results. Given that learners from quintile 4 and 5 schools performed noticeably better in their matric examinations than those from quintile 1-3 schools, one would expect greater differences in completion rates between learners from different quintiles. It therefore appears that while attending a quintile 1-3 school largely precludes learners from gaining access to university, those who do make it into university 
tend perform almost on par with their quintile 4 and 5 counterparts. In other words, the quintile of secondary school attended appears to be more closely associated with university access than university success.

Table 9.2: University enrolment, exit, and completion for learners from quintile $1-3$ schools in the 2008 matric cohort (2009 - 2014)

\begin{tabular}{|c|c|c|c|c|c|c|}
\hline & 2009 & 2010 & 2011 & 2012 & 2013 & 2014 \\
\hline & \multicolumn{6}{|c|}{ Percentage of quintile 1 - 3 learners ${ }^{1}$} \\
\hline Enrolled & 6.4 & 8.2 & 8.5 & 8.0 & 6.6 & 4.8 \\
\hline - First-time entering & 6.4 & 2.8 & 1.2 & 0.7 & 0.5 & 0.3 \\
\hline - Non-entering undergraduate & - & 5.3 & 7.3 & 7.1 & 5.7 & 4.0 \\
\hline - Non-entering postgraduate & - & - & - & 0.2 & 0.4 & 0.5 \\
\hline Not enrolled & 93.6 & 91.8 & 91.5 & 92.0 & 93.4 & 95.2 \\
\hline -Non-participants & 93.6 & 90.8 & 89.6 & 88.9 & 88.5 & 88.1 \\
\hline - Exit HE - Completers ${ }^{\mathrm{a}}$ & - & 0.0 & 0.0 & 0.3 & 1.5 & 3.1 \\
\hline - Exit HE - Non-Completers ${ }^{\mathrm{a}}$ & - & 0.7 & 1.5 & 2.2 & 3.0 & 4.0 \\
\hline Completers $^{\mathrm{a}}$ & 0.0 & 0.1 & 0.8 & 2.5 & 4.2 & 5.3 \\
\hline - Completers (non-cumulative) & 0.0 & 0.0 & 0.8 & 1.7 & 1.6 & 1.2 \\
\hline Dropouts $^{\mathrm{a}}$ & 0.7 & 1.5 & 2.2 & 3.0 & 4.0 & - \\
\hline \multirow[t]{2}{*}{ - Dropouts (non-cumulative) } & 0.7 & 0.8 & 0.8 & 0.8 & 1.0 & - \\
\hline & \multicolumn{6}{|c|}{ Percentage of quintile 4 learners ${ }^{2}$} \\
\hline Enrolled & 15.0 & 17.2 & 17.1 & 15.5 & 12.6 & 9.4 \\
\hline - First-time entering & 15.0 & 4.5 & 1.7 & 0.9 & 0.8 & 0.6 \\
\hline - Non-entering undergraduate & - & 12.7 & 15.4 & 14.0 & 10.7 & 7.5 \\
\hline - Non-entering postgraduate & - & - & - & 0.6 & 1.1 & 1.3 \\
\hline Not enrolled & 85.0 & 82.8 & 82.9 & 84.5 & 87.4 & 90.6 \\
\hline -Non-participants & 85.0 & 80.5 & 78.8 & 77.9 & 77.1 & 76.5 \\
\hline - Exit HE - Completers ${ }^{\mathrm{a}}$ & - & 0.0 & 0.0 & 0.7 & 3.2 & 6.3 \\
\hline - Exit HE - Non-Completers ${ }^{\mathrm{a}}$ & - & 1.5 & 3.0 & 4.5 & 5.9 & 7.8 \\
\hline Completers $^{\mathrm{a}}$ & 0.0 & 0.1 & 2.1 & 5.7 & 8.7 & 10.8 \\
\hline - Completers (non-cumulative) & 0.0 & 0.1 & 2.0 & 3.6 & 3.1 & 2.1 \\
\hline Dropouts $^{\mathrm{a}}$ & 1.5 & 3.0 & 4.5 & 5.9 & 7.8 & - \\
\hline \multirow[t]{2}{*}{ - Dropouts (non-cumulative) } & 1.5 & 1.5 & 1.6 & 1.4 & 1.9 & - \\
\hline & \multicolumn{6}{|c|}{ Percentage of quintile 5 learners ${ }^{3}$} \\
\hline Enrolled & 34.0 & 36.3 & 35.7 & 32.4 & 24.9 & 17.9 \\
\hline - First-time entering & 34.0 & 6.4 & 2.2 & 1.1 & 0.9 & 0.6 \\
\hline - Non-entering undergraduate & - & 29.9 & 33.5 & 28.2 & 19.7 & 13.1 \\
\hline - Non-entering postgraduate & - & - & 0.0 & 3.1 & 4.3 & 4.2 \\
\hline Not enrolled & 66.0 & 63.7 & 64.3 & 67.6 & 75.1 & 82.1 \\
\hline -Non-participants & 66.0 & 59.6 & 57.4 & 56.2 & 55.4 & 54.8 \\
\hline - Exit HE - Completers ${ }^{\mathrm{a}}$ & - & 0.0 & 0.0 & 1.5 & 8.2 & 15.4 \\
\hline - Exit HE - Non-Completers ${ }^{\mathrm{a}}$ & - & 2.6 & 5.1 & 7.4 & 9.4 & 11.9 \\
\hline Completers $^{\mathrm{a}}$ & 0.0 & 0.1 & 6.3 & 15.3 & 21.5 & 25.2 \\
\hline - Completers (non-cumulative) & 0.0 & 0.1 & 6.2 & 9.0 & 6.2 & 3.7 \\
\hline Dropouts $^{\mathrm{a}}$ & 2.6 & 5.1 & 7.4 & 9.4 & 11.9 & - \\
\hline - Dropouts (non-cumulative) & 2.6 & 2.5 & 2.3 & 2.0 & 2.5 & - \\
\hline
\end{tabular}

NOTES: Estimates are expressed as a percentage of the number of learners from ${ }^{[1]}$ quintile $1-3$ schools, ${ }^{[2]}$ quintile 4 schools, and ${ }^{[3]}$ quintile 5 schools in the 2008 matric cohort. Completers refer to students who successfully completed undergraduate qualifications between 2009 and 2014 whereas dropouts refer to students who left university prior to 2014 without having completed any undergraduate qualification. [a]Numbers are cumulative. 
Table 9.3 summarises university access rates for the 2008 matric cohort as well as completion, dropout and retention rates for those learners from the 2008 matric cohort who entered undergraduate studies in 2009 , the year immediately following the writing of their matric examinations. This is especially important considering that the extent of delayed entry differs significantly by school quintile.

The table shows that there was virtually no difference in completion rates for learners from quintile 1-3 schools and those from quintile 4 schools among 2009 first-time entering undergraduate students from the 2008 matric cohort. The six-year completion rate for 2009 FTEN students from quintile 1-3 schools was 54.0\%, while $54.2 \%$ of their counterparts from quintile 4 completed undergraduate qualifications within six years of enrolling. The six-year completion rate for students from quintile 5 schools was substantially higher, at $62.9 \%$. Differences in dropout rates between 2009 FTEN students from different quintile schools were slightly more pronounced: $33.3 \%$ of 2009 FTEN students from quintile 1-3 schools had dropped out of university by the end of 2014 , while $30.8 \%$ of those from quintile 4 schools and $23.9 \%$ from quintile 5 schools did so.

Table 9.3: University access, completion, dropout, and retention rates (\%) for the 2008 matric cohort (2009 2014), by school quintile

\begin{tabular}{lcccccc}
\hline & $\begin{array}{c}\text { 1 year } \\
(2009)\end{array}$ & $\begin{array}{c}\text { 2 years } \\
(2010)\end{array}$ & $\begin{array}{c}\text { 3 years } \\
(2011)\end{array}$ & $\begin{array}{c}\text { 4 years } \\
(2012)\end{array}$ & $\begin{array}{c}\text { 5 years } \\
(2013)\end{array}$ & $\begin{array}{c}\text { 6 years } \\
(2014)\end{array}$ \\
\hline & \multicolumn{5}{c}{ Quintile 1 - 3 learners } \\
Access rate & 6.4 & 9.2 & 10.4 & 11.1 & 11.5 & 11.9 \\
Completion rate & 0.3 & 0.8 & 12.4 & 32.9 & 46.2 & 54.0 \\
Dropout rate & 10.9 & 17.0 & 22.5 & 27.6 & 33.3 & - \\
Retention rate $^{\mathbf{a}}$ & 83.6 & 77.5 & 60.5 & 36.3 & 20.4 & - \\
\hline & & \multicolumn{7}{c}{ Quintile 4 learners } \\
Access rate & 15.0 & 19.5 & 21.2 & 22.1 & 22.9 & 23.5 \\
Completion rate & 0.2 & 0.5 & 13.6 & 32.9 & 46.3 & 54.2 \\
Dropout rate & 10.1 & 15.5 & 20.6 & 25.1 & 30.8 & - \\
Retention rate & 84.2 & 78.4 & 60.8 & 38.8 & 22.7 & - \\
\hline & & \multicolumn{7}{c}{ Quintile 5 learners ${ }^{3}$} & & \\
Access rate & 34.0 & 40.4 & 42.6 & 43.8 & 44.6 & 45.2 \\
Completion rate & 0.1 & 0.3 & 18.4 & 41.5 & 55.2 & 62.9 \\
Dropout rate & 7.6 & 12.2 & 16.2 & 19.7 & 23.9 & - \\
Retention rate $^{\mathbf{a}}$ & 87.7 & 83.2 & 61.3 & 36.4 & 20.8 & - \\
\hline
\end{tabular}

NOTES: Access rates are calculated for learners from ${ }^{[1]}$ quintile $1-3$ schools, ${ }^{[2]}$ quintile 4 schools, and ${ }^{[3]}$ quintile 5 schools from the 2008 matric cohort while completion, dropout, and retention rates are only determined for students from this group who enrolled in undergraduate studies for the first time in 2009. Access, completion, and dropout rates are cumulative. ${ }^{[a]}$ The retention rate presented in the table reflects the percentage of students from the 2009 first-time entering group who had not yet completed any qualification, but were still enrolled in undergraduate studies in the following year.

Figure 9.2 summarises the findings presented in the Table 9.3. The figure shows that while there was some variation in university completion and dropout rates across all quintiles, the greatest difference was in the rates for students from quintile 5 schools and those from the rest of the schooling system.

Given the differences in matric performance between school quintiles, it is only to be expected that there will also be differences in the various university outcomes for learners from different school quintiles.. Figure 9.3 
replicates Figure 9.2, but only for learners from the 2008 matric cohort who achieved Bachelor passes in the NSC exams.

Figure 9.2: University access, completion, and dropout rates (\%) for the 2008 matric cohort (2009 - 2014), by school quintile

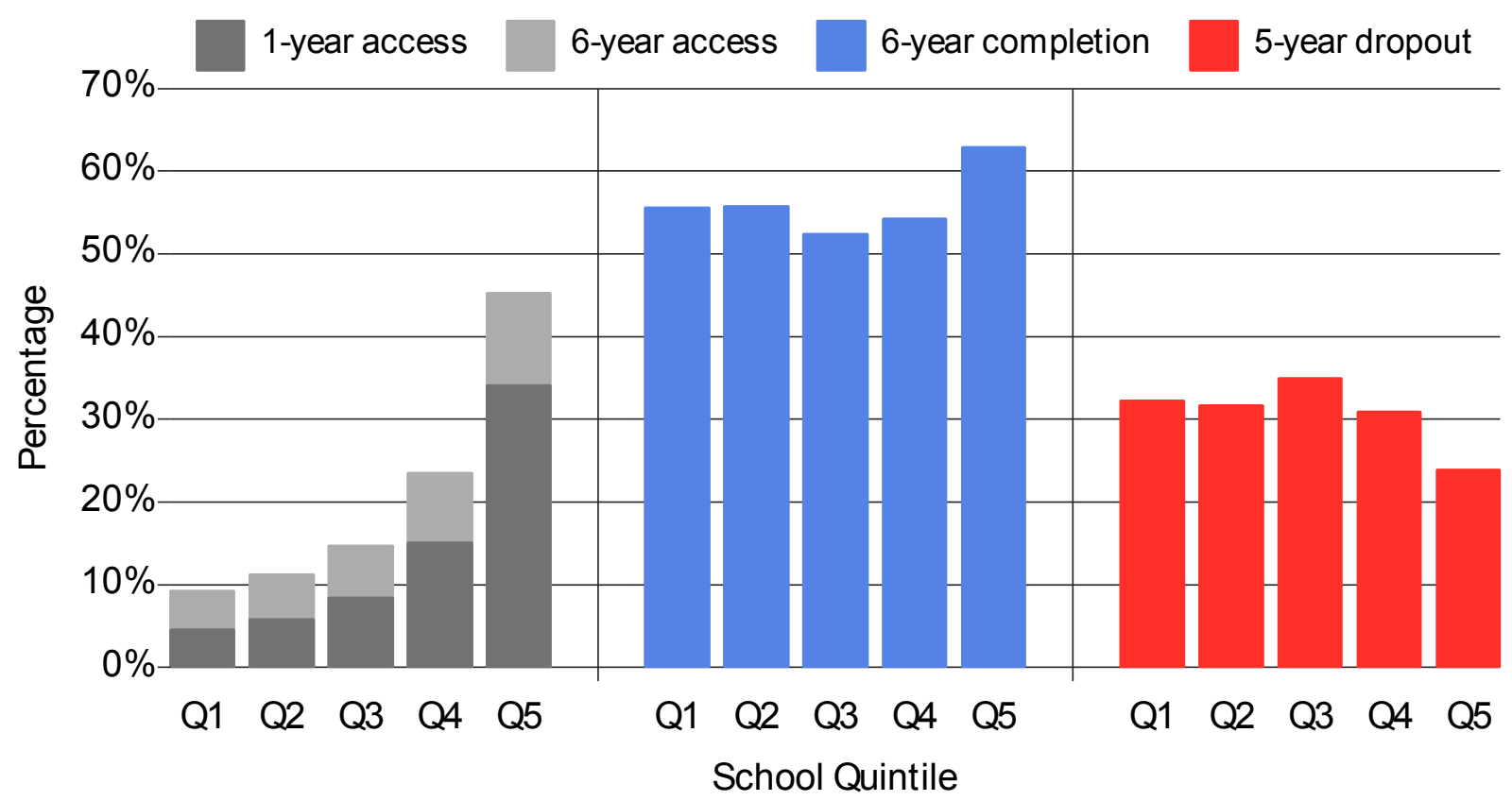

NOTES: Bars represent the 1-year access, 6-year access, 6-year completion, and 5-year dropout rates for learners from different school quintiles from the 2008 matric cohort. Completion and dropout rates are shown only for those learners from each NSC subgroup who enrolled in undergraduate studies for the first time in 2009. Access, completion, and dropout rates are cumulative.

Figure 9.3: University access, completion, and dropout rates (\%) for learners who achieved Bachelor passes in the 2008 NSC, by school quintile

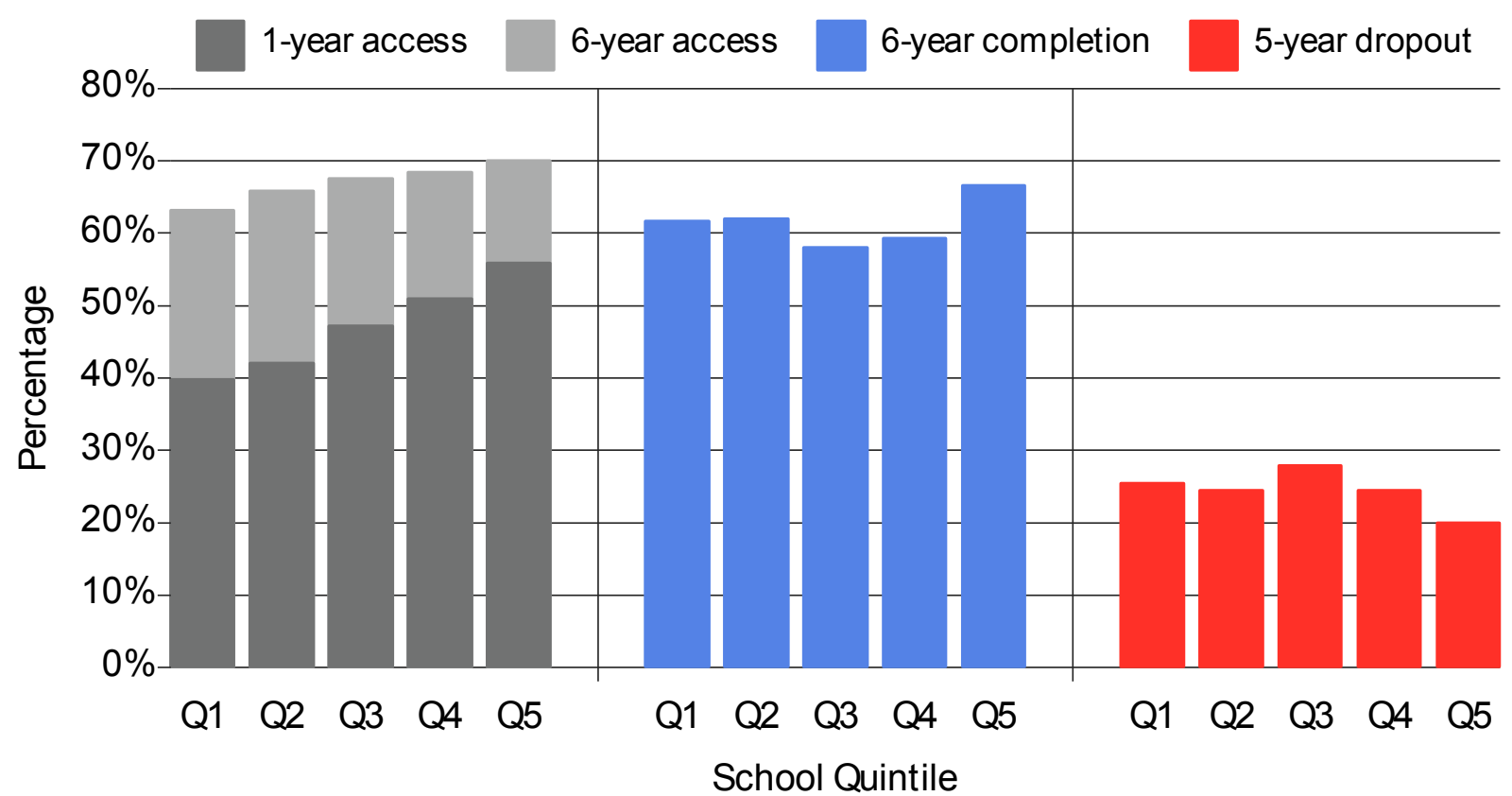

NOTES: Figures are only calculated for learners from the 2008 matric cohort who achieved Bachelor passes. Bars represent the 1-year access, 6-year access, 6-year completion, and 5-year dropout rates for each race group from the 2008 matric cohort. Completion and dropout rates are shown only for those learners from each NSC subgroup who enrolled in undergraduate studies for the first time in 2009. Access, completion, and dropout rates are cumulative.

The figure indicates that although the university access rates for Bachelor passers from quintile $1-4$ schools are much higher than they are when one considers all learners from these quintiles, they still remain lower by 
between 8 and 2 percentage points than the access rates for comparable learners from quintile 5 schools (numerical data is presented in Tables A19 and A20 in the Appendix). This is particularly true in the case of access to undergraduate degree programmes. Again, there is evidence that delayed university entry is more prevalent among learners from lower quintile schools, even when those learners achieve Bachelor passes. This can be seen from the fact that the 6-year access rate differentials across quintiles are much smaller than the 1year access rate differentials.

\section{2. University performance by school wealth index}

Though the official school poverty quintile provides some indication of learners' socio-economic backgrounds, it is unfortunately only a crude indicator. Using Census 2011 Small Area Layer data in conjunction with school location data, it was possible to construct a wealth index for each school among the 2008 matric cohort.

15 Though not necessarily reflecting the socio-economic status of all learners in a school, this index should provide a reasonably accurate description of the prevailing socio-economic status level in a school's immediate surroundings and may, therefore, provide a better indication of learners' socio-economic backgrounds than the school poverty quintile classification. In fact, Figure 9.4 shows that there is not just considerable variation in the wealth index within each school quintile, but also a fair amount of overlap in the wealth index between school quintiles.

Figure 9.4: Wealth index distributions for the 2008 matric cohort, by school quintile

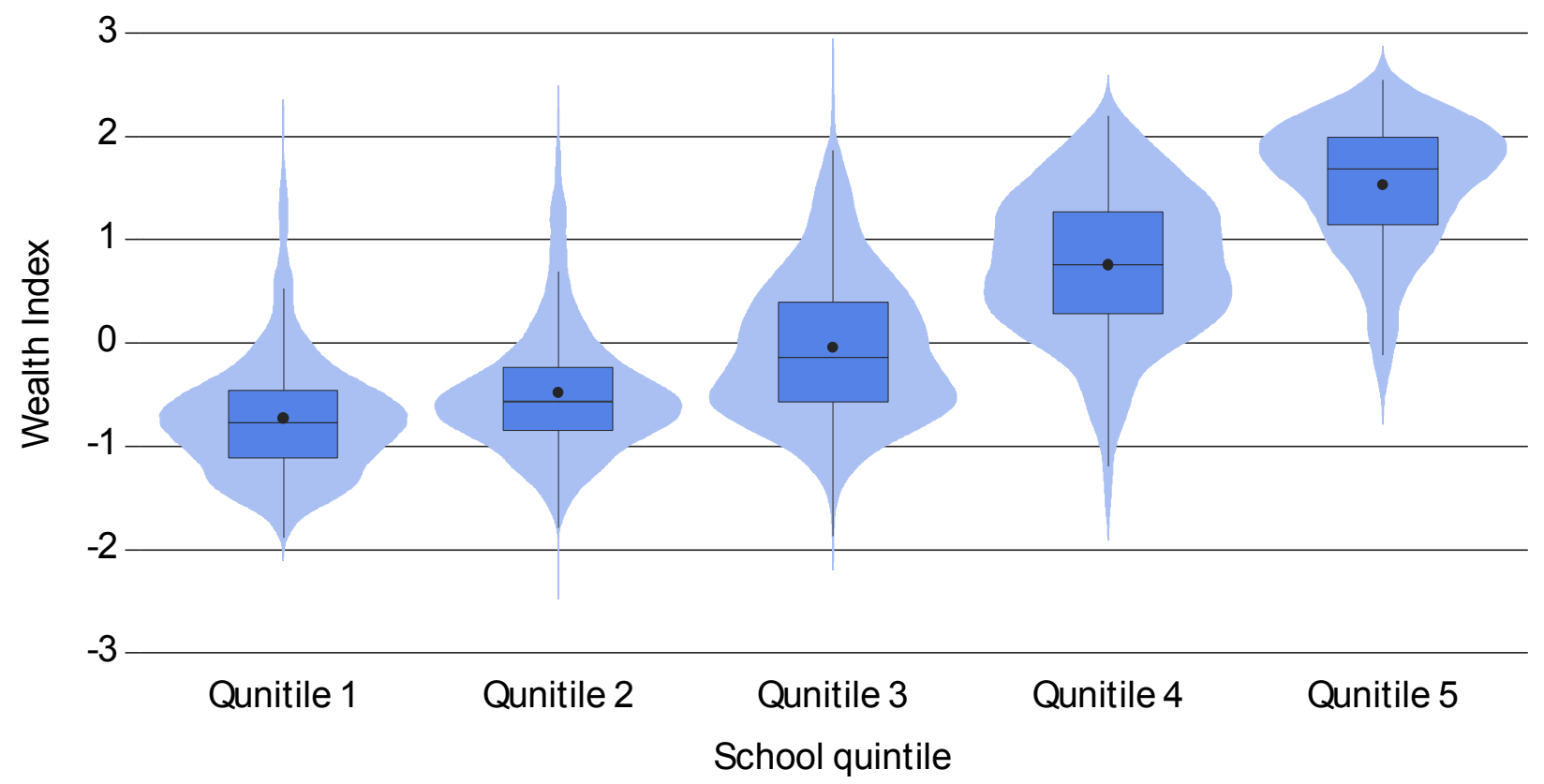

NOTES: Each violin plot shows the entire wealth index distribution for a particular poverty quintile of schools among 2008 matric cohort. The superimposed box plots furthermore the 25 th, 50 th, and 75 th percentiles of the wealth index, with each dot indicating the average level of the wealth index for the school quintile in question. Note that the sample includes only those schools attended by learners from the 2008 matric cohort.

Figure 9.5 illustrates the relationship between the expected 1-year access, 6-year access, 6-year completion, and 5-year dropout rates for learners from the 2008 matric cohort (2009 - 2014), and the school wealth index. The figure confirms that university access and completion are positively associated with the wealth index of

\footnotetext{
${ }^{15}$ See the appendix at the end of this report for more details about the methodology underlying the estimation of the school wealth index.
} 
the schools that learners attended. The figure further suggests that increases in the wealth index are more closely associated with increases in university access rates than completion or dropout rates. Nevertheless, it is clear that all three of these university outcomes varied across the wealth index distribution.

As was the case when looking at school quintiles, it is likely that the aforementioned associations between school wealth index and university outcomes may partially be due to differences in matric performance for learners from schools with different wealth indices. In fact, Figure 9.5 shows that the association between university access rates and the wealth index is very closely related to the association between the wealth index and the Bachelor pass rate among the 2008 matric cohort. In other words, it may be the case that the university access rate for the 2008 matric cohort increased with the wealth index, largely because learners from schools in wealthier areas performed better in the NSC than those from schools in poorer areas. Figure 9.6 therefore replicates Figure 9.5, but only for the learners from the cohort who achieved Bachelor passes.

Figure 9.5: Expected bachelor pass, access, completion, and dropout rates for learners from the 2008 matric cohort (2009-2014), by wealth index

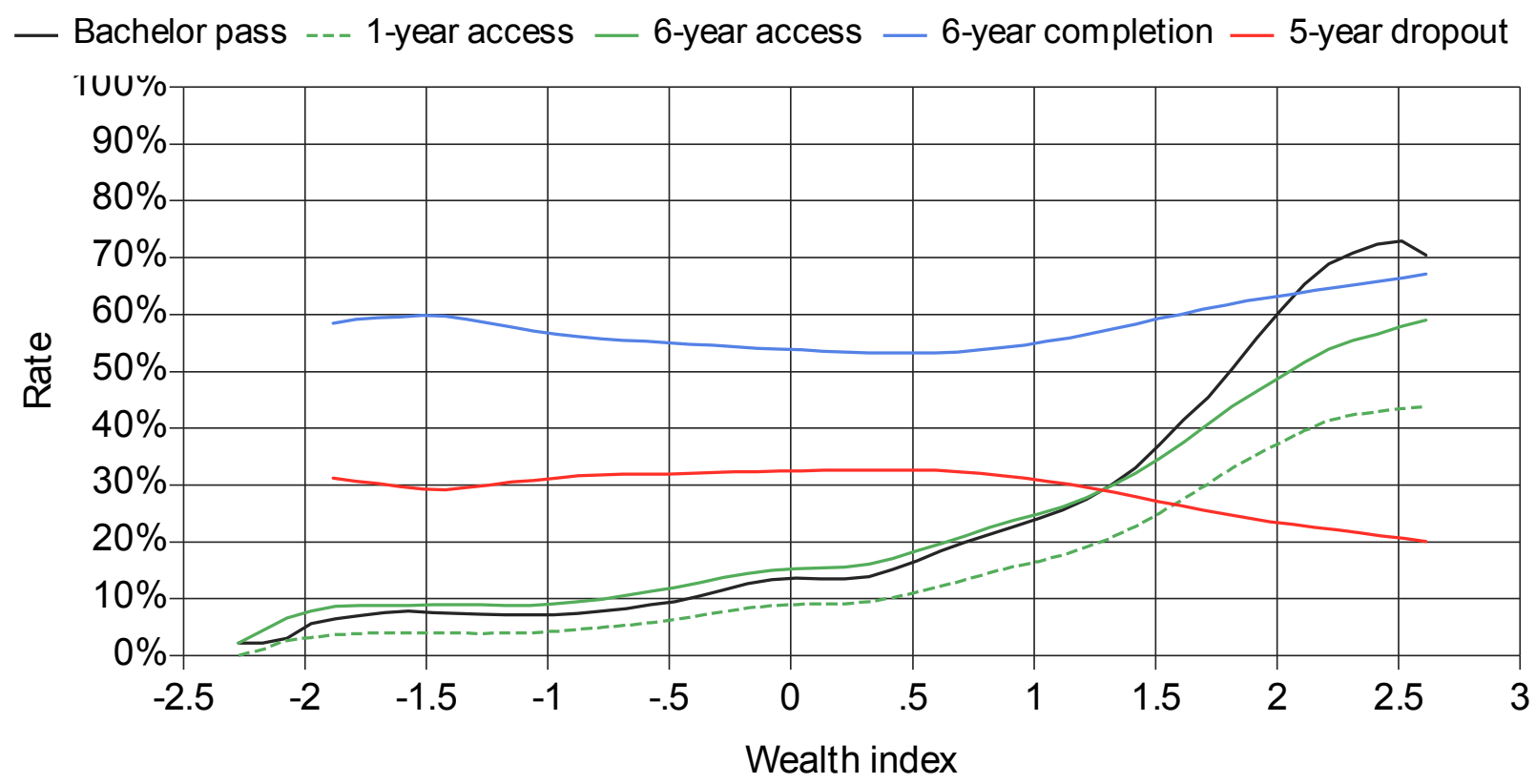

NOTES: Lines represent the expected bachelor pass, 6-year access, 1-year access, 6-year completion, and 5-year dropout rates conditional on the school wealth index for learners from the 2008 matric cohort and were drawn using local polynomial regression. The curves for completion and dropout are only drawn for those learners from the cohort who enrolled in undergraduate studies for the first time in 2009.

When considering the full 2008 matric cohort, the difference in the 6-year access rates for learners from schools in the poorest areas was around 50 percentage points lower than the access rate for learners from schools in the wealthiest areas. However, this difference is reduced to just 10 percentage points when considering only those learners who achieved Bachelor passes. Figure 9.6 thus shows that the association between the wealth index and university access rates for the 2008 matric cohort is much weaker when one considers learners who performed similarly in the NSC exams. 
Figure 9.6: Expected access, completion, and dropout rates for learners from the 2008 matric cohort who achieve Bachelor passes (2009-2014), by school wealth index

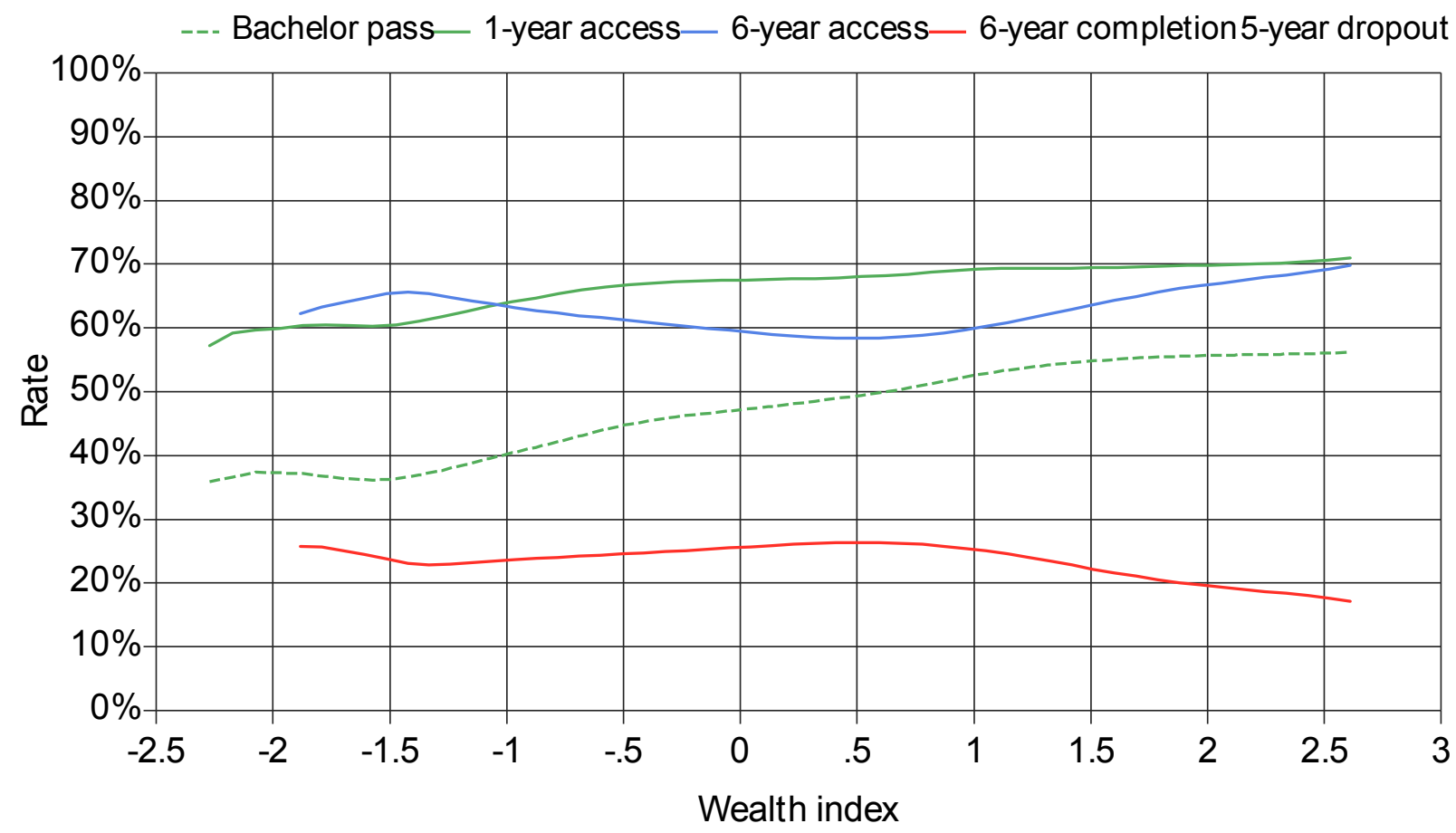

NOTES: Lines represent the expected bachelor pass, 6-year access, 1-year access, 6-year completion, and 5-year dropout rates conditional on the school wealth index for learners from the 2008 matric cohort who achieved Bachelor passes and were drawn using local polynomial regression. The curves for completion and dropout are only drawn for those learners from the cohort who enrolled in undergraduate studies for the first time in 2009.

\subsection{NSFAS awards and school quintile}

Table 9.4 provides information on NSFAS for university participants from the 2008 matric cohort during their first year of undergraduate studies. ${ }^{16}$ This group includes all learners who enrolled in undergraduate studies at some stage between 2009 and 2014. On the basis that NSFAS awards are supposed to be targeted toward needy students, the information is further disaggregated by school quintile. This is not meant to imply that there is a definite corollary between having attended a certain quintile school and one's own socio-economic status. However, it is reasonable to expect that, on average, learners from lower quintile schools will have lower levels of socio-economic status than those from higher quintile schools.

Table 9.4 shows that of the 112402 learners from the 2008 matric cohort who enrolled in undergraduate programmes between 2009 and 2014, 26.7\% received NSFAS awards during their first year of studies. As expected, there appears to be a fairly strong association between school quintile and the likelihood of having received a NSFAS award: nearly half of students from quintile 1 and 2 schools received NSFAS awards in their first year of studies ( $46.7 \%$ and $45.8 \%$, respectively). By comparison, only $11.1 \%$ of learners from quintile 5 schools followed suit. It is also evident that fairly large numbers of students from the lower quintile schools applied for NSFAS awards in their first year of studies, but were either not deemed eligible for those awards or were turned down for other, unknown reasons.

\footnotetext{
16 The HEMIS data used in this study contains only limited information on NSFAS, noting only whether students applied for, were eligible for, and/or received NSFAS loans in a particular year of study.
} 
Table 9.3: NSFAS award recipiency in first year of undergraduate studies for learners from the 2008 matric cohort, by school quintile

\begin{tabular}{lrrrrrr}
\hline & \multicolumn{1}{c}{ All } & Quintile 1 & Quintile 2 & Quintile 3 & Quintile 4 & Quintile 5 \\
\cline { 2 - 6 } Students & 112402 & 9882 & 14177 & 19919 & 16727 & 43453 \\
column \% & 100.0 & 100.0 & 100.0 & 100.0 & 100.0 & 100.0 \\
Received & 29963 & 4615 & 6493 & 8095 & 4687 & 4810 \\
\hline column \% & 26.7 & 46.7 & 45.8 & 40.6 & 28.0 & 11.1 \\
Did not & 82439 & 5267 & 7684 & 11824 & 12040 & 38643 \\
column \% & 73.3 & 53.3 & 54.2 & 59.4 & 72.0 & 88.9 \\
- Applied & 3172 & 446 & 697 & 707 & 465 & 681 \\
column \% & 2.8 & 4.5 & 4.9 & 3.5 & 2.8 & 1.6 \\
- Applied, & 8027 & 931 & 1289 & 1770 & 1260 & 2274 \\
- column \% & 7.1 & 9.4 & 9.1 & 8.9 & 7.5 & 5.2 \\
- Did not & 71240 & 3890 & 5698 & 9347 & 10315 & 35688 \\
column \% & 63.4 & 39.4 & 40.2 & 46.9 & 61.7 & 82.1 \\
\hline
\end{tabular}

NOTES: Figures are only calculated for learners from the 2008 matric cohort who enrolled in undergraduate studies at some stage between 2009 and 2014. Completion and dropout rates are shown only for those learners from each cohort subgroup who enrolled in undergraduate studies for the first time in 2009. ${ }^{[a]}$ The HEMIS data groups students who did not get NSFAS awards, students who did not apply for NSFAS awards, and students for whom no information about NSFAS recipiency was available in one category. It is thus possible that the "Did not apply" group may include some individuals who did actually apply for NSFAS awards and even some who may have been awarded NSFAS awards.

Figure 9.7: University completion and dropout rates (\%) for learners from quintile $1-3$ schools in the 2008 matric cohort by NSFAS recipiency in first year of undergraduate studies, $(2009-2014)$

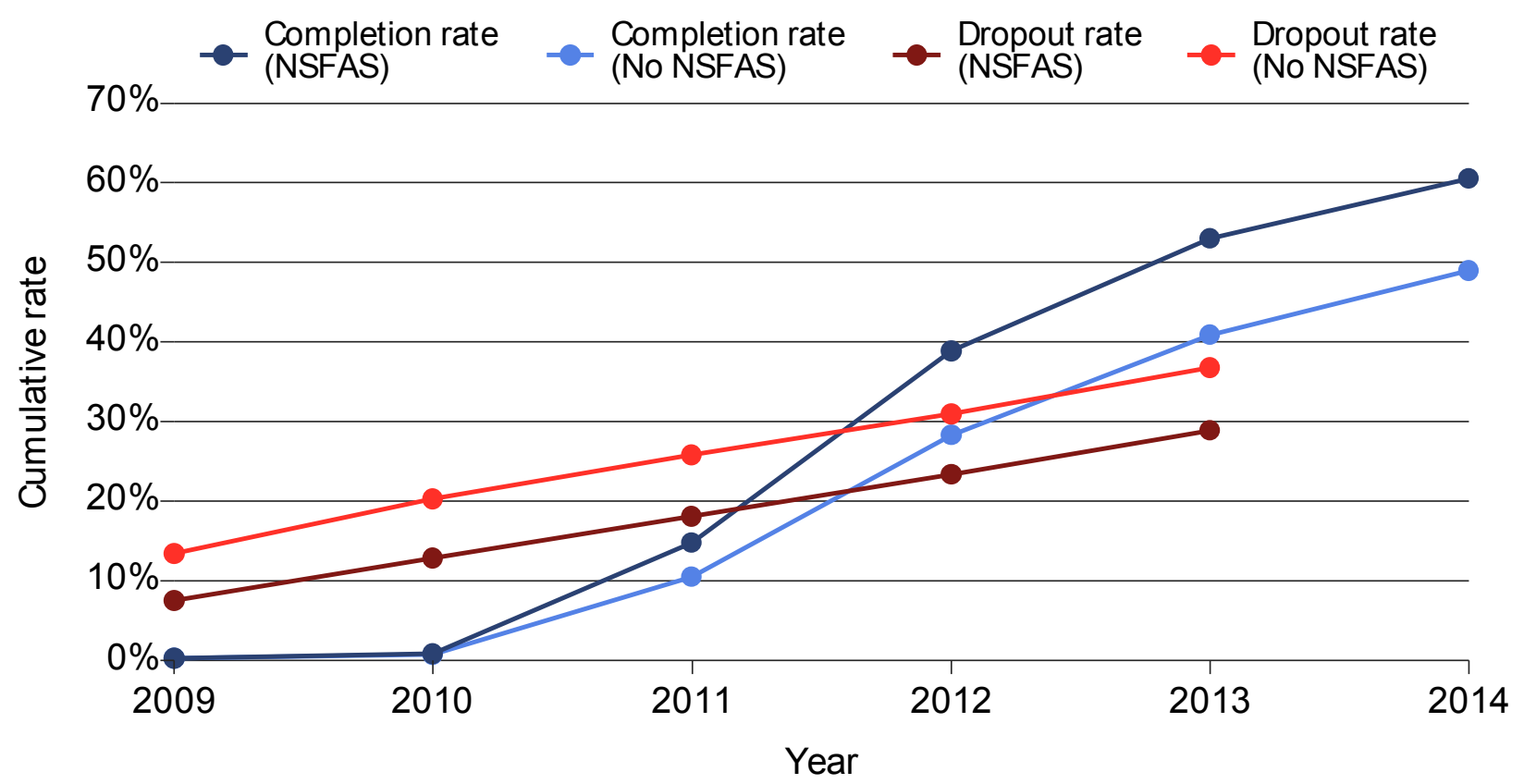

NOTES: Figures are calculated only for those learners from the 2008 matric cohort who attended quintile 1 - 3 school and who enrolled in undergraduate studies for the first time in 2009. Completion and dropout rates are cumulative. NSFAS refers to students from this group who received NSFAS awards in their first year of studies.

Figure 9.7 suggests that quintile 1 - 3 learners who received NSFAS awards in their first year of studies performed better with regard to programme throughput than those learners who did not. This can be seen in the clear difference in completion rates among NSFAS and non-NSFAS students as well as the higher dropout rates for non-NSFAS students than for those with NSFAS loans. However, this does not necessarily imply any causal linkage between receiving a NSFAS loan and programme completion or retention. It is important to 
remember, for example, that NSFAS awards are supposed to be awarded partly on the basis of academic merit. It is therefore quite plausible that, on average, learners who received NSFAS loans would have performed better than those who did not, regardless of whether they were awarded the loans.

\section{4. School performance}

Figure 9.8 shows average university access, completion, and dropout rates for learners from the 2008 matric cohort by the Bachelor pass rate of the schools that they attended.

It is clear from the figure that learners' university performance is associated with the performance of the secondary school they attended, as measured by the percentage of learners in the school who achieved Bachelor passes. University access and completion rates are clearly positively associated with school performance, while dropout rates are negatively associated with school performance. In other words, learners from schools with proportionally more Bachelor passes tend to perform better in terms of university completion and dropout rates.

Another way of measuring school performance is by the average matric grade achieved by learners attending a particular school. Figure 9.9 presents university access, dropout and completion rates by the average matric performance of secondary schools. Unsurprisingly, the same general patterns between university performance and school performance can be observed when school performance is measured by average matric performance as when it is measured by proportion of Bachelor passes.

Figure 9.8: Expected access, completion, and dropout rates for learners from the 2008 matric cohort by Bachelor pass rate in learner's school (\%) (2009 - 2014)

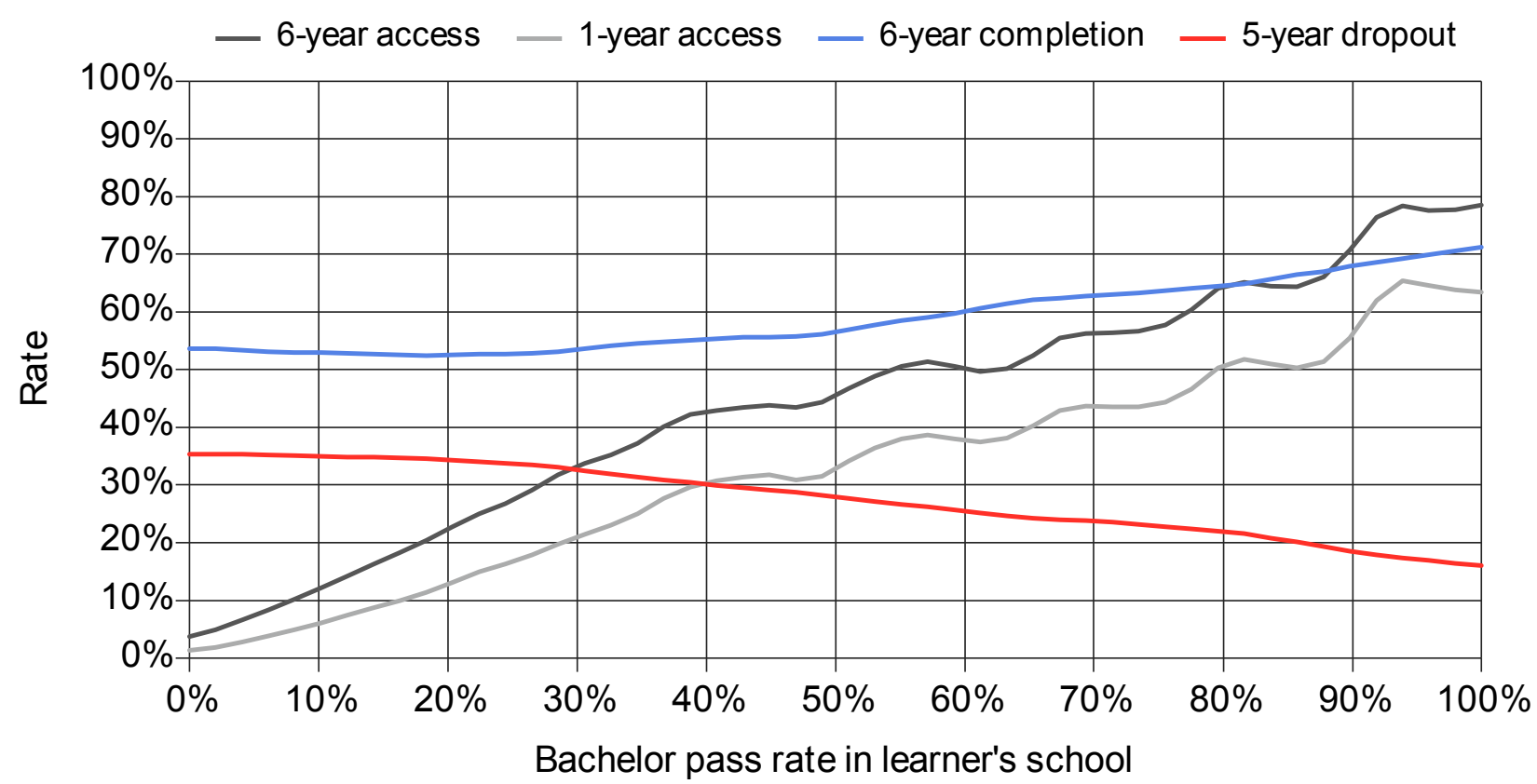

NOTES: Lines represent the expected 6-year access, 1-year access, 6-year completion, and 5-year dropout rates conditional on the Bachelor pass rate in a learner's school for learners from the 2008 matric cohort and were drawn using local polynomial regression. The curves for completion and dropout are only drawn for those learners from the cohort who enrolled in undergraduate studies for the first time in 2009.

This clear association between school performance and expected university outcomes echoes the results of Van Broekhuizen (2016: 52) and, as he argues, implies that differences in quality of schooling are likely to 
perpetuate inequalities of educational opportunities, including opportunities for access to and success through the university system. Lorenz curves and gini coefficients can be used to investigate the extent of these inequalities. Figure 9.10 shows the distribution of matric candidates, Bachelor passes, university participants, and university completers among the 6413 schools in the 2008 matric cohort.

Figure 9.9: Expected access, completion, and dropout rates for learners from the 2008 matric cohort by overall matric average achievement in learner's school (\%) (2009 - 2014)

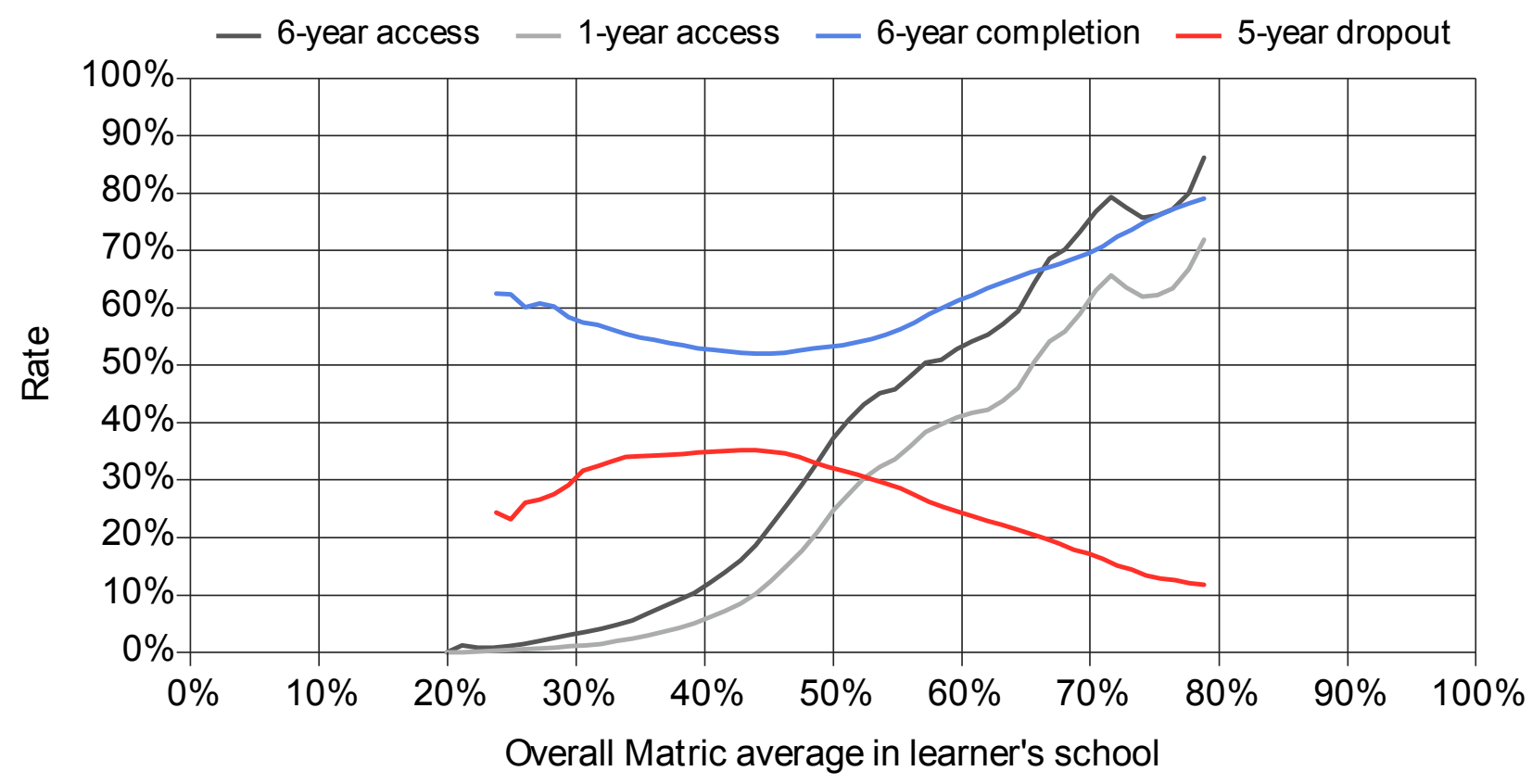

NOTES: Lines represent the expected 6-year access, 1-year access, 6-year completion, and 5-year dropout rates conditional on the overall Matric average achieved in a learner's school for learners from the 2008 matric cohort and were drawn using local polynomial regression. The curves for completion and dropout are only drawn for those learners from the cohort who enrolled in undergraduate studies for the first time in 2009.

Figure 9.10: Distribution of NSC candidates, Bachelor passes, university participants, and university completers among schools in the 2008 matric cohort

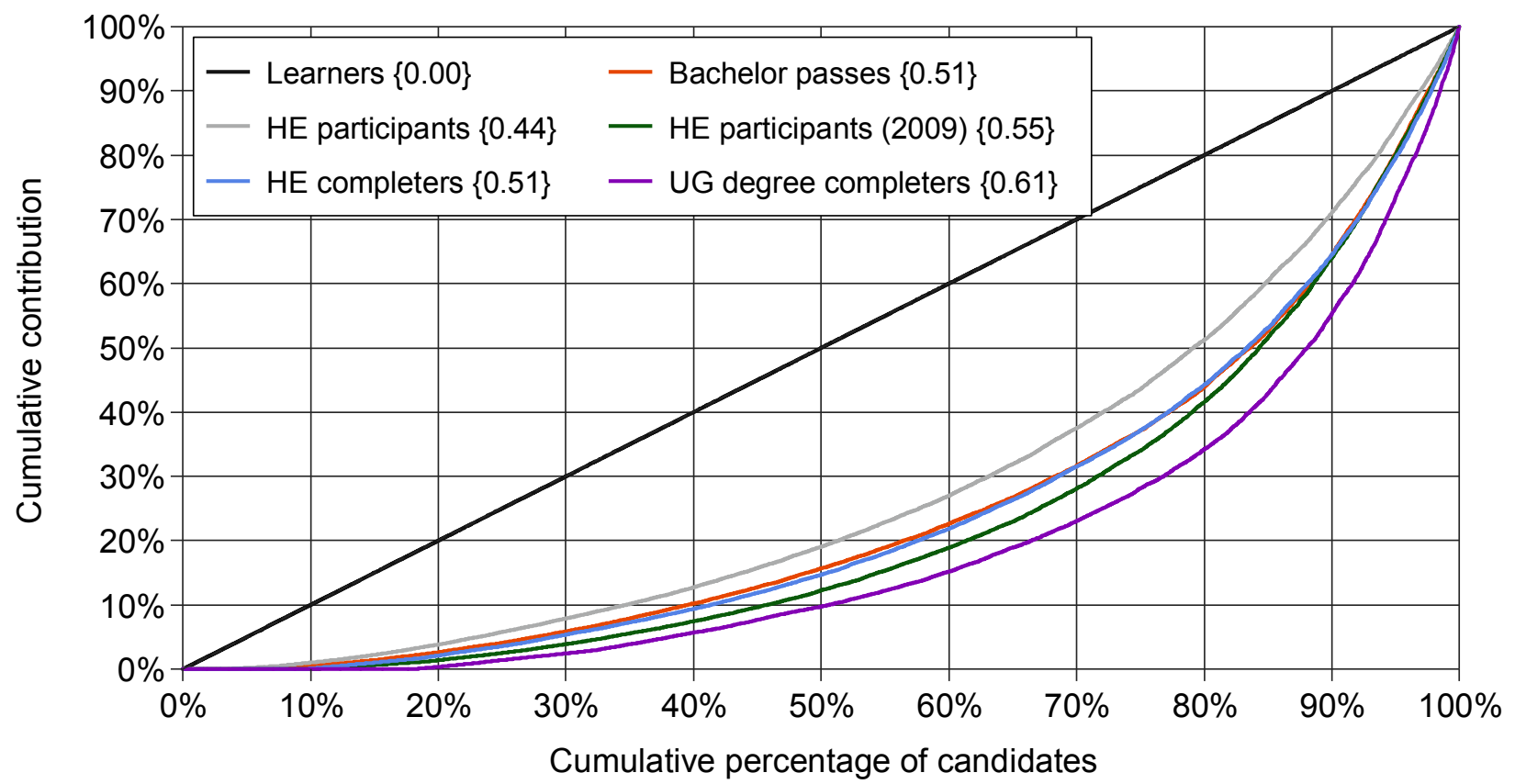

NOTES: Lines denote the cumulative percentage of candidates in the 2008 matric cohort that accounted for a given cumulative percentage of NSC candidates, NSC Bachelor passes, HE participants, and HE completers in the cohort. Candidates are grouped by school, with schools being ranked from smallest to largest based on their contributions to each of the outcomes under consideration. The 45-degree line denotes the line of perfect equality. Figures in the curly braces reflect the estimates gini coefficients associated with the respective Lorenz curves. 
The extent of inequality in the distribution of matric performance and university performance between schools is striking. The figure shows, for example, that the best-performing $40 \%$ of schools in the cohort accounted for around $78 \%$ of all Bachelor passes. Even more worryingly, $85 \%$ of undergraduate degree completers between 2009 and 2014 from the 2008 matric cohort came from just $40 \%$ of schools in the country. It therefore appears that there is a small number of well-performing schools which delivered the bulk of successful undergraduates from the 2008 matric cohort.

\section{Multivariate analysis}

\subsection{Racial differentials in university access, completion, conversion, and dropout}

The descriptive analysis on the association between race and university flows for the 2008 matric cohort showed that matriculants from different race groups not only have vastly different levels of matric achievement, on average, but that they also subsequently face vastly different expected outcomes in terms of access to and success at university. Given the primacy of matric achievement in determining university access, and indications that matric achievement may also be predictive of university throughput and retention, a central objective of this chapter is to determine to what extent racial differentials in university access, completion, and dropout can be explained by differences in average their matric performance.

Table 10.1: Estimated racial differentials in university access, completion, conversion, and dropout rates for the 2008 matric cohort, without further control variables

\begin{tabular}{lccccc}
\hline & 1-year access & 6-year access & $\begin{array}{c}\text { 6-year } \\
\text { conversion }\end{array}$ & $\begin{array}{c}\text { 6-year } \\
\text { completion }\end{array}$ & 5-year dropout \\
\cline { 2 - 6 } Coloured & $0.040^{* * *}$ & $0.032 * * *$ & $0.018 * * *$ & 0.003 & $0.018^{* * *}$ \\
Asian & $0.263 * * *$ & $0.267 * * *$ & $0.168 * * *$ & $0.086 * * *$ & $-0.092 * * *$ \\
White & $0.256^{* * *}$ & $0.308^{* * *}$ & $0.227 * * *$ & $0.181 * * *$ & $-0.140 * * *$ \\
\hline $\mathrm{N}$ & 560921 & 560921 & 560921 & 72537 & 72537 \\
Adjusted $\mathrm{R}^{2}$ & 0.056 & 0.052 & 0.048 & 0.023 & 0.018 \\
\hline
\end{tabular}

NOTES: All linear probability models (LPM) were estimated via Ordinary Least Squares (OLS). * Significant at the $10 \%$ level ** Significant at the $5 \%$ level $* * *$ Significant at the $1 \%$ level. Significance levels are based on robust standard errors. The 1-year access, 6 -year access, and 6 -year conversion rate samples include all matriculants from the 2008 matric cohort. The 6-year completion and 5-year dropout rate samples include only those matriculants from the 2008 matric cohort who enrolled in undergraduate studies for the first time in 2009. Reference categories are as follows: Race (Black).

Tables 10.1 to 10.3 show the results from three sets of rudimentary linear probability regression models (LPM) of racial differentials in university access, completion, conversion ${ }^{17}$, and dropout for matriculants from the 2008 national matric cohort, before and after taking matric performance into account. Table 10.1 reports the size and significance of the association between race and university outcomes. Since 'black' is the reference category, these coefficients represent the difference in university outcomes between matriculants of other races

\footnotetext{
17 In this report, the 'conversion rate' reflects the cumulative percentage of learners from the 2008 matric cohort who completed undergraduate qualifications within a specific years of writing the NSC exams, regardless of when they entered or even if they ever entered undergraduate studies. This rate gives an indication of the extent to which learners were able to convert writing the NSC exams into an opportunity to subsequently complete undergraduate qualifications. See the 'Important definitions and caveats' section in the Appendix for other definitions used in this report.
} 
listed and black African matriculants. For example, the coefficient on 1-year access for coloured matriculants means coloured matriculants are 4 percentage points more likely than black matriculants to access university in the year immediately succeeding matric. It is clear from Table 10.1 that there are significant differences in university access, throughput, and retention between race groups. White and Asian matriculants from the cohort are not only significantly more likely to access university than black and coloured matriculants, but those who entered undergraduate study in 2009 are also significantly more likely to graduate within six years and less likely to drop out within five years.

Table 10. 2 also includes controls for the pass results achieved in the 2008 matric examinations. The magnitudes and direction of the differences in access, completion, conversion, and dropout rate between race groups change significantly once the matric pass result is taken into account. White matriculants from the 2008 matric cohort were, on average, less likely to access university within 1 to 6 years of writing the matric examinations than their black counterparts, once differences in the types of matric passes achieved have been taken into account. This differs from Table 10.1, where matric pass types were not taken into account. In Table 10.1 white matriculants were 25.6 percentage points more likely to access university in the year following matric than their black counterparts when no other factors are controlled for. This changes in Table 10.2 to white matriculants being 4.1 percentage points less likely to access university in the year following matric when the effect of different matric pass types is controlled for. This suggests that the differences in university access between white and black matriculants are largely driven by differences in the matric achievement of white and black matriculants. White matriculants performed much better in matric, on average, than black matriculants, and it is this difference which largely accounts for white matriculants being more likely than black matriculants to access university. Similarly, the coefficients for Asian matriculants imply that they too are more likely to attend university than black matriculants largely because of their better performance in matric.

The differences in completion rates reported in Table 10.2 suggest that white and Asian matriculants were still more likely to complete their undergraduate programmes within six years of entering undergraduate study than black matriculants, even after controlling for pass type. This suggests that while differences in university access is largely driven by matric achievement, this is not in equal measure the case for completion rates. Black and white matriculants do not face the same probability of completing an undergraduate qualification within six years, even when they achieved the same type of matric pass. Nevertheless, the association between race and dropout rate does become smaller when controlling for type of matric pass, thus implying that at least part of the variation in dropout rates between matriculants from different races is due to racial differences in matric performance. 
Table 10.2: Estimated racial differentials in university access, completion, conversion, and dropout rates for the 2008 matric cohort after controlling for matric pass result

\begin{tabular}{|c|c|c|c|c|c|}
\hline \multirow[b]{2}{*}{ Coloured } & \multirow{2}{*}{$\begin{array}{r}\text { 1-year access } \\
-0.028^{* * *}\end{array}$} & \multirow{2}{*}{$\begin{array}{r}\text { 6-year access } \\
-0.072^{* * *}\end{array}$} & \multicolumn{2}{|c|}{ 6-year conversion 6-year completion } & \multirow{2}{*}{$\begin{array}{r}\text { 5-year dropout } \\
0.047^{* * *}\end{array}$} \\
\hline & & & $-0.033 * * *$ & $-0.021 * * *$ & \\
\hline Asian & $0.050 * * *$ & $-0.025 * * *$ & $0.008 * * *$ & $0.038 * * *$ & $-0.033^{* * *}$ \\
\hline White & $-0.041 * * *$ & $-0.097 * * *$ & $0.004 * *$ & $0.128 * * *$ & $-0.074 * * *$ \\
\hline Higher Certificate & $0.017 * * *$ & $0.055 * * *$ & $0.014 * * *$ & 0.001 & 0.014 \\
\hline Diploma & $0.110 * * *$ & $0.236 * * *$ & $0.080 * * *$ & 0.104 & -0.121 \\
\hline Bachelor & $0.521 * * *$ & $0.714 * * *$ & $0.391 * * *$ & $0.296^{* *}$ & $-0.354 * *$ \\
\hline $\mathrm{N}$ & 560878 & 560878 & 560878 & 72537 & 72537 \\
\hline Adjusted $\mathrm{R}^{2}$ & 0.339 & 0.415 & 0.249 & 0.050 & 0.066 \\
\hline
\end{tabular}

Table 10.3 also replicates Table 10.1, but this time average matric achievement is used as a measure of individual matric performance, instead of the type of matric pass achieved. When this measure of matric achievement is used, the coefficient on 'white' decreases by a further 5.3 percentage points, which suggests an even stronger association between matric performance and one-year access than shown in Table 10.2. The implication of this coefficient is that for matriculants who performed similarly in matric, white matriculants were 9.4 percentage points less likely to access university within a year of graduating than black matriculants. In addition, white matriculants who did enroll in university in 2009 were 4.9 percentage points more likely to drop out within five years of enrolling in university than their black counterparts who achieved the same average mark in matric. Table 10.3 also shows that white matriculants were statistically no more likely than black matriculants to complete an undergraduate qualification within six years of enrolling in university, after controlling for the effect of average matric mark. Since the matric average mark is a better measure of matric performance than type of pass achieved, these estimates suggest individual matric performance drives even more of the association between race and university outcomes than can be inferred from the estimates in Table 10.2 .

Similar patterns are observed when comparing Asian and coloured matriculants with black matriculants. The size of the associations between race and 1-year access falls notably in comparison to the estimates in Table 10.2 when using matric average achievement as a control for matric performance, suggesting once more that matric achievement drives even more of the association between race and university access than is suggested by the estimates in Table 10.2.

These findings suggest that racial differentials in university access, completion, conversion, and dropout in South Africa can be explained away almost entirely by differences in matric achievement.

These results confirm that racial differentials in university outcomes are most likely explained by racial differentials in scholastic achievement, as is suggested in the descriptive analysis of this report. A comparison of the estimates in Tables 10.2 and 10.3 shows that matric average marks are more predictive of university 
outcomes than the type of matric pass achieved. The fact that a more direct measure of matric achievement, namely matric average mark, is more predictive of university outcomes than a less direct measure such as matric pass type, provides support for the notion that achievement in matric is indicative of a matriculant's chances of university access and success.

Table 10.3: Estimated racial differentials in university access, completion, conversion, and dropout rates for the 2008 matric cohort after controlling for matric average achievement

\begin{tabular}{|c|c|c|c|c|c|}
\hline & 1-year access & 6-year access & 6-year conversion & $\begin{array}{c}\text { 6-year } \\
\text { completion }\end{array}$ & 5-year dropout \\
\hline Coloured & $-0.043 * * *$ & $-0.079 * * *$ & $-0.047 * * *$ & $-0.038 * * *$ & $0.059 * * *$ \\
\hline Asian & $0.024 * * *$ & $-0.053 * * *$ & $-0.020 * * *$ & $-0.067 * * *$ & $0.062 * * *$ \\
\hline White & $-0.094 * * *$ & $-0.161 * * *$ & $-0.048 * * *$ & -0.005 & $0.049 * * *$ \\
\hline Matric average $(\%)$ & $0.015 * * *$ & $0.021 * * *$ & $0.012 * * *$ & $0.014 * * *$ & $-0.014 * * *$ \\
\hline $\bar{N}$ & 560305 & 560305 & 560305 & 72526 & 72526 \\
\hline Adjusted R2 & 0.325 & 0.392 & 0.257 & 0.095 & 0.107 \\
\hline
\end{tabular}

\subsection{Correlates of university access, completion, conversion, and dropout}

In light of the discussion above, it is possible to categorise most of the pre-university correlates that are available in the data into one of three groups: (1) demographic factors such as age, gender, and race; (2) matriculant-level matric performance factors, including the type of pass achieved, the matric average achieved, specific subjects offered in the matric examinations and the performance in those subjects; and (3) school type and school-level matric performance factors, including school quintile, school wealth index, bachelor pass rate, and province of location. All of these determinants potentially could have had an important bearing on the observed university outcomes for matriculants from the 2008 matric cohort.

The primary objective of the multivariate analysis is to identify the partial correlations between the various pre-entry and university-specific and programme-specific correlates and 1-year access, 6-year access, 6-year conversion, 6-year completion, and 5-year dropout rates among the 2008 matric cohort. To this end, an attempt was made to include as many critical covariates in the linear probability models as was feasible, while still maintaining relative parsimony and representativeness. The set of variables included in the model was ultimately subject to limitations imposed by the data used and, consequently, is by no means exhaustive. Notably absent from the models are indicators of home background (such as parental education and household structure) and measures of an individual's socio-economics status (for example personal income, household income and labour market status). Unfortunately, neither the matric data, nor the version of the HEMIS data used in this study contains any information on matriculant home background or individual socio-economic status. 


\subsubsection{Demographics}

Table 10.4 presents results from the full linear probability model for modelling university access, completion, conversion, and dropout rates among matriculants from the 2008 matric cohort for the period 2009 - 2014. The results for each main set of correlates in the regressions are discussed in turn below.

In terms of age, overage matriculants from the 2008 matric cohort were, on average, still less likely to access university, less likely to complete university programmes, and more likely to drop out of university than appropriate age matriculants, even once other factors have been taken into account.

Turning attention to gender, female matriculants from the cohort were, on average and with all else held constant, statistically significantly more likely to access university over the short or long term than their male counterparts. Perhaps even more notably, female matriculants from the cohort who entered undergraduate studies in 2009 had a much higher (7.4 percentage points) likelihood of completing their studies than males who did the same. Similarly, the 5 -year dropout rate for female students from this group was 5.8 percentage points lower, on average, than the estimated rates for their male counterparts. This provides further evidence that female students generally perform better in terms of throughput than males (Soudien, 2010:14). Ultimately, female matriculants were slightly more likely to have acquired undergraduate qualifications within six years of writing the 2008 matric examinations than the male matriculants from the cohort.

When considering racial differences in university outcomes, Table 10.4 shows that once differences in matric performance, in school characteristics and in school performance have been taken into account, black matriculants from the 2008 matric cohort were significantly more likely to enrol in university than matriculants from all three of the other race groups. The estimates suggest that the 6-year access rates for coloured and Asian matrics were respectively 9.7 and 13.9 percentage points lower than the access rate for black matriculants, once other factors have been controlled for. The greatest difference in terms of conditional access rates was clearly between black and white matriculants: the 6-year access rate for white matriculants was 23.2 percentage points lower than it was for black matriculants from the cohort, after taking into account all other inter-group differences. Once again, though, this has to be seen against a background where a far smaller proportion of black learners reach matric or perform well enough to enter universities.

These estimates in the full model specification provide compelling evidence that differences in university access between race groups are largely driven by underlying differences in matric performance and, to a lesser extent, by school characteristics and school performance. A comparison between Table 10.3 and Table 10.4 suggests that it is mainly differences in matriculant matric performance, rather than differences in school type and school performance, that explain why Asian and white matriculants from the cohort had significantly higher unconditional 1-year and 6-year university access rates than coloured or black matriculants. In other words, Asian and white matriculants generally performed better in matric than their black and coloured counterparts, and it is largely this which explains the greater university access of white and Asian matriculants.

The results from the LPM for 5-year dropout shows that coloured and Asian students among the 2009 FTEN undergraduate intake from the 2008 matric cohort were significantly more likely to drop out of university 
within 5 years than black students, while the dropout rate of white students was not statistically significantly different from that of black students. Once again, as shown in Table 10.1, this suggests the differences in dropout rates observed between black and white matriculants are most likely due to differences in matric performance and school-level characteristics between black and white matriculants.

The estimates in Table 10.4 further show that even after controlling for a range of pre-entry and universitylevel correlates, white matriculants who entered university in 2009 were still significantly more likely to finish their undergraduate studies within six years than coloured, Asian and, in particular, black students. Specifically, a large gap ( 8 percentage points) in the 6-year completion rates of black and white matriculants respectively is discernable, even when controlling for matric performance, school type and school performance, as well as university-specific and programme-specific factors. In other words, when comparing a black and white matriculant from the 2008 matric cohort who attended high schools with the same matric average mark as well as wealth index, and where both enrolled for the same programme at the same university, the white matriculant would be more likely to complete her undergraduate programme and be no more likely to drop out of university within six years of enrolment than the black matriculant. This suggests that there are other factors, which are not included in the model specification, which are correlated with race and impact on the university throughput of matriculants.

\subsubsection{Matric performance}

Table 10.4 shows that 2008 matric candidates who passed the 2008 matric examinations with Bachelor passes were considerably (38.3 percentage points) more likely to enrol in university between 2009 and 2014 than matriculants who achieved Higher Certificate passes, even after other measures of matric performance, as well as school and demographic factors, are accounted for. The 6-year conversion rate for Bachelor passers from the cohort was also significantly higher than for other matriculants.

The coefficients on the matric average achievement variable are statistically significant and economically meaningful in terms of all five of the university outcome measures considered. The results suggest that a percentage point increase in a matriculant's matric average mark is associated with approximately a 1 percentage point increase in the 1-year access rate, the 6-year access rate, the 6-year conversion rate, and the 6-year completion rate, and a similar decrease in the 5-year dropout rate, on average, while holding all other factors constant.

This is a major finding. Since university entry is, to a large extent, explicitly based on matric performance, it would be reasonable to expect that a significant part of the association between matric performance and undergraduate programme completion or university dropout would already be captured by selection into university. The mere fact that selection into university reduces the heterogeneity in academic ability among students means that one should expect the association between the matric average and completion or dropout to be weaker than, for example, the association between the matric average and university access . The fact that this is observed not to be the case provides strong support for the notion that matric performance is extremely important in explaining both university access and success - even after controlling for schooling type. 
The last set of results regarding matriculant performance in Table 10.4 pertain to the specific gateway subjects that matriculants offered in the 2008 matric examinations. In general, matriculants who offered Mathematics and/or English Home language rather than Mathematical Literacy and/or English First Additional Language as subjects were statistically significantly more likely to access university and complete undergraduate programmes, and less likely to drop out of university than matriculants who did not offer those subjects, conditional on the other variables included in the regression models. This suggests that participation in Mathematics and English Home Language has a positive association with university outcomes that is independent of performance in those subjects and even matric achievement overall. Note again that this does not imply causality. Instead, participation in these subjects may be associated with other underlying factors that impact positively on subsequent university outcomes, such as being academically more ambitious, etc. Amongst other things, the option of taking English Home language or Mathematics does not exist for many matriculants from large parts of the school system; the choice of these subjects is already to an extent a reflection of privilege.

The particularly strong positive conditional association between taking Mathematics as opposed to Mathematical Literacy and subsequent university outcomes for the 2008 matric cohort warrants additional emphasis. It is remarkable that the estimated 6-year completion rate for 2009 FTEN undergraduate students from the 2008 matric cohort who offered Mathematics was almost 13 percentage points higher and the 5-year dropout rate about 13 percentage points lower than the equivalent rates for students who took Mathematical Literacy. Were one to consider two matriculants from the cohort who were otherwise identical in all respects measured in Table 10.4, the matriculant who offered Mathematics would be expected to have a 5.6 percentage points greater probability of accessing university and completing an undergraduate qualification within six years of writing the matric examinations than the matriculant who offered Mathematical Literacy.

The results in terms of participation in Physical Sciences are difficult to interpret, particularly given the descriptive findings elsewhere in this report. Specifically, the coefficients on the Physical Sciences dummy variables in the regressions are either statistically insignificant or go in the opposite direction than one would expect. The fact that this subject is far less commonly taken may affect the accuracy of estimates.

The results with regard to gateway subject participation indicate that selection into university and subsequent undergraduate performance is clearly not only dependent on overall levels of matric performance, as measured by the matric pass type or matric average achievement, but also on the set of subjects offered in the NSC examinations. 
Table 10.4: Correlates of university access, completion, conversion, and dropout rates for the 2008 matric cohort (2009 - 2014)

\begin{tabular}{|c|c|c|c|c|c|c|}
\hline & & $\begin{array}{l}1 \text {-year } \\
\text { access }\end{array}$ & $\begin{array}{l}6 \text {-year } \\
\text { access }\end{array}$ & $\begin{array}{c}\text { 6-year } \\
\text { conversion }\end{array}$ & $\begin{array}{c}\text { 6-year } \\
\text { completion }\end{array}$ & $\begin{array}{c}\text { 5-year } \\
\text { dropout }\end{array}$ \\
\hline \multirow{6}{*}{ 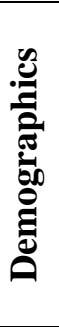 } & Underage & 0.005 & $0.025 * * *$ & $0.024 * * *$ & $0.037 * *$ & $-0.025^{*}$ \\
\hline & Overage & $-0.002 * * *$ & $-0.021 * * *$ & $-0.002 * *$ & $-0.024 * * *$ & $0.033 * * *$ \\
\hline & Female & $0.005 * * *$ & $0.010 * * *$ & $0.016 * * *$ & $0.074 * * *$ & $-0.058 * * *$ \\
\hline & Coloured & $-0.052 * * *$ & $-0.097 * * *$ & $-0.044 * * *$ & $-0.036^{* * *}$ & $0.066^{* * *}$ \\
\hline & Asian & $-0.058 * * *$ & $-0.139 * * *$ & $-0.058 * * *$ & -0.003 & $0.047 * * *$ \\
\hline & White & $-0.194 * * *$ & $-0.232 * * *$ & $-0.079 * * *$ & $0.080 * * *$ & 0.006 \\
\hline \multirow{21}{*}{ 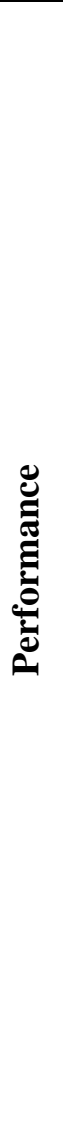 } & Did not achieve & $0.078 * * *$ & $0.035 * * *$ & $0.075 * * *$ & 0.057 & -0.028 \\
\hline & Diploma pass & $0.002 * *$ & $0.090 * * *$ & $-0.016 * * *$ & 0.013 & $-0.060 * * *$ \\
\hline & Bachelor pass & $0.229 * * *$ & $0.383 * * *$ & $0.128 * * *$ & $0.035 * * *$ & $-0.116^{* * *}$ \\
\hline & Matric average (\%) & $0.011 * * *$ & $0.010 * * *$ & $0.011 * * *$ & $0.014 * * *$ & $-0.011 * * *$ \\
\hline & Mathematics & $0.053 * * *$ & $0.063 * * *$ & $0.056^{* * *}$ & $0.128 * * *$ & $-0.132 * * *$ \\
\hline & Physical Sciences & $-0.013 * * *$ & -0.001 & $-0.010 * * *$ & 0.002 & $-0.013 * * *$ \\
\hline & English Home Lang & $0.027 * * *$ & $0.040 * * *$ & $0.025 * * *$ & $0.033 * * *$ & $-0.028 * * *$ \\
\hline & Bachelor pass rate $(\%)$ & $0.002 * * *$ & $0.001 * * *$ & $0.000 * * *$ & $-0.001 * * *$ & $0.001 * * *$ \\
\hline & Wealth Index & $0.007 * * *$ & $0.008 * * *$ & $0.005 * * *$ & -0.002 & -0.001 \\
\hline & Quintile 2 & $-0.005 * * *$ & $-0.004 * * *$ & $-0.004 * * *$ & -0.011 & 0.011 \\
\hline & Quintile 3 & $-0.003 * * *$ & $-0.002^{*}$ & $-0.008 * * *$ & $-0.046^{* * *}$ & $0.045^{* * *}$ \\
\hline & Quintile 4 & $0.009 * * *$ & $0.015 * * *$ & $-0.005 * * *$ & $-0.046^{* * *}$ & $0.023 * * *$ \\
\hline & Quintile 5 & $0.027 * * *$ & $0.025 * * *$ & 0.001 & $-0.017^{*}$ & 0.003 \\
\hline & Eastern Cape & $0.061 * * *$ & $0.072 * * *$ & $0.035 * * *$ & $0.026 * * *$ & $-0.047 * * *$ \\
\hline & Northern Cape & -0.001 & $-0.016^{* * *}$ & $-0.014 * * *$ & -0.012 & -0.000 \\
\hline & Free State & $0.043 * * *$ & $0.031 * * *$ & $0.007 * * *$ & $-0.022 * *$ & 0.005 \\
\hline & KwaZulu Natal & -0.001 & $0.004 *$ & $-0.011 * * *$ & $-0.031 * * *$ & $0.015^{* *}$ \\
\hline & North West & $0.005 * *$ & $-0.012 * * *$ & $-0.017 * * *$ & -0.012 & 0.006 \\
\hline & Gauteng & $-0.011 * * *$ & $-0.020 * * *$ & $-0.035 * * *$ & $-0.070 * * *$ & $0.041 * * *$ \\
\hline & Mpumalanga & $0.010 * * *$ & $0.011 * * *$ & $-0.008 * * *$ & $-0.045 * * *$ & $0.024 * * *$ \\
\hline & Limpopo & $0.026^{* * *}$ & $0.028 * * *$ & -0.002 & 0.003 & $-0.029 * * *$ \\
\hline \multirow{5}{*}{ 䛼 } & NSFAS award & & & & $0.069 * * *$ & $-0.047 * * *$ \\
\hline & Degree & & & & $-0.069 * * *$ & -0.001 \\
\hline & $\mathrm{BCM}$ & & & & $-0.043 * * *$ & $0.034 * * *$ \\
\hline & SET & & & & $-0.123 * * *$ & $0.060 * * *$ \\
\hline & UNISA & & & & $-0.264 * * *$ & $0.109 * * *$ \\
\hline & $\mathrm{N}$ & 547950 & 547950 & 547950 & 72026 & 72026 \\
\hline & Adjusted $\mathrm{R}^{2}$ & 0.397 & 0.46 & 0.307 & 0.152 & 0.143 \\
\hline
\end{tabular}

NOTES: All linear probability models (LPM) were estimated via Ordinary Least Squares (OLS). * Significant at the $10 \%$ level ** Significant at the $5 \%$ level *** Significant at the $1 \%$ level. Significance levels are based on robust standard errors. The 1 -year access, 6 -year access, and 6-year conversion rate samples include all learners from the 2008 matric cohort. The 6-year completion and 5-year dropout rate samples include only those candidates from the 2008 matric cohort who enrolled in undergraduate studies for the first time in 2009.Reference categories are as follows: Age (appropriate age); Gender (Male); Race (Black); Pass type (Higher Certificate pass); Math subject offered (Mathematical Literacy); English subject offered (English First Additional Language); School quintile (Quintile 1-3); School province (Western Cape); Broad undergraduate qualification type (Undergraduate non-degree); Broad field of study (HSS); HEI (All contact HEIs). 


\subsubsection{School performance and characteristics}

Interestingly, the multivariate analysis reveals that there is no significant association between the performance of the high school attended by a particular matriculant (measured as the school's Bachelor pass rate) and her chances of university success. ${ }^{18}$ While there is a clear positive association between school performance and university access, there is no such association for completion rates: the six-year completion rate for students from schools with higher Bachelor pass rates was in fact marginally lower than that for students from schools with lower Bachelor pass rates. This result is similar to that in Van Broekhuizen (2016:96). While it may seem odd that students from better-performing schools (in terms of the Bachelor pass rate) would be less likely to complete their programmes than matriculants from schools with weaker overall matric performance, it is important to interpret this coefficient in the context of the findings presented in the preceding section. The coefficient effectively implies that, for any two students with precisely the same level of matric average achievement, the one from the weaker performing school would have been more likely to complete her undergraduate studies within six years than the one from the better performing school, conditional on all other factors being held constant. In other words, students who performed comparatively well in matric in 2008 relative to the average matric performance in their schools were more likely to successfully complete their programmes than students who performed comparatively less well relative to other matriculants in their schools. This constitutes an important result, signifying that good performers in weak schools may stand a better chance of success that their performance levels alone would indicate.

A similar pattern is observable for students from high schools in different income quintiles. Learners from quintile 4 or 5 schools were more likely to access university than matriculants from quintile 1 - 3 schools, even after taking other factors into account. However, students from quintile 4 and 5 schools performed no better in terms of programme completion than their counterparts from quintile 1 - 3 schools and, in the case of quintile 4 matriculants, actually performed worse. This is a remarkable finding, especially considering the disadvantages (in terms of academic support, greater need for adjustment to university culture, etc.) faced by matriculants from lower quintile schools when they do actually make it to university. Again, it may be associated with a greater academic ability of students from weaker schools than their performance in matric may indicate.

The coefficients on the province variables suggest that large differences in university outcomes between matriculants from different provinces remain, even after controlling for learner matric performance as well as other school factors and university-related factors. Specifically, learners from Eastern Cape schools are 7.2 percentage points more likely to access university within six years of matriculation than their counterparts from Western Cape schools. Matriculants from schools in the Free State, Mpumalanga and Limpopo were also statistically significantly more likely (by $3.1,1.1$ and 2.8 percentage points, respectively) to access university within six years than matriculants from schools in the Western Cape. Conversely, matriculants from the 2008

\footnotetext{
${ }^{18}$ Though the coefficients on the 'Bachelor pass rate (\%)' variables are statistically significant in all six of the LPMs, they are so small in magnitude that the implied associations between school performance and university outcomes are effectively negligible once other factors have been taken into account.
} 
matric cohort from schools in Gauteng were 2 percentage points less likely to access university over this period than those from schools in the Western Cape. These provincial differences in 6-year access rates, even when all the factors included in the model specification are controlled for, suggest that there exists some factor which is correlated with province as well as university access which is not accounted for in the model.

Provincial differences in completion rates are also discernable: matriculants from schools in the Eastern Cape were 2.6 percentage points more likely to complete their qualifications within six years of enrolling in university than their Western Cape counterparts. On the other hand, matriculants from the Free State, KwaZulu Natal, Gauteng and Mpumalanga were 2.2, 3.1, 7 and 4.5 percentage points less likely to complete undergraduate qualifications than their Western Cape counterparts, respectively.

\subsubsection{Qualification and university correlates}

The HEMIS data used in this research project includes information on whether or not students received any National Student Financial Aid Scheme (NSFAS) loans or bursaries. This is the only variable in the data that provides some indication of students' socio-economic backgrounds and financial means, since NSFAS loans are awarded largely on the basis of financial need, though not all students who are needy necessarily receive NSFAS assistance. 2009 FTEN undergraduate students from the 2008 matric cohort who received NSFAS awards in their first year were not only more likely to complete their programmes within six years, but also significantly less likely to drop out of university within five years. This result is in line with the findings of De Villiers et al. (2013:71), who show that NSFAS students from the 2000 - 2004 national first-time entering undergraduate cohorts performed significantly better than non-NSFAS students in terms of both throughput and retention. The result presented here is even stronger than what is implied by the descriptive analysis presented in De Villiers et al. (2013). The statistically significant coefficients on the NSFAS variable in Table 10.4 suggest that NSFAS-supported students perform better than non-NSFAS students, on average, even after differences in matric performance, school-level factors, and other university-specific and programme-specific factors have been taken into account. Though more detailed information would be needed in order to explain precisely why this is the case, De Villiers et al. (2013:71) speculate that NSFAS awards may enable financially needy students to continue with their studies, even when they need to repeat failed courses or academic years. The financial support provided by NSFAS might therefore enable students who would otherwise have dropped out of university to continue their studies, leading to a larger proportion of NSFAS students completing a qualification within six years than is the case for non-NSFAS students.

In terms of fields of study, Table 10.4 shows a statistically significant association between the broad types and fields of study of undergraduate programmes for which students enrolled and the likelihood that they completed those qualifications within the first six years after writing the 2008 matric examinations. Unsurprisingly, the results indicate that students who enrolled in (potentially) more academically challenging qualifications with longer minimum study time requirements were significantly less likely to complete their programmes within six years than students who enrolled in (potentially) easier, short-duration programmes. The implied differences are substantial. On average and with all else held constant, the 6-year completion rates 
for students who entered undergraduate degree programmes in 2009 was 6.9 percentage points lower than the equivalent completion rate for students who entered undergraduate non-degree programmes. Again, given the nature of the other control variables included in the regressions, this result is likely to be driven mainly by differences in the regulation periods associated with the different qualification types rather than differences in the underlying academic abilities of students who enrol for those types of qualifications. The fact that there were no statistically significant differences in the extent of dropout between students enrolled in undergraduate degree or undergraduate non-degree programmes adds further support to this hypothesis.

In terms of broad field of study, students who enrolled in HSS programmes had statistically significantly higher 6-year completion rates, on average, than students enrolled in BCM or SET programmes, after other pre-entry correlates were taken into account. The 6-year completion rates for SET students, in particular, were significantly lower (12.3 percentage points), on average, than the 6-year completion rate for HSS students. This supports the notion that HSS programmes may, on average, be less academically demanding than BCM and SET programmes. It is also found that BCM and SET students were statistically significantly more likely to drop out of university within five years of study than HSS students.

Lastly, the regressions show that 2009 FTEN undergraduate students from the 2008 matric cohort who commenced with undergraduate studies at UNISA had statistically significantly lower 6-year completion and higher 5-year drop-out rates than students who enrolled at contact universities. Based on the discussion and descriptive analysis regarding universities, it is to be expected that students who study via UNISA will take longer to complete their programmes than students who study at contact universities. However, the multivariate analysis presented in Table 10.4 shows that this holds true even when a range of other factors have been taken into account. Even with other factors being taken into account, the 6-year completion rate for UNISA students is 26.4 percentage points lower, on average and with all else held constant, than the 6-year completion rates for students who enrolled in other parts of the university system. 


\section{References}

Blom, R., 2014. The Value of Designated Subjects in Terms of Likely Student Success in Higher Education, Pretotia: Higher Education South Africa.

Parker, D. \& Sheppard, C., 2015. How HEMIS and the Development Grants can be used to improve SA student success., Johannesburg. Available at: http://siyaphumelela.org.za/wp-content/uploads/2015/05/ParkerSheppard-15-May.pdf.

DBE. 2010. National Examinations and Assesment: Report on the National Senior Certificate Examination Results 2009. Pretoria: Department of Basic Education.

De Villiers, P., Van Wyk, C. and Van der Berg, S. (2013). The first five years project - a cohort study of students awarded NSFAS loans in the first five years 2000 - 2004. Stellenbosch Economic Working Paper 11/13. University of Stellenbosch.

Scott, I., Yeld, N. \& Hendry, J., 2007. Higher Education Monitor: A Case for Improving Teaching and Learning in South African higher education, Cape Town.

Soudien, C. (2010). Transformation in higher education: A briefing paper. Pretoria: Development Bank of Southern Africa.

Van Broekhuizen, H. (2016). Graduate unemployment, Higher Education access and success, and teacher production in South Africa. Ph.D. thesis. Faculty of Economic and Management Sciences, Stellenbosch University. 


\section{A Appendix}

\section{Important definitions and caveats*}

*This section adapted from Van Broekhuizen (2016:47 - 51)

University 'access rates', 'completion rates', 'dropout rates', and 'retention rates' are commonly used terms in the university literature. Yet, their intended meanings can differ substantially from one study to the next and they are rarely estimated using a single, consistent methodology. To avoid potential confusion, each of these metrics is therefore explicitly defined below. Note that the definitions listed are based on the author's reading of the international literature on the quantitative analysis of university outcomes based on unit-record learner and/or student data. As a result, the definitions given do not necessarily correspond to those in other studies.

\section{Important definitions}

access rate: expresses the cumulative number of individuals from a given cohort who have participated in university within a given number of years, as a percentage of the total number of individuals in that cohort.

appropriate age: all learners who are either 17 or 18 years of age by the end of the 31 st of December of the year in which they write the NSC exams.

completer: any individual who has successfully completed a formal undergraduate or otherwise-specified university academic programme/qualification.

completion rate: expresses the cumulative number of 'completers' from a given first-time entering undergraduate cohort who completed their studies within a specific number of years, as a percentage of the total number of students in that cohort.

conversion rate: expresses the cumulative number of 'completers' from a given matric cohort who enrolled in and completed undergraduate university programmes within a specific number of years, as a percentage of the total number of learners in that cohort.

dropout: any student who, having been enrolled for an undergraduate programme, exits the university system without having completed any formal academic qualification and without subsequently returning to the university system. This implies that students can only be classified as dropouts if they (a) exit the public university system for good and (b) do not complete any undergraduate qualification.

dropout rate: expresses the cumulative number of dropouts from a given first-time entering under- graduate cohort who dropped out within a specified number of years, as a percentage of the total number of students in that cohort.

first-time entering student/cohort: any individual or group of individuals who enrol in formal undergraduate studies for the first time in the public university system.

matric: Grade 12 learners who write the NSC.

matriculant: any Grade 12 learner who has written the NSC exams. In this report 'matriculant', 'matric learner', 'matric candidate', and 'NSC candidate' are used interchangeably to refer to such learners. 
non-completer: any student who is enrolled for a formal undergraduate qualification, but who has not yet successfully completed that qualification.

non-participant any individual who has not enrolled in university as first-time entering undergraduate student at some stage.

participant: any individual who has enrolled in university as first-time entering undergraduate student at some stage.

retention rate: denotes the number of 'non-completers' from a given first-time entering undergraduate cohort who are still enrolled after a given number of years, as a percentage of the total number of students in that cohort.

undergraduate degree: Any accredited undergraduate degree programme that has been classified as one of the following qualification types in the HEMIS database: General Academic Bachelor's Degree; Professional First Bachelor's Degree (4 years or more); Baccalaureus Technologiae Degree; Professional First Bachelor's Degree (3 years); Bachelor's Degree (360); or Bachelor's Degree (480). In some of the tables and graphs presented in this report, 'undergraduate degree' has been abbreviated as 'UG degree'.

undergraduate non-degree: Any accredited undergraduate programme that is not a degree programme and has been classified as one of the following qualification types in the HEMIS database: Undergraduate Diploma or Certificate (3 yrs); Undergraduate Diploma or Certificate (1 or 2 years); National Certificate; National Higher Certificate; National Diploma; National Higher Diploma; Higher Certificate; Advanced Certificate; Diploma; or Advanced Diploma. In some of the tables and graphs presented in this report, 'undergraduate degree' has been abbreviated as 'UG non-degree'.

wealth index: The 2011 census Small Area wealth index for a school's immediate surrounding area. See 'The school wealth index' section below.

\section{Important abbreviations}

BCM: Business, commerce, and management

FTEN: First-time entering

HEMIS: Higher Education Management Information System

HSS: Humanities and Social Sciences

NSFAS: National Student Financial Aid Scheme

SET: Science, Engineering, and Technology

\section{Important caveats}

Short-term measures of university access, completion, and dropout are likely to understate the full extent of university access, completion, and dropout for any cohort under consideration. In theory, the solution to this problem would be to track cohorts over extended periods of time as they progress through the university system. However, this is virtually never feasible given the data constraints. The HEMIS data used in this report, for example, allows learners from the 2008 matric matric cohort to be tracked through the university system for a maximum of six years, depending on when they enrolled in undergraduate studies for the first time. Since 
the integrated HEMIS data used in the analysis was only available up to 2014, it follows that subsequent matric cohorts could not be tracked into and through the university system for the same number of years.

Working with short-run time frames has important implications for the validity of university access, completion, and dropout estimates. For example, it is technically only possible to definitively categorise students as dropouts if it is known that they never return to university to continue their studies. Unfortunately, this is simply not possible given the data constraints. The implications for the accuracy of the dropout rates presented above are twofold. First, they are virtually guaranteed to be upward-biased estimates of the true short-run dropout rates since at least some of the non-completers who were apparently no longer enrolled in university in 2014 according to HEMIS data may have returned to complete their studies in

2015 or thereafter. Second, the short-run dropout rate estimates will understate the ultimate extent of dropout for each cohort since some non-completers who were still enrolled by the end of 2014 are likely to have dropped out in 2015 or thereafter. Similar implications also hold for short-run estimates of university access and completion rates, though these do not tend to be quite as severe as they are in the case of dropout estimation.

Without access to more data, there is very little that can be done about the aforementioned issues and they serve as important caveats to the inferences that can be drawn from the analysis presented above.

\section{The school wealth index}

Because the precise geographical location of most South African schools are generally well documented, it is possible to use GIS to in combination with other data sources to determine the prevailing socio-economic status in a school's immediate surroundings.

The 2011 Census Small Area Layer is the most detailed geographical level at which Census data is available for analysis and divides South Africa up into 84907 distinct "Small Areas". These Small Areas generally correspond to suburbs or villages and are created by combining one or more neighbouring enumeration areas (EA) that conform to specific criteria such as population thresholds, area size, geographical constraints, and land use type. While the population sizes across Small Areas vary from 1 to $11717,95 \%$ of the Small Areas have populations of less than 1080 people.

Census 2011 included a number of questions on household assets and access to services. 12 of these assets or access items pertained specifically to the socio-economic status of the household. For each Small Area, an analysis was conducted to determine what percentage of households have access to each of the 12 items. Multiple correspondence analysis (MCA) was subsequently used to convert these percentages into an index which was then standardised to have a mean of zero and a standard deviation of 1 . For the sake of simplicity, this index is referred to as the wealth index throughout this report. Using the gps coordinates for the schools in the 2008 matric sample, schools were then mapped to specific Small Areas and assigned the corresponding values of the wealth index. 


\section{Supporting Tables}

Table A.1: NSC exam results for the 2008 - 2013 matric cohorts

\begin{tabular}{|c|c|c|c|c|c|c|}
\hline & \multicolumn{6}{|c|}{ Matric Cohort } \\
\hline & 2008 & 2009 & 2010 & 2011 & 2012 & 2013 \\
\hline Candidates & 561615 & 562581 & 537352 & 495829 & 509881 & 553073 \\
\hline column \% & 100.0 & 100.0 & 100.0 & 100.0 & 100.0 & 100.0 \\
\hline Did not achieve & 210807 & 221429 & 172068 & 146215 & 135658 & 119881 \\
\hline column \% & 37.5 & 39.4 & 32.0 & 29.5 & 26.6 & 21.7 \\
\hline Passed & 350808 & 341152 & 365284 & 349614 & 374223 & 433192 \\
\hline column $\%$ & 62.5 & 60.6 & 68.0 & 70.5 & 73.4 & 78.3 \\
\hline - SNE/NSC & 299 & 644 & 760 & 568 & 428 & 255 \\
\hline column \% & 0.1 & 0.1 & 0.1 & 0.1 & 0.1 & 0.0 \\
\hline - Higher Certificate & 108230 & 95834 & 91486 & 85839 & 87524 & 93082 \\
\hline column $\%$ & 19.3 & 17.0 & 17.0 & 17.3 & 17.2 & 16.8 \\
\hline - Diploma & 130614 & 133262 & 146489 & 142000 & 152207 & 170491 \\
\hline column \% & 23.3 & 23.7 & 27.3 & 28.6 & 29.9 & 30.8 \\
\hline - Bachelor & 111665 & 111412 & 126549 & 121207 & 134064 & 169364 \\
\hline column \% & 19.9 & 19.8 & 23.6 & 24.4 & 26.3 & 30.6 \\
\hline
\end{tabular}

NOTES: Figures printed in black reflect the numbers of learners who wrote and achieved particular pass results in the NSC examinations for each of the 2008 - 2013 matric cohorts. Figures printed in grey express the number of learners who achieved a particular pass result as a percentage of the number of candidates in the cohort. 
Table A.2: University access rates (\%) for the 2008 - 2013 matric cohorts, by pass type

\begin{tabular}{|c|c|c|c|c|c|c|c|}
\hline & \multirow[b]{2}{*}{ Year ${ }^{a}$} & \multicolumn{6}{|c|}{ Matric Cohort } \\
\hline & & 2008 & 2009 & 2010 & 2011 & 2012 & 2013 \\
\hline \multirow{6}{*}{ 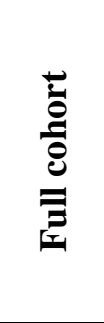 } & 1 & 13.0 & 11.7 & 12.3 & 10.0 & 13.6 & 14.6 \\
\hline & 2 & 16.7 & 16.4 & 17.7 & 14.2 & 18.7 & - \\
\hline & 3 & 18.2 & 18.3 & 19.7 & 15.7 & - & - \\
\hline & 4 & 19.0 & 19.3 & 20.6 & - & - & - \\
\hline & 5 & 19.6 & 19.9 & - & - & - & - \\
\hline & 6 & 20.0 & - & - & - & - & - \\
\hline \multirow{6}{*}{ 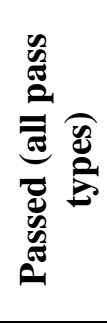 } & 1 & 20.7 & 19.3 & 18.0 & 14.2 & 18.5 & 18.7 \\
\hline & 2 & 26.8 & 26.7 & 25.8 & 20.0 & 25.4 & - \\
\hline & 3 & 29.0 & 29.6 & 28.5 & 22.0 & - & - \\
\hline & 4 & 30.3 & 31.0 & 29.7 & - & - & - \\
\hline & 5 & 31.2 & 31.8 & - & - & - & - \\
\hline & 6 & 31.9 & - & - & - & - & - \\
\hline \multirow{6}{*}{ Uُّ } & 1 & 1.6 & 0.9 & 0.5 & 0.3 & 0.5 & 0.5 \\
\hline & 2 & 2.8 & 2.3 & 1.7 & 1.3 & 1.9 & - \\
\hline & 3 & 3.7 & 3.5 & 2.6 & 2.1 & - & - \\
\hline & 4 & 4.4 & 4.2 & 3.2 & - & - & - \\
\hline & 5 & 5.0 & 4.8 & - & - & - & - \\
\hline & 6 & 5.5 & - & - & - & - & - \\
\hline \multirow{6}{*}{ 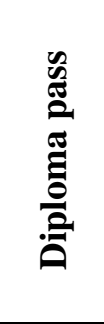 } & 1 & 10.6 & 8.5 & 5.7 & 4.4 & 5.0 & 4.4 \\
\hline & 2 & 16.4 & 15.3 & 12.1 & 9.0 & 10.2 & - \\
\hline & 3 & 19.0 & 18.7 & 14.9 & 10.9 & - & - \\
\hline & 4 & 20.6 & 20.4 & 16.2 & - & - & - \\
\hline & 5 & 21.7 & 21.4 & - & - & - & - \\
\hline & 6 & 22.5 & - & - & - & - & - \\
\hline \multirow{6}{*}{ 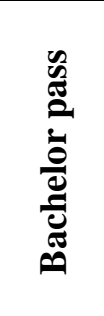 } & 1 & 51.2 & 48.3 & 45.0 & 35.4 & 45.6 & 43.1 \\
\hline & 2 & 62.2 & 61.5 & 59.3 & 46.4 & 58.0 & - \\
\hline & 3 & 65.3 & 65.2 & 63.1 & 49.2 & - & - \\
\hline & 4 & 66.8 & 66.8 & 64.6 & - & - & - \\
\hline & 5 & 67.8 & 67.7 & - & - & - & - \\
\hline & 6 & 68.5 & - & - & - & - & - \\
\hline
\end{tabular}

NOTES: Figures represent the cumulative percentage of the respective matric cohorts who enrolled in undergraduate studies in the public university system within a specified number of years after writing the NSC exams, disaggregated by the type of pass achieved in the NSC exams. ${ }^{[a]}$ Number of years following the NSC exams (e.g. 1 year represents the year immediately following the year in which the NSC was written). 
Table A.3: The 2008 matric cohort after six years

\begin{tabular}{|c|c|c|c|c|c|c|}
\hline & \multicolumn{6}{|c|}{2008 matric cohort subgroup } \\
\hline & All & Passes & $\begin{array}{l}\text { Certificate } \\
\text { pass }\end{array}$ & $\begin{array}{c}\text { Diploma } \\
\text { pass }\end{array}$ & $\begin{array}{c}\text { Bachelor } \\
\text { pass }\end{array}$ & $\begin{array}{l}\text { Enrolled in } \\
\text { university }\end{array}$ \\
\hline Cohort & 561792 & 350871 & 108250 & 130636 & 111685 & 112402 \\
\hline column $\%$ & 100.0 & 100.0 & 100.0 & 100.0 & 100.0 & 100.0 \\
\hline Enrolled in UG studies & 112402 & 111801 & 5919 & 29385 & 76488 & 112402 \\
\hline column \% & 20.0 & 31.9 & 5.5 & 22.5 & 68.5 & 100.0 \\
\hline - UG degree & 70632 & 70431 & 1133 & 6665 & 62630 & 70632 \\
\hline column \% & 12.6 & 20.1 & 1.0 & 5.1 & 56.1 & 62.8 \\
\hline Completed UG qualification & 55721 & 55594 & 1503 & 10301 & 43788 & 55721 \\
\hline column \% & 9.9 & 15.8 & 1.4 & 7.9 & 39.2 & 49.6 \\
\hline - UG degree & 38229 & 38188 & 320 & 2869 & 34998 & 38229 \\
\hline column \% & 6.8 & 10.9 & 0.3 & 2.2 & 31.3 & 34.0 \\
\hline Enrolled in PG studies & 13466 & 13461 & 61 & 640 & 12760 & 13466 \\
\hline column $\%$ & 2.4 & 3.8 & 0.1 & 0.5 & 11.4 & 12.0 \\
\hline Completed PG qualification & 9727 & 9723 & 23 & 356 & 9344 & 9727 \\
\hline column \% & 1.7 & 2.8 & 0.0 & 0.3 & 8.4 & 8.7 \\
\hline Non-completers enrolled in & 22429 & 22166 & 1588 & 6568 & 14008 & 22429 \\
\hline column $\%$ & 4.0 & 6.3 & 1.5 & 5.0 & 12.5 & 20.0 \\
\hline Dropped-out before 2014 & 34163 & 33952 & 2825 & 12507 & 18615 & 34163 \\
\hline column \% & 6.1 & 9.7 & 2.6 & 9.6 & 16.7 & 30.4 \\
\hline
\end{tabular}

NOTES: Figures printed in black reflect the numbers of learners from each of the 2008 matric cohort subgroups. Figures printed in grey express the number of learners in a particular category as a percentage of the number of candidates from the relevant subgroup. 
Table A.4: NSC exam results for the 2008 matric cohort, by province

\begin{tabular}{|c|c|c|c|c|c|c|c|c|c|c|}
\hline & All & WC & EC & NC & FS & $\mathbf{K Z}$ & NW & GA & MP & $\mathbf{L P}$ \\
\hline Candidates & 561624 & 43964 & 60711 & 10081 & 30282 & 143696 & 33280 & 95925 & 54600 & 89085 \\
\hline row \% & 100.0 & 7.8 & 10.8 & 1.8 & 5.4 & 25.6 & 5.9 & 17.1 & 9.7 & 15.9 \\
\hline column $\%$ & 100.0 & 100.0 & 100.0 & 100.0 & 100.0 & 100.0 & 100.0 & 100.0 & 100.0 & 100.0 \\
\hline Did not achieve & 210788 & 9303 & 29916 & 2745 & 8595 & 60588 & 10573 & 22605 & 26111 & 40352 \\
\hline row \% & 100.0 & 4.4 & 14.2 & 1.3 & 4.1 & 28.7 & 5.0 & 10.7 & 12.4 & 19.1 \\
\hline column $\%$ & 37.5 & 21.2 & 49.3 & 27.2 & 28.4 & 42.2 & 31.8 & 23.6 & 47.8 & 45.3 \\
\hline Passed (all) & 350836 & 34661 & 30795 & 7336 & 21687 & 83108 & 22707 & 73320 & 28489 & 48733 \\
\hline row $\%$ & 100.0 & 9.9 & 8.8 & 2.1 & 6.2 & 23.7 & 6.5 & 20.9 & 8.1 & 13.9 \\
\hline column $\%$ & 62.5 & 78.8 & 50.7 & 72.8 & 71.6 & 57.8 & 68.2 & 76.4 & 52.2 & 54.7 \\
\hline - SNE/NSC pass & 299 & 24 & 11 & 3 & 8 & 160 & 2 & 36 & 21 & 34 \\
\hline row $\%$ & 100.0 & 8.0 & 3.7 & 1.0 & 2.7 & 53.5 & 0.7 & 12.0 & 7.0 & 11.4 \\
\hline column $\%$ & 0.1 & 0.1 & 0.0 & 0.0 & 0.0 & 0.1 & 0.0 & 0.0 & 0.0 & 0.0 \\
\hline - Higher Certificate pass & 108246 & 7213 & 10790 & 2226 & 6620 & 26174 & 7335 & 17054 & 10882 & 19952 \\
\hline row $\%$ & 100.0 & 6.7 & 10.0 & 2.1 & 6.1 & 24.2 & 6.8 & 15.8 & 10.1 & 18.4 \\
\hline column $\%$ & 19.3 & 16.4 & 17.8 & 22.1 & 21.9 & 18.2 & 22.0 & 17.8 & 19.9 & 22.4 \\
\hline - Diploma pass & 130616 & 12855 & 11285 & 3085 & 8715 & 30463 & 8892 & 27153 & 10663 & 17505 \\
\hline row $\%$ & 100.0 & 9.8 & 8.6 & 2.4 & 6.7 & 23.3 & 6.8 & 20.8 & 8.2 & 13.4 \\
\hline column $\%$ & 23.3 & 29.2 & 18.6 & 30.6 & 28.8 & 21.2 & 26.7 & 28.3 & 19.5 & 19.6 \\
\hline - Bachelor pass & 111675 & 14569 & 8709 & 2022 & 6344 & 26311 & 6478 & 29077 & 6923 & 11242 \\
\hline row $\%$ & 100.0 & 13.0 & 7.8 & 1.8 & 5.7 & 23.6 & 5.8 & 26.0 & 6.2 & 10.1 \\
\hline column $\%$ & 19.9 & 33.1 & 14.3 & 20.1 & 20.9 & 18.3 & 19.5 & 30.3 & 12.7 & 12.6 \\
\hline
\end{tabular}

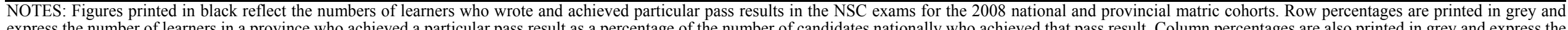

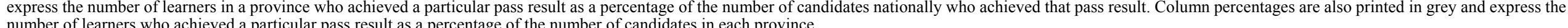


Table A.5: The 2008 national and provincial matric cohorts after six years (end of 2014)

\begin{tabular}{|c|c|c|c|c|c|c|c|c|c|c|}
\hline & \multicolumn{10}{|c|}{2008 matric cohort school province } \\
\hline & All & WC & EC & NC & FS & KZ & NW & GA & MP & LP \\
\hline Cohort & 561667 & 43966 & 60711 & 10081 & 30282 & 143720 & 33280 & 95927 & 54600 & 89100 \\
\hline column $\%$ & 100.0 & 100.0 & 100.0 & 100.0 & 100.0 & 100.0 & 100.0 & 100.0 & 100.0 & 100.0 \\
\hline Enrolled in UG studies & 112402 & 11808 & 12143 & 1531 & 7008 & 26277 & 5958 & 26011 & 7101 & 14565 \\
\hline column $\%$ & 20.0 & 26.9 & 20.0 & 15.2 & 23.1 & 18.3 & 17.9 & 27.1 & 13.0 & 16.3 \\
\hline Enrolled in UG degree & 70632 & 8924 & 6847 & 1097 & 4664 & 15687 & 4011 & 17658 & 3735 & 8009 \\
\hline column $\%$ & 12.6 & 20.3 & 11.3 & 10.9 & 15.4 & 10.9 & 12.1 & 18.4 & 6.8 & 9.0 \\
\hline Completed UG qualification & 55721 & 6819 & 6440 & 774 & 3515 & 12713 & 2898 & 12235 & 3303 & 7024 \\
\hline column $\%$ & 9.9 & 15.5 & 10.6 & 7.7 & 11.6 & 8.8 & 8.7 & 12.8 & 6.0 & 7.9 \\
\hline Completed UG degree & 38229 & 5423 & 3986 & 607 & 2523 & 7980 & 2173 & 9257 & 1987 & 4293 \\
\hline column $\%$ & 6.8 & 12.3 & 6.6 & 6.0 & 8.3 & 5.6 & 6.5 & 9.7 & 3.6 & 4.8 \\
\hline Enrolled in PG studies & 13466 & 1977 & 1427 & 205 & 911 & 2796 & 802 & 3568 & 515 & 1265 \\
\hline column $\%$ & 2.4 & 4.5 & 2.4 & 2.0 & 3.0 & 1.9 & 2.4 & 3.7 & 0.9 & 1.4 \\
\hline Completed PG qualification & 9727 & 1602 & 1045 & 156 & 675 & 1847 & 582 & 2690 & 347 & 783 \\
\hline column $\%$ & 1.7 & 3.6 & 1.7 & 1.5 & 2.2 & 1.3 & 1.7 & 2.8 & 0.6 & 0.9 \\
\hline Non-completers enrolled in 2014 & 22426 & 1856 & 2258 & 267 & 1253 & 5448 & 1118 & 5354 & 1554 & 3318 \\
\hline column $\%$ & 4.0 & 4.2 & 3.7 & 2.6 & 4.1 & 3.8 & 3.4 & 5.6 & 2.8 & 3.7 \\
\hline Dropped-out before 2014 & 34163 & 3123 & 3439 & 490 & 2235 & 8074 & 1940 & 8404 & 2242 & 4216 \\
\hline column \% & 6.1 & 7.1 & 5.7 & 4.9 & 7.4 & 5.6 & 5.8 & 8.8 & 4.1 & 4.7 \\
\hline
\end{tabular}

a percentage of the number of candidates from the relevant provincial/national subgroup. 
Table A.6: University access, completion, and dropout rate summaries for the 2008 Western Cape matric cohort, by school district

\begin{tabular}{lcccccc}
\hline & & & \multicolumn{3}{c}{ Bachelor pass candidates } \\
\cline { 5 - 7 } & $\begin{array}{c}\text { Share of } \\
\text { provincial } \\
\text { learners }\end{array}$ & $\begin{array}{c}\text { Bachelor } \\
\text { pass rate }\end{array}$ & $\begin{array}{c}\text { 6-year } \\
\text { access rate }\end{array}$ & $\begin{array}{c}\text { 1-year } \\
\text { access rate }\end{array}$ & $\begin{array}{c}\text { 6-year } \\
\text { completion } \\
\text { rate }\end{array}$ & $\begin{array}{c}\text { 5-year } \\
\text { dropout } \\
\text { rate }\end{array}$ \\
\hline Cape Winelands & 14.4 & 36.8 & 68.2 & 52.3 & 71.5 & 19.5 \\
Eden And Central Karoo & 10.0 & 33.8 & 60.9 & 44.7 & 68.6 & 21.6 \\
Metro Central & 18.3 & 37.5 & 70.2 & 52.3 & 68.8 & 18.3 \\
Metro East & 16.2 & 24.8 & 63.2 & 48.4 & 67.0 & 22.3 \\
Metro North & 18.2 & 34.7 & 64.8 & 48.8 & 71.8 & 18.9 \\
Metro South & 14.8 & 30.7 & 68.3 & 49.9 & 66.0 & 23.4 \\
Overberg & 3.4 & 31.6 & 54.9 & 39.7 & 71.4 & 21.6 \\
West Coast & 4.7 & 34.6 & 55.4 & 43.1 & 67.5 & 21.6 \\
\hline NOTES: Fignyyyyy & & & & & &
\end{tabular}

NOTES: Figures are only estimated for learners from the 2008 Western Cape matric cohort. Access, completion, and dropout rates are only estimated for learners from the cohort who achieved Bachelor passes. Furthermore, completion and dropout rates are estimated only for those learners from this latter group who enrolled in undergraduate studies for the first time in 2009.

Table A.7: University access, completion, and dropout rate summaries for the 2008 Northern Cape matric cohort, by school district

\begin{tabular}{lcccccc}
\hline & & & \multicolumn{3}{c}{ Bachelor pass candidates } \\
\cline { 5 - 7 } & $\begin{array}{c}\text { Share of } \\
\text { provincial } \\
\text { learners }\end{array}$ & $\begin{array}{c}\text { Bachelor } \\
\text { pass rate }\end{array}$ & $\begin{array}{c}\text { 6-year } \\
\text { access rate }\end{array}$ & $\begin{array}{c}\text { 1-year } \\
\text { access rate }\end{array}$ & $\begin{array}{c}\text { 6-year } \\
\text { completion } \\
\text { rate }\end{array}$ & $\begin{array}{c}\text { 5-year } \\
\text { dropout } \\
\text { rate }\end{array}$ \\
\hline Frances Baard & 39.6 & 22.6 & 60.0 & 44.3 & 63.8 & 20.9 \\
John Taolo Gaetsewe & 18.0 & 11.6 & 55.2 & 33.8 & 60.6 & 28.2 \\
Namakwa & 9.1 & 27.7 & 37.4 & 27.6 & 58.6 & 30.0 \\
Pixley Ka Seme & 15.0 & 15.6 & 57.4 & 38.7 & 62.6 & 26.4 \\
Siyanda & 18.0 & 22.3 & 61.9 & 48.5 & 70.9 & 21.4 \\
\hline
\end{tabular}

NOTES: Figures are only estimated for learners from the 2008 Northern Cape matric cohort. Access, completion, and dropout rates are only estimated for learners from the cohort who achieved Bachelor passes. Furthermore, completion and dropout rates are estimated only for those learners from this latter group who enrolled in undergraduate studies for the first time in 2009. 
Table A.8: University access, completion, and dropout rate summaries for the 2008 Eastern Cape matric cohort, by school district

\begin{tabular}{|c|c|c|c|c|c|c|}
\hline & \multirow[b]{2}{*}{$\begin{array}{c}\text { Share of } \\
\text { provincial } \\
\text { learners }\end{array}$} & \multirow[b]{2}{*}{$\begin{array}{l}\text { Bachelor } \\
\text { pass rate }\end{array}$} & \multicolumn{4}{|c|}{ Bachelor pass candidates } \\
\hline & & & $\begin{array}{c}\text { 6-year } \\
\text { access rate }\end{array}$ & $\begin{array}{c}\text { 1-year } \\
\text { access rate }\end{array}$ & $\begin{array}{c}\text { 6-year } \\
\text { completion } \\
\text { rate }\end{array}$ & $\begin{array}{c}\text { 5-year } \\
\text { dropout } \\
\text { rate }\end{array}$ \\
\hline Amajuba & 0.1 & 9.2 & 66.7 & 50.0 & 33.3 & 66.7 \\
\hline Butterworth & 5.0 & 7.0 & 74.8 & 60.0 & 65.9 & 23.0 \\
\hline Coflmvaba & 2.8 & 9.7 & 81.0 & 63.2 & 66.0 & 19.4 \\
\hline Cradock & 1.4 & 22.3 & 69.6 & 56.5 & 75.0 & 14.4 \\
\hline Dutywa & 4.0 & 5.8 & 78.6 & 60.7 & 64.7 & 21.2 \\
\hline East London & 9.4 & 22.3 & 78.4 & 62.2 & 65.8 & 18.9 \\
\hline Fort Beaufort & 3.1 & 11.7 & 87.2 & 68.8 & 68.0 & 18.7 \\
\hline Graaff-Reinet & 1.3 & 21.8 & 70.1 & 48.9 & 68.2 & 23.5 \\
\hline Grahamstown & 1.6 & 26.3 & 76.1 & 61.8 & 54.4 & 25.0 \\
\hline King Williams Town & 8.2 & 10.7 & 83.6 & 67.2 & 67.1 & 18.8 \\
\hline Lady Frere & 2.1 & 8.5 & 76.9 & 59.3 & 67.2 & 23.4 \\
\hline Libode & 4.9 & 8.5 & 66.8 & 43.9 & 66.7 & 22.5 \\
\hline Lusikisiki & 4.7 & 5.8 & 74.7 & 50.0 & 75.9 & 10.8 \\
\hline Maluti & 2.9 & 10.8 & 74.1 & 48.7 & 60.9 & 18.5 \\
\hline Mbizana & 4.6 & 5.8 & 82.8 & 54.6 & 74.2 & 11.2 \\
\hline Metro North & 0.0 & 0.0 & - & - & - & - \\
\hline Mt Fletcher & 2.0 & 9.3 & 75.7 & 48.6 & 75.9 & 16.7 \\
\hline Mt Frere & 2.9 & 6.9 & 74.0 & 42.3 & 67.3 & 25.0 \\
\hline Mthata & 7.5 & 15.8 & 84.3 & 69.4 & 68.7 & 16.7 \\
\hline Ngcobo & 2.3 & 7.2 & 81.8 & 58.6 & 63.8 & 20.7 \\
\hline Nkangala & 0.0 & 0.0 & - & - & - & - \\
\hline Pinetown & 0.2 & 9.4 & 90.9 & 72.7 & 87.5 & 0.0 \\
\hline Port Elizabeth & 12.9 & 26.0 & 77.6 & 65.0 & 64.2 & 23.1 \\
\hline Queenstown & 4.2 & 17.1 & 78.6 & 63.9 & 59.7 & 23.7 \\
\hline Qumbu & 2.8 & 6.6 & 73.7 & 57.0 & 67.7 & 20.0 \\
\hline Sedibeng West & 0.1 & 9.4 & 100.0 & 80.0 & 75.0 & 25.0 \\
\hline Sterkspruit & 3.2 & 12.1 & 73.2 & 56.6 & 61.7 & 27.8 \\
\hline Uitenhage & 5.9 & 22.0 & 71.0 & 57.9 & 68.1 & 22.4 \\
\hline
\end{tabular}

NOTES: Figures are only estimated for learners from the 2008 Eastern Cape matric cohort. Access, completion, and dropout rates are only estimated for learners from the cohort who achieved Bachelor passes. Furthermore, completion and dropout rates are estimated only for those learners from this latter group who enrolled in undergraduate studies for the first time in 2009. 
Table A.9: University access, completion, and dropout rate summaries for the 2008 Free State matric cohort, by school district

\begin{tabular}{lcccccc}
\hline & & & \multicolumn{4}{c}{ Bachelor pass candidates } \\
\cline { 5 - 7 } & $\begin{array}{c}\text { Share of } \\
\text { provincial } \\
\text { learners }\end{array}$ & $\begin{array}{c}\text { Bachelor } \\
\text { pass rate }\end{array}$ & $\begin{array}{c}\text { 6-year } \\
\text { access rate }\end{array}$ & $\begin{array}{c}\text { 1-year } \\
\text { access rate }\end{array}$ & $\begin{array}{c}\text { 6-year } \\
\text { completion } \\
\text { rate }\end{array}$ & $\begin{array}{c}\text { 5-year } \\
\text { dropout } \\
\text { rate }\end{array}$ \\
\hline Fezile Dabi & 18.7 & 17.2 & 70.9 & 55.6 & 65.6 & 22.0 \\
Lejweleputswa & 20.8 & 20.9 & 69.7 & 55.6 & 62.1 & 25.5 \\
Motheo & 30.2 & 26.5 & 74.9 & 61.0 & 67.4 & 20.5 \\
Thabo Mofutsanyana & 26.9 & 17.9 & 69.7 & 52.0 & 55.0 & 31.0 \\
Xhariep & 3.4 & 17.6 & 57.5 & 39.2 & 60.6 & 26.8 \\
\hline
\end{tabular}

NOTES: Figures are only estimated for learners from the 2008 Free State matric cohort. Access, completion, and dropout rates are only estimated for learners from the cohort who achieved Bachelor passes. Furthermore, completion and dropout rates are estimated only for those learners from this latter group who enrolled in undergraduate studies for the first time in 2009.

Table A.10: University access, completion, and dropout rate summaries for the 2008 North West matric cohort, by school district

\begin{tabular}{lcccccc}
\hline & & & \multicolumn{3}{c}{ Bachelor pass candidates } \\
\cline { 5 - 7 } & $\begin{array}{c}\text { Share of } \\
\text { provincial } \\
\text { learners }\end{array}$ & Bachelor & $\begin{array}{c}\text { 6-year } \\
\text { pass rate }\end{array}$ & $\begin{array}{c}\text { 1-year } \\
\text { access rate } \\
\text { access rate }\end{array}$ & $\begin{array}{c}\text { 6-year } \\
\text { completion } \\
\text { rate }\end{array}$ & $\begin{array}{c}\text { 5-year } \\
\text { dropout } \\
\text { rate }\end{array}$ \\
\hline Bojanala & 38.9 & 20.0 & 62.3 & 43.2 & 60.4 & 24.4 \\
Dr Kenneth Kaunda & 18.4 & 27.1 & 63.9 & 50.3 & 66.4 & 21.8 \\
Dr Ruth Segomotsi Mompati & 16.3 & 13.6 & 68.0 & 51.0 & 62.6 & 25.4 \\
Ngaka Modiri Molema & 21.1 & 16.4 & 70.7 & 51.5 & 61.8 & 25.5 \\
\hline
\end{tabular}

NOTES: Figures are only estimated for learners from the 2008 North West matric cohort. Access, completion, and dropout rates are only estimated for learners from the cohort who achieved Bachelor passes. Furthermore, completion and dropout rates are estimated only for those learners from this latter group who enrolled in undergraduate studies for the first time in 2009.

Table A.11: University access, completion, and dropout rate summaries for the 2008 Mpumalanga matric cohort, by school district

\begin{tabular}{lcccccc}
\hline & & & \multicolumn{3}{c}{ Bachelor pass candidates } \\
\cline { 5 - 7 } & $\begin{array}{c}\text { Share of } \\
\text { provincial } \\
\text { learners }\end{array}$ & $\begin{array}{c}\text { Bachelor } \\
\text { pass rate }\end{array}$ & $\begin{array}{c}\text { 6-year } \\
\text { access rate }\end{array}$ & $\begin{array}{c}\text { 1-year } \\
\text { access rate }\end{array}$ & $\begin{array}{c}\text { 6-year } \\
\text { completion } \\
\text { rate }\end{array}$ & $\begin{array}{c}\text { 5-year } \\
\text { dropout } \\
\text { rate }\end{array}$ \\
\hline Bohlabela & 24.0 & 4.9 & 61.4 & 37.0 & 65.0 & 21.5 \\
Ehlanzeni & 27.8 & 15.2 & 67.7 & 44.7 & 65.4 & 22.6 \\
Gert Sibande & 22.1 & 15.6 & 58.4 & 40.7 & 60.7 & 25.8 \\
Nkangala & 25.8 & 14.7 & 62.5 & 41.3 & 58.5 & 25.7 \\
\hline
\end{tabular}

NOTES: Figures are only estimated for learners from the 2008 Mpumalanga matric cohort. Access, completion, and dropout rates are only estimated for learners from the cohort who achieved Bachelor passes. Furthermore, completion and dropout rates are estimated only for those learners from this latter group who enrolled in undergraduate studies for the first time in 2009. 
Table A.12: University access, completion, and dropout rate summaries for the 2008 KwaZulu Natal matric cohort, by school district

\begin{tabular}{lcccccc}
\hline & & & \multicolumn{4}{c}{ Bachelor pass candidates } \\
\cline { 5 - 7 } & $\begin{array}{c}\text { Share of } \\
\text { provincial } \\
\text { learners }\end{array}$ & $\begin{array}{c}\text { Bachelor } \\
\text { pass rate }\end{array}$ & $\begin{array}{c}\text { 6-year } \\
\text { access rate }\end{array}$ & $\begin{array}{c}\text { 1-year } \\
\text { access rate }\end{array}$ & $\begin{array}{c}\text { 6-year } \\
\text { completion } \\
\text { rate }\end{array}$ & $\begin{array}{c}\text { 5-year } \\
\text { dropout } \\
\text { rate }\end{array}$ \\
\hline Amajuba & 5.0 & 17.7 & 63.9 & 45.9 & 59.9 & 25.3 \\
Ilembe & 5.5 & 11.1 & 66.3 & 45.1 & 61.7 & 21.8 \\
Pinetown & 12.5 & 24.4 & 66.7 & 52.2 & 62.5 & 23.4 \\
Sisonke & 4.8 & 12.2 & 70.9 & 45.2 & 63.2 & 23.4 \\
Ugu & 7.5 & 15.7 & 68.4 & 46.1 & 61.4 & 22.7 \\
Umgungundlovu & 9.1 & 22.9 & 66.5 & 48.5 & 61.1 & 23.4 \\
Umkhanyakude & 8.1 & 7.0 & 67.7 & 46.4 & 70.4 & 19.0 \\
Umlazi & 15.4 & 34.4 & 72.8 & 57.4 & 62.4 & 22.5 \\
Umzinyathi & 4.9 & 10.1 & 54.5 & 34.5 & 63.0 & 25.2 \\
Uthukela & 6.9 & 15.8 & 62.6 & 40.7 & 59.9 & 26.4 \\
Uthungulu & 10.4 & 11.8 & 71.3 & 49.9 & 62.0 & 23.5 \\
Zululand & 9.9 & 12.6 & 64.1 & 42.5 & 59.0 & 24.1 \\
\hline
\end{tabular}

NOTES: Figures are only estimated for learners from the $2008 \mathrm{KwaZulu}$ Natal matric cohort. Access, completion, and dropout rates are only estimated for learners from the cohort who achieved Bachelor passes. Furthermore, completion and dropout rates are estimated only for those learners from this latter group who enrolled in undergraduate studies for the first time in 2009.

Table A.13: University access, completion, and dropout rate summaries for the 2008 Limpopo matric cohort, by school district

\begin{tabular}{|c|c|c|c|c|c|c|}
\hline & \multirow[b]{2}{*}{$\begin{array}{c}\text { Share of } \\
\text { provincial } \\
\text { learners }\end{array}$} & \multirow[b]{2}{*}{$\begin{array}{l}\text { Bachelor } \\
\text { pass rate }\end{array}$} & \multicolumn{4}{|c|}{ Bachelor pass candidates } \\
\hline & & & $\begin{array}{c}\text { 6-year } \\
\text { access rate }\end{array}$ & $\begin{array}{c}\text { 1-year } \\
\text { access rate }\end{array}$ & $\begin{array}{c}\text { 6-year } \\
\text { completion } \\
\text { rate }\end{array}$ & $\begin{array}{c}\text { 5-year } \\
\text { dropout } \\
\text { rate }\end{array}$ \\
\hline Lebowakgomo & 6.2 & 13.6 & 79.4 & 57.4 & 61.4 & 21.6 \\
\hline Mogalakwena & 5.8 & 9.9 & 67.7 & 45.1 & 61.1 & 25.3 \\
\hline Mopani & 15.6 & 8.9 & 76.3 & 57.5 & 62.7 & 21.4 \\
\hline Polokwane & 18.2 & 17.1 & 78.7 & 62.0 & 60.6 & 22.3 \\
\hline Riba Cross & 4.8 & 4.9 & 73.7 & 48.8 & 65.7 & 16.7 \\
\hline Sekhukhune & 15.0 & 7.5 & 71.4 & 49.3 & 64.6 & 18.9 \\
\hline Tshipise Sagole & 4.3 & 14.8 & 77.1 & 59.7 & 62.9 & 20.4 \\
\hline Tzaneen & 4.6 & 13.7 & 75.9 & 57.2 & 68.5 & 17.1 \\
\hline Vhembe & 21.6 & 15.5 & 82.8 & 64.5 & 62.8 & 20.7 \\
\hline Waterberg & 3.3 & 21.2 & 57.8 & 42.7 & 64.8 & 22.5 \\
\hline
\end{tabular}


Table A.14: University access, completion, and dropout rate summaries for the 2008 Gauteng matric cohort, by school district

\begin{tabular}{lcccccc}
\hline & & & \multicolumn{4}{c}{ Bachelor pass candidates } \\
\cline { 5 - 7 } & $\begin{array}{c}\text { Share of } \\
\text { provincial } \\
\text { learners }\end{array}$ & $\begin{array}{c}\text { Bachelor } \\
\text { pass rate }\end{array}$ & $\begin{array}{c}\text { 6-year } \\
\text { access rate }\end{array}$ & $\begin{array}{c}\text { 1-year } \\
\text { access rate }\end{array}$ & $\begin{array}{c}\text { 6-year } \\
\text { completion } \\
\text { rate }\end{array}$ & $\begin{array}{c}\text { 5-year } \\
\text { dropout } \\
\text { rate }\end{array}$ \\
\hline Ekurhuleni North & 9.3 & 33.8 & 62.6 & 46.3 & 58.4 & 22.9 \\
Ekurhuleni South & 9.5 & 25.0 & 63.1 & 46.8 & 56.7 & 27.2 \\
Gauteng East & 7.8 & 20.8 & 59.7 & 42.5 & 59.1 & 24.3 \\
Gauteng North & 1.5 & 23.9 & 57.4 & 39.6 & 50.7 & 29.9 \\
Gauteng West & 5.3 & 32.6 & 58.6 & 42.6 & 63.3 & 23.3 \\
Johannesburg Central & 8.2 & 24.4 & 64.0 & 48.5 & 55.7 & 28.3 \\
Johannesburg East & 7.1 & 37.9 & 67.8 & 51.5 & 56.3 & 27.3 \\
Johannesburg North & 7.1 & 32.9 & 70.0 & 51.9 & 61.1 & 22.7 \\
Johannesburg South & 6.1 & 23.0 & 65.5 & 49.1 & 58.4 & 28.4 \\
Johannesburg West & 4.6 & 31.2 & 65.5 & 49.6 & 56.7 & 28.6 \\
Sedibeng East & 2.9 & 34.7 & 72.4 & 59.7 & 67.8 & 21.4 \\
Sedibeng West & 6.1 & 17.5 & 67.2 & 51.5 & 63.2 & 23.1 \\
Tshwane North & 5.9 & 35.2 & 66.5 & 45.8 & 59.3 & 24.0 \\
Tshwane South & 11.7 & 45.5 & 74.2 & 58.6 & 66.8 & 18.7 \\
Tshwane West & 6.4 & 27.1 & 69.5 & 51.2 & 58.7 & 24.4 \\
\hline
\end{tabular}

NOTES: Figures are only estimated for learners from the 2008 Gauteng matric cohort. Access, completion, and dropout rates are only estimated for learners from the cohort who achieved Bachelor passes. Furthermore, completion and dropout rates are estimated only for those learners from this latter group who enrolled in undergraduate studies for the first time in 2009. 
Table A.15: Undergraduate completion rates for learners from the 2008 matric cohort who entered undergraduate studies in 2009 , by university of first enrolment

\begin{tabular}{lcccccc}
\hline & $\mathbf{1}$ year & $\mathbf{2}$ years & $\mathbf{3}$ years & $\mathbf{4}$ years & $\mathbf{5}$ years & $\mathbf{6}$ years \\
& $(2009)$ & $(2010)$ & $(2011)$ & $(2012)$ & $(2013)$ & $(2014)$ \\
\cline { 2 - 3 } & 1.5 & 4.1 & 22.6 & 45.9 & 58.5 & 66.1 \\
UCT & 0.0 & 0.0 & 13.3 & 42.2 & 58.8 & 68.8 \\
CUT & 0.3 & 0.8 & 16.0 & 33.3 & 44.6 & 50.9 \\
DUT & 0.9 & 0.9 & 22.5 & 41.9 & 54.7 & 64.3 \\
UFH & 0.0 & 0.0 & 18.2 & 50.1 & 66.6 & 75.0 \\
UFS & 0.0 & 0.1 & 16.7 & 40.0 & 56.8 & 65.4 \\
UJ & 0.0 & 0.0 & 14.3 & 32.5 & 45.7 & 52.6 \\
UKZN & 0.0 & 0.0 & 12.4 & 40.3 & 60.9 & 69.1 \\
UL & 0.0 & 0.1 & 13.6 & 42.1 & 60.4 & 74.7 \\
NMMU & 0.5 & 0.8 & 18.8 & 39.5 & 51.6 & 58.9 \\
NWU & 0.0 & 0.0 & 27.1 & 56.5 & 68.6 & 74.0 \\
UP & 0.0 & 0.3 & 17.6 & 41.6 & 56.9 & 65.4 \\
RHODES & 0.0 & 0.0 & 21.3 & 45.0 & 53.7 & 57.8 \\
UNISA & 0.1 & 0.6 & 3.6 & 9.8 & 18.1 & 26.3 \\
US & 0.0 & 0.0 & 24.6 & 56.2 & 67.7 & 74.4 \\
TUT & 0.3 & 1.1 & 12.1 & 29.8 & 42.2 & 49.7 \\
UNIVEN & 0.0 & 1.3 & 9.8 & 40.8 & 60.1 & 72.6 \\
VUT & 0.0 & 0.0 & 13.6 & 32.0 & 44.6 & 54.7 \\
WSU & 0.2 & 1.2 & 14.5 & 34.3 & 47.6 & 54.0 \\
UWC & 0.1 & 0.3 & 9.5 & 31.4 & 46.5 & 53.0 \\
WITS & 0.0 & 0.1 & 10.4 & 29.7 & 41.5 & 47.9 \\
UZ & 0.0 & 0.4 & 17.6 & 46.4 & 58.2 & 63.9 \\
MUT & 0.0 & 0.0 & 18.6 & 37.1 & 50.1 & 59.7 \\
\hline NOTES: Figures reflect the cumulative percentage of 2009 FTEN undergraduate students from the 2008 matric cohort who successfully completed \\
undergraduate qualifications after a certain number of years, by the university of FTEN. Note that this implies that all completers who commenced with \\
their undergraduate \\
undergraduate qualification at a given university would contribute to the completion rate for that university, even if they ended up completing their
\end{tabular}


Table A.16: Undergraduate degree completion rates for learners from the 2008 matric cohort who entered undergraduate degree programmes in 2009 , by university of first enrolment

\begin{tabular}{lcccccc}
\hline & $\mathbf{1}$ year & $\begin{array}{c}\mathbf{2} \text { years } \\
(2009)\end{array}$ & $\begin{array}{c}\text { 3 years } \\
(2010)\end{array}$ & $\begin{array}{c}\text { 4 years } \\
(2011)\end{array}$ & $\begin{array}{c}\mathbf{5} \text { years } \\
(2012)\end{array}$ & $\begin{array}{c}\mathbf{6} \text { years } \\
(2013)\end{array}$ \\
\cline { 2 - 7 } CPUT & 0.0 & 0.0 & 0.0 & 54.5 & 67.9 & 75.9 \\
UCT & 0.0 & 0.0 & 13.3 & 42.1 & 58.4 & 68.4 \\
CUT & 0.0 & 0.0 & 0.0 & 21.8 & 37.0 & 46.0 \\
DUT & 0.0 & 0.0 & 0.0 & 53.0 & 80.3 & 90.9 \\
UFH & 0.0 & 0.0 & 18.4 & 49.9 & 65.7 & 73.4 \\
UFS & 0.0 & 0.0 & 16.5 & 39.6 & 56.3 & 64.5 \\
UJ & 0.0 & 0.0 & 14.4 & 33.4 & 46.4 & 53.6 \\
UKZN & 0.0 & 0.0 & 12.3 & 39.7 & 59.9 & 68.0 \\
UL & 0.0 & 0.0 & 13.5 & 41.6 & 59.3 & 72.9 \\
NMMU & 0.0 & 0.0 & 14.8 & 38.4 & 52.0 & 61.0 \\
NWU & 0.0 & 0.0 & 26.9 & 56.3 & 67.9 & 73.0 \\
UP & 0.0 & 0.0 & 17.3 & 41.3 & 56.4 & 64.8 \\
RHODES & 0.0 & 0.0 & 21.3 & 44.5 & 53.1 & 57.1 \\
UNISA & 0.0 & 0.0 & 3.7 & 11.6 & 21.2 & 30.4 \\
US & 0.0 & 0.0 & 24.6 & 56.1 & 67.5 & 74.1 \\
TUT & 0.0 & 0.0 & 0.4 & 37.9 & 64.1 & 75.0 \\
UNIVEN & 0.0 & 0.0 & 8.5 & 40.2 & 59.5 & 71.5 \\
VUT & 0.0 & 0.0 & 0.0 & 0.0 & 18.2 & 27.3 \\
WSU & 0.0 & 0.0 & 9.4 & 36.7 & 58.2 & 69.1 \\
UWC & 0.0 & 0.0 & 9.2 & 31.2 & 46.0 & 52.3 \\
WITS & 0.0 & 0.0 & 10.3 & 29.6 & 41.4 & 47.7 \\
UZ & 0.0 & 0.0 & 10.9 & 46.2 & 60.3 & 66.9 \\
MUT & 0.0 & 0.0 & 0.0 & 0.0 & 0.0 & 0.0 \\
\hline NOTES: & 0.0 & & & \\
\hline
\end{tabular}

NOTES: Figures reflect the cumulative percentage of 2009 FTEN undergraduate degree students from the 2008 matric cohort who successfully completed undergraduate degrees after a certain number of years, by the university of FTEN. Note that this implies that all completers who commenced with their undergraduate degrees at a given university would contribute to the completion rate for that universities, even if they ended up completing their undergraduate degrees at other universities. 
Table A.17: Undergraduate dropout rates for learners from the 2008 matric cohort who entered undergraduate degree programmes in 2009 , by university of first enrolment

\begin{tabular}{|c|c|c|c|c|c|c|}
\hline & $\begin{array}{l}11 \text { year } \\
(2009)\end{array}$ & $\begin{array}{c}2 \text { years } \\
(2010)\end{array}$ & $\begin{array}{c}3 \text { years } \\
(2011)\end{array}$ & $\begin{array}{l}4 \text { years } \\
(2012)\end{array}$ & $\begin{array}{c}5 \text { years } \\
(2013)\end{array}$ & $\begin{array}{l}6 \text { years } \\
(2014)\end{array}$ \\
\hline CPUT & 11.0 & 17.7 & 22.3 & 26.9 & 31.2 & 11.0 \\
\hline UCT & 2.4 & 3.6 & 6.1 & 8.3 & 11.0 & 2.4 \\
\hline CUT & 16.3 & 23.9 & 30.0 & 35.2 & 39.3 & 16.3 \\
\hline DUT & 9.4 & 15.6 & 21.6 & 26.2 & 31.6 & 9.4 \\
\hline UFH & 5.3 & 8.8 & 11.0 & 14.8 & 20.6 & 5.3 \\
\hline UFS & 5.5 & 10.2 & 14.4 & 18.5 & 23.3 & 5.5 \\
\hline UJ & 13.1 & 18.8 & 23.9 & 28.3 & 33.4 & 13.1 \\
\hline UKZN & 4.3 & 8.1 & 11.1 & 14.4 & 18.7 & 4.3 \\
\hline UL & 2.3 & 5.7 & 9.0 & 13.3 & 18.9 & 2.3 \\
\hline NMMU & 9.1 & 15.3 & 20.0 & 25.1 & 29.8 & 9.1 \\
\hline NWU & 7.1 & 11.5 & 15.1 & 18.4 & 21.4 & 7.1 \\
\hline UP & 5.6 & 8.7 & 11.2 & 13.3 & 16.7 & 5.6 \\
\hline RHODES & 6.3 & 8.3 & 12.1 & 15.7 & 19.6 & 6.3 \\
\hline UNISA & 15.6 & 24.6 & 31.7 & 37.4 & 45.5 & 15.6 \\
\hline US & 2.8 & 4.8 & 7.1 & 8.6 & 10.8 & 2.8 \\
\hline TUT & 16.9 & 25.6 & 31.1 & 36.6 & 42.1 & 16.9 \\
\hline UNIVEN & 5.5 & 8.3 & 10.8 & 16.3 & 22.1 & 5.5 \\
\hline VUT & 8.3 & 13.2 & 21.4 & 29.2 & 36.2 & 8.3 \\
\hline WSU & 8.4 & 14.0 & 22.5 & 29.2 & 35.6 & 8.4 \\
\hline UWC & 10.6 & 17.4 & 23.2 & 27.9 & 34.3 & 10.6 \\
\hline WITS & 6.5 & 9.3 & 11.8 & 14.9 & 20.0 & 6.5 \\
\hline $\mathrm{UZ}$ & 8.2 & 12.0 & 18.9 & 23.7 & 28.4 & 8.2 \\
\hline MUT & 5.5 & 12.6 & 17.4 & 22.2 & 27.7 & 5.5 \\
\hline
\end{tabular}

NOTES: Figures reflect the cumulative percentage of 2009 FTEN undergraduate students from the 2008 matric cohort who were no longer enrolled in university in 2014 without having completed any undergraduate qualifications before exiting the public university system., by the university of FTEN. Note that this implies that all dropouts who commenced with their undergraduate studies at a given university would contribute to the dropout rate for that university, even if they ended up enrolling at another university before leaving the system. 
Table A.18: The 2008 matric cohort after six years (end of 2014), by school quintile

\begin{tabular}{|c|c|c|c|c|c|c|}
\hline & \multirow[b]{2}{*}{ All } & \multicolumn{5}{|c|}{2008 matric school quintile } \\
\hline & & Q 1 & Q 2 & Q 3 & Q 4 & Q5 \\
\hline Cohort & 537592 & 107492 & 126897 & 135944 & 71191 & 96068 \\
\hline column $\%$ & 100.0 & 100.0 & 100.0 & 100.0 & 100.0 & 100.0 \\
\hline Enrolled in UG studies & 104156 & 9882 & 14177 & 19917 & 16727 & 43453 \\
\hline column $\%$ & 19.4 & 9.2 & 11.2 & 14.7 & 23.5 & 45.2 \\
\hline Enrolled in UG degree & 65004 & 4692 & 6928 & 10099 & 9756 & 33529 \\
\hline column \% & 12.1 & 4.4 & 5.5 & 7.4 & 13.7 & 34.9 \\
\hline Completed UG qualification & 51706 & 4496 & 6452 & 8815 & 7707 & 24236 \\
\hline column $\%$ & 9.6 & 4.2 & 5.1 & 6.5 & 10.8 & 25.2 \\
\hline Completed UG degree & 35240 & 2335 & 3437 & 4908 & 4811 & 19749 \\
\hline column $\%$ & 6.6 & 2.2 & 2.7 & 3.6 & 6.8 & 20.6 \\
\hline Enrolled in PG studies & 12346 & 610 & 944 & 1392 & 1578 & 7822 \\
\hline column $\%$ & 2.3 & 0.6 & 0.7 & 1.0 & 2.2 & 8.1 \\
\hline Completed PG qualification & 8910 & 363 & 580 & 905 & 1046 & 6016 \\
\hline column $\%$ & 1.7 & 0.3 & 0.5 & 0.7 & 1.5 & 6.3 \\
\hline Non-completers enrolled in 2014 & 20745 & 2240 & 3119 & 4154 & 3469 & 7763 \\
\hline column \% & 3.9 & 2.1 & 2.5 & 3.1 & 4.9 & 8.1 \\
\hline Dropped-out before 2014 & 31625 & 3139 & 4600 & 6937 & 5538 & 11411 \\
\hline column $\%$ & 5.9 & 2.9 & 3.6 & 5.1 & 7.8 & 11.9 \\
\hline
\end{tabular}

NOTES: Figures printed in black reflect the numbers of learners from each of the 2008 matric cohort subgroups. Column percentages are printed in grey and express the number of learners in a particular row as a percentage of the number of candidates from the relevant subgroup.

Table A.19: NSC pass type and university access, completion, and dropout rate summaries for the 2008 matric cohort, by school quintile

\begin{tabular}{lccccc}
\hline & Quintile 1 & Quintile 2 & Quintile 3 & Quintile 4 & Quintile 5 \\
\cline { 2 - 5 } Share of matric cohort & 20.0 & 23.6 & 25.3 & 13.2 & 17.9 \\
Bachelor Pass & 7.5 & 9.3 & 12.1 & 22.4 & 53.2 \\
6-year access rate & 9.2 & 11.2 & 14.7 & 23.5 & 45.2 \\
- UG degree $^{\text {a }}$ & 4.4 & 5.5 & 7.4 & 13.7 & 34.9 \\
1-year access rate $^{-}$ & 4.5 & 5.7 & 8.4 & 15.0 & 34.0 \\
- UG degree $^{\text {b }}$ & 2.5 & 3.3 & 4.9 & 10.0 & 28.0 \\
6-year completion rate $^{\text {- }}$ & 55.5 & 55.7 & 52.3 & 54.2 & 62.9 \\
- UG degree $^{\text {c }}$ & 57.6 & 56.6 & 54.3 & 55.2 & 64.4 \\
5-year dropout rate & 32.2 & 31.7 & 34.9 & 30.8 & 23.9 \\
- UG degree $^{\text {d }}$ & 20.9 & 19.8 & 22.6 & 21.4 & 18.3 \\
\hline
\end{tabular}

NOTES: Completion and dropout rates are estimated only for those learners from each 2008 NSC subgroup who enrolled in undergraduate studies for the first time in 2009. ${ }^{[a]}$ Percentage of learners in each 2008 NSC subgroup who enrolled for an undergraduate degree programme at some stage between 2009 and 2014. ${ }^{[b]}$ Percentage of learners in each 2008 NSC subgroup who enrolled for an undergraduate degree programme in 2009. ${ }^{[c]}$ Percentage of learners who enrolled for an undergraduate degree programme in 2009 from each 2008 NSC subgroup and successfully completed undergraduate degrees by the end of 2014. ${ }^{[\mathrm{d}]}$ Percentage of learners who enrolled for an undergraduate degree programme in 2009 from each 2008 NSC subgroup, but dropped out of university before 2014 without completing any undergraduate qualification. 
Table A.20: University access, completion, and dropout rate summaries for learners who achieved Bachelor passes in the $2008 \mathrm{NSC}$, by school quintile

\begin{tabular}{|c|c|c|c|c|c|}
\hline & Quintile 1 & Quintile 2 & Quintile 3 & Quintile 4 & Quintile 5 \\
\hline Share of Bachelor passes & 7.8 & 11.4 & 16.0 & 15.4 & 49.4 \\
\hline 6-year access rate & 63.2 & 65.8 & 67.6 & 68.4 & 70.0 \\
\hline - UG degree ${ }^{a}$ & 44.6 & 47.8 & 49.6 & 53.1 & 62.0 \\
\hline 1-year access rate & 39.7 & 42.0 & 47.2 & 50.9 & 55.8 \\
\hline - UG degree ${ }^{b}$ & 28.6 & 31.3 & 35.6 & 40.9 & 50.4 \\
\hline 6-year completion rate & 61.6 & 62.0 & 58.0 & 59.3 & 66.5 \\
\hline - UG degree ${ }^{c}$ & 58.0 & 57.3 & 55.2 & 56.0 & 65.2 \\
\hline 5-year dropout rate & 25.5 & 24.5 & 27.8 & 24.5 & 20.0 \\
\hline - UG degree ${ }^{d}$ & 21.2 & 20.2 & 23.2 & 21.3 & 17.9 \\
\hline
\end{tabular}

NOTES: Figures are only estimated for learners from the 2008 matric cohort who achieved Bachelor passes. Completion and dropout rates are estimated only for those learners from each cohort subgroup who enrolled in undergraduate studies for the first time in 2009. ${ }^{[a]}$ Percentage of learners in each 2008 NSC subgroup who enrolled for an undergraduate degree programme at some stage between 2009 and 2014. ${ }^{[b]}$ Percentage of learners in each 2008 NSC subgroup who enrolled for an undergraduate degree programme in 2009. ${ }^{[c]}$ Percentage of learners who enrolled for an undergraduate degree programme in 2009 from each 2008 NSC subgroup and successfully completed undergraduate degrees by the end of 2014. ${ }^{[d]}$ Percentage of learners who enrolled for an undergraduate degree programme in 2009 from each 2008 NSC subgroup, but dropped out of university before 2014 without completing any undergraduate qualification. 